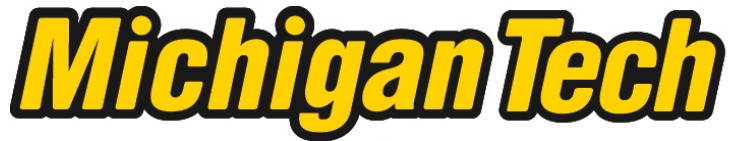 \\ Michigan Technological University Create the Future Digital Commons @ Michigan Tech
}

Dissertations, Master's Theses and Master's Reports - Open

Dissertations, Master's Theses and Master's

Reports

2006

Time-domain models for power system stability and unbalance

Ramanathan Arunachalam

Michigan Technological University

Follow this and additional works at: https://digitalcommons.mtu.edu/etds

Part of the Electrical and Computer Engineering Commons

Copyright 2006 Ramanathan Arunachalam

\section{Recommended Citation}

Arunachalam, Ramanathan, "Time-domain models for power system stability and unbalance", Master's Thesis, Michigan Technological University, 2006.

https://doi.org/10.37099/mtu.dc.etds/42

Follow this and additional works at: https://digitalcommons.mtu.edu/etds

Part of the Electrical and Computer Engineering Commons 


\title{
TIME-DOMAIN MODELS FOR POWER SYSTEM STABILITY AND UNBALANCE
}

\author{
By \\ RAMANATHAN ARUNACHALAM
}

A Thesis

Submitted in partial fulfillment of the requirements

for the degree of

MASTER OF SCIENCE IN ELECTRICAL ENGINEERING

\section{MICHIGAN TECHNOLOGICAL UNIVERSITY}

June, 2006

Copyright () Ramanathan Arunachalam 2006 
This thesis, "Time-Domain Models for Power System Stability and Unbalance", is hereby approved in partial fulfillment of the requirements of the Degree of Master of Science in Electrical Engineering.

DEPARTMENT OF ELECTRICAL ENGINEERING

Signatures:

Thesis advisor:

Dr. Bruce A. Mork

Department Chair:

Dr. Timothy J. Schulz

Date: 


\section{ABSTRACT}

It is an important and difficult challenge to protect modern interconnected power system from blackouts. Applying advanced power system protection techniques and increasing power system stability are ways to improve the reliability and security of power systems. Phasor-domain software packages such as Power System Simulator for Engineers (PSS/E) can be used to study large power systems but cannot be used for transient analysis. In order to observe both power system stability and transient behavior of the system during disturbances, modeling has to be done in the time-domain. This work focuses on modeling of power systems and various control systems in the Alternative Transients Program (ATP).

ATP is a time-domain power system modeling software in which all the power system components can be modeled in detail. Models are implemented with attention to component representation and parameters. The synchronous machine model includes the saturation characteristics and control interface. Transient Analysis Control System is used to model the excitation control system, power system stabilizer and the turbine governor system of the synchronous machine. Several base cases of a single machine system are modeled and benchmarked against PSS/E. A two area system is modeled and inter-area and intra-area oscillations are observed. The two area system is reduced to a two machine system using reduced dynamic equivalencing. The original and the reduced systems are benchmarked against PSS/E. This work also includes the simulation of single-pole tripping using one of the base case models. Advantages of single-pole tripping and comparison of system behavior against three-pole tripping are studied.

Results indicate that the built-in control system models in PSS/E can be effectively reproduced in ATP. The benchmarked models correctly simulate the power system dynamics. The successful implementation of a dynamically reduced system in ATP shows promise for studying a small sub-system of a large system without losing the dynamic behaviors. Other aspects such as relaying can be investigated using the benchmarked models. It is expected that this work will provide guidance in modeling different control systems for the synchronous machine and in representing dynamic equivalents of large power systems.

Ramanathan Arunachalam, June 8, 2006 


\section{ACKNOWLEDGMENT}

I would like to thank my advisor, Dr. Bruce Mork for his invaluable guidance and also for the time he took to offer me encouragement, insight, and direction. I would like to express my gratitude to Dr. Leonard Bohmann for his regular feedback, which has helped me immensely. This work was an introductory part of NSF project ECS-0501479.

I should thank both the faculty and the staff of the Electrical Engineering department for all their help and support throughout the period of my education here at Michigan Tech.

Special thanks to the committee members, Dr. Dennis Wiitanen and Dr. Gordon Parker, for taking their time to review my work; your insights and suggestions are greatly appreciated.

I would like to extend my gratitude to Dr. Dmitry Ischenko, for helping me out with the TACS and ATP files during the initial stages of this research. I would like to thank my friend, Ms. Ruchi Singh, for helping me with the PSS/E data; her willingness to coordinate with me made my research work a lot easier.

I thank my parents Mr. Arunachalam Rm. and Mrs. Visalakshi Ar. for their moral and financial support, without which I wouldn't have gotten this far. I would also like to thank my sister and brother-in-law, Mrs. Unnamalai C and Mr. Chockalingam $\mathrm{Kr}$, without whose support and motivation my post graduate education in the United States would have been impossible.

Above all, I would like to thank God for all that he has given, and has continued to give me. Last but not the least, I would like to thank my friends both here and back home, for being there for me during my good and difficult days.

I want to dedicate this work to my nephew, Karuppiah C. (Ramu), who is the object of my love and affection. 


\section{TABLE OF CONTENTS}

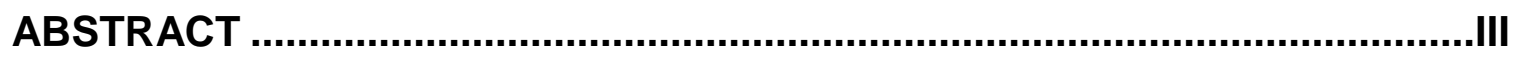

ACKNOWLEDGMENT ….......................................................................... IV

TABLE OF CONTENTS ............................................................................

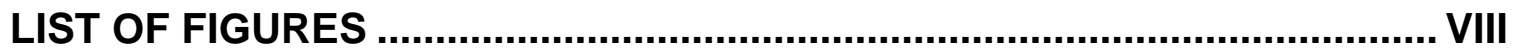

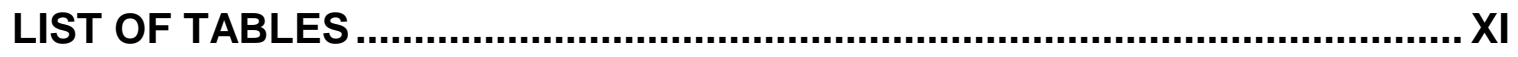

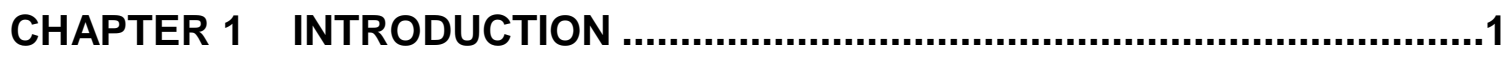

CHAPTER 2 BACKGROUND INFORMATION AND EXISTING WORK...........5

$2.1 \quad$ LITERATURE SEARCH ……..............................................................................................................

2.2 POWER SYSTEM DYNAMICS AND STABILITY ……….............................................................

2.3 ATP AND TACS MODELING.................................................................................................11

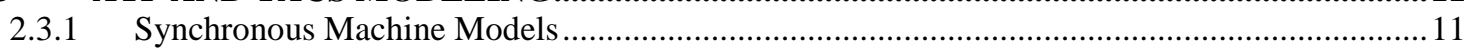

2.3.2 Transmission Line Models ................................................................................................ 12

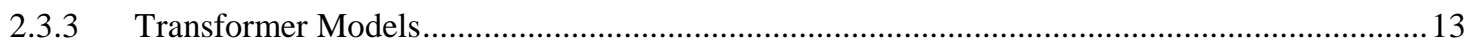

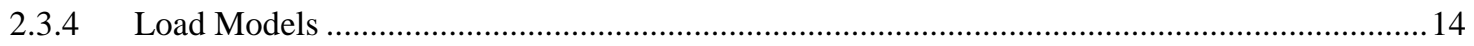

2.3.5 Transfer Functions and Initial Conditions ................................................................... 15

2.4 SYNCHRONOUS MACHINE CONTROLS ...........................................................................16

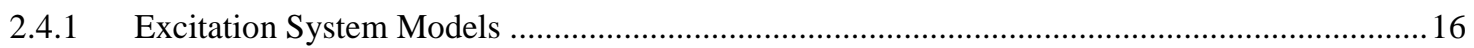

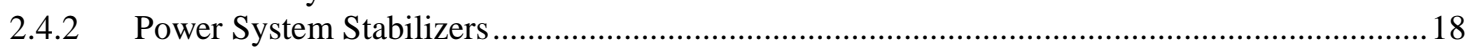

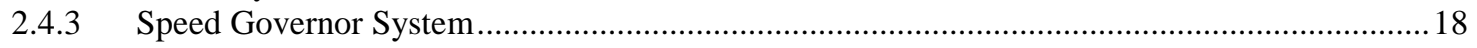

2.5 INTRODUCTION TO PSS/E ...................................................................................................20

2.6 DYNAMIC REDUCTION OF POWER SYSTEM ………...........................................................21

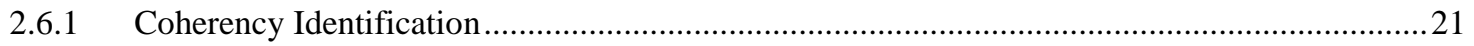

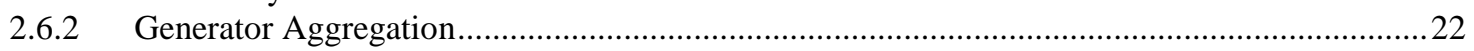

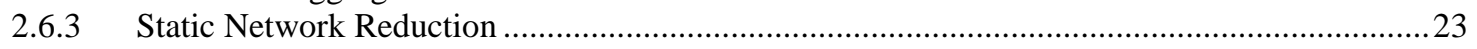

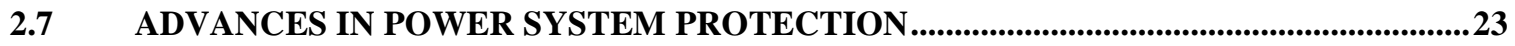

CHAPTER 3 POWER SYSTEM MODELING USING ATP ...........................25

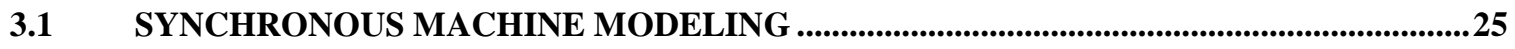

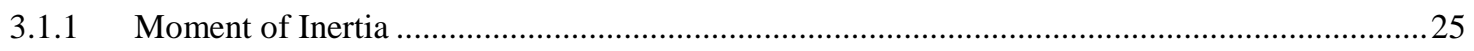

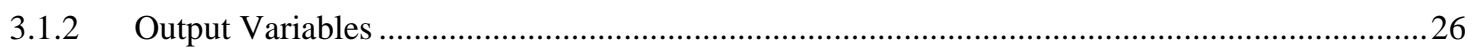




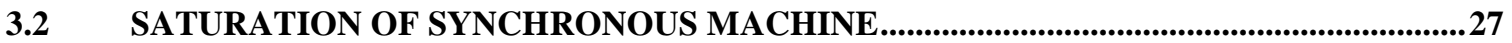

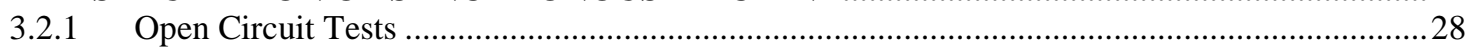

3.3 EXCITATION CONTROL SYSTEM, SPEED GOVERNOR AND POWER SYSTEM

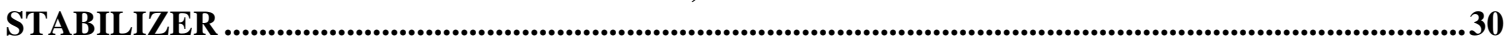

3.4 TRANSFORMER MODELING............................................................................................32

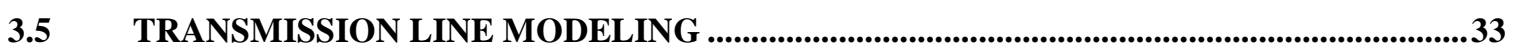

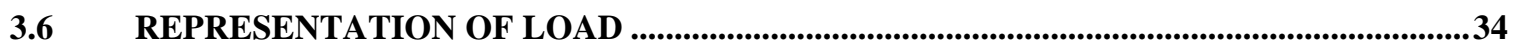

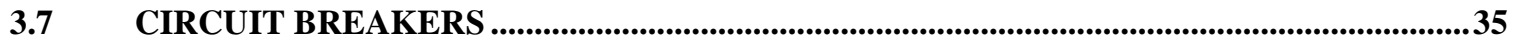

CHAPTER 4 MODELING OF SINGLE-MACHINE CASES ...........................36

4.1 SINGLE MACHINE SYSTEM ..........................................................................................36

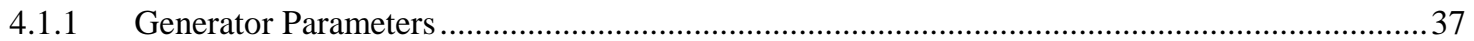

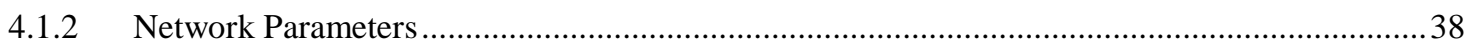

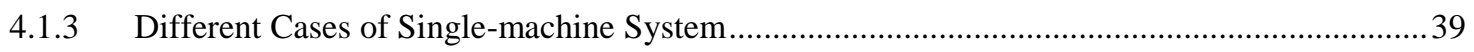

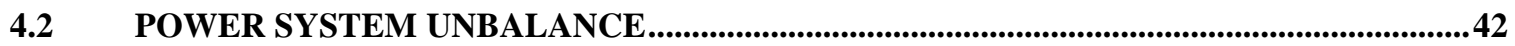

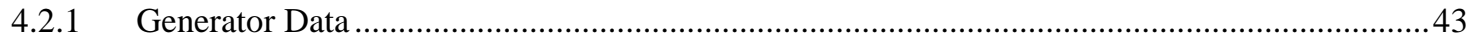

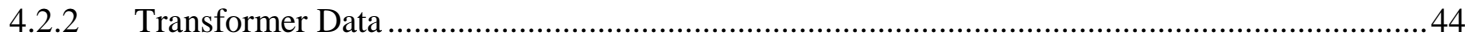

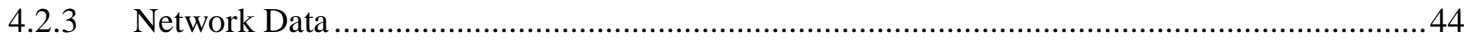

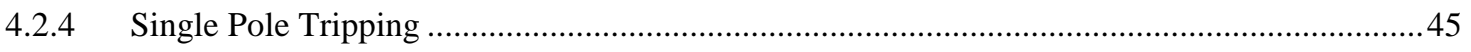

CHAPTER 5 DYNAMIC REDUCTION AND POWER SWINGS .....................47

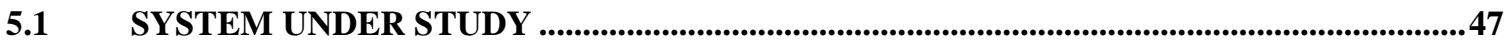

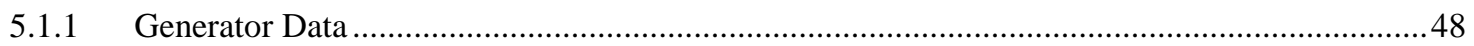

5.1.2 Transformer and Transmission Line Data.............................................................................. 49

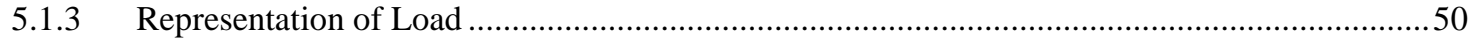

5.2 POWER SYSTEM DISTURBANCES ..............................................................................51

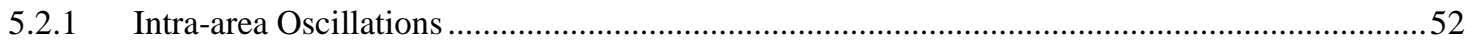

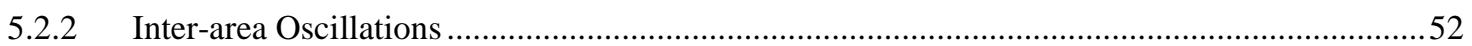

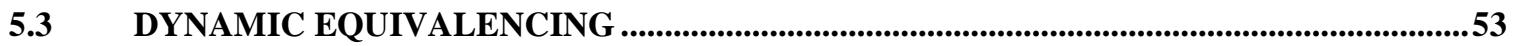

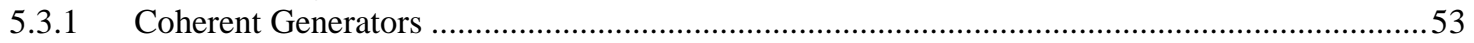

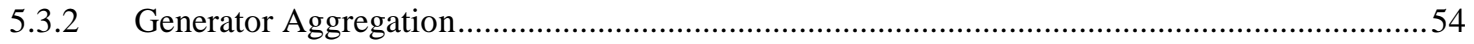

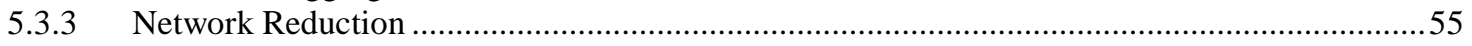

CHAPTER 6 SIMULATIONS AND RESULTS .............................................58

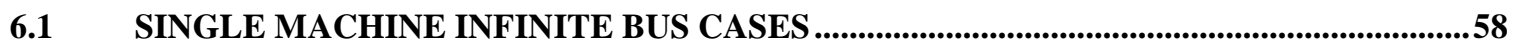

6.1.1 Generator Dynamics With and Without Excitation Control Systems ........................................59

6.1.2 Effects of Generator Saturation and Armature Resistance ......................................................61

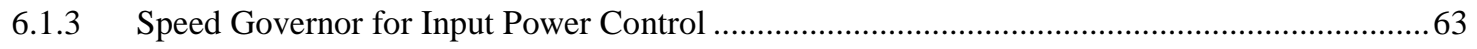

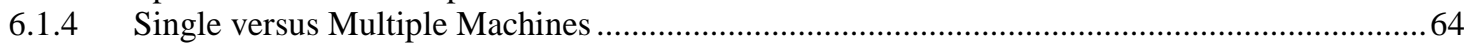

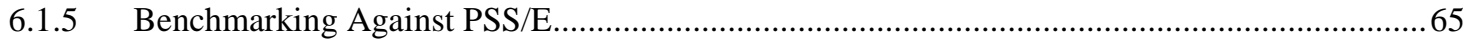

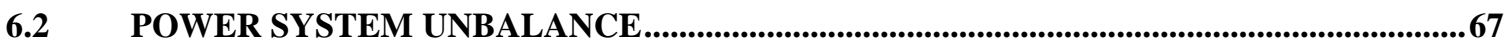


6.2.1 Generator Stability during Different Unbalance Conditions ................................................68

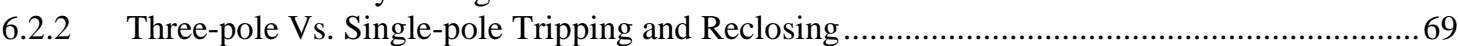

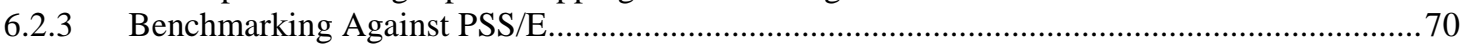

6.3 DYNAMIC EQUIVALENCING ............................................................................................72

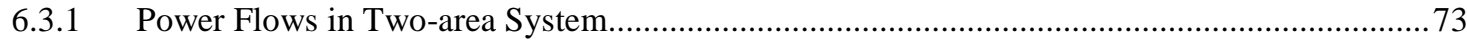

6.3.2 Stability Studies in Two-area System ........................................................................... 74

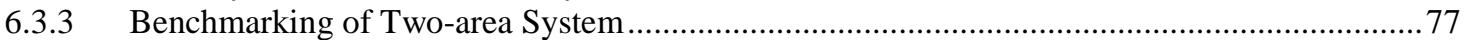

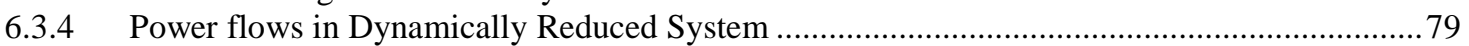

6.3.5 Benchmarking the Reduced System in ATP ................................................................... 81

6.3.6 Benchmarking of Reduced System in PSS/E ................................................................. 83

CHAPTER 7 CONCLUSIONS AND RECOMMENDATIONS $\ldots \ldots \ldots \ldots \ldots \ldots \ldots \ldots . . . . . . . . . . . . .65$

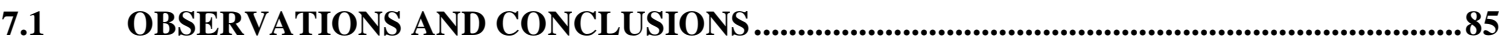

$7.2 \quad$ RECOMMENDATIONS.............................................................................................................................8

REFERENCES..........................................................................................91

APPENDIX A MODEL PARAMETERS …...................................................93

A.1 OPEN-CIRCUIT CHARACTERISTICS .....................................................................................93

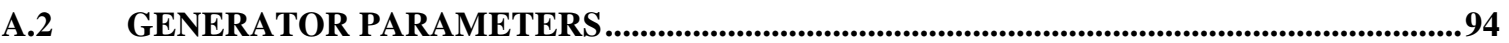

A.3 TACS DATA …………………….............................................................................................................96

A.4 LOAD DATA ………..............................................................................................................................98

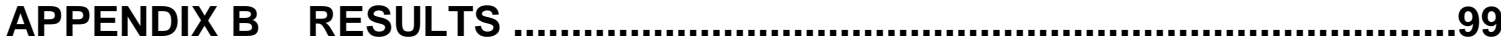

B.1 SINGLE MACHINE SYSTEM BENCHMARKING .................................................................99

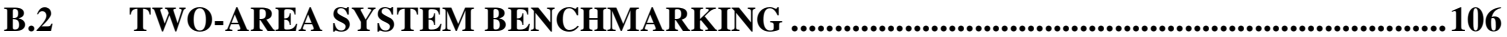

APPENDIX C PROGRAM FILES …..........................................................11

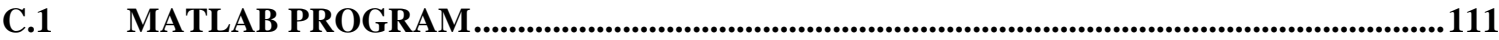

C.2 ATP SAMPLE INPUT DATA CASE...................................................................................112

C.2.1 Saturated single machine system with three-phase line fault ...............................................112

C.2.2 Two-area system with a thee-phase line fault in line 6-7 .....................................................115 


\section{LIST OF FIGURES}

Figure 1.1: System under study ................................................................................... 3

Figure 2.1: Classification of power system stability [10] ............................................. 8

Figure 2.2: Stator and rotor circuits of a synchronous machine [9] .............................. 9

Figure 2.3: SM 59 synchronous machine model ........................................................... 12

Figure 2.4: Characteristics of load models, power against voltage................................ 14

Figure 2.5: Characteristics of load models, current against voltage .............................. 15

Figure 2.6: General transfer function and initial condition block ................................. 15

Figure 2.7: Functional block diagram of excitation control system ............................. 17

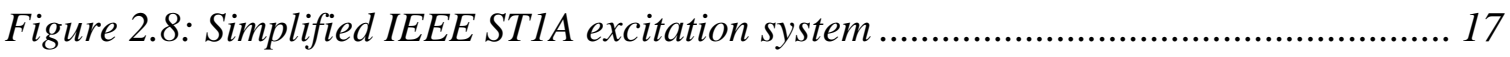

Figure 2.9: Simplified Power System Stabilizer ......................................................... 18

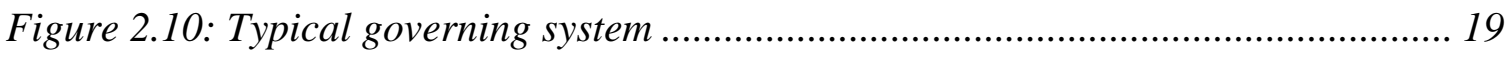

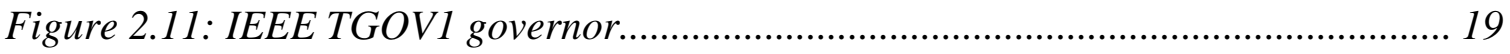

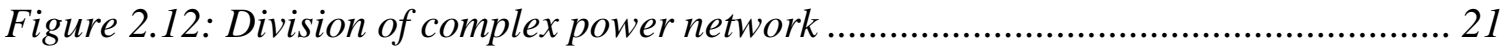

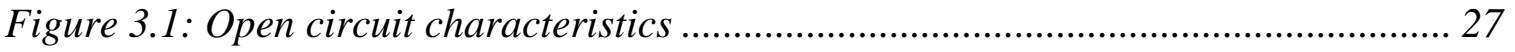

Figure 3.2: SM data cards 1 and la for the unsaturated machine under study ............. 28

Figure 3.3: SM data cards 1 and la for the saturated machine under study .................. 28

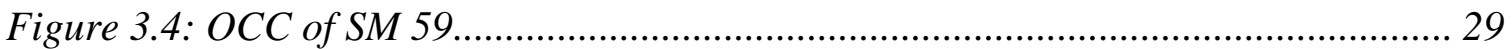

Figure 3.5: IEEE ST1A excitation system model ........................................................ 30

Figure 3.6: EEST1 Power System Stabilizer model..................................................... 31

Figure 3.7: TGOV1 speed governor model ............................................................. 32

Figure 3.8: Three-phase transformer connections ...................................................... 33

Figure 3.9: Lumped RLC pi equivalent transmission line ............................................. 34

Figure 3.10: Constant impedance load model............................................................ 34

Figure 4.1: Single machine system under study ....................................................... 36

Figure 4.2: Single machine system with excitation controls (Case 5a)........................... 38

Figure 4.3: Circuit breakers with compensation for numerical oscillations .................. 39

Figure 4.4: Four Machine System (Case 5i) .............................................................. 41

Figure 4.5: Control using Speed Governor System (Case 5h) ..................................... 42

Figure 4.6: Single-machine system with sequence data ................................................ 42

Figure 4.7: Single machine system in ATP (Case 2a) ................................................ 43 
Figure 4.8: Basic diagram of single-pole tripping .................................................... 45

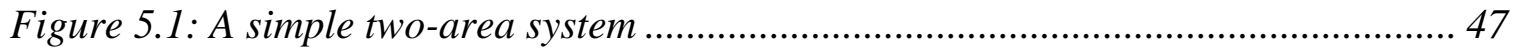

Figure 5.2: Two-area system modeled in ATP (Case 3a)........................................... 51

Figure 5.3: Rotor angles (in degree) for a fault in area 1(Case $3 a$ ) ...............................54

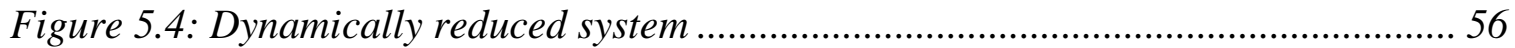

Figure 5.5: Rotor angles of machines in Area 1 (Cases $3 a$ and $4 a$ ) .............................. 57

Figure 6.1: Rotor angle for different types of excitation control (Cases 1a, 1b, \&1c) .... 59

Figure 6.2: Terminal voltage for different excitation controls (Cases $1 a, 1 b$, \& 1c)...... 60

Figure 6.3: Instantaneous and per unit terminal voltage (Case 1a) .............................. 61

Figure 6.4: Machine models with and without saturation (Cases 1e \& 1a).................... 61

Figure 6.5: Rotor angles of machine models with and without $R_{a}($ Cases $1 f$ and $1 a)$...... 63

Figure 6.6: Machine models with and without governor (Cases $1 d \& 1$ ) ..................... 63

Figure 6.7: Four machines and single machine system (Cases $5 g$ \& 5a) ...................... 65

Figure 6.8: Rotor angles of system with AVR and PSS (case 1a)..................................66

Figure 6.9: Rotor angles of system with AVR, PSS and governor (Case 1d)..................66

Figure 6.10: Terminal voltages of ATP and PSS/E (Case 1a) .....................................67

Figure 6.11: Rotor angles for different faults (Cases $2 a, 2 b, 2 c$ and $3 d$ )....................... 68

Figure 6.12: Single- and three-pole tripping and reclosing (Cases $2 b \& 2 e)$................. 69

Figure 6.13: Single and three-pole tripping and reclosing (Cases $2 b \& 2 e)$................... 70

Figure 6.14: Unbalance faults, benchmarking against PSS/E (Cases $2 a$ \& 2c)............ 71

Figure 6.15: Power flow Area 1 to Area 2 (Case 3a)................................................... 73

Figure 6.16: Average power flow between areas 1 and 2 after disturbance (Case 3a)... 74

Figure 6.17: Rotor angles for a three-phase line fault in line 6-7 (Case 3a).................. 75

Figure 6.18: Rotor angles for a three-phase line fault in line 11-9 (Case 3b)................ 75

Figure 6.19: Terminal voltages of G1 and G2 for a fault in Area 2 (Case 3b).............. 76

Figure 6.20: Terminal voltages for a fault in Area 1 (Case 3a).................................. 76

Figure 6.21: Rotor angles of machines in Area 1 (Case 3a) ........................................ 77

Figure 6.22: Rotor angles of machines in Area 2 (Case 3a) ...................................... 78

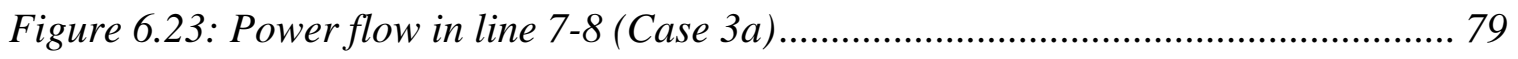

Figure 6.24: Power flow in line 8-9 (Case 3a)........................................................... 79

Figure 6.25: Power flow into Area 2 for disturbance in Area 1 (Case 4a)..................... 80 
Figure 6.26: Power flow between into Area 2 for disturbance in Area 2 (Case 4b)....... 81

Figure 6.27: Rotor angles of machines in Area 1 (Cases $3 a$ and $4 a$ ) ............................. 82

Figure 6.28: Rotor angles (in degree) of machine is area 2 ....................................... 82

Figure 6.29: Rotor angles of reduced system (Case 4a) ............................................... 83

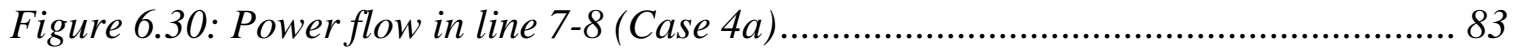

Figure B.1: Comparison of field voltage (Cases $1 a, 1 b$, and 1c) ................................. 99

Figure B.2: LG fault, with and without $\mathrm{Ra}$ (Case 2b) ............................................... 99

Figure B.3: Rotor angle for different excitation systems (cases $1 a, 1 b, 1 c, \& 1 d$ ) ........ 100

Figure B.4: Rotor angles for line tripping and reclosing (Case 5a) ............................ 100

Figure B.5: Rotor angles -constant Efd (Case 1b) ................................................. 101

Figure B.6: Rotor angles - with AVR (Case 1c) ...................................................... 101

Figure B.7: Rotor angles with saturated generator model (Case 1e) .......................... 102

Figure B.8: Terminal Voltage for different fault types (Cases $2 a, 2 b, 2 c$ and $2 d$ )........ 102

Figure B.9: Rotor angles - single-pole and three-pole tripping (Case $2 b$ and $2 e$ ) ........ 103

Figure B.10: Rotor angles for a LG fault (Case 2b)................................................. 103

Figure B.11: Rotor angles of G1 for faults in Area 1 (Case 3a, c, d, and e)................ 106

Figure B.12: Rotor angles of G4 for faults in Area 1 (Case 3a, $c, d$, and e)................ 107

Figure B.13: Terminal Voltage of G3 for faults in Area 1 (Case 3a, c, d, and e)......... 108

Figure B.14: Rotor angles in Area 1 (Case 3a, c, d, and e) ..................................... 108

Figure B.15: Terminal voltages in Area 2 (Case 3f) ................................................. 109

Figure B.16: Rotor angles for line tripping and reclosing (Case 3a) .......................... 109

Figure B.17: Field voltage control for line tripping and reclosing (Case 3a).............. 110

Figure B.18: Rotor angles for remote and local faults (Case $3 a$ and $3 b$ ).................... 110 


\section{LIST OF TABLES}

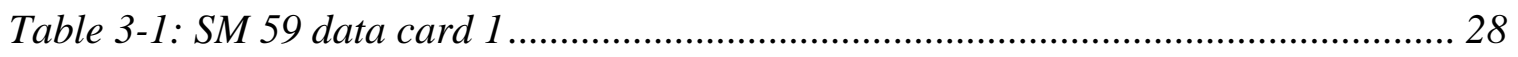

Table 3-2: SM 59 data card la .................................................................................. 28

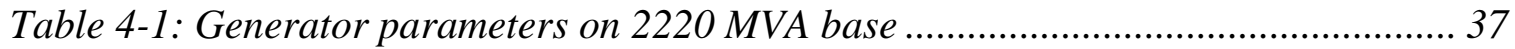

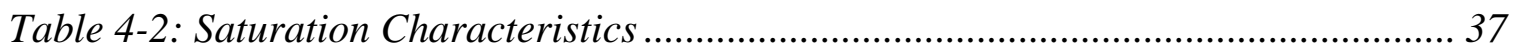

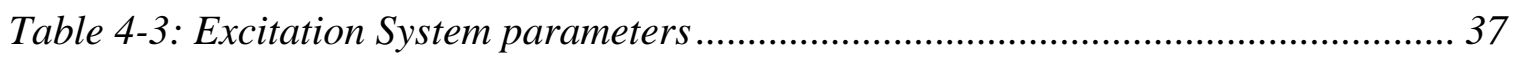

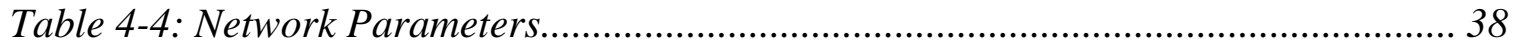

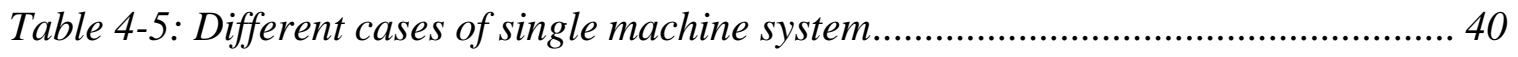

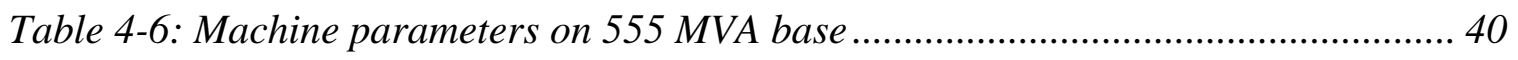

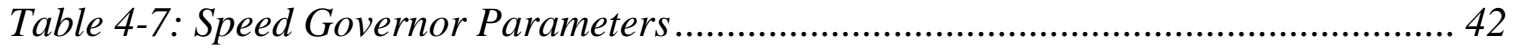

Table 4-8: Generator data on 1000 MVA base .......................................................... 43

Table 4-9: Saturation characteristics of 1000 MVA machine ........................................ 43

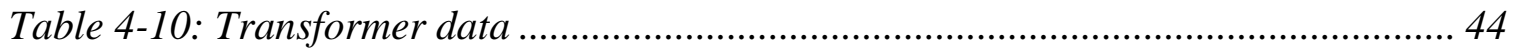

Table 4-11: Network Parameters with Sequence Data................................................ 45

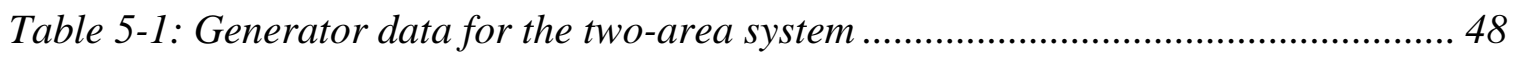

Table 5-2: Saturation characteristics of the two-area system ......................................... 48

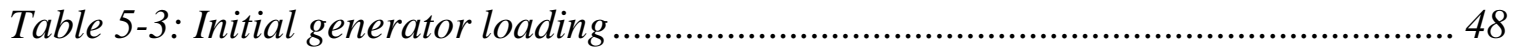

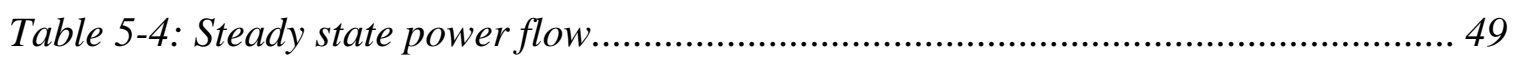

Table 5-5: Transmission line data for the two-area system .......................................... 50

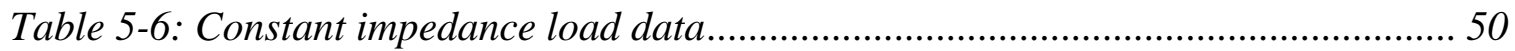

Table 5-7: Generator parameters of the reduced system ............................................. 55

Table 5-8: Initial generator loading of the reduced system ........................................... 55

Table 5-9: Network parameters of the reduced system ................................................. 57

Table 6-1: Three-phase line fault in one of the transmission lines at generator end....... 58

Table 6-2: Fault in one of the transmission line at generator end (with AVR and PSS).. 68

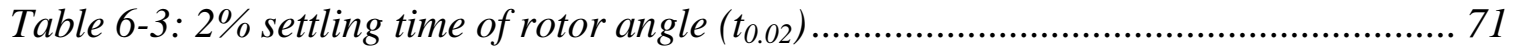

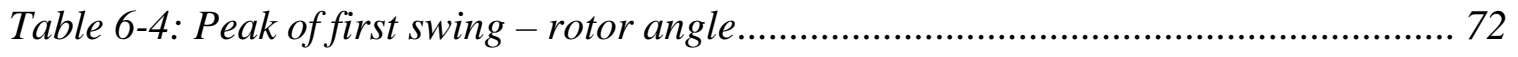

Table 6-5: Different cases of the two-area system...................................................... 72

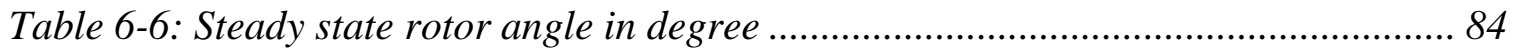

Table 6-7: Peak of first swing of power flow ............................................................ 84 
Table A-1: O. C test results for saturation points $S(1.0)$ and $S(1.2)$............................. 93

Table A-2: O.C. test results for saturation points $S(0.8)$ and $S(1.2)$............................ 93

Table A-3: O.C. test results for unsaturated machine model ....................................... 94

Table A-4: Load-flow results for the reduced system .................................................... 98

Table A-5: Constant impedance load data for the reduced system ................................ 98

Table B-1: Steady state rotor angle (in degree) ....................................................... 104

Table B-2: Peak of first swing of rotor angle (degree).............................................. 104

Table B-3: Frequency of rotor angle oscillations $(\mathrm{Hz})$.............................................. 104

Table B-4: Steady-state terminal voltage (p.u)...................................................... 105

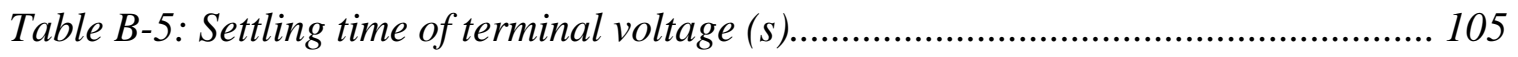

Table B-6: Frequency of terminal voltage oscillations $(\mathrm{Hz})$...................................... 105

Table B-7: Steady-state power flow between Areal and Area 2 ................................. 106

Table B-8: Frequency of power flow between Area 1 and Area 2.............................. 107 


\section{CHAPTER 1 INTRODUCTION}

The huge increase in the demand for electricity in recent years along with the deregulation of power industry has put lot of pressure on power system operators. The cost and economical impact of blackouts are also increasing and it has become mandatory for utilities to supply reliable power to all the customers. The August 14, 2003 blackout of the eastern interconnection is a wake-up call to power system operators. In order to avoid such blackouts more emphasis should be given on power system protection. Reliability of the power system can be improved by correctly simulating various power system events and their impacts on the whole interconnected grid.

Observing power swings using real-time recorders can help in learning the mistakes and plan for future. But it is important to predict system behaviors and take precautionary actions to avoid blackouts. In order to make reliable predictions about system behaviors, we must continually develop and apply modern modeling and simulation tools to be used for power system studies. The Alternative Transients Program (ATP) is one such tool used to model various power system components and perform time-domain transient simulations. ATP can also be used for stability studies. This additional feature of ATP can be tested by comparing the models and results with a phasor-domain simulation tool designed to perform stability analysis. One such tool is Power System Simulator for Engineers (PSS/E).

ATP, a time-domain simulation package, can be used to study both power system transients and power system stability. Some of the features of ATP are:

- Time step can range from very low (less than $0.1 \mu \mathrm{s}$ ) for transient simulations to very high $(1 \mathrm{~ms})$ for stability studies.

- TACS, an s-block control system, is used to represent power system controls.

- Trapezoidal integration method is used for the simulations.

- Length of simulations can vary from a few milliseconds to a few seconds, to observe high-frequency oscillations and power swings respectively.

- Graphical User Interface (GUI) is used for entering input data.

- ATP can be used to model 1000's of buses. 
PSS/E, a phasor-domain simulation package, can be used only for load flow, short-circuit, and stability studies. Some features of PSS/E are:

- PSS/E performs phasor-domain network analysis and is not capable of transient simulations.

- In PSS/E, machine and control dynamics are simulated in time-domain. Smallest possible time step size is $8.333 \mathrm{~ms}$.

- All IEEE standard control systems for synchronous machine are available as built-in blocks.

- Modified Euler's integration method is used for the simulations.

- Length of the simulation is always higher than hundreds of milliseconds.

- Input data files are used to enter data.

- Maximum number of buses that can be modeled in PSS/E is 150,000.

Load shedding, system separation and islanding, advances in tripping and reclosing techniques, and out-of-step protection are some areas which need special attention in order to keep the grid intact at times when it is taxed to its limit.

One of the objectives of this research is to model a power system in ATP for stability studies and benchmark the system against PSS/E. It is usual practice to model the source as an ideal voltage source in ATP, but this comes with the cost of losing the generator dynamics. This research work involves detailed modeling of synchronous machine and its control interfaces. Saturation characteristics of synchronous machine models are observed by conducting open-circuit tests. Another approximation used while modeling power systems in ATP is to represent large power system as Thevenin shortcircuit equivalent or infinite bus. The results of such reduced systems may not be reliable as the dynamics of rotating machines are neglected. Solving this problem by representing large power systems as their dynamic equivalents and helping future researchers in modeling large power systems is another objective of this research work.

Different single machine cases are modeled and used for studying balanced and unbalanced faults. Single-pole tripping and reclosing strategy is modeled and compared with traditional three-pole tripping and reclosing strategy. A two-area system is modeled in ATP and then replaced by a dynamically reduced system. PSS/E, which can handle large power system models but limited only for stability studies in phasor-domain, is used to obtain the dynamic equivalents. The two-area system with four machines is reduced to 
a two-machine system. The reduced system is then benchmarked against the original system and the PSS/E models.

Representing synchronous machines with control interfaces and dynamic equivalents in ATP is a real challenge and will be a milestone in power system protection and stability studies. Benchmarked cases of single machine systems and two-area system will help future works on advanced protection techniques and wide area monitoring. Figure 1.1 shows the two-area system under study. Future work can involve modeling Mid-continent Area Power Pool (MAPP) systems both in ATP and PSS/E and comparing the results against the June 1998 event [13].

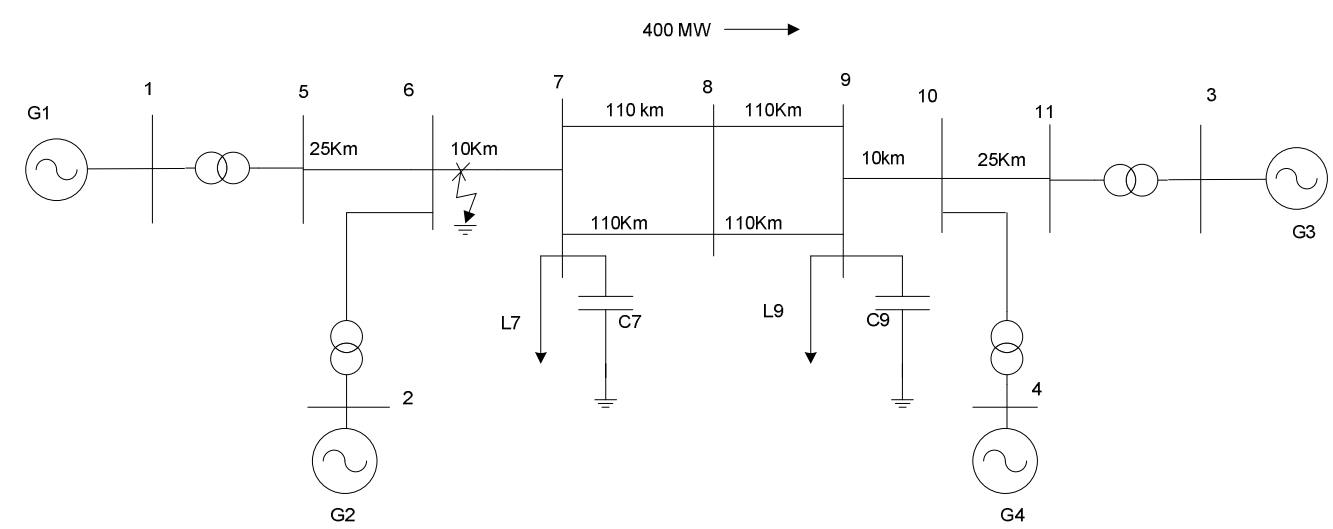

Figure 1.1: System under study

In summary, the specific objectives are:

- Modeling of synchronous machine and its control interfaces in ATP to observe generator dynamics.

- Representing excitation control system, power system stabilizer and speed governing system using TACS.

- Conducting open-circuit tests to study the saturation characteristics of generator.

- Modeling several single-machine cases in ATP to study rotor angle and voltage stability.

- Studying power system unbalance and single-pole tripping and reclosing strategy using the single-machine cases.

- Model a two-area system to study small signal stability of power system.

- Dynamically reduce the two-area system and model the reduced system for stability and transient studies.

- Compare or "benchmark" all the cases with PSS/E to test the ability of ATP to perform stability studies. 
In this thesis, Chapter 2 presents the pre-existing work on power system modeling and stability studies, an introduction to ATP and its graphical user interface ATPdraw, single pole tripping and reclosing techniques, implementation modules for various components and control systems in ATP, representation of dynamic equivalents in ATP and an introduction to PSS/E.

Chapter 3 describes synchronous machine modeling along with its control interfaces. Details of excitation control system, power system stabilizer and turbine governor system are included. It also includes the details of transmission line models, transformer models and load models used to represent the systems under study.

Chapter 4 outlines the modeling of a single machine system. Implementation of different base cases for the study of balanced and unbalanced faults is discussed. The system implementation is covered with details of parameters at the component level.

Chapter 5 describes the modeling of the two-area system under study. Modeling of reduced system and observing power swings for different power system disturbances are also discussed.

Chapter 6 explains the simulation and results obtained by applying various faults in the system. It also includes benchmarking of all the cases against PSS/E.

Chapter 7 provides conclusions and recommendation for future research. 


\section{CHAPTER 2 \\ BACKGROUND INFORMATION AND EXISTING WORK}

This chapter provides information about preexisting work in power system protection, discusses the dynamic equivalencing of large power systems, power system stability, and the details of the basic tools used for simulation. The discussion includes the details of control system models and its modeling tool Transient Analysis of Control System (TACS).

\subsection{LITERATURE SEARCH}

Modeling of a highly interconnected power system is very important in order to investigate and avoid cascading faults and blackouts. Different types of power system faults, instabilities and advanced power system operation and protection techniques can be studied only if there is a reliable model.

The final report of August, 2003 blackout [20] and its technical analysis [15] give the complete details and causes of that major blackout. They are interesting sources of information for the motivation of this research. Size and cost of major blackouts make it mandatory for the power system operators to improve the reliability of the modern power systems. Implementation of new protection schemes and modifications of the existing control technologies are the only way to prevent the power system blackouts. It is important to investigate cause and effects, before implementing any changes. Modeling power system on real-time basis and simulating different operating condition is the only way to do this. Modeling power systems in different types of simulation tools and benchmarking them against each other is one of the major tasks in preventing the blackouts. The disturbance in northern Mid-continent Area Power Pool (MAPP) and northwestern Ontario region during June 1998 is one such event which can be used for benchmarking power system models. The final report on this disturbance [13] discusses the power swings and the different instabilities, which can be compared by modeling and simulating similar events. The voltage, rotor angle and frequency waveforms during this event at various buses can be used in the process of comparison and benchmarking.

Modeling dynamic and transient behavior of synchronous machines is a major task. Kundur [9] talks about the details of synchronous machine modeling, small signal 
stability and transient stability, representation of transmission lines, transformers and loads. The relation between the $\mathrm{dq} 0$ parameters and the phase co-ordinates, flux linkages, self and mutual inductances of the rotor and stator windings, and mechanical input equations and swing equations discussed in [9] give clear understanding of synchronous machine parameters. This information will give strong background knowledge in representing the synchronous machine parameters in software tools. The excitation system models, power system stabilizers, and speed governing system and their interaction with synchronous machines described in [5], [6], [7], [8], [9] and [12] help in representing the control system models. Details of the control system blocks, different standards used for hydro and steam units, typical time constants, gain values, recommendations in the usage of different control systems, and effects of the control system parameters on power system stability discussed in the above mentioned references help in gaining in-depth knowledge required to model these control systems.

The Alternate Transients Program (ATP) is the main simulation tool used in this research work. [3], [11] and [14] explain the theory, rules in modeling various components and expanded capability of this tool in power system studies. Power system stability as discussed in [9] and [10] helps with understanding the different types of power system stability and their importance while simulating modern interconnected power systems.

Out-of-step protection, system islanding, single-pole tripping and reclosing, and load shedding are the main areas of interest. Bhargava [2] and Esztergalyos [4] discuss the transient analysis of single-pole tripping and reclosing strategies in transmission lines which can be simulated and analyzed in a large power system. Advantages and difficulties in implementing single-pole tripping and reclosing in comparison with the traditional three-pole tripping strategy can be understood from studying the 1998 MAPP system disturbance [13]. A reduced dynamic equivalent is very important when doing detailed local modeling. This helps in reducing the size of the system with the advantage of preserving the dynamics of the system which has to be reduced. Tripathi [16], Wang [21] and Yang [22] develop methods for dynamic equivalencing of large interconnected power system. 


\subsection{POWER SYSTEM DYNAMICS AND STABILITY}

Major blackouts since 1920 have made it clear that power system instability is an important problem that must be dealt with to have secure operation of power systems. Transient angle instability has been the dominant stability problem, but nowadays voltage instability, frequency instability, and inter-area oscillations have also become major stability problems. A clear understanding of different types of instabilities and how they are inter-related is essential for satisfactory modeling of power systems. A systematic basis for classifying power system stability is discussed in Kundur [10]. Power system stability is similar to stability of any other dynamic system and hence the mathematical theory of stability of dynamic systems will help in understanding the power system stability.

"Power system stability is the ability of an electric power system, for a given initial operating condition, to regain a state of operating equilibrium after being subjected to a physical disturbance, with most system variables bounded so that practically the entire system remains intact. [10]"

Stability is a condition of equilibrium between opposing forces. Depending on the network topology, system operating condition and the nature of disturbance, different sets of opposing forces may experience imbalance in their equilibrium resulting in different forms of instability. In order to identify the causes of instability and develop corrective measures, it is necessary to classify power system stability. Figure 2.1 gives the classification of power system stabilities. However, for a given situation, any one form of instability may not occur in its pure form. The instabilities are inter-related and there is always possibility of one form of instability resulting in another form.

Even though the classification of power system stability is an effective framework for dealing with specific problems, the overall stability of the system should be given importance. Solutions to one type of instability should not be at the cost of another form of instability. A system is said to be secure when it is stable not only during the above discussed power system instabilities but also during other contingencies such as equipment failure. Reliability is the overall objective for the power system design. The 
system will be reliable when it is secure. Stability analysis is thus an integral component of system security and reliability assessment.

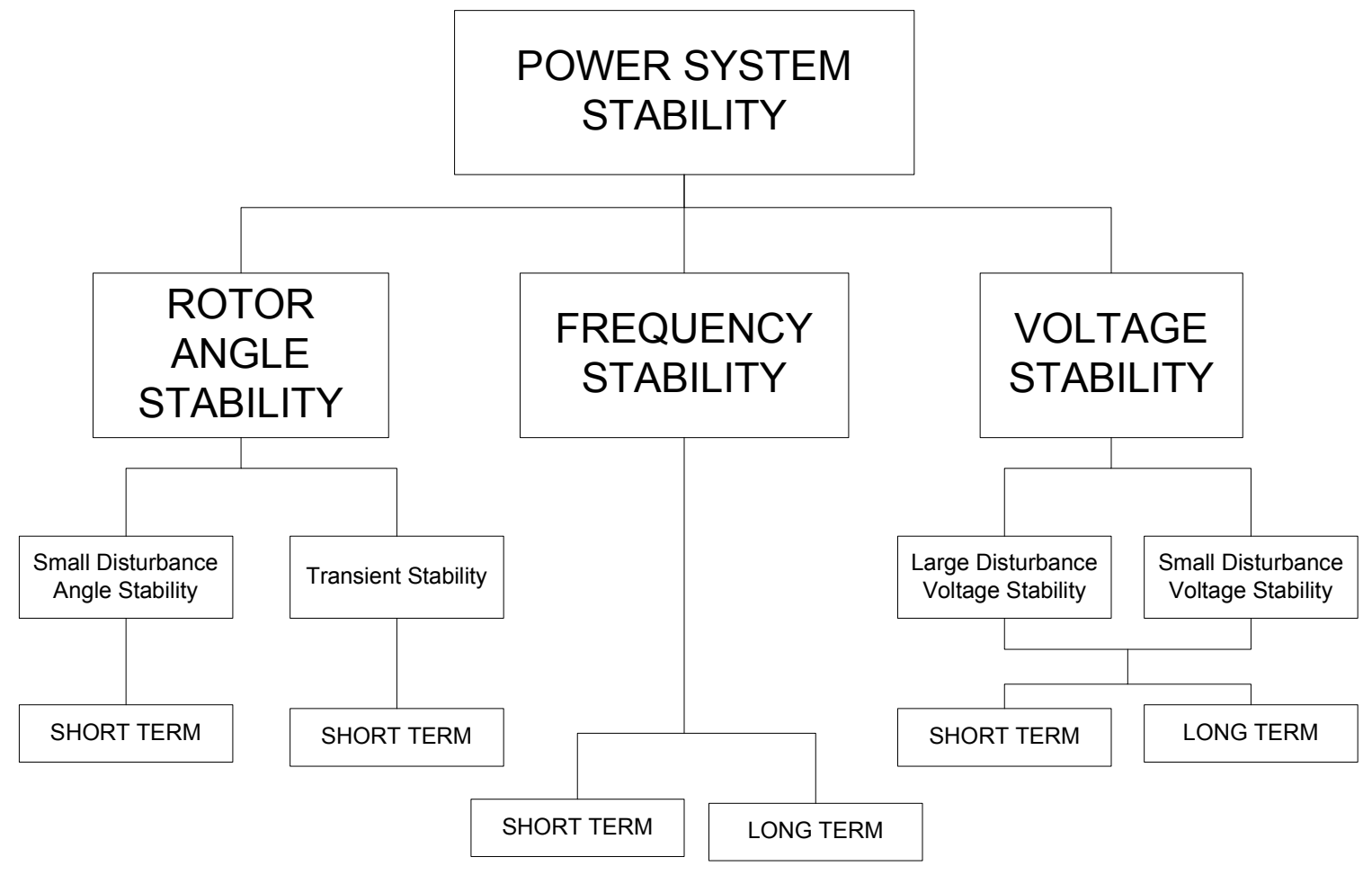

Figure 2.1: Classification of power system stability [10]

The synchronous machine is of central importance in stability studies as most instabilities are directly related to rotating machines. The synchronous machine model discussed in Kundur [9] gives clear idea about the mathematical relations and dynamics of the machine.

Synchronous machines consist of two essential elements: the field and the armature. The field winding carries direct current and produces a magnetic field which induces alternating voltages in the armature windings. The armature windings usually operate at a voltage that is considerably higher than that of the field and thus they require more space for insulation. They are also subjected to high transient currents and induced forces and must have adequate mechanical strength. When carrying balanced three-phase currents, the armature will produce a magnetic field in the air-gap rotating at synchronous speed. The air-gap flux $\left(\mathrm{B}_{\mathrm{AG}}\right)$ is the difference of field flux $\left(\mathrm{B}_{\mathrm{FIELD}}\right)$ and armature flux $\left(\mathrm{B}_{\mathrm{ARM}}\right)$. There are two basic rotor structures used, depending on the rotating speed. Hydraulic turbines operate at low speeds and the rotors have large number of poles which 
are salient or projected. Steam and gas turbines operate at high speeds and the rotors are round (or cylindrical) with two or four poles. Figure 2.2 shows the stator and rotor circuits of a synchronous machine.
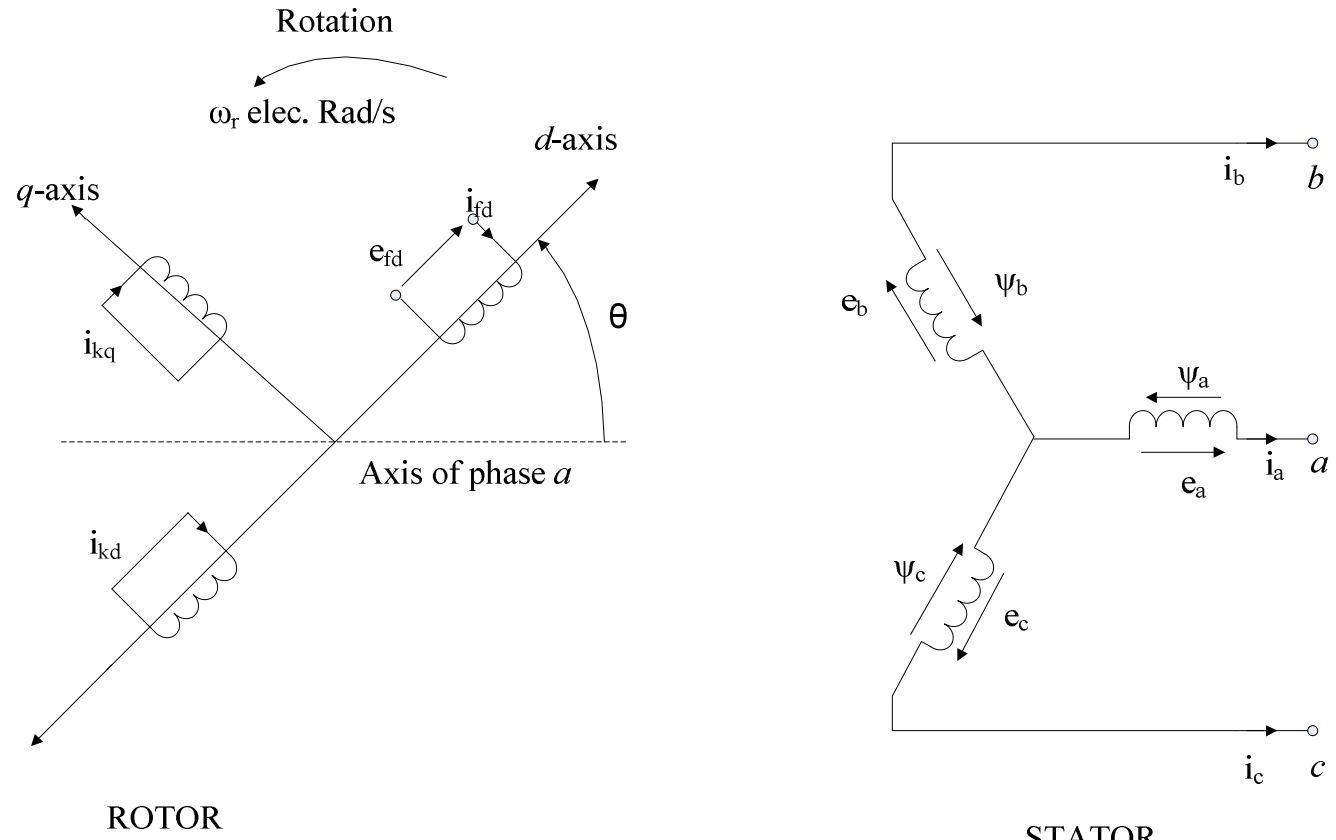

Figure 2.2: Stator and rotor circuits of a synchronous machine [9]

The following notations are used in writing the equations for stator and rotor circuits.

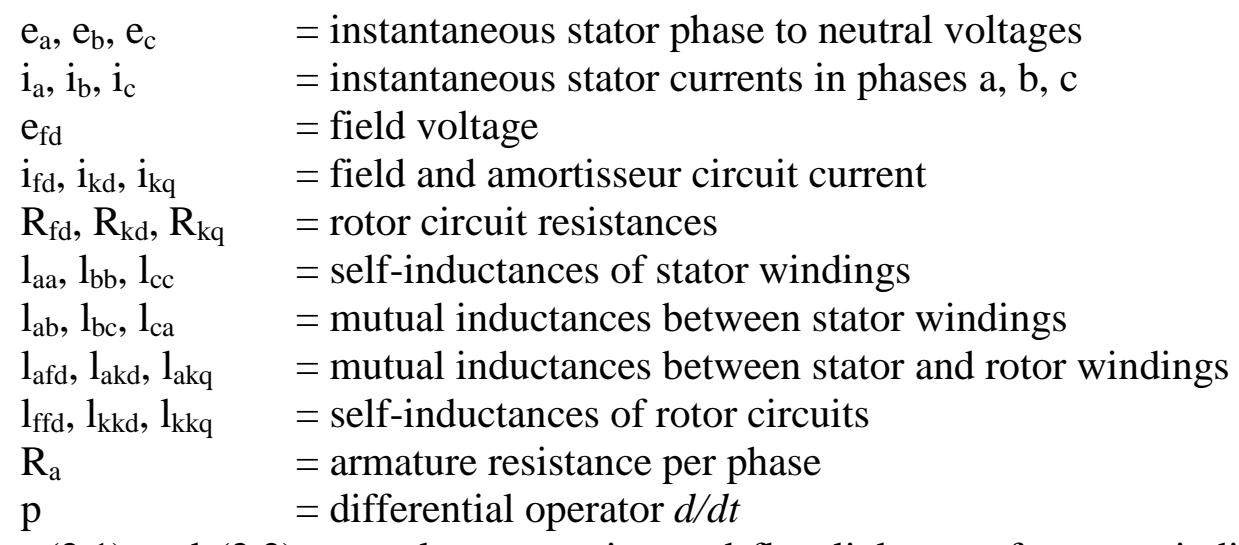

(2.1) and (2.2) are voltage equation and flux linkages of stator winding ' $a$ ' and similar expression apply to voltage equations and flux linkages of stator windings ' $b$ ' and 'c'. 


$$
\begin{gathered}
e_{a}=\frac{d \psi_{a}}{d t}-R_{a} i_{a} \\
\psi_{a}=-l_{a a} i_{a}-l_{a b} i_{b}-l_{a c} i_{c}+l_{a f d} i_{f d}+l_{a k d} i_{k d}+l_{a k q} i_{k q}
\end{gathered}
$$

Similarly, (2.3) through (2.8) give the rotor voltage equations and flux linkages.

$$
\begin{gathered}
e_{f d}=p \psi_{f d}+R_{f d} i_{f d} \\
0=p \psi_{k d}+R_{k d} i_{k d} \\
0=p \psi_{k q}+R_{k q} i_{k q} \\
\psi_{f d}=L_{f f d} i_{f d}+L_{f k d} i_{k d}-L_{a f d}\left[i_{a} \cos \theta+i_{b} \cos \left(\theta-\frac{2 \pi}{3}\right)+i_{c} \cos \left(\theta+\frac{2 \pi}{3}\right)\right] \\
\psi_{k d}=L_{f k d} i_{f d}+L_{k k d} i_{k d}-L_{a k d}\left[i_{a} \cos \theta+i_{b} \cos \left(\theta-\frac{2 \pi}{3}\right)+i_{c} \cos \left(\theta+\frac{2 \pi}{3}\right)\right] \\
\psi_{k d}=L_{k k q} i_{k q}+L_{a k q}\left[i_{a} \sin \theta+i_{b} \sin \left(\theta-\frac{2 \pi}{3}\right)+i_{c} \sin \left(\theta+\frac{2 \pi}{3}\right)\right]
\end{gathered}
$$

(2.9) and (2.10) give the instantaneous three-phase power output of the stator $\left(\mathrm{P}_{\mathrm{t}}\right)$ and the air-gap torque $\left(\mathrm{T}_{\mathrm{e}}\right)$. The air-gap torque is obtained by dividing the power transferred across the air-gap by the rotor speed in mechanical radians per second.

$$
\begin{gathered}
P_{t}=e_{a} i_{a}+e_{b} i_{b}+e_{c} i_{c} \\
T_{e}=\frac{3}{2}\left(\psi_{d} i_{q}-\psi_{q} i_{d}\right) \frac{\omega_{r}}{\omega_{\text {mech }}}
\end{gathered}
$$

When there is an unbalance in torques acting on the rotor, there will be a net torque causing acceleration or deceleration. The combined inertia of the generator and prime mover is accelerated by the unbalance in the applied torques. (2.11) is the equation of motion.

$$
J \frac{d \omega_{m}}{d t}=T_{a}=T_{m}-T_{e}
$$

where

$$
\begin{array}{ll}
\mathrm{J} & =\text { combined moment of inertia of generator and turbine, } \mathrm{kg} \cdot \mathrm{m}^{2} \\
\omega & =\text { angular velocity of the rotor, mech. rad/s } \\
\mathrm{t} & =\text { time, } \mathrm{S} \\
\mathrm{T}_{\mathrm{a}} & =\text { accelerating torque in N.m } \\
\mathrm{T}_{\mathrm{m}} & =\text { mechanical torque in N.m } \\
\mathrm{T}_{\mathrm{e}} & =\text { electromagnetic torque in N.m }
\end{array}
$$


(2.11) can be normalized in terms of per unit inertia constant $\mathrm{H}$, defined as the kinetic energy in watt-seconds at rated speed divided by the VA base. Using $\omega_{0 \mathrm{~m}}$ to denote rated angular velocity in mechanical radians per second, the inertia constant is given by (2.12).

$$
H=\frac{1}{2} \frac{J \omega_{0 m}^{2}}{V A_{b a s e}}
$$

It is often desirable to include a component of damping torque, not accounted for in the calculation of $\mathrm{T}_{\mathrm{e}}$ separately. This is accomplished by adding a term proportional to speed deviation in the equation of motion and the equation in terms of rotor angle $\delta$, yielding the form of the swing equation given in (2.13).

$$
\frac{2 H}{\omega_{0}} \frac{d^{2} \delta}{d t^{2}}=T_{m}-T_{e}-\frac{K_{D}}{\omega_{0}} \frac{d \delta}{d t}
$$

\subsection{ATP AND TACS MODELING}

ATP, the royalty-free version of Electromagnetic Transient Program (EMTP), is the most widely used power system transient simulation program. ATP along with its Transient Analysis of Control System (TACS) is a sophisticated tool available not only for transient studies but also for detailed representation of the modern interconnected power systems and related controls. This feature of ATP can be used for this research in modeling power systems with detailed representation of the synchronous machine models. [3] and [11] discuss the "rules" in modeling power system components and the theory behind it. ATPdraw, the graphical user interface of ATP is a powerful and userfriendly tool for building models and running transient simulations. A few major components used to represent the power system under study are discussed in the following sections.

\subsubsection{Synchronous Machine Models}

The machine model used for the simulations is SM59, which is a synchronous machine with 8 TACS control interface points. The input parameters and their units for SM59 are listed in Appendix A.2. A total of 21 machine parameters (listed in Appendix 
A) can be accessed via the eight TACS node. Of this 21 machine parameters, two are inputs to the machine and the remainder are outputs from the machine. The field voltage input and the mechanical power input are controlled using the excitation system and the speed governor system respectively. The outputs from the machine that are most often used for control applications are field winding current, voltage applied to field winding, electromagnetic torque of the machine, rotor angle, angular velocity, and shaft torque. TACS outputs from the machine should be coupled to the control system blocks using a TACS coupler.

The moment of inertia and self-damping coefficients of the machine can be specified either in English units or in metric units. The time constants to the machine can be based on open circuit or short circuit measurements. SM59 also has the feature of representing multiple machines connected to a single generator bus as a single equivalent machine. When a single machine is used to represent the parallel machines, a proportionality factor should be used to split the real and reactive power among the machines during initialization. Phasor angle specified in the input parameters will be the angle of phase ' $a$ ' armature voltage and phase ' $b$ ' and ' $c$ ' voltages will lag and lead phase ' $a$ ' voltage by $120^{\circ}$ respectively. Figure 2.3 shows the synchronous machine model GUI with eight TACS control interface points.

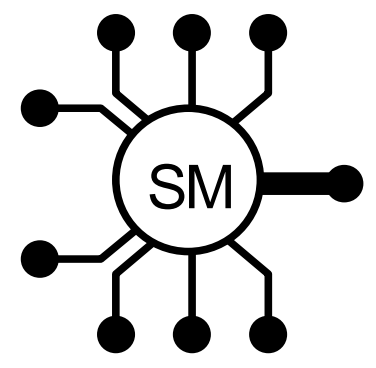

Figure 2.3: SM 59 synchronous machine model

\subsubsection{Transmission Line Models}

Transmission lines can be represented as lumped parameter or distributed parameter. There are two types of lumped parameter transmission line models available: RLC Pi equivalent and RL coupled line models. In distributed parameter transmission line model, transposed (Clarke) and un-transposed (KCLee) are the two models available 
in representing the transmission lines. Different models can be used for different number of phases. Lumped parameter RLC Pi equivalent transmission line model with sequence data is used when positive and zero sequence of the transmission network has to be represented. The transformer data given as input are just the phase values and converted into matrix ( 3 by 3 ) for computational purposes by ATP [3].

The JMarti transmission line is an advanced frequency-dependent transmission line model. The line/cable module of ATPDRAW creates the model by using the LINE CONSTANTS [3] supporting routine. LINE CONSTANTS requires that the physical details of transmission line design be provided. The line data is quite flexible to accommodate different kinds of lines based on their physical dimensions like conductor diameter, line length, phase spacing, tower height, and other factors like earth resistivity and the presence of skin effect [2].

\subsubsection{Transformer Models}

Ideal transformers in ATPDRAW just transform the voltage without any loses are saturation. Both single-phase and three-phase ideal transformers are available. The transformer impedance should be represented as RL series impedance when ideal transformers are used. Ideal transformers are modeled as Type 14 source [3] internally in ATP and hence both primary and secondary windings are grounded.

SATTRAFO is a three-phase saturable transformer with most common configurations. It can be used as a three or two winding transformer and can have all the phase shifts with auto, zigzag, delta and wye connection possibilities. The transformer can be core type or shell type. SATTRAFO can be represented as a 3 legged core type or 3/5 legged shell type transformer. Each winding of the transformer has to be represented by the rated voltage, resistance and inductance of the winding. The saturation characteristic of the transformer is represented with the help of current/flux characteristic curve. SATTRAFO model includes the saturation characteristics of the transformer and can have all type of connections. BCTRAN and HYBRID models are more advanced models. 


\subsubsection{Load Models}

Representing loads in power system modeling and stability studies is important because an increase or a decrease in the load directly affects the rotor angle and voltage stability of the system. Loads can be represented as constant power, constant current and constant impedance loads depending on real-time parameters of the loads. Much of the domestic loads and some industrial load consist heating and lighting, especially in winter, and in load models these were considered as constant impedances [1]. Figure 2.4 and Figure 2.5 show the load characteristics of three different models. In ATPdraw, a constant impedance load can be represented with the help of parallel resistors, inductors and capacitors. The value of the passive components corresponds to the real power, reactive power and the power factor of the load. A constant current load can be represented by a current source in ATPdraw.

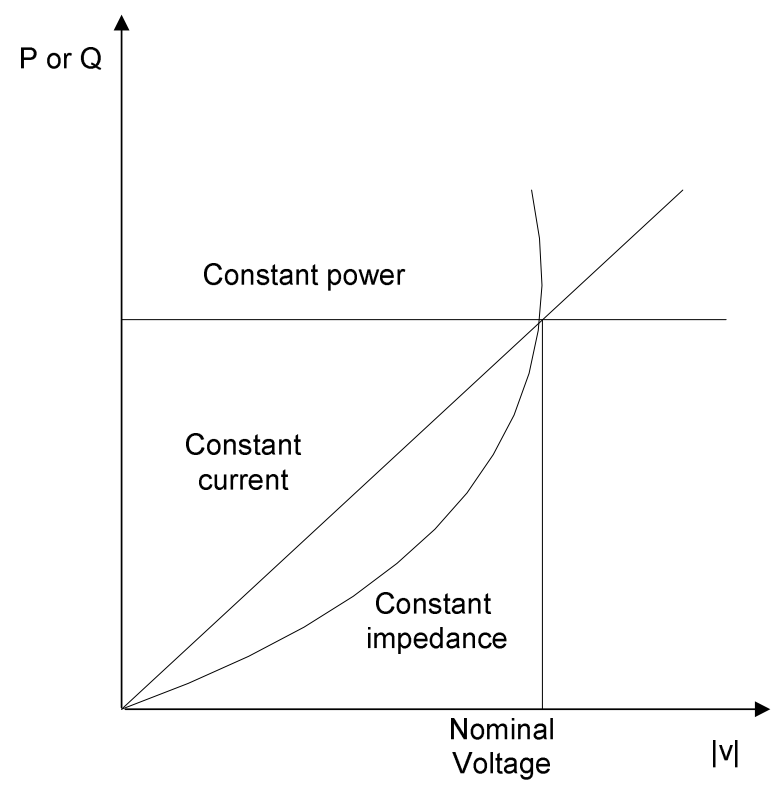

Figure 2.4: Characteristics of load models, power against voltage

The current source is connected to the power system in such a way that it draws a constant current from the source(s) of the power system. The representation of constant power load is possible, but difficult in ATPdraw. The constant power load models have to be built with the help of the parallel passive components whose power consumption is controlled with the help of TACS functions. For this research, constant current and/or constant impedance load models are used. Since the benchmarking of the power systems 
are done against PSS/E, the type of the load models are decided depending on the requirements by PSS/E in representing the power system loads.

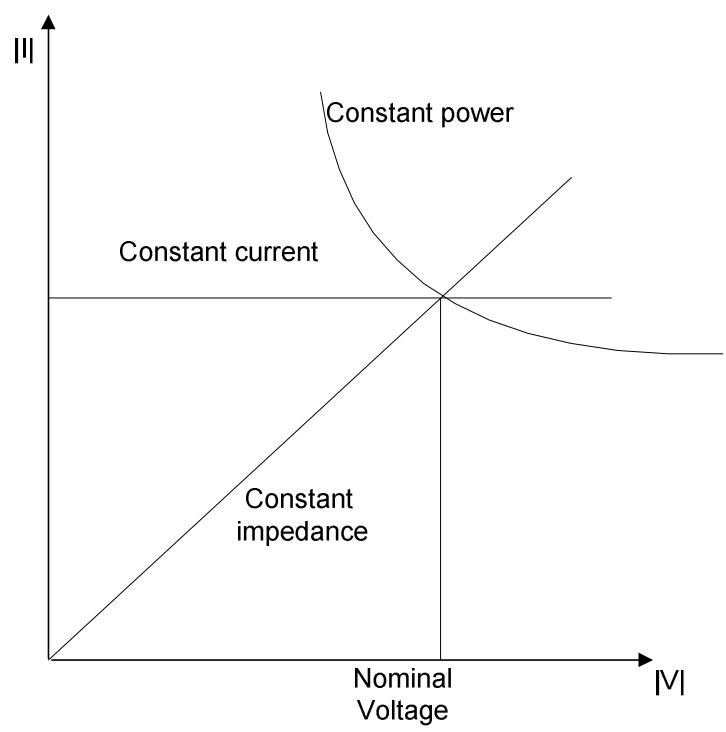

Figure 2.5: Characteristics of load models, current against voltage

\subsubsection{Transfer Functions and Initial Conditions}

The general transfer function model available in TACS is used to represent the time delays, PI controllers and PID controllers present in the power system stabilizers, speed governors and excitation system models. The general transfer function model is in sdomain and can have a maximum of five input signals, two limits (maximum and minimum) and an output signal, as shown in Figure 2.6.

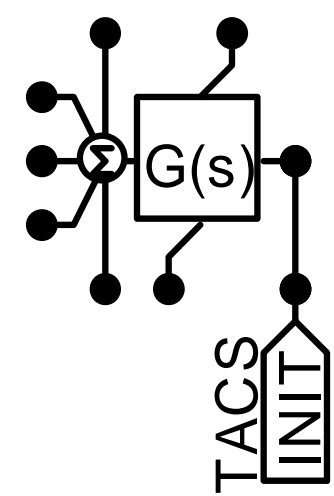

Figure 2.6: General transfer function and initial condition block

The signals can be selected as a positive input, a negative input or an output. The transfer function can have a maximum of seven poles and seven zeros. In other words, 
the maximum order of the transfer function is seven. A gain can be included in the transfer function block to represent the gain of the system. It is necessary to specify the initial conditions for each of the transfer functions because TACS functions are included into ATP simulations only at time $\mathrm{t}=0$. Otherwise the default initial condition for all TACS functions is zero. The zero initial value increases the settling time and often results in over damped oscillations. In order to make the system stable and reduce the settling time, it is very important to specify the steady-state conditions (the conditions before time $t=0 \mathrm{~s}$ ) as initial conditions. The initial conditions are given to the outputs of the transfer functions using INIT function of TACS. The values of initial conditions are found from steady-state analysis results and by simulating open-loop control systems. The values calculated for the initial conditions are thus used to initiate the time step calculations. Input parameters of TACS functions are given in Appendix A.3.

\subsection{SYNCHRONOUS MACHINE CONTROLS}

Though different models used in ATPDRAW to represent the power system are discussed, it is very important to discuss the representation of synchronous machine model. Modeling the synchronous generator and its control system is one of the major objectives of this research. Complete modeling of a synchronous machine includes excitation control, power system stabilizer and speed governor system. Almost all utilities in the United States use the IEEE standard controllers and TACS is an effective tool to model these control systems. In this section, the details of the standard control systems are discussed.

\subsubsection{Excitation System Models}

When the behavior of synchronous machine is to be simulated accurately, it is essential that the excitation systems are modeled with sufficient details. IEEE standards [6] describe in detail the recommended practice on the excitation system models for power system stability studies. Figure 2.7 represents the functional blocks of the excitation system.

The excitation control elements include both excitation regulating and stabilizing functions. The terminal voltage transducer represents the converter used to obtain DC input for the exciter from the AC terminal voltage of the machine. The suffixes UEL and 
OEL represent the over excitation and under excitation limits of the synchronous machine.

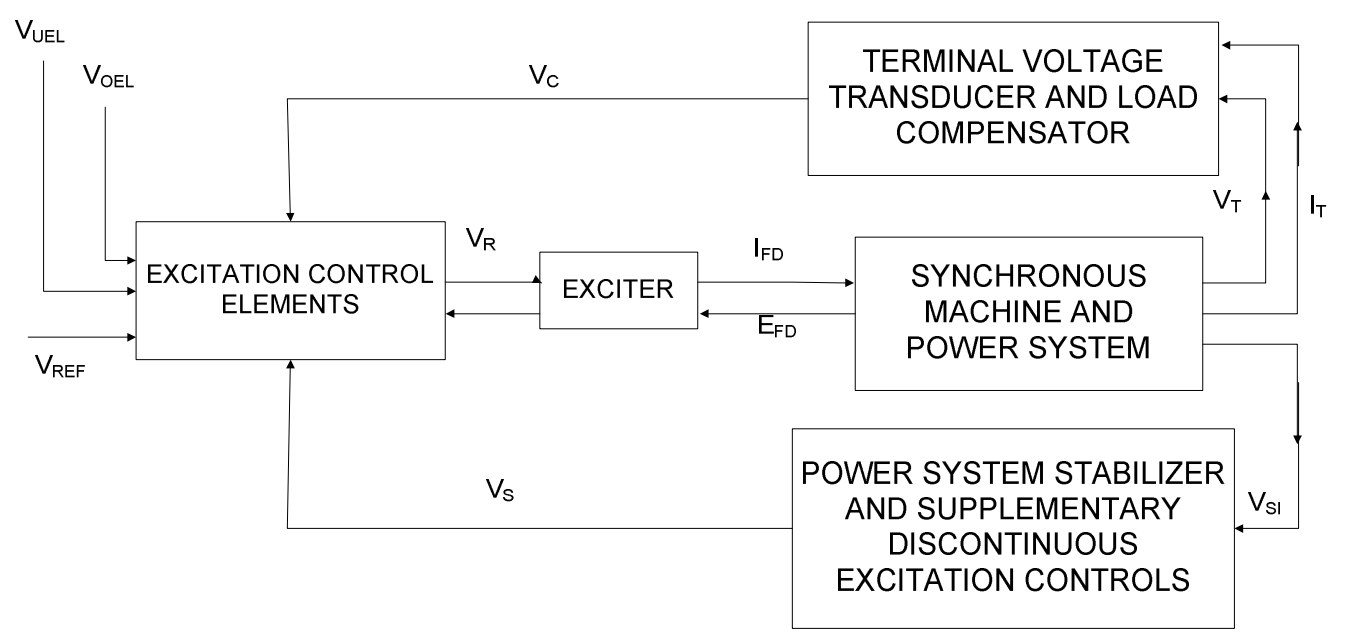

Figure 2.7: Functional block diagram of excitation control system

There are three distinctive types of excitation systems and they are identified on the basis of the excitation power source as Type DC, Type AC and Type ST. A Type DC excitation system utilizes a DC generator as source of excitation. Type AC excitation systems utilizes an alternator and a stationary or rotating rectifiers to produce the direct current needed for the synchronous machine field. And a Type ST Excitation system utilizes transformers or auxiliary generator windings and rectifiers for the source of excitation.

Type AC and ST excitation systems allow only positive current flow to the field of the machine, although some systems allow negative current flow until the voltage decays to zero. When the synchronous machine induces the flow of negative current special provisions should be made to allow the current in these types of exciters. Figure 2.8 shows the simplified IEEE ST1A excitation control system [6].

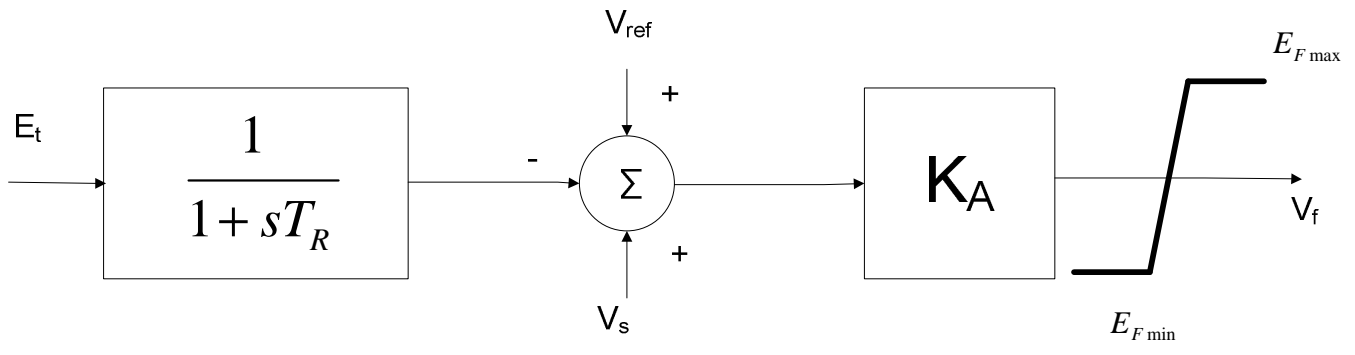

Figure 2.8: Simplified IEEE ST1A excitation system 


\subsubsection{Power System Stabilizers}

Power system stabilizers are used to enhance damping of power system oscillations through excitation control. Power, shaft speed, and terminal frequency are the commonly used inputs for the power system stabilizers. The stabilizer models described in [6] are consistent with the excitation models within the range of frequency response. Stabilizer parameters should be consistent with the type of input signal specified in the stabilizer model in order to provide similar damping characteristics. For pumping units, the stabilizers will be used with the synchronous machine operating either in the generating or in pumping modes. But different parameters are required for the two modes. Different types of power system stabilizers are available and block diagrams of all of them are discussed in [12]. The output of power system stabilizers is control voltage $\left(\mathrm{V}_{\mathrm{s}}\right)$, which is given to the summation block in the excitation system model to increase the damping of power system oscillations. A simplified power system stabilizer, which is used to provide improved stability, is given in Figure 2.9.

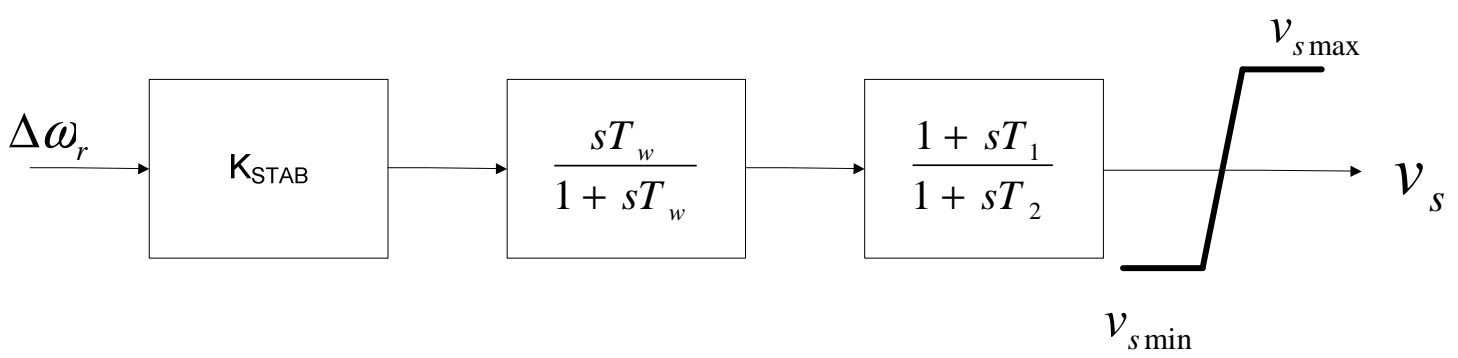

Figure 2.9: Simplified Power System Stabilizer

\subsubsection{Speed Governor System}

The speed governor controls the angular velocity of the synchronous machine by controlling the mechanical power input. Two major types of turbines used in power system are steam and hydro turbines. There are different speed governors for these two types of turbines. Wind turbines are increasingly present and they have a separate control system to control the mechanical power output from the turbine.

Excitation system models and power system stabilizers and their vital role in the power system stability were discussed in the previous sections. Speed governor system is 
equally important as it influences power system stability to a great extent. Figure 2.10 shows a typical turbine control system.

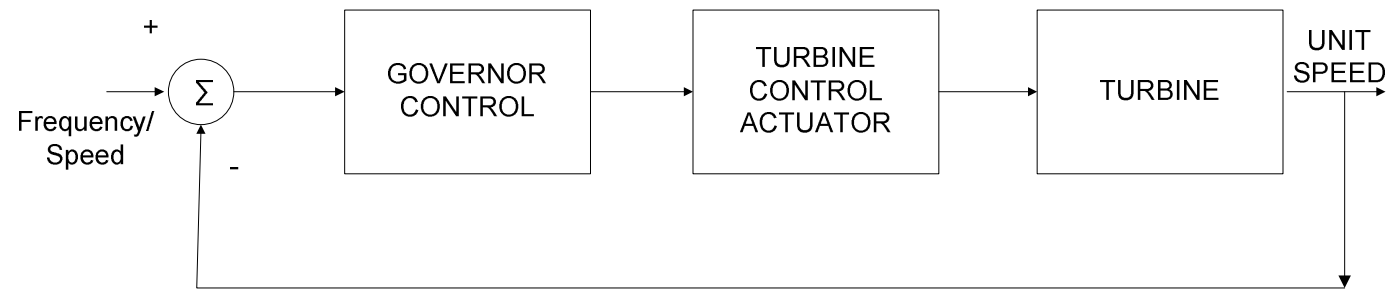

Figure 2.10: Typical governing system

The steam turbine control systems as described in [7] include the speed, load, pressure and valve controls. The purpose of the steam turbine control is to control the speed of the high speed rotor by controlling the mechanical power input. During power swings and power system faults, it is very important to maintain the power system frequency and the synchronism of rotating machine. Pressure and speed of the steam should be controlled so that the power system oscillations are damped out faster and the system returns to stability.

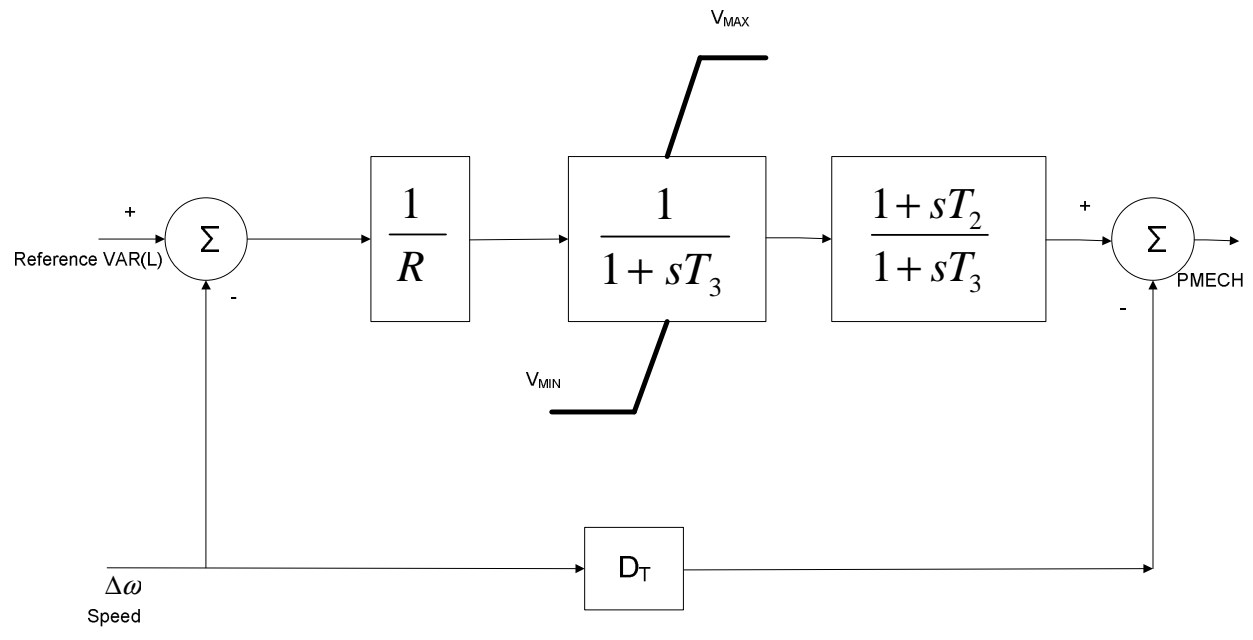

Figure 2.11: IEEE TGOV1 governor

The hydroelectric turbine governing systems as described in [8] looks similar to the steam turbine control systems. But the parameters used for hydroelectric are very different from those used for a steam turbine governor. The rotor speed of the synchronous machine coupled to a hydroelectric turbine is very slow. The synchronous machine in a pumping station will act both as a generator and as a motor and hence the 
turbine control system for such a machine is more sophisticated and requires separate parameters for generator versus motor. Figure 2.11 shows IEEE TGOV1 which is one type of steam turbine governors.

\subsection{INTRODUCTION TO PSS/E}

Another major objective of this research is to benchmark the power system models against PSS/E. PSS/E is a software tool used for transmission planning. It is an integrated, interactive program for simulating, analyzing and optimizing power system performance and it has advanced and proven methods in many technical areas including power flow, optimal power flow, balanced or unbalanced fault analysis, dynamic simulation, extended-term dynamic simulation, open access and pricing, transfer limit analysis, and network reduction. The fault analysis program is fully integrated with the power flow program and the system model includes exact treatment of transformer phase shifts and the actual voltage profile. There is a special feature included in the program for performing independent pole switching which can be used for the analysis of singlepole tripping and reclosing strategies. The power flow program is a powerful planning tool to optimize the transmission system. Steady-state analysis is carried out using the power flow program and it is necessary to carry out the power flow analysis before fault analysis and dynamic simulations. Long-term effects in the frequency deviation caused by the primer mover response and voltage changes caused by the protective equipments can be studied. Variable time-step integration technique is used by PSS/E to minimize the time taken for long-term simulations.

PSS/E can handle very large data base which can include the details of a very large interconnected power system. For example, 108 of thousands of buses in the Midcontinent Area Power Pool (MAPP) system can be studied by doing power flow, fault and dynamic analyses. Also dynamic reduction of such a large power system is possible in PSS/E which is described in Section 2.6.

ATP, which is used for detailed modeling of power system equipments and transient analysis, can utilize the reduced system from PSS/E for the power system stability studies of a largely interconnected power system. Benchmarking ATP against PSS/E will be an important milestone in the reliable computer modeling of 
interconnected power systems. Work similar to this is being done by Singh [19] in a parallel project using PSS/E.

\subsection{DYNAMIC REDUCTION OF POWER SYSTEM}

When stability studies are made in a very large inter-connected power system, it is neither possible nor necessary to model the whole system. The common practice is to represent the system outside the area of interest as a reduced system. If the dynamics of rotating machines are to be preserved for stability studies, then dynamic reduction is the best way to represent the system. As described by Wang [19] and Yang [20], dynamic equivalencing is a three-step process, in which a large system can be reduced into a smaller system retaining the dynamics of the former. Figure 2.12 represents the general power system and the external area is the system that has to be reduced into a dynamic equivalent.

The internal area of interest can be modeled in ATP in detail and the remaining external area can be represented by its dynamic equivalent. Identifying the coherent generators, aggregating them, and reducing the network are the three steps in dynamic equivalencing.

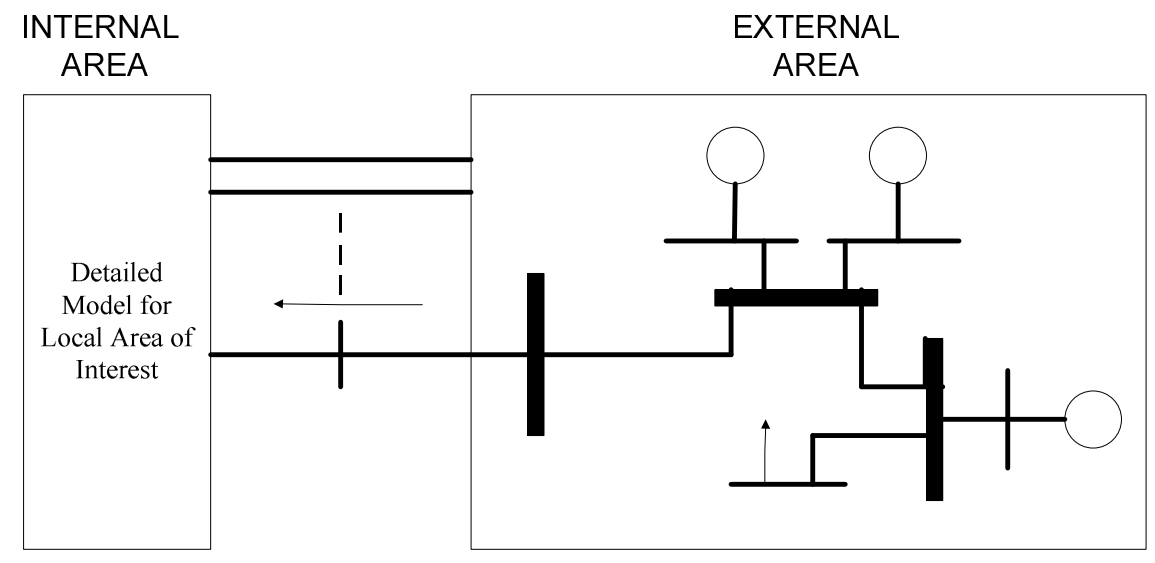

Figure 2.12: Division of complex power network

\subsubsection{Coherency Identification}

Some of the generators in a large interconnected power system tend to swing together after a power system disturbance. The capability of PSS/E in performing dynamic simulations can be used to simulate a large interconnected power system and 
these coherent generators can be identified. Two generators are coherent if the angular difference between them remains constant within a certain tolerance over a time period following a power system perturbation.

$$
\frac{V_{i}(t)}{V_{j}(t)} e^{j\left(\delta_{i}(t)-\delta_{j}(t)\right)}=\text { const } .
$$

Assuming the voltage magnitudes are constant, (2.14) can be further simplified into (2.15).

$$
\delta_{i}(t)-\delta_{j}(t)=\text { const }
$$

In order to identify group of coherent generators, different types of faults can be applied to the system and the rotor angles of the all synchronous generators are observed.

\subsubsection{Generator Aggregation}

After the coherent groups of generators are identified, the generators in a group have to be aggregated into a single generator. All the generator buses in the group can be replaced by a single equivalent bus whose voltage is the average voltage of all the generators buses. (2.16) and (2.17) give the mathematical representation of the voltage and the phase angle of the equivalent bus.

$$
\begin{aligned}
& V_{t}=\frac{\sum_{k=1}^{n} V_{K}}{n} \\
& \theta_{t}=\frac{\sum_{k=1}^{n} \theta_{K}}{n}
\end{aligned}
$$

The connections between the equivalent bus and the other terminal buses are represented via an ideal transformer, whose ratio is given by (2.18).

$$
\alpha_{k}=\frac{V_{k}}{V_{t}}
$$


Where $\mathrm{V}_{\mathrm{k}}$ and $\mathrm{V}_{\mathrm{t}}$ are the complex voltages of the buses ' $k$ ' and ' $t$ ' respectively. The mechanical and electrical powers of the equivalent generator are the sum of the mechanical and electrical powers of the generators in the same coherent group. The angular frequencies of the coherent generators are almost identical and assumed to be same. The inertia and damping constants of the equivalent generator are the sum of those of the generators in the group and the equivalent transient reactance is found by paralleling all transient reactances.

\subsubsection{Static Network Reduction}

In order to reduce the size and complexity of the power system, some of the load buses have to be deleted. This is done by network reduction. Gauss elimination method is applied on the admittance matrix and the loads are eliminated. The node equation of the power system is given by (2.19).

$$
\left[\begin{array}{c}
I_{R} \\
I_{E}
\end{array}\right]=\left[\begin{array}{ll}
Y_{R R} & Y_{R E} \\
Y_{E R} & Y_{E E}
\end{array}\right]\left[\begin{array}{c}
V_{R} \\
V_{E}
\end{array}\right]
$$

Where the subscripts $\mathrm{R}$ and $\mathrm{E}$ represent the nodes to be retained and eliminated respectively. The reduced equation is given by (2.20), where $K_{1}$ represents the distribution matrix which passes the node currents from the eliminated buses to the retained buses and $Y_{R}$ represents the reduced admittance matrix.

$$
I_{R}=Y_{R} V_{R}+K_{1} I_{E}
$$

\subsection{ADVANCES IN POWER SYSTEM PROTECTION}

Single-pole tripping and auto reclosing is an advanced strategy in power system protection. This has been made practicable with the advent of $\mathrm{SF}_{6}$ and vacuum circuit breakers whose poles may be separately tripped and closed. As more than $75 \%$ of the power system faults are single line to ground fault, tripping of all three poles during such a fault is not necessary and also is one of the major problems as more power flow is interrupted than necessary. 
Bhargava [2] discusses the transient analysis of single-pole tripping and reclosing strategies. Advanced studies of power system transients using ATP were done to accurately estimate the influence of the secondary arc and recovery voltage during singlepole tripping and reclosing. The effects of different type of transformer models on secondary arc are carefully studied. Reclosing can be difficult if the line trips while heavily loaded. The voltage angle across the open breaker poles can easily exceed the maximum synchronism check angle, blocking automatic three-pole reclosing. Results from Bhargava [2] indicate that single-pole tripping can be safely performed.

An important means of preventing a total cascading blackout is to provide fast detection of stability problems and to develop methods of temporarily dividing power system into separate islands by means of disconnecting transmission tie lines. Subsequent resynchronization allows restoring normal operating conditions.

When an interconnected power system has become separated into islands, the islands may have an excess of load, overloading the generating units. This will decrease the system frequency and can damage the turbines. To avoid this problem, under frequency load shedding is widely used [9]. But, this traditional load shedding method is too slow in some cases. Hence, an advanced load shedding techniques such as adaptive methods considering the rate of frequency change should be used. And automatic undervoltage load shedding can also be used to prevent voltage instability and voltage collapse.

Wide Area Monitoring (WAM) is a method of real-time monitoring of system dynamics over large geographic areas. Transmission capacity can be increased by online monitoring of the system safety, stability limits and capabilities. Phasor measurement units (PMUs) are required to monitor the state variables and the data has to be shared over the wide area. Data transfer is done by Ethernet or wide area network and means should be provided to enable data security. System wide installed phasor measurement units send their measured data to a central computer, where snapshots of the dynamic system behavior are made available online. This new quality of system information opens up a wide range of new applications to assess and actively maintain system's stability in case of voltage, angle or frequency instability, thermal overload, and oscillations. Wide Area Monitoring is a new technology under development and lot of research is going on this field [21]. 


\section{CHAPTER 3 POWER SYSTEM MODELING USING ATP}

This chapter explains the modeling implementation for various power system components using ATP. Calculations involved in determining various parameters for the models are presented with appropriate examples. The synchronous machine model and its control systems, open circuit characteristics of the generator, transformer and transmission line models and the representation of load are presented in detail.

\subsection{SYNCHRONOUS MACHINE MODELING}

Modeling of the synchronous machine is a key to this work given that power system dynamics is one of the main objectives. The list of input parameters for the synchronous machine model (SM TYPE 59) is given in Appendix A.2. Other than unit conversion for $(\mathrm{J})$, all other parameters can be directly entered. (It is usual practice to use the inertia constant $(\mathrm{H})$ for the synchronous machine modeling). The value of field current which will produce the rated 1.0 per unit armature voltage on the air gap line is entered for AGLINE. This is an indirect specification of the mutual inductance between the field and the armature of the machine.

\subsubsection{Moment of Inertia}

Number of poles of the synchronous machine is specified. Number of poles (p) of the machines is not given in Kundur [9] and hence assumed to be 2 for all the machine models. Since electrical rotor angle is of interest, it is not necessary to have accurate number of poles. Inertia constant $(\mathrm{H})$ is converted into moment of inertia $(\mathrm{J})$ based on a 2-pole machine. (3.1) through (3.3) give the relation between $\mathrm{J}, \mathrm{H}, \mathrm{p}$, frequency (f) and the system base (MVA).

$$
\begin{aligned}
& H=\frac{1}{2} \frac{J(2 \pi R P M / 60)^{2} * 10^{-6}}{M V A-\text { rating }} \\
& H=5.48 * 10^{-9} \frac{J(R P M)^{2}}{M V A-\text { rating }}
\end{aligned}
$$




$$
R P M=120 * f / p
$$

As an example, for the 2220-MVA, 20-kV, 60-Hz, 2-pole synchronous machine used for the simulations with inertia constant $(\mathrm{H})$ of 3.5 , the moment of inertia is calculated as

$$
J=\frac{3.5 * 2220}{5.48 * 10^{-9} * 3600^{2}}=0.1094 * 10^{6} \mathrm{~kg}-\mathrm{m}^{2}
$$

The moment of inertia can be entered either in English $\left(\mathrm{WR}^{2}\right)$ units $\left(\mathrm{lb} \cdot \mathrm{ft}^{2}\right)$ or in the metric units $\left(\mathrm{kg}-\mathrm{m}^{2}\right)$. Metric units are used for this work.

\subsubsection{Output Variables}

The synchronous machine model outputs the phase currents, amortisseur circuit currents, field voltage, mechanical force, velocity, rotor angle, and torque. The field voltage and the rotor angle have to be modified to get the actual values. From ATP rule book [11] and EMTP theory book [3], the field voltage is given by (3.5).

$$
v_{f}=-R_{f} i_{f}=-\frac{d \lambda_{f}}{d t}
$$

Hence, the field voltage output is always negative and the output in the PLOTXY (the plot program used by ATP) must be negated to get the actual field voltage.

Rotor angle is used to observe, compare and benchmark various power system models and operating conditions. The relation between the rotor angle given as the output by ATP and the electrical angle $\left(\delta_{\mathrm{e}}\right)$ is given by the following relation.

$$
\delta_{e}=\frac{p}{2} \delta_{j}-90-\alpha
$$

- $\delta_{j}$ is the angle indicated as ANG1 in the output file of ATP

- $\quad \mathrm{p}$ is the number of poles

- $\alpha$ is the angle of the phase A voltage at time $t=0$ as specified in the input parameters.

An offset of $-(90+\alpha)$ is added to the angle output (ANG1) to get the internal rotor angle $\left(\delta_{\mathrm{i}}\right)$ and if the number of poles is not 2 , then ANG1 is multiplied by a factor of $\mathrm{p} / 2$. 


\subsection{SATURATION OF SYNCHRONOUS MACHINE}

TYPE-59 model in ATPDraw GUI is an unsaturated machine model and changes have to be made manually in the ATP data file to include the saturation characteristics. The following figure shows the open circuit characteristic curve of the saturated SM 59 model along with the air-gap line. SM 59 machine model uses a "two-slope" method to describe the saturation characteristic of the machine. The first slope is the slope of the air gap line which is determined using AD1 and S1. The second slope determines the saturation region of the curve and it uses the slope determined using AD2 and S2. Hence it is important to use appropriate values of S1 and S2 to make the SM 59 model similar to a real synchronous machine.

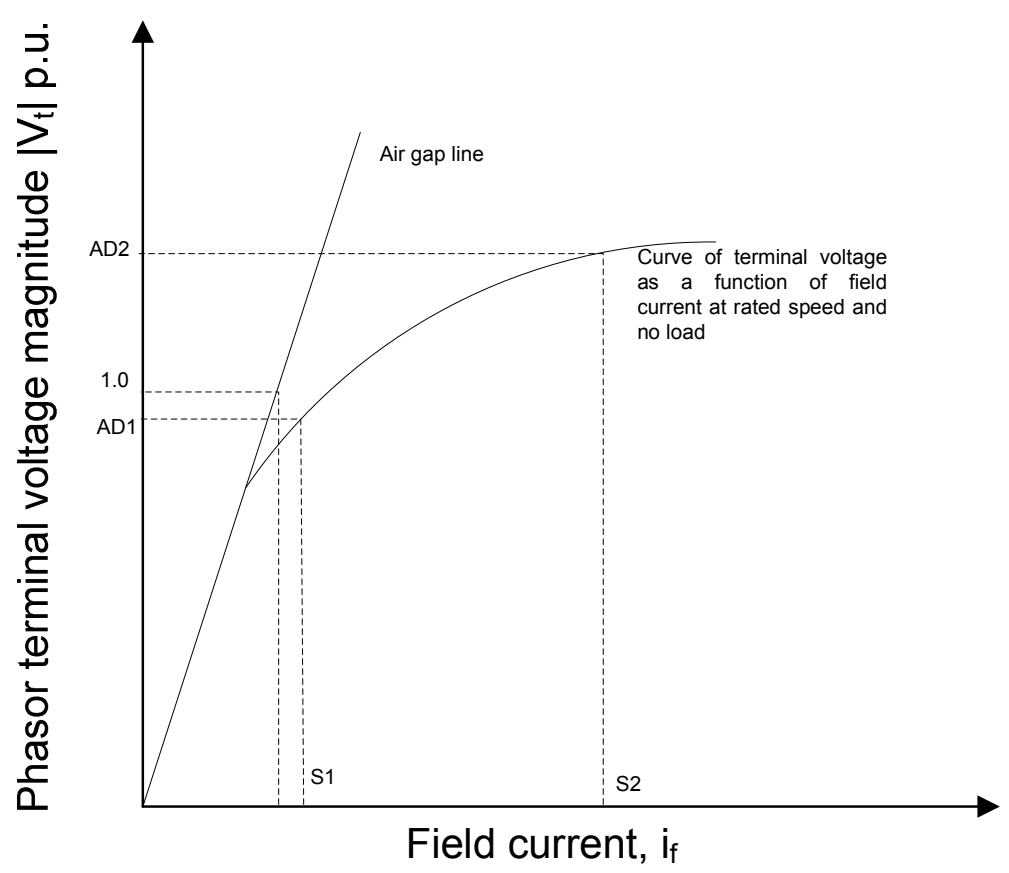

Figure 3.1: Open circuit characteristics

A negative sign in the value of AGLINE act as a flag if the machine is saturable. The changes are made in the first two lines under the heading "Parameter fitting" in the ATP data file. Table 3-1 and Table 3-2 show the first two data cards of TYPE 59 machine model. The d-axis saturation characteristics are entered in the first line of the data card. The value of field currents which produce per unit terminal voltage given in the columns $\mathrm{AD} 1$ and $\mathrm{AD} 2$ are entered in the columns S1 and S2 respectively. The 
typical values for $\mathrm{AD} 1$ and $\mathrm{AD} 2$ are 1.0 and 1.2 per unit. If the q-axis saturation is unknown then a negative value is entered in the AGLQ column and in this case the saturation in q-axis is same as the d-axis. If the q-axis saturation characteristics are known, then a positive value is entered in the AGLQ column. The value of field currents which produce per unit terminal voltage given in the columns AQ1 and AQ2 are entered in the columns S1Q and S2Q respectively.

Table 3-1: SM 59 data card 1

\begin{tabular}{|l|l|l|l|l|l|l|l|l|l|l|l|}
\hline Col. & $1-2$ & $3-4$ & 5 & $7-$ & $11-20$ & $21-30$ & $31-40$ & $41-$ & $51-60$ & $61-$ & $71-$ \\
& & & 6 & 10 & & & & 50 & & 70 & 80 \\
\hline Data & N & K & K & NP & SMOUT & SMOUT & R & R & AGLIN & S1 & S2 \\
& U & M & E & & P & Q & MVA & KV & E & & \\
& M & A & X & & & & & & & & \\
& A & C & C & & & & & & & & \\
& C & & & & & & & & & & \\
\hline
\end{tabular}

Table 3-2: SM 59 data card 1a

\begin{tabular}{|l|l|l|l|l|l|l|l|l|}
\hline Col. & $1-10$ & $11-20$ & $21-30$ & $31-40$ & $\begin{array}{l}41- \\
50\end{array}$ & $51-60$ & $\begin{array}{l}61- \\
70\end{array}$ & $\begin{array}{l}71- \\
80\end{array}$ \\
\hline Data & & AD1 & AD2 & AQ1 & AQ2 & AGLQ & $\begin{array}{l}\text { S1 } \\
\text { Q }\end{array}$ & $\begin{array}{l}\text { S2 } \\
\text { Q }\end{array}$ \\
\hline
\end{tabular}

The data cards for the unsaturated and saturated 2220 MVA, $20 \mathrm{kV}, 2$ pole machines under study is given in Figure 3.2 and Figure 3.3 respectively. The two per unit terminal voltages for which the field currents are specified are 1.0 and 1.2 per unit.

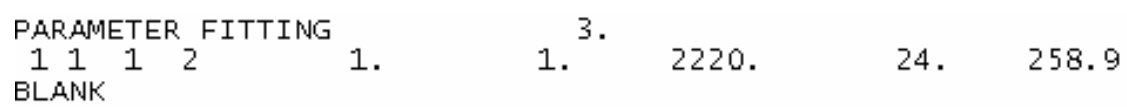

Figure 3.2: SM data cards 1 and 1a for the unsaturated machine under study

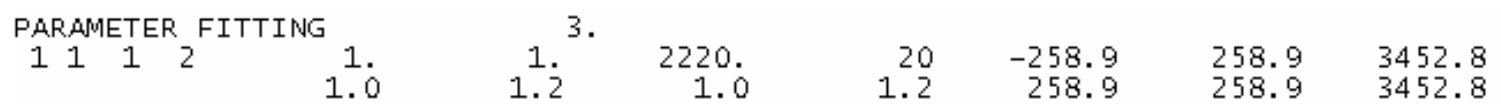

Figure 3.3: SM data cards 1 and 1a for the saturated machine under study

\subsubsection{Open Circuit Tests}

Open circuit tests were carried out for the 2220-MVA, 20-kV machines with and without saturation characteristics. The synchronous machine TYPE 59 was modeled with 
phase terminals loaded with a very high resistance $(10 \mathrm{M} \Omega)$ and the open circuit no-load terminal voltage was observed for different field voltages. The field current is varied by varying the dc field voltage input of the SM 59 model using the TACS node. To test the curve-fitting methods, two open-circuit tests were simulated using two different pairs of $\mathrm{S} 1$ and S2 values. The first test is carried out using the field current values which produce 1.0 and 1.2 per unit terminal voltage and the second test is carried out using the field current values which produce 0.8 and 1.2 per unit. Figure 3.4 shows the open circuit characteristics of the SM 59 machine with two different saturation data. The tabulation of the readings obtained for all the simulations are given in Appendix A(Tables A.1 through A.3).

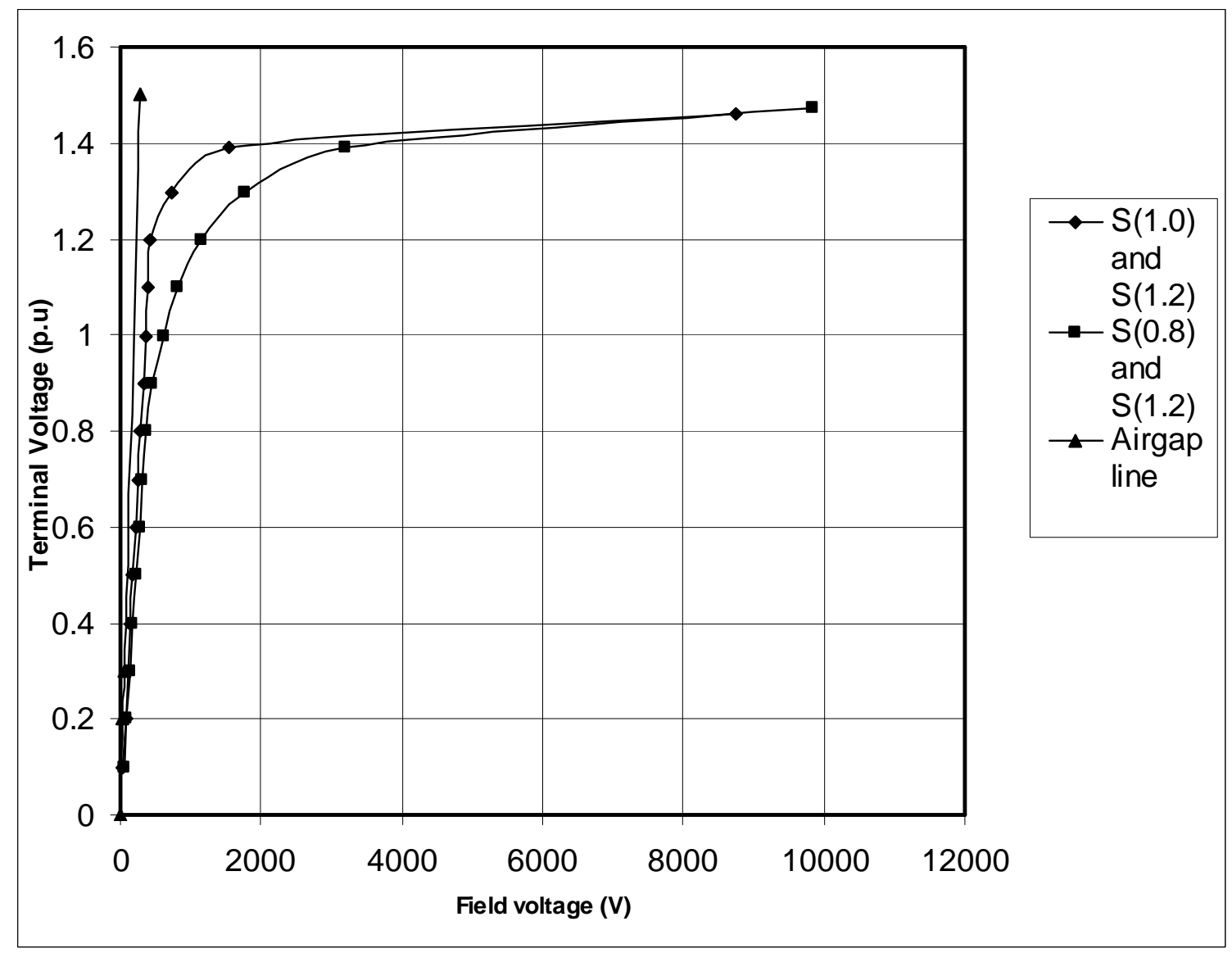

Figure 3.4: OCC of SM 59

The open circuit representation of the first test which uses 1.0 and 1.2 for AD1 and AD2 respectively is used for this work. 


\subsection{EXCITATION CONTROL SYSTEM, SPEED GOVERNOR AND POWER SYSTEM STABILIZER}

The field voltage and the mechanical power input to the machine are the two variables which are available for control input via TACS nodes of the SM 59 synchronous machine model. Excitation system, speed governing system, and power system stabilizers are the three different control system used to control the synchronous machine. It is general practice to use a power system stabilizer with an excitation control system or a speed governor with an excitation control system. All these control systems are modeled for different simulations in this research work. It is necessary to specify the initial condition at each level of the control system as there is a time-step delay between the main ATP electrical circuit model and TACS control blocks. The values specified in the initial condition blocks are taken as the value of the respective levels before time $t=$ 0 . In the ATPDraw GUI, TACS nodes with positive inputs are shown in red color (with a value of 1) and the nodes with negative inputs are shown in blue color (with a value of 2).

IEEE ST1A, a static excitation control system, is the type of control system used for controlling the field voltage input. This control system needs two inputs: per unit terminal voltage $\left(\mathrm{E}_{\mathrm{t}}\right)$ and error signal $\left(\mathrm{V}_{\mathrm{s}}\right)$ from the stabilizer. The per-unit terminal voltage is calculated using the root mean square value of the instantaneous phase voltages divided by the base voltage. The error signal from the stabilizer is non-zero only during system disturbances. For this work, this error signal is obtained from the power system stabilizer output. Figure 3.5 shows the TACS modeling of IEEE ST1 excitation control system corresponding to Figure 2.5.

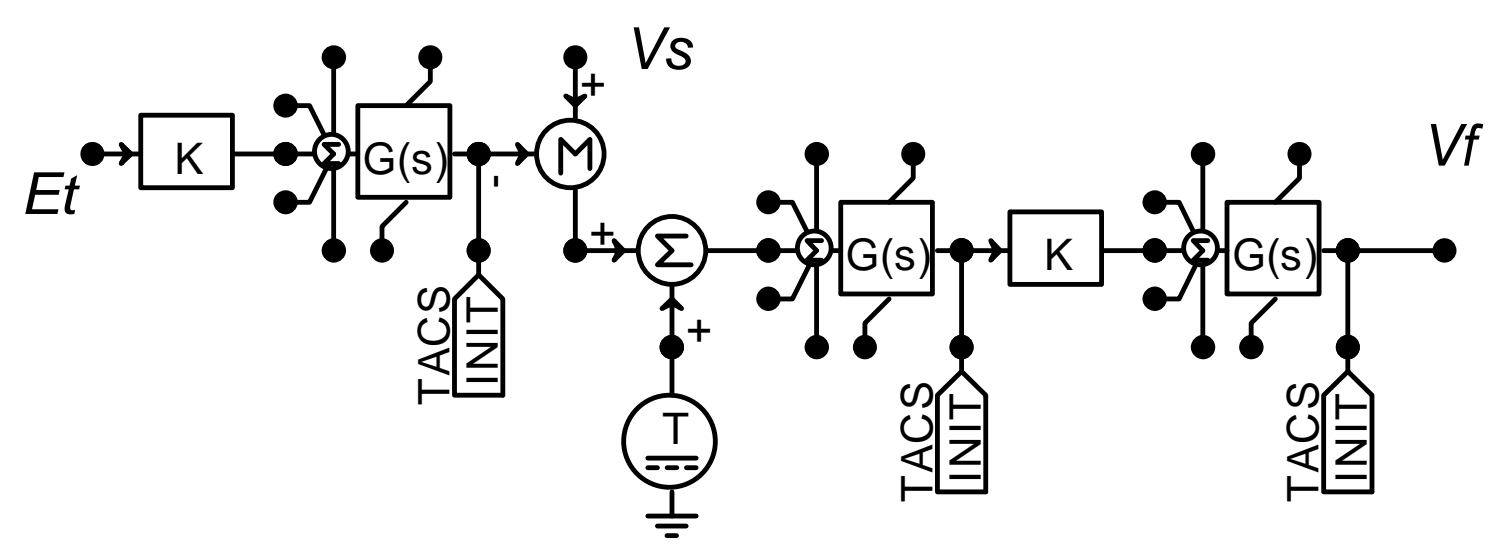

Figure 3.5: IEEE ST1A excitation system model 
The numerical value of $V_{f}$ will be used by the ATP logic for scaling the field voltage value $\mathrm{E}_{\mathrm{FD}}$ of the machine. This scaling is not simply a "multiplication factor", some history terms are involved. If the machine parameter $\mathrm{E}_{\mathrm{FD}}$ has to be scaled using $\mathrm{V}_{\mathrm{f}}$ then relations (3.7) and (3.8) will be applied.

$$
\begin{gathered}
E_{F D}(1)=E_{F D}(2)=E_{F D}(0) * V_{f}(0) \\
E_{F D}(i)=E_{F D}(i-1) * \frac{V_{f}(i-2)}{V_{f}(i-3)} \text { for }, i \geq 3
\end{gathered}
$$

If the logic of the scaling factor has to be modeled and temporarily bypass the associated dynamics, then the TACS value is set to unity. If this TACS node is not used for control, then the ATP logic will simply hold the field voltage of the machine constant, at the value obtained by the steady-state solution.

EEST1 is the type of power system stabilizer used and Figure 3.6 shows the TACS modeling. The block diagram of this power system stabilizer is given in Figure 2.6.

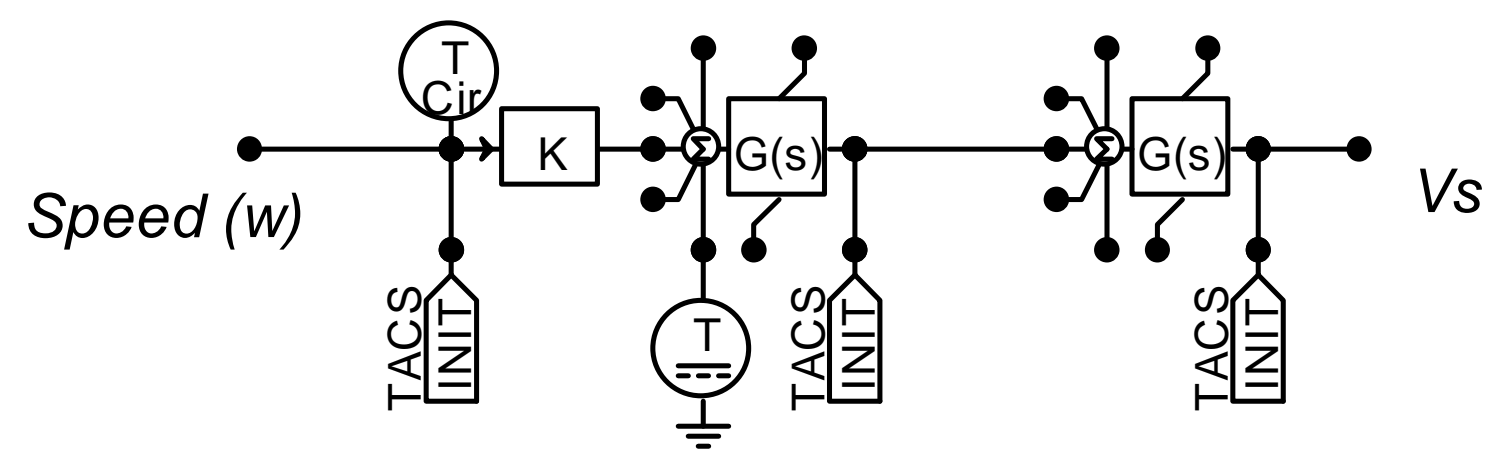

Figure 3.6: EEST1 Power System Stabilizer model

The speed of the rotor is the input which is then converted into its per-unit value. The change in the speed with respect to rated speed $\left(\omega_{0}\right)$ is given as the input to the control system block. The output of the stabilizer is the error signal $\left(\mathrm{V}_{\mathrm{s}}\right)$, which is given to the summation block in the excitation control system to increase the stability of the machine.

TGOV1 is the type of speed governor used in controlling the mechanical power output of the steam turbines. Speed governors help in increasing the stability of the 
power system and are responsible for rotor angle stability in the absence of power system stabilizers. The input to this turbine speed governor system is the rotor speed and it is controlled with respect to the rated speed, $\omega_{0}$. The output of the governor is the mechanical power and this is given as one of the TACS inputs to the SM 59 synchronous machine model. The block diagram is shown in section 2.4.3 (Figure 2.7) and the TACS modeling of TGOV1, turbine governor system, is given in Figure 3.7.

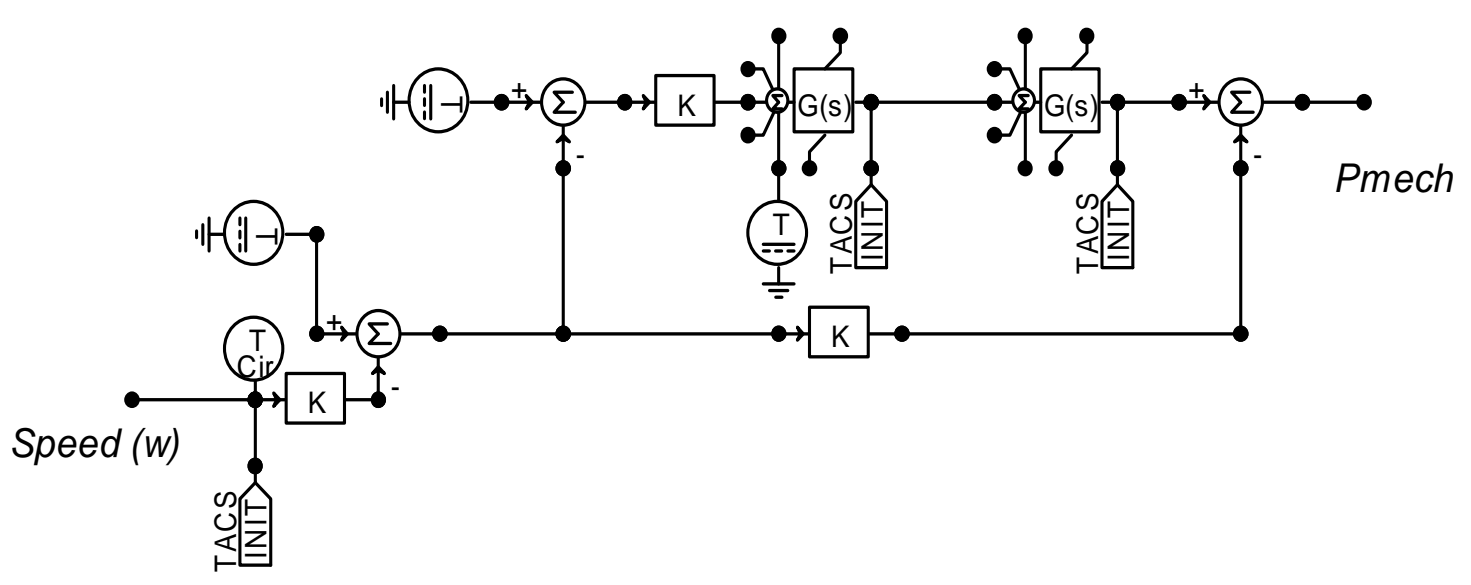

Figure 3.7: TGOV1 speed governor model

\subsection{TRANSFORMER MODELING}

Since the main objective of this work is to observe the dynamics of synchronous generator, a simple transformer model without any saturation is sufficient. More sophisticated saturable transformer models can be used in future when effects of transformer saturation have to be taken into account.

Ideal three-phase transformers shall be used. ATPDraw provides Wye-Wye connected idea three-phase transformer models. There is no delta-connected ideal transformer available but three single-phase transformers can be connected to represent needed winding connections. Wye-Delta transformer models used in the simulations are modeled in such a way that the high voltage is always wye connected and leading the delta side by $30^{\circ}$.

The primary-to-secondary winding ratio is given as the input parameter ' $n$ '. The ideal single phase transformer is modeled internally as Type 14 voltage source. If the 
transformer is ungrounded then there will be voltage of amplitude $1 \mathrm{E}-20 \mathrm{~V}$, phase angle of 0 and a frequency of $0 \mathrm{~Hz}$. In order to avoid singularity of the augmentation matrix, resistors of very low value $(10 \mathrm{n} \Omega)$ are connected between the windings. The polarity marks are provided in the models and care should be taken so that right polarities are used. Figure 3.8 shows the connections for a three-phase wye-delta transformer with $30^{\circ}$ phase shift

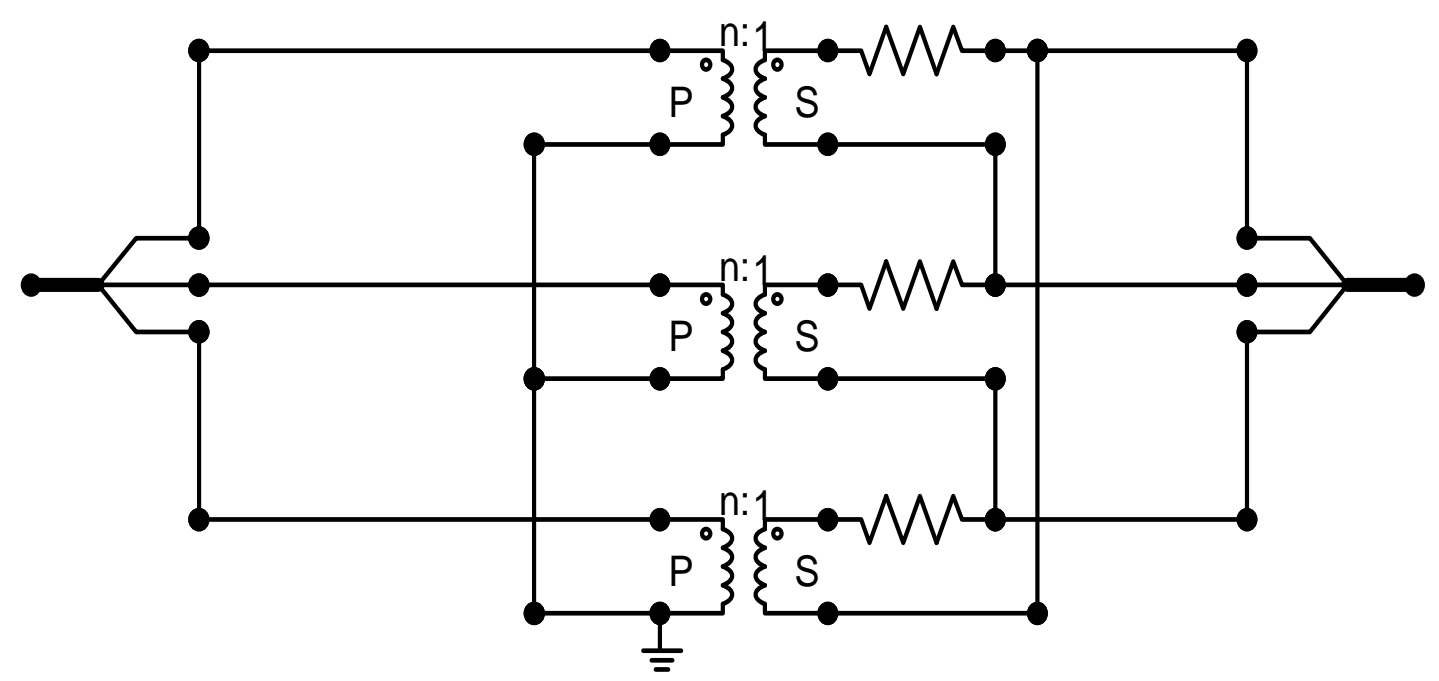

Figure 3.8: Three-phase transformer connections

\subsection{TRANSMISSION LINE MODELING}

Depending on needs, there are several different transmission line models available in ATP. Single-phase inductances with numerical damping are used to represent the reactance of the transmission line for initial simulations where only a series inductance is needed. They are replaced by three-phase lumped RLC pi equivalent with sequence data transmission line models for all other simulations.

The following are the advantages of the lumped RLC pi equivalent three phase with sequence data transmission line model (LINEPI3S).

- It is very simple.

- Phase resistances and reactances are entered directly without any calculations.

- The transmission line is modeled as pi equivalent in PSS/E and hence it is easy to benchmark the models.

- The length of the transmission line can be varied. 
- Positive and zero sequence data handling capability helps in studying both balanced and unbalanced faults.

- Absence of zero sequence data can be easily handled as the zero sequence data will be accounted only during unbalanced fault conditions.

- Inductance can be specified either in $\mathrm{mH} / \mathrm{m}$ or in $\mathrm{Ohm} / \mathrm{m}$.

- Capacitance can be specified either in $\mu \mathrm{F} / \mathrm{m}$ or $\mu \mathrm{Mho} / \mathrm{m}$.

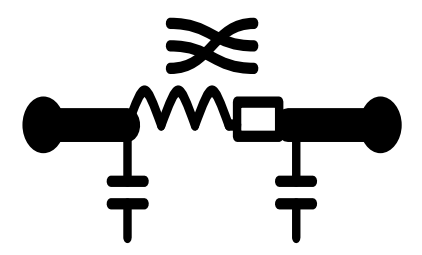

Figure 3.9: Lumped RLC pi equivalent transmission line

\subsection{REPRESENTATION OF LOAD}

Another important issue in modeling power systems is the representation of loads. There are two types of load, static and dynamic load. In this research only static loads are modeled and they are modeled as constant impedance loads. Different ways of representing load are discussed in Section 2.3.4. Single-phase resistors, inductors and capacitors are connected in parallel as shown below to represent the real and reactive power.

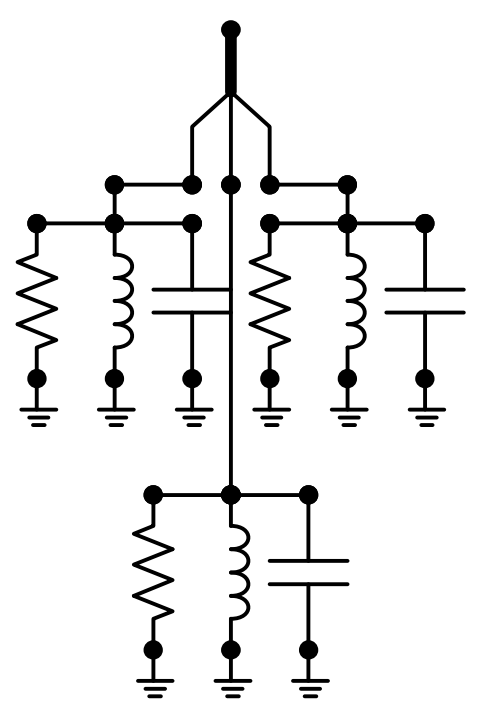

Figure 3.10: Constant impedance load model 
The concurrent research using PSS/E [19] uses load flow simulation to establish initial conditions. The voltage magnitude and the phase angle at each load bus are found. The magnitude of the voltage at the load bus and the real and reactive loads during steady state are used to find the value of the resistors, inductors and capacitors.

If $\mathrm{P}$ and $\mathrm{Q}$ are real and reactive powers in MW and MVAR respectively and $|\mathrm{V}|$ is the magnitude of the line to line voltage in $\mathrm{kV}$, the values of the resistors and inductors are determined using (3.9) and (3.10)

$$
\begin{gathered}
R=\frac{|V|^{2}}{P} \Omega \\
X_{L}=\frac{|V|^{2}}{Q} \Omega
\end{gathered}
$$

If capacitor banks are used to supply reactive power, then the value of the capacitors can be calculated using reactive power supplied $\left(\mathrm{Q}_{c}\right)$ in the following relation.

$$
X_{C}=\frac{|V|^{2}}{Q_{C}} \Omega
$$

The passive components are connected in parallel and the load model is shown in Figure. 3.10.

\subsection{CIRCUIT BREAKERS}

Circuit breakers are represented by ideal three-phase switches. Since the switches can perform only two operations (opening and closing at specified times), additional switches are connected in parallel to model the reclosing of circuit breakers. The switches open at current zero and they can be modeled to open at specified current $\operatorname{margin}\left(\mathrm{I}_{\mathrm{m}}\right)$. 


\section{CHAPTER 4 MODELING OF SINGLE-MACHINE CASES}

In this chapter, several base cases are modeled in ATP in ordered to observe power system stability in time domain. Behavior of the system during unbalanced faults is studied. The base cases include comparison of four individual generator against one aggregated generator, power system stabilizer against speed governor, and single-pole tripping during single line to ground fault against three-pole tripping.

\subsection{SINGLE MACHINE SYSTEM}

A single machine system connected to an infinite bus is modeled in order to observe the stability of the synchronous machine. A power plant with four generators running in parallel is used for this study. The machine parameters, network reactances, excitation system parameters and the pre-fault system conditions are taken from Kundur [9]. The four generators at the plant are represented by an equivalent generator. The transformer is represented by the transformer reactance and it is connected to the infinite bus through parallel circuit transmission lines. A three-phase-to-ground fault is applied at the end of the transmission line (circuit 2) at the transformer side. The voltage and rotor angle stability of the synchronous machine are observed during and after the fault. The single-machine system is shown in Figure 4.1 and the network reactances are in per unit on 2220 MVA base.

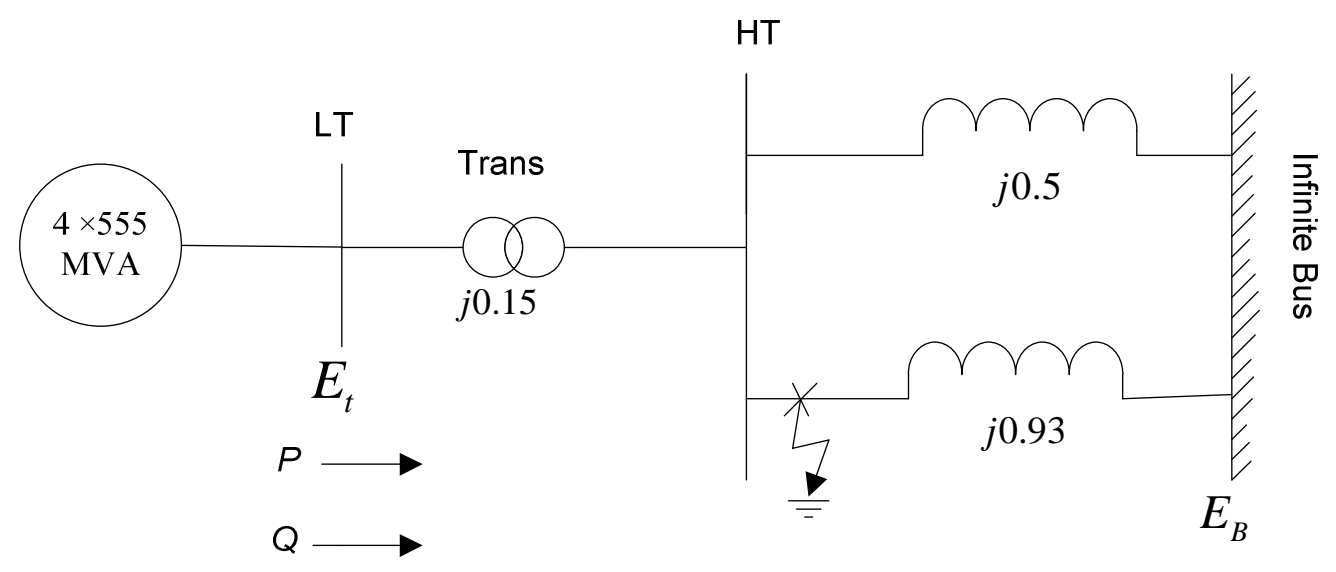

Figure 4.1: Single machine system under study 


\subsubsection{Generator Parameters}

Four 555 MVA, $24 \mathrm{kV}$ generators are represented as an equivalent 2220-MVA, 24-kV synchronous machine. The time constants are based on short-circuit measurements. The generator parameters on 2220 MVA base are given below.

Table 4-1: Generator parameters on 2220 MVA base

\begin{tabular}{|c|c|c|c|c|c|c|c|}
\hline $\mathbf{R}_{\mathbf{a}}$ & $\mathbf{X}_{\mathbf{L}}$ & $\mathbf{X}_{\mathbf{d}}$ & $\mathbf{X}_{\mathbf{q}}$ & $\mathbf{X}_{\mathbf{d}}{ }^{\prime}$ & $\mathbf{X}_{\mathbf{q}}{ }^{\prime}$ & $\mathbf{X}_{\mathbf{d}}{ }^{\prime \prime}$ & $\mathbf{X}_{\mathbf{q}}{ }^{\prime \prime}$ \\
\hline$(\mathrm{pu})$ & $(\mathrm{pu})$ & $(\mathrm{pu})$ & $(\mathrm{pu})$ & $(\mathrm{pu})$ & $(\mathrm{pu})$ & $(\mathrm{pu})$ & $(\mathrm{pu})$ \\
\hline 0.003 & 0.15 & 1.81 & 1.76 & 0.3 & 0.65 & 0.25 & 0.25 \\
\hline $\mathbf{T}_{\mathbf{d o}}{ }^{\prime}$ & $\mathbf{T}_{\mathbf{q o}}{ }^{\prime}$ & $\mathbf{T}_{\mathbf{d o}}{ }^{\prime \prime}$ & $\mathbf{T}_{\mathbf{q o}}{ }^{\prime \prime}$ & $\mathbf{X}_{\mathbf{0}}$ & $\mathbf{X}_{\mathbf{c a n}}$ & \multicolumn{2}{|c|}{ Inertia } \\
\hline$(\mathrm{s})$ & $(\mathrm{s})$ & $(\mathrm{s})$ & $(\mathrm{s})$ & $(\mathrm{pu})$ & $(\mathrm{pu})$ & $\mathrm{H}(\mathrm{s})$ & $\mathrm{J}\left(\mathrm{Mkgm}^{2}\right)$ \\
\hline 8 & 1 & 0.03 & 0.07 & 0.15 & 0.15 & 3.5 & 0.109404 \\
\hline
\end{tabular}

The parameters given above are unsaturated values and the effect of saturation is represented by assuming that $\mathrm{d}$-axis and $\mathrm{q}$-axis have similar saturation characteristics.

Table 4-2: Saturation Characteristics

\begin{tabular}{|c|c|c|c|}
\hline \multirow{2}{*}{ Saturation } & Terminal Voltage & \multicolumn{2}{|c|}{ Field Current } \\
\cline { 2 - 4 } & $\mathrm{E}_{\mathrm{t}}(\mathrm{pu})$ & $(\mathrm{pu})$ & $(\mathrm{A})$ \\
\hline $\mathrm{S}(1.0)$ & 1.0 & 0.03 & 258.9 \\
\hline $\mathrm{S}(1.2)$ & 1.2 & 0.4 & 3452.8 \\
\hline
\end{tabular}

During the pre-fault condition the voltage magnitude at the generator terminal is 1.0 p.u. and the phase angle of phase $\mathrm{A}$ is $28.34^{\circ}$. The excitation system is modeled using IEEE type ST1A excitation control system and ESST1 power system stabilizer. Modeling of these control systems is explained in Section 3.3. The terminal voltage in per unit is calculated using TACS by finding the root mean square value of the instantaneous voltage at the generator terminal. The angular velocity of the machine is obtained as TACS output from the SM 59 machine model and the scaling factor of the field voltage $\left(\mathrm{V}_{\mathrm{f}}\right)$ is given as TACS input to control the excitation of the machine. The initial conditions are specified at each stage of the control system based on the steadystate operating conditions. The excitation system parameters used for Automatic Voltage Regulator (AVR) and the Power System Stabilizer (PSS) are given in Table 4-3.

Table 4-3: Excitation System parameters

\begin{tabular}{|c|c|c|c|c|c|c|c|c|c|}
\hline $\mathbf{K}_{\mathbf{A}}$ & $\mathbf{T}_{\mathbf{R}}$ & $\mathbf{E}_{\mathbf{F} \max }$ & $\mathbf{E}_{\mathbf{F} \min }$ & $\mathbf{K}_{\mathbf{S T A B}}$ & $\mathbf{T}_{\mathrm{W}}$ & $\mathbf{T}_{\mathbf{1}}$ & $\mathbf{T}_{\mathbf{2}}$ & $\mathbf{V}_{\mathbf{s} \min }$ & $\mathbf{V}_{\mathbf{s} \min }$ \\
\hline 200 & $0.015 \mathrm{~s}$ & 7.0 & -6.4 & 9.5 & $1.41 \mathrm{~s}$ & $0.154 \mathrm{~s}$ & $0.033 \mathrm{~s}$ & 0.2 & -0.2 \\
\hline
\end{tabular}




\subsubsection{Network Parameters}

The two transmission lines are modeled as three-phase lumped RLC Pi equivalent transmission line model and the reactances are specified in actual values. The actual reactances of the network are calculated from the base impedance (4.1) and per unit values.

$$
Z_{\text {base }}=\frac{24^{2}}{2220}=0.2594 \Omega
$$

Table 4-4: Network Parameters

\begin{tabular}{|c|c|c|}
\hline Reactances & Per unit value & Actual Value $(\mathbf{\Omega})$ \\
\hline Transformer & $\mathrm{j} 0.15$ & 0.03892 \\
\hline Transmission line 1 & $\mathrm{j} 0.50$ & 0.12973 \\
\hline Transmission line 2 & $\mathrm{j} 0.93$ & 0.24129 \\
\hline
\end{tabular}

Power system dynamics of the single-machine system connected to infinite bus is investigated for three different cases.

i. Constant field voltage or manual control

ii. Field voltage control with Automatic Voltage Regulator (AVR)

iii. Field voltage control with AVR and Power System Stabilizer (PSS)

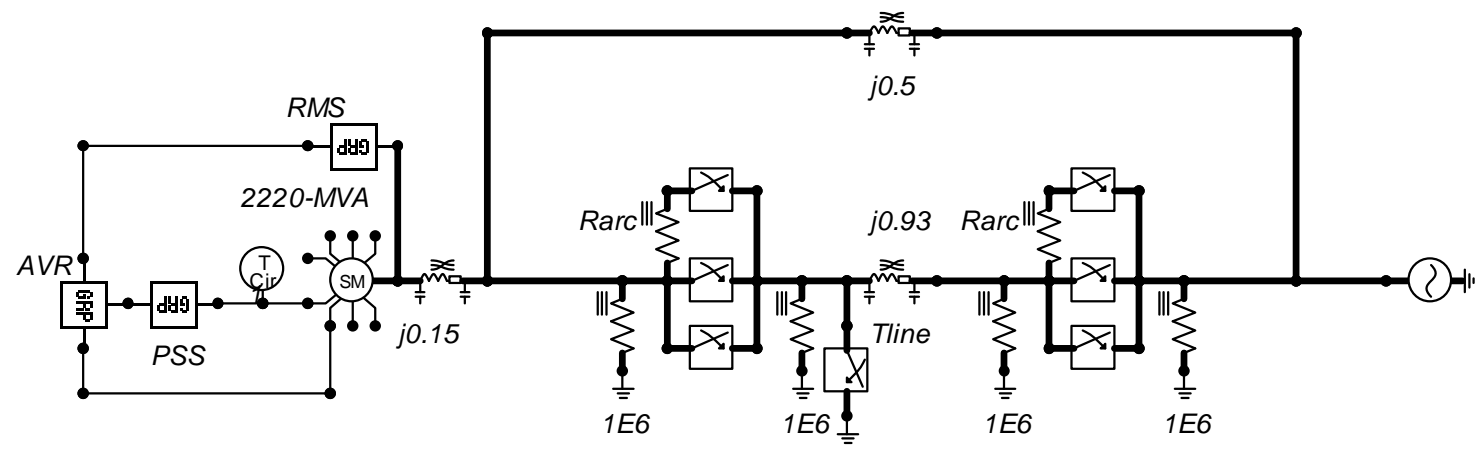

Figure 4.2: Single machine system with excitation controls (Case 5a)

Figure 4.2 shows the single-machine model with both AVR and PSS (Case 5a) for the field voltage control. The control system blocks are compressed into a macro group and only the compressed groups (GRP) are shown in Figure 4.2. 


\subsubsection{Different Cases of Single-machine System}

Four different types of faults, i.e., three-phase to ground fault, single-line-toground fault, line-to-line fault, and double-line-to-ground fault are applied in the transformer side of the transmission line (circuit 2). The fault is applied at time $t=5.0 \mathrm{~s}$ and the duration of fault is $0.07 \mathrm{~s}$. At time $\mathrm{t}=5.07 \mathrm{~s}$, two switches representing the circuit breakers at the ends of the transmission line trip the line and clear the fault from the system. The fault is removed from the system at $\mathrm{t}=5.08 \mathrm{~s}$ and reclosing is performed at time $\mathrm{t}=5.1 \mathrm{~s}$ to bring back the tripped transmission line into service. For modeling purposes, the reclosing is performed by two additional switches placed in parallel with the switches representing the breakers.

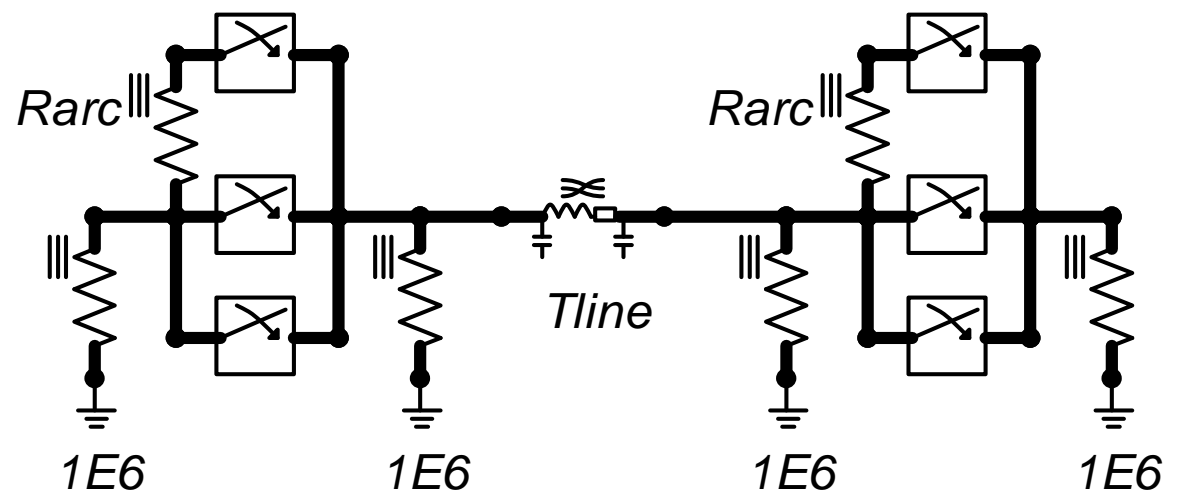

Figure 4.3: Circuit breakers with compensation for numerical oscillations

The trapezoidal integration method used by ATP may sometimes result in numerical oscillations while closing or opening switches in a circuit which has inductors. As the models used have their transmission lines represented by inductive reactances, numerical oscillations are inevitable during the simulations. Numerical damping resistors are used in parallel with the inductors to avoid these oscillations. However, short lived numerical oscillations are still seen for few cycles once the switches are opened. These oscillations did not affect the peak of first swing, frequency and settling time of the terminal voltage. But resistors of very high values (in $\mathrm{M} \Omega$ range) are added in shunt with the switches to help controlling the peak of these numerical oscillations. When the switch opens, a resistor of range 0.5-5 $\Omega$ (representing arc resistances) is connected in parallel for half-a-cycle duration. This helped in eliminating the numerical oscillations. 
Figure 4.3 shows the ATP modeling of transmission line and circuit breakers with resistors to mitigate numerical oscillations.

All the simulations are repeated for the models with and without excitation controls. Table 4-5 summarizes different test cases.

Table 4-5: Different cases of single machine system

\begin{tabular}{|c|c|c|c|}
\hline Fault Clearance & Type of fault & Fault time & Type of control \\
\hline \multirow{3}{*}{$0.07 \mathrm{~s}$} & Single-line to Ground & Removed before & Constant $\mathrm{E}_{\mathrm{fd}}$ \\
\cline { 2 - 2 } & Double-line to Ground & first reclosing & With AVR \\
\hline $0.1 \mathrm{~s}$ & Line to line & $\begin{array}{c}\text { Removed after } \\
\text { first reclosing }\end{array}$ & $\begin{array}{c}\text { with AVR and } \\
\text { PSS }\end{array}$ \\
\cline { 2 - 3 } & Three-phase to Ground & PSS \\
\hline
\end{tabular}

The single machine used for the simulations is an equivalent for four machine system operating in a power plant. Hence in order to observe the dynamics of individual generating units and benchmark the equivalent aggregate generator, the four machines are modeled individually.

The four machines are assumed to be identical and pre-fault voltage magnitude and phase angles are same as that of the equivalent machine. The machine base is changed to 555 MVA and the machine parameters on this base are given in Table 4-6. Figure 4.4 shows the four-machine system modeled in ATP.

Table 4-6: Machine parameters on 555 MVA base

\begin{tabular}{|c|c|c|c|c|c|c|c|}
\hline $\mathbf{R}_{\mathbf{a}}$ & $\mathbf{X}_{\mathbf{L}}$ & $\mathbf{X}_{\mathbf{d}}$ & $\mathbf{X}_{\mathbf{q}}$ & $\mathbf{X}_{\mathbf{d}}{ }^{\prime}$ & $\mathbf{X}_{\mathbf{q}}{ }^{\prime}$ & $\mathbf{X}_{\mathbf{d}}{ }^{\prime \prime}$ & $\mathbf{X}_{\mathbf{q}}{ }^{\prime \prime}$ \\
\hline$(\mathrm{pu})$ & $(\mathrm{pu})$ & $(\mathrm{pu})$ & $(\mathrm{pu})$ & $(\mathrm{pu})$ & $(\mathrm{pu})$ & $(\mathrm{pu})$ & $(\mathrm{pu})$ \\
\hline 0.0012 & 0.6 & 7.24 & 7.04 & 1.2 & 2.6 & 1 & 1 \\
\hline $\mathbf{T}_{\mathbf{d o}}{ }^{\prime}$ & $\mathbf{T}_{\mathbf{q o}}{ }^{\prime}$ & $\mathbf{T}_{\mathbf{d o}}{ }^{\prime \prime}$ & $\mathbf{T}_{\mathbf{q o}}{ }^{\prime \prime}$ & $\mathbf{X}_{\mathbf{o}}$ & $\mathbf{X}_{\mathbf{c a n}}$ & \multicolumn{2}{|c|}{ Inertia } \\
\hline$(\mathrm{s})$ & $(\mathrm{s})$ & $(\mathrm{s})$ & $(\mathrm{s})$ & $(\mathrm{pu})$ & $(\mathrm{pu})$ & $\mathrm{H}(\mathrm{s})$ & $\mathrm{J}\left(\mathrm{Mkgm}^{2}\right)$ \\
\hline 8 & 1 & 0.03 & 0.07 & 0.6 & 0.6 & 3.5 & 0.027351 \\
\hline
\end{tabular}

It is general practice to use speed governor (GOV) to control the mechanical power input of the synchronous machine. The automatic voltage regulator (AVR) controls the terminal voltage of the machine to a preset value and in the process the damping of the oscillations is reduced. The power system stabilizer increases the damping ratio of the system decreasing the settling time of the oscillations. Speed governors control the angular velocity of the synchronous machine and help in improving the stability much slower than PSS. 


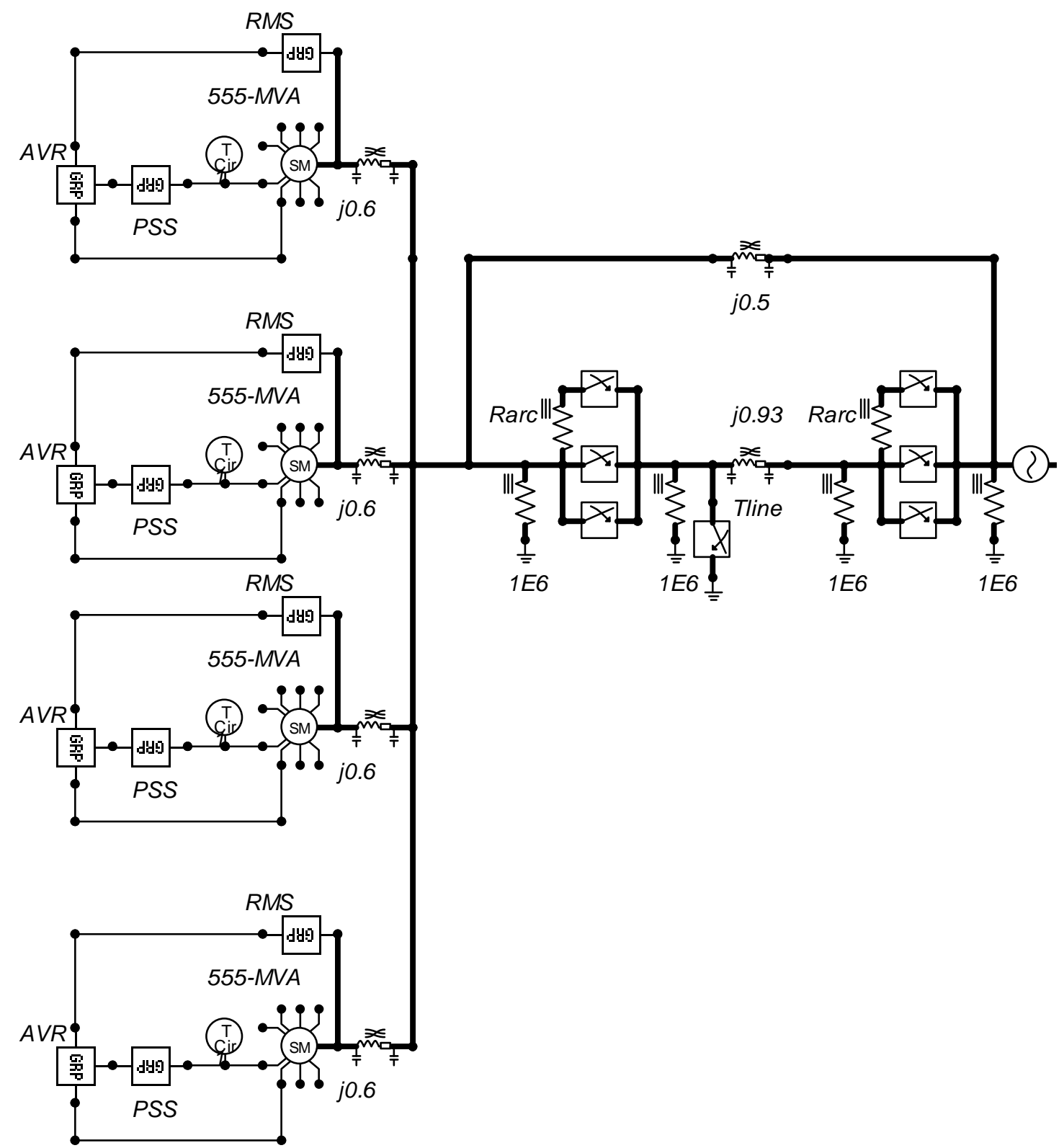

Figure 4.4: Four Machine System (Case 5i)

As both the power system stabilizer and the speed governor help in improving the damping and reduce the settling time of the system, the PSS is removed in order to see how the governor alone responds. Power system oscillations are also observed with both PSS and GOV. The parameters used for the governor (described in Section 3.3) are given in Table 4-7 and implemented ATP model is given in Figure 4.5. 
Table 4-7: Speed Governor Parameters

\begin{tabular}{|c|c|c|c|c|c|c|}
\hline $\mathbf{R}$ & $\mathbf{T}_{\mathbf{1}}$ & $\mathbf{V}_{\max }$ & $\mathbf{V}_{\min }$ & $\mathbf{T}_{\mathbf{2}}$ & $\mathbf{T}_{\mathbf{3}}$ & $\mathbf{D}_{\mathbf{t}}$ \\
\hline 0.05 & 0.5 & 1 & 0.3 & 1 & 1 & 0 \\
\hline
\end{tabular}

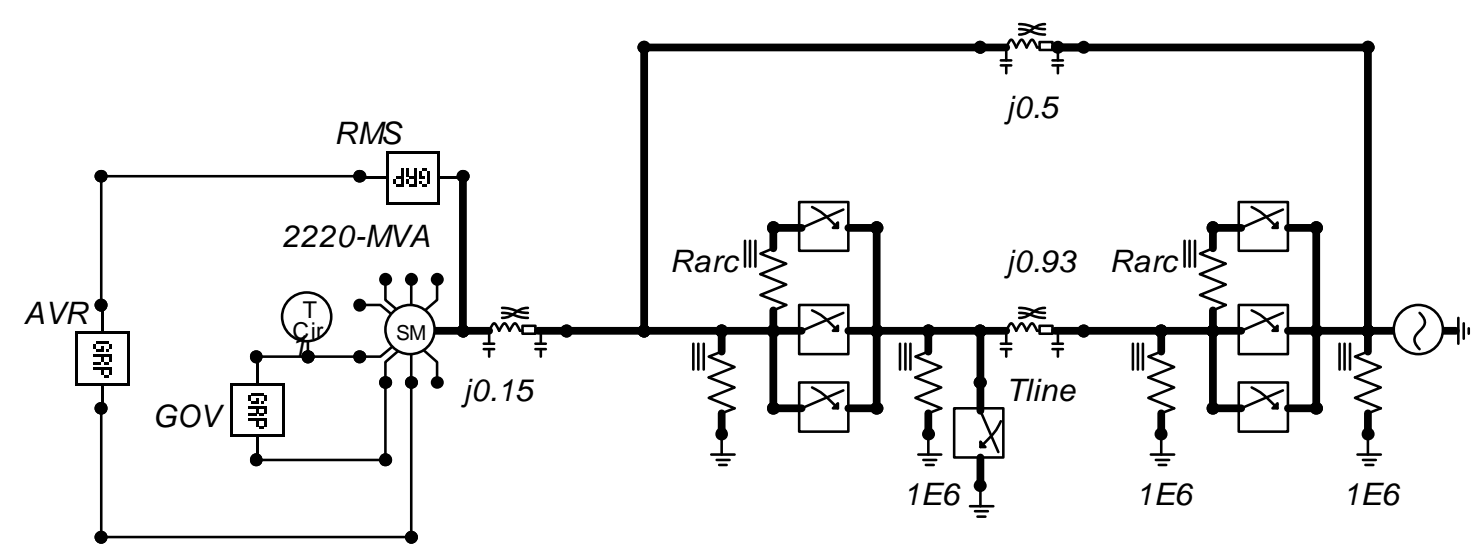

Figure 4.5: Control using Speed Governor System (Case 5h)

\subsection{POWER SYSTEM UNBALANCE}

As majority of the power system faults are single-line-to-ground faults, it is very important to study power system unbalance. A 1000-MVA, 20-kV generator connected to infinite bus is modeled in order to study the power system unbalance and single-pole tripping and reclosing.

Figure 4.6 shows the single machine system under study with positive and zero sequence network parameters specified on 1000-MVA and 20-kV base.

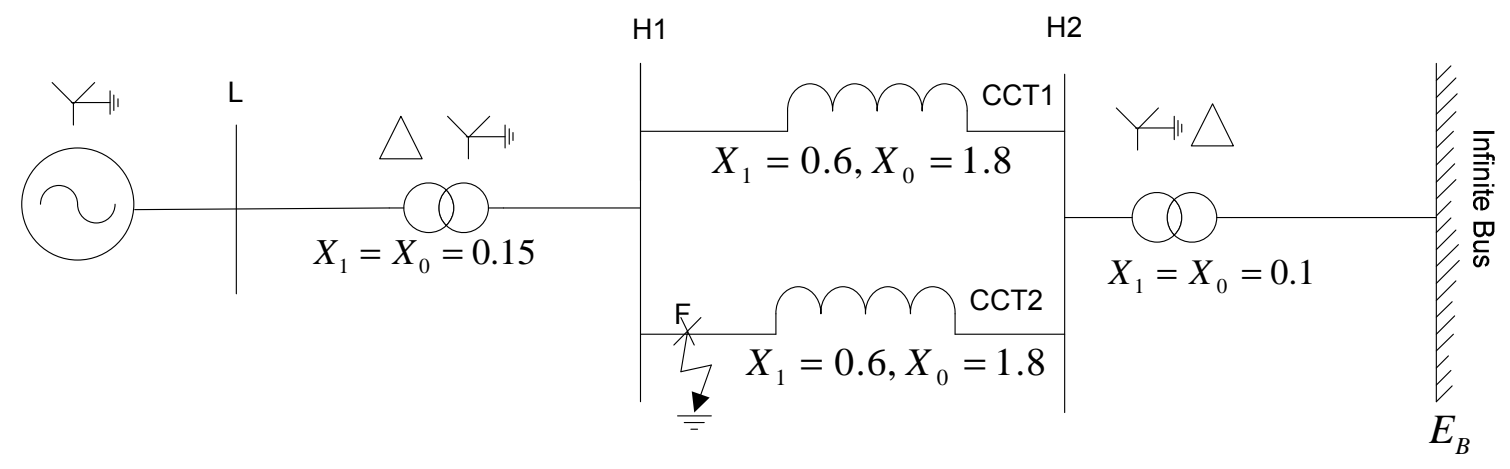

Figure 4.6: Single-machine system with sequence data 


\subsubsection{Generator Data}

This 1000-MVA 20-kV generator is modeled in ATP with AVR and PSS. The zero sequence reactance of the synchronous machine is included in the modeling of SM 59. The generator parameters given below are unsaturated values and the effect of saturation is included by assuming both d-axis and q-axis have same characteristics.

Table 4-8: Generator data on 1000 MVA base

\begin{tabular}{|c|c|c|c|c|c|c|c|}
\hline $\mathbf{R}_{\mathbf{a}}$ & $\mathbf{X}_{\mathbf{L}}$ & $\mathbf{X}_{\mathbf{d}}$ & $\mathbf{X}_{\mathbf{q}}$ & $\mathbf{X}_{\mathbf{d}}{ }^{\prime}$ & $\mathbf{X}_{\mathbf{q}}{ }^{\prime}$ & $\mathbf{X}_{\mathbf{d}}{ }^{\prime \prime}$ & $\mathbf{X}_{\mathbf{q}}{ }^{\prime \prime}$ \\
\hline$(\mathrm{pu})$ & $(\mathrm{pu})$ & $(\mathrm{pu})$ & $(\mathrm{pu})$ & $(\mathrm{pu})$ & $(\mathrm{pu})$ & $(\mathrm{pu})$ & $(\mathrm{pu})$ \\
\hline 0.0003 & 0.6 & 1.81 & 1.76 & 0.3 & 0.65 & 0.25 & 0.25 \\
\hline $\mathbf{T}_{\mathbf{d o}}{ }^{\prime}$ & $\mathbf{T}_{\mathbf{q o}}{ }^{\prime}$ & $\mathbf{T}_{\mathbf{d o}}{ }^{\prime \prime}$ & $\mathbf{T}_{\mathbf{q o}}{ }^{\prime \prime}$ & $\mathbf{X}_{\mathbf{o}}$ & $\mathbf{R}_{\mathbf{o}}$ & \multicolumn{2}{|c|}{ Inertia } \\
\hline$(\mathrm{s})$ & $(\mathrm{s})$ & $(\mathrm{s})$ & $(\mathrm{s})$ & $(\mathrm{pu})$ & $(\mathrm{pu})$ & $\mathrm{H}(\mathrm{s})$ & $\mathrm{J}\left(\mathrm{Mkgm}^{2}\right)$ \\
\hline 8 & 1 & 0.03 & 0.07 & 0.04 & 0.005 & 3.5 & 0.049281 \\
\hline
\end{tabular}

Table 4-9: Saturation characteristics of 1000 MVA machine

\begin{tabular}{|c|c|c|c|}
\hline \multirow{2}{*}{ Saturation } & Terminal Voltage & \multicolumn{2}{|c|}{ Field Current } \\
\cline { 2 - 4 } & $\mathrm{E}_{\mathrm{t}}(\mathrm{pu})$ & $(\mathrm{pu})$ & $(\mathrm{A})$ \\
\hline $\mathrm{S}(1.0)$ & 1.0 & 0.03 & 139.9 \\
\hline $\mathrm{S}(1.2)$ & 1.2 & 0.4 & 1865.52 \\
\hline
\end{tabular}

The pre-fault terminal voltage magnitude is 1.0 per unit and phase angle is $28.34^{\circ}$. The infinite bus is kept at a magnitude of 0.90081 per unit and phase angle of $0^{\circ}$. The excitation control parameters for this system are the same as that of the single machine system discussed in Section 4.7. Figure 4.7 shows the single machine system modeled in ATP.

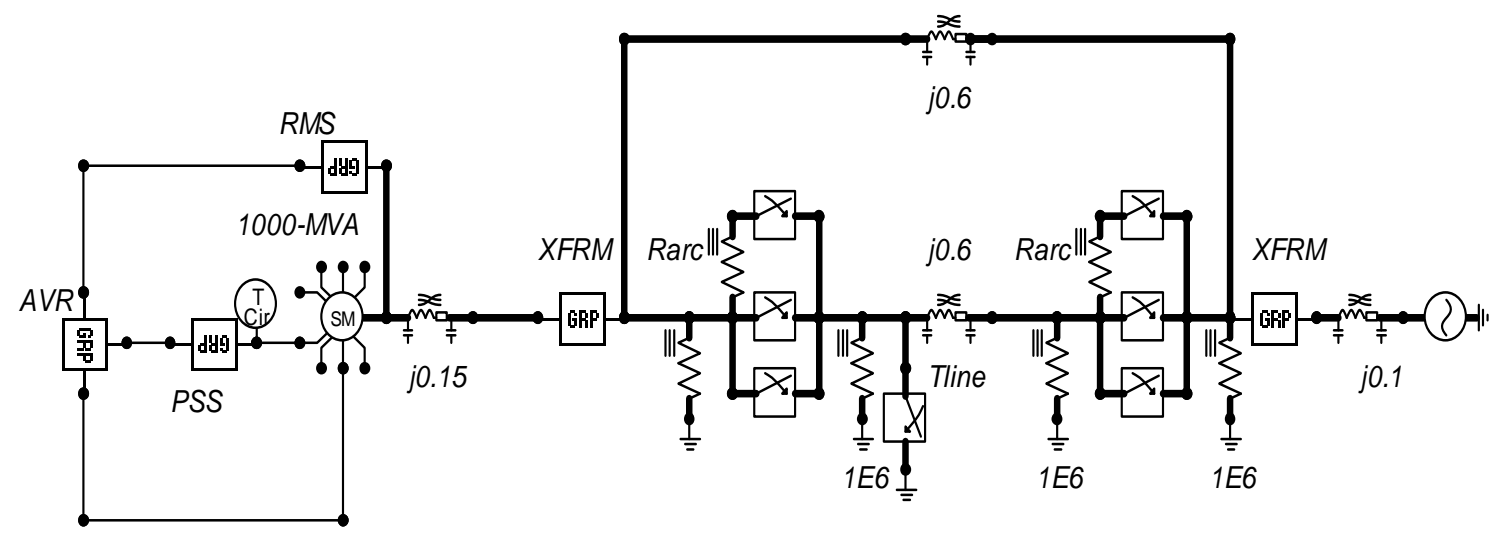

Figure 4.7: Single machine system in ATP (Case 2a) 


\subsubsection{Transformer Data}

There are two transformers in the system, one 0n the generator side and the other on the infinite bus side. The delta-grounded wye transformer on the generator side steps up the voltage from $20 \mathrm{kV}$ to $345 \mathrm{kV}$. Three single-phase transformers with turns ratio of 0.05797:1 are used to model the three-phase transformer. Delta and wye connections of a three-phase transformer with a $30^{\circ}$ phase shift are discussed in Section 3.4. The stepdown transformer on the infinite bus side is grounded wye-delta and it steps down the $345-\mathrm{kV}$ transmission voltage to $110-\mathrm{kV}$. Three single-phase transformers with turns ratio of 3.1363:1 are used to model the three-phase transformer.

The positive sequence and the zero sequence reactances are represented as actual reactances referred to the low-voltage sides of the transformer. Table 4-10 gives the base impedance, per unit and actual values of the transformer reactances.

Table 4-10: Transformer data

\begin{tabular}{|l|c|c|c|c|}
\hline \multicolumn{2}{|c|}{} & $\begin{array}{c}\text { Reactance } \\
(\mathbf{p u})\end{array}$ & $\begin{array}{c}\text { Base } \\
\text { impedance }(\mathbf{\Omega})\end{array}$ & $\begin{array}{c}\text { Actual } \\
\text { reactance }(\mathbf{\Omega})\end{array}$ \\
\hline \multirow{2}{*}{$\begin{array}{l}\mathrm{T} 1 \\
20 \mathrm{kV}-345 \mathrm{kV}\end{array}$} & Positive sequence & 0.15 & $\frac{20^{2}}{1000}=0.4$ & 0.06 \\
\cline { 2 - 5 } & Zero sequence & 0.15 & $\frac{20^{2}}{1000}=0.4$ & 0.06 \\
\hline $\begin{array}{l}\mathrm{T} 2 \\
345 \mathrm{kV}-110 \mathrm{kV}\end{array}$ & Positive sequence & 0.10 & $\frac{110^{2}}{1000}=12.1$ & 1.21 \\
\cline { 2 - 5 } & Zero sequence & 0.10 & $\frac{110^{2}}{1000}=12.1$ & 1.21 \\
\hline
\end{tabular}

\subsubsection{Network Data}

The two $345-\mathrm{kV}$ transmission lines are identical and only their inductive reactances are considered for modeling purposes. The per unit values of the transmission line reactances both for positive and zero sequence are given in Figure 4.5. The actual reactances in Ohms are used for modeling in ATP using lumped RLC pi-equivalent transmission line model.

$$
Z_{\text {base }}=\frac{20^{2}}{1000}=0.4 \Omega
$$


Table 4-11: Network Parameters with Sequence Data

\begin{tabular}{|c|c|c|c|}
\hline & Reactances & Per unit value & Actual Value $(\boldsymbol{\Omega})$ \\
\hline Transmission & Positive sequence & $\mathrm{j} 0.6$ & 0.24 \\
\cline { 2 - 4 } line 1 & Zero sequence & $\mathrm{j} 1.8$ & 0.72 \\
\hline Transmission & Positive sequence & $\mathrm{j} 0.6$ & 0.24 \\
\cline { 2 - 4 } line 2 & Zero sequence & $\mathrm{j} 1.8$ & 0.72 \\
\hline
\end{tabular}

The fault is applied at the end of the transmission line 2 near the bus H1. Circuit breakers on both ends of the transmission lines are modeled using three-phase time controlled switches and additional switches are connected in parallel to perform reclosing during faults. Different types of faults as discussed in Section 4.1 are applied and generator dynamics are observed. Rotor angle and voltage stability of the synchronous machine during unbalance fault conditions are studied. The model implemented can be used for future work on relaying aspects and studying the mho characteristics during line faults.

\subsubsection{Single Pole Tripping}

A comparison between a three-pole trip and a single-pole trip for a single-line to ground fault can be helpful in understanding the impact of voltage regulation during power system transients. The difference in angles across the circuit breaker poles before reclosing the breaker is a very important constraint while bringing a system back into operation. Figure 4.8 shows the basic schematics of the single-pole tripping scenario.

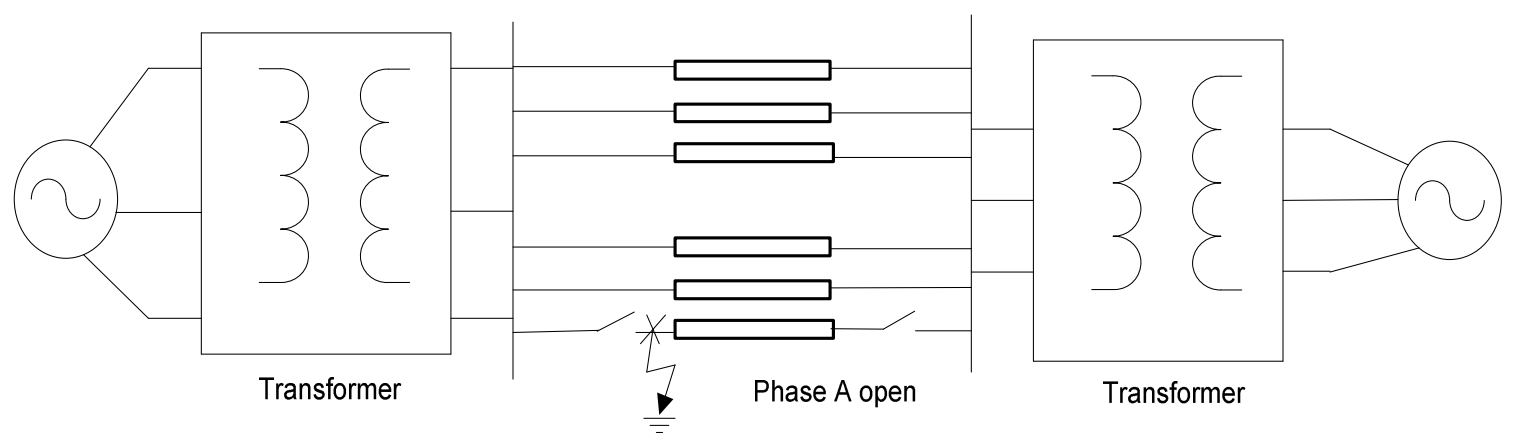

Figure 4.8: Basic diagram of single-pole tripping 
For a single-line-to-ground fault at $\mathrm{H} 1$, all three phases are tripped to clear the fault. After the dead time, the phases are reclosed. Under similar conditions of fault occurrence, a single-pole trip and reclose is then employed to check for the differences in the two tripping and reclosing strategies.

To analyze the feasibility of single-pole tripping and reclosing at the two ends of the transmission line, different single-line-to-ground fault scenarios are studied. Each switching scenario had a unique system configuration with particular system conditions. This was based on having faults at different locations along the line, different excitation control systems for the machine, different fault durations, and different transmission line models. Attention was focused on the transient bus voltages, sustained bus over-voltages the power flow, and the rotor angle oscillations.

In this study, circuit breaker representation is simplified to that of an ideal threephase time controlled switch. The traveling waves during the reclosing will cause very large over-voltages near the open-circuited line. Since lumped RLC Pi equivalent transmission line models are used for simulations, this problem is could not be studied. In single-pole tripping, power is transferred through the two phases which are not opened. The difference in power transferred to the infinite bus during the single-pole tripping and three-pole tripping is compared. The difference in the power flow for the two different strategies will affect the accelerating and decelerating torques of the generator and hence the system stability. Rotor angle swings and power swings during the faults in both the cases are investigated. 


\section{CHAPTER 5 \\ DYNAMIC REDUCTION AND POWER SWINGS}

In this chapter, a two-area system with four generator buses and two load buses is modeled to observe inter-area and intra-area oscillations during power system disturbances. Rotor angle stability, power swings and voltage stability of the fourmachine system are investigated. The four-machine system is dynamically reduced to a two-machine system by identifying and aggregating the coherent generators. The reduced system is benchmarked against the original system.

\subsection{SYSTEM UNDER STUDY}

The system consists of two similar areas connected by a week tie lines. Each area consists of two generating units, each having a rating of $900 \mathrm{MVA}$ and $20 \mathrm{kV}$. The system parameters are taken from Kundur [9]. Generators G1, G2, G3 and G4 are connected to buses 1, 2, 3 and 4 respectively. G1 and G2 operate in Area 1 and G3 and G4 operate in Area 2. The transmission voltage is $230 \mathrm{kV}$ and step-up transformers are used at each generator terminal to transform $20 \mathrm{kV}$ to $230 \mathrm{kV}$. Loads of $972.15 \mathrm{MVA}$ at 0.9946 lagging power factor and 1769.82 MVA at 0.9984 lagging power factor are connected to buses 7 and 9 respectively. Reactive power of 200 MVAr and 350 MVAr are injected with help of capacitor banks to the load buses 7 and 9 respectively. The system is modeled in such a way that there is a power flow of $400 \mathrm{MW}$ from Area 1 to Area 2 under steady state conditions.

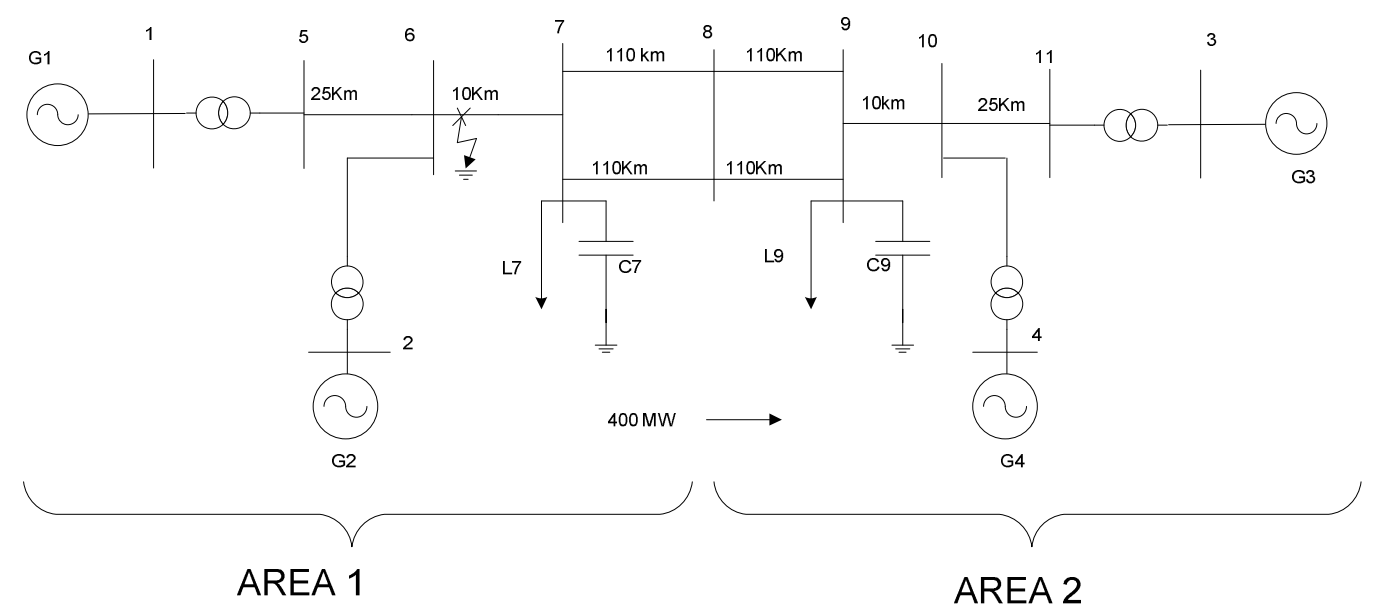

Figure 5.1: A simple two-area system 


\subsubsection{Generator Data}

All the generators are identical and Table 5-1 gives the generator parameters on $900 \mathrm{MVA}$ and $20 \mathrm{kV}$ base.

Table 5-1: Generator data for the two-area system

\begin{tabular}{|c|c|c|c|c|c|c|c|c|}
\hline $\mathbf{R}_{\mathbf{a}}$ & $\mathbf{X}_{\mathbf{L}}$ & $\mathbf{X}_{\mathrm{d}}$ & $X_{q}$ & $\mathbf{X}_{\mathbf{d}}{ }^{\prime}$ & $\mathbf{X}_{\mathbf{q}}^{\prime}$ & \multicolumn{2}{|c|}{$\mathbf{X}_{d}{ }^{\prime \prime}$} & $\mathbf{X}_{\mathbf{q}}{ }^{\prime \prime}$ \\
\hline$(\mathrm{pu})$ & $(\mathrm{pu})$ & $(\mathrm{pu})$ & $(\mathrm{pu})$ & (pu) & $(\mathrm{pu})$ & \multicolumn{2}{|c|}{ (pu) } & (pu) \\
\hline 0.00025 & 0.2 & 1.8 & 1.7 & 0.3 & 0.55 & \multicolumn{2}{|c|}{0.25} & 0.25 \\
\hline & & & & \multicolumn{5}{|c|}{ Inertia } \\
\hline $\mathbf{T}_{\mathrm{do}}$, & $\mathbf{T}_{\mathbf{q o}}{ }^{\prime}$ & $\mathbf{T}_{\mathrm{do}}{ }^{\prime \prime}$ & $T_{q 0}{ }^{\prime \prime}$ & \multicolumn{2}{|c|}{ G1 \& G2 } & \multicolumn{3}{|c|}{ G3 \& G4 } \\
\hline$(\mathrm{s})$ & (s) & $(\mathrm{s})$ & $(\mathrm{s})$ & $\mathrm{H}(\mathrm{s})$ & $\mathrm{J}\left(\mathrm{Mkgm}^{2}\right)$ & $\mathrm{H}(\mathrm{s})$ & \multicolumn{2}{|c|}{$\mathrm{J}\left(\mathrm{Mkgm}^{2}\right)$} \\
\hline 8 & 0.4 & 0.03 & 0.05 & 6.5 & 0.08237 & 6.175 & \multicolumn{2}{|c|}{0.078251} \\
\hline
\end{tabular}

The generator parameters given in Table 5-1 are the unsaturated values. From these, ATP determines the effect of saturation, which is considered to be same in both daxis and q-axis of the synchronous machine. The value of field currents that produce 1.0 per unit and 1.2 per unit terminal voltage on the synchronous machine are given in Table 5-2 and are used for modeling open-circuit characteristic in the ATP synchronous machine model.

Table 5-2: Saturation characteristics of the two-area system

\begin{tabular}{|c|c|c|c|}
\hline \multirow{2}{*}{ Saturation } & Terminal Voltage & \multicolumn{2}{|c|}{ Field Current } \\
\cline { 2 - 4 } & $\mathrm{E}_{\mathrm{t}}(\mathrm{pu})$ & $(\mathrm{pu})$ & $(\mathrm{A})$ \\
\hline $\mathrm{S}(1.0)$ & 1.0 & 0.03 & 125.9 \\
\hline $\mathrm{S}(1.2)$ & 1.2 & 0.4 & 1678.97 \\
\hline
\end{tabular}

Area 1 exports $400 \mathrm{MW}$ of power to area 2 and the generating units are loaded as given in Table 5-3, during the steady state operating conditions. The load flow simulation is done in PSS/E for the two-area system. The load flow results from [19] are used as initial steady state values for the generator buses while modeling in ATP. Table $5-4$, gives the power flow solution of the system under steady state condition.

Table 5-3: Initial generator loading

\begin{tabular}{|c|c|c|c|c|}
\hline Generator & $\begin{array}{c}\text { Real Power } \\
\text { P (MW) }\end{array}$ & $\begin{array}{c}\text { Reactive Power } \\
\text { Q (MVAr) }\end{array}$ & $\begin{array}{c}\text { Bus voltage } \\
\text { magnitude (p.u.) }\end{array}$ & $\begin{array}{c}\text { Bus voltage } \\
\text { phase angle }\left({ }^{\circ}\right)\end{array}$ \\
\hline G1 & 700 & 185 & 1.03 & 20.2 \\
\hline G2 & 700 & 235 & 1.01 & 10.5 \\
\hline G3 & 719 & 176 & 1.03 & -6.8 \\
\hline G4 & 700 & 202 & 1.01 & -17.0 \\
\hline
\end{tabular}


Table 5-4: Steady state power flow

\begin{tabular}{|c|c|c|c|c|c|}
\hline $\begin{array}{c}\text { From } \\
\text { bus }\end{array}$ & $\begin{array}{c}\text { To } \\
\text { bus }\end{array}$ & $\begin{array}{c}\text { Real Power } \\
\text { P (MW) }\end{array}$ & $\begin{array}{c}\text { Reactive Power } \\
\text { Q (MVAr) }\end{array}$ & $\begin{array}{c}\text { Bus voltage } \\
\text { magnitude (p.u.) }\end{array}$ & $\begin{array}{c}\text { Bus voltage } \\
\text { phase angle }{ }^{\circ} \text { ) }\end{array}$ \\
\hline 1 & 5 & 700 & 185 & 1.0051 & 19.40 \\
\hline 5 & 6 & 700 & 104 & 1.0000 & 42.73 \\
\hline 2 & 6 & 700 & 235 & 1.0447 & 9.06 \\
\hline 6 & 7 & 1388 & 133 & 1.0000 & 32.64 \\
\hline 7 & L7 & 904 & -93.4 & 0.9850 & 24.61 \\
\hline 7 & 8 & 464 & 27.4 & 0.9850 & 24.61 \\
\hline 8 & 9 & 452 & -65.4 & 0.9760 & 11.43 \\
\hline 9 & L8 & 1727 & -244 & 0.9900 & -1.46 \\
\hline 10 & 9 & 1305 & 78.9 & 1.0075 & 6.53 \\
\hline 4 & 10 & 700 & 202 & 1.0480 & -16.95 \\
\hline 11 & 10 & 614 & 48 & 1.0000 & 16.54 \\
\hline 3 & 11 & 614 & 109 & 1.0000 & -6.80 \\
\hline
\end{tabular}

\subsubsection{Transformer and Transmission Line Data}

Step-up transformers connected to each generator are modeled as ideal wye-wye three phase transformer with turns-ratio of 0.086956:1 and the off-nominal ratio is taken as 1.0. Transformer reactances are represented in the low voltage side and its actual value calculated from per unit value is used for modeling. The transformer impedance is as $0+\mathrm{j} 0.15$ per unit on $900 \mathrm{MVA}$ and $20 / 230 \mathrm{kV}$ base.

$$
\begin{gathered}
Z_{\text {lbase }}=\frac{20^{2}}{900}=0.4444 \Omega \\
Z_{\text {actual }}=0.4444 * j 0.15=j 0.06667 \Omega
\end{gathered}
$$

Nominal voltage of the transmission system is $230 \mathrm{kV}$. Three-phase lumped RLC pi-equivalent transmission line model is used for modeling the transmission lines. The line lengths are identified in Figure 5.1. The parameters of the line in per unit on 100 MVA and $230 \mathrm{kV}$ base is given in (5.3) through (5.6).

$$
\begin{aligned}
\mathrm{R} & =0.0001 \mathrm{pu} / \mathrm{km} \\
\mathrm{X}_{\mathrm{L}} & =0.001 \mathrm{pu} / \mathrm{km} \\
\mathrm{B}_{\mathrm{C}} & =0.00175 \mathrm{pu} / \mathrm{km} \\
Z_{\text {base }} & =\frac{230^{2}}{100}=529 \Omega
\end{aligned}
$$


The transmission line parameters calculated from base, per unit and length of the lines are given Table 5-5. In ATP, the actual values per kilometer length of the transmission line are used as input parameter of lumped RLC pi equivalent transmission line models and length of the line segments is varied for different transmission lines.

Table 5-5: Transmission line data for the two-area system

\begin{tabular}{|c|c|c|c|}
\hline $\begin{array}{c}\text { Transmission } \\
\text { line }\end{array}$ & $\begin{array}{c}\mathbf{R} \\
(\boldsymbol{\Omega})\end{array}$ & $\begin{array}{c}\mathbf{X}_{\mathbf{L}} \\
(\boldsymbol{\Omega})\end{array}$ & $\begin{array}{c}\mathbf{B}_{\mathbf{C}} \\
(\boldsymbol{\mu M h o})\end{array}$ \\
\hline $5-6$ & 1.3225 & 13.225 & 0.13232 \\
\hline $6-7$ & 0.529 & 5.29 & 0.33081 \\
\hline $7-8$ & 5.819 & 58.19 & 0.03007 \\
\hline $8-9$ & 5.819 & 58.19 & 0.03007 \\
\hline $9-10$ & 0.529 & 5.29 & 0.33081 \\
\hline $10-11$ & 1.3225 & 13.225 & 0.13232 \\
\hline
\end{tabular}

\subsubsection{Representation of Load}

Load is modeled as described in Section 3.6. A splitter is used to separate the phases at the three-phase ATP nodes representing bus 7 and bus 9. Loads are modeled as constant impedance load using a single-phase resistor and inductor connected in parallel to represent real and reactive load respectively for each phase. In this system, there is some reactive power injections represented by a single-phase capacitor connected in parallel with the load impedance. Since the load is balanced, identical RLC values are used for all three phases. All the three components are connected to ground. Using load bus voltage magnitudes obtained from the load flow simulations (Table 5-4) and actual loads of the system, the loads are represented in ATP. Load impedances for each of the load buses are calculated from (3.9), (3.10) and (3.11). Table 5-6 gives the actual loads and load impedances at each load bus.

Table 5-6: Constant impedance load data

\begin{tabular}{|c|c|c|c|c|c|c|}
\hline \multirow{2}{*}{ Bus } & \multicolumn{2}{|c|}{ Real Power } & \multicolumn{2}{c|}{ Reactive Power } & \multicolumn{2}{c|}{ Reactive Power Supplied } \\
\cline { 2 - 7 } & $\mathbf{P}_{\mathbf{L}}(\mathbf{M W})$ & $\mathbf{R}_{\mathbf{L}}(\mathbf{\Omega})$ & $\mathbf{Q}_{\mathbf{L}}(\mathbf{M V A r})$ & $\mathbf{X}_{\mathbf{L}}(\mathbf{\Omega})$ & $\mathbf{Q}_{\mathbf{C}}(\mathbf{M V A r})$ & $\mathbf{B}_{\mathbf{C}}(\boldsymbol{\mu} \mathbf{M h o})$ \\
\hline 7 & 967 & 51.15 & 100 & 494.66 & 200 & 4043.16 \\
\hline 9 & 1767 & 29.28 & 100 & 517.42 & 350 & 6764.25 \\
\hline
\end{tabular}




\subsection{POWER SYSTEM DISTURBANCES}

The two-area system discussed in the last section is subjected to various disturbances and inter- and intra-area oscillations are studied. Different power system faults are applied at lines 6-7 and 10-9 and at the load buses 7 and 9. Rotor angle and terminal voltage of the machines in each area are compared to observe the intra-area oscillations. Inter-area oscillations are observed by comparing the machines in different areas. Power swings during system disturbance are observed in the tie lines connecting Area 1 and Area 2. Results are shown in Chapter 6.

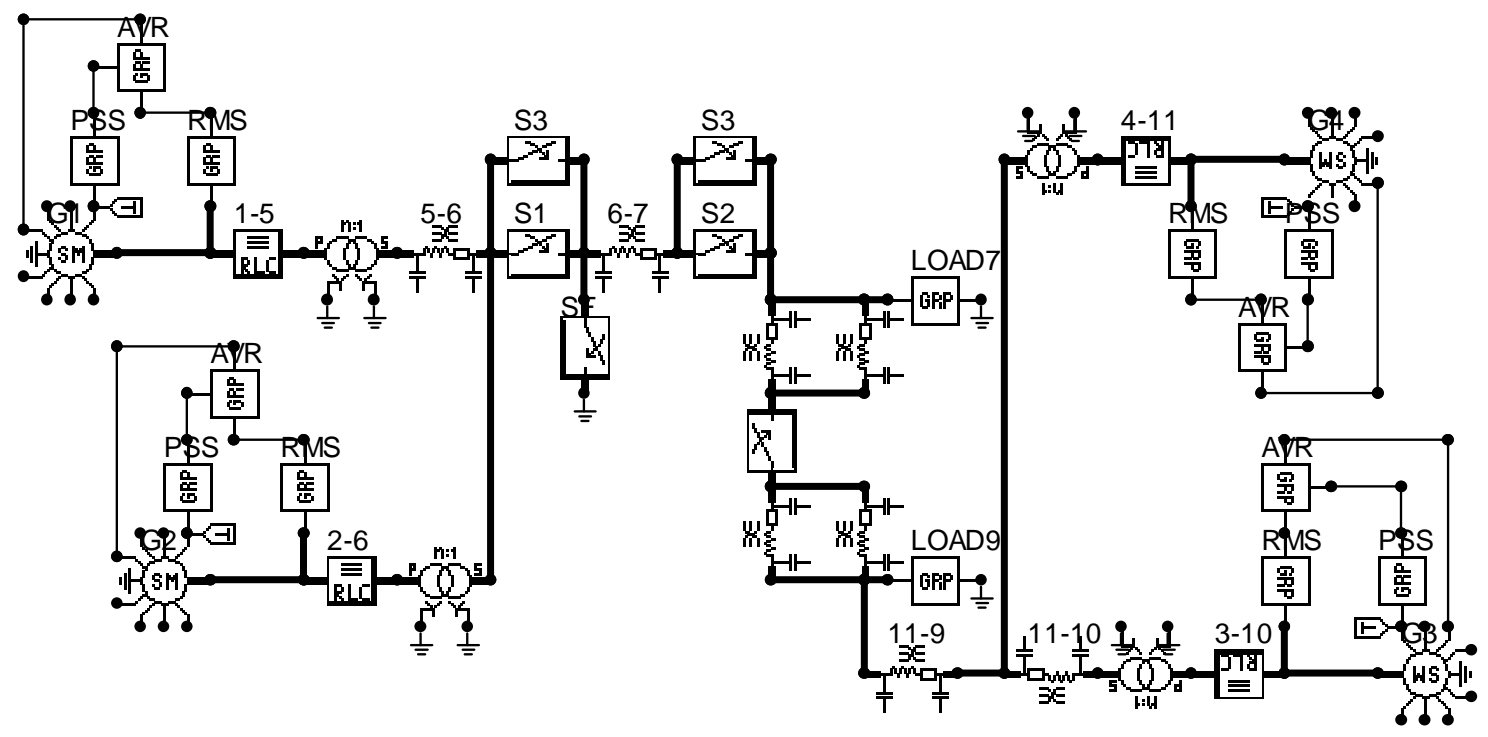

Figure 5.2: Two-area system modeled in ATP (Case 3a)

A three-phase-to-ground fault is applied in line 6-7 (Case 3a) near bus 6 at time $\mathrm{t}=5.0 \mathrm{~s}$ and circuit breakers trip the line out of service at time $\mathrm{t}=5.07 \mathrm{~s}$. The line is brought back to service by reclosing the switches at time $t=5.1 \mathrm{~s}$. Generators G1 and G2, which are close to the fault and removed totally from the system for $0.07 \mathrm{~s}$, will have transient over voltages while reclosing and voltage and rotor angle swings. Generators G3 and G4 which have to supply both the loads for $0.07 \mathrm{~s}$ also have voltage and rotor angle swings. The power flow from Area 1 to Area 2 during this fault condition is greatly affected and the power flow is observed by placing a three-phase time controlled switch between Area 1 and Area 2. This switch is closed before time $\mathrm{t}=0 \mathrm{~s}$ and remains closed and is used only to observe the power flow between the areas. A similar three- 
phase to ground fault is applied in line 10-9 (Case 3b) near bus 9 and power system oscillations are observed.

\subsubsection{Intra-area Oscillations}

In large power systems, small-signal stability problems may be either local or global in nature. Local problems may be associated with rotor angle oscillations of a single generator against the rest of the power system. Generator G1 swinging against rest of the system is a local generator mode oscillation and it is similar to the single machine infinite bus system discussed in Chapter 4. Local problems may also be associated with oscillations between the rotors of a few generators close to each other. Oscillations between G1 and G2 in area 1 and between G3 and G4 in area 2 are called intra-area oscillations. For the fault in the line 6-7, intra-area oscillations are observed for generators G1 and G2. The intra-area oscillation between machine G3 and G4 is negligible for the fault in line 6-7. But for a fault in line 11-9, intra-area oscillations are more pronounced in Area 2 and negligible in Area 1. Results are presented and discussed in Chapter 6.

\subsubsection{Inter-area Oscillations}

Global small-signal stability problems are caused by interactions among large groups of generators and have widespread effects. They involve oscillations of a group of generators in one area swinging against a group of generators in another area. These inter-area oscillations can be seen in the two-area system under study. The rotor angles and terminal voltages of all generators in the system are observed for different fault conditions. For all the cases, it is found that generators in Area 1 swing together and generators in Area 2 swing together. Though the inter-machine oscillations are present, they are negligible. Inter-area oscillations can be in high frequency modes in which subgroups of generators swing against each other and low frequency mode in which generators in one part of the system swing against the other part. The system under study is small and hence the high frequency mode inter-area oscillations cannot be studied. But the generators in area 1 (G1 and G2) swing against the generators in area 2 (G3 and G4). This makes the system very suitable to observe the low frequency mode inter-area oscillations. For different faults applied to the system, frequency of the inter-area 
oscillations is observed to be less than $1 \mathrm{~Hz}$. Analysis of Essentially Spontaneous Oscillations in Power System (AESOP) algorithm and Modified Arnoldi Method (MAM) can be used to analyze the power system oscillations by computing the Eigen values of the system [9]. MATLAB is one of the software packages which can be used to find the eigen-values.

\subsection{DYNAMIC EQUIVALENCING}

It is difficult to model in entirety a very large detailed power system in ATP. The traditionally way of dealing with large power systems in ATP is to construct a detailed model of the small local area of interest and represent the remaining system as Thevenin multi-port equivalent. When the system is represented as short circuit equivalent, the dynamic behaviors of the rotating masses in the system are lost. The dynamic behavior of the system will not be lost if the large power system is reduced and represented as dynamic equivalent (Section 2.6). The concept of dynamic equivalencing is tested and the reduced system is modeled in ATP for the two-area system under discussion. The four-machine system is reduced to a two-machine system and benchmarked against the original system. This is one important milestone in power system modeling, as advancements will help in study of very large power systems in ATP.

\subsubsection{Coherent Generators}

Coherent generators can be identified by investigating the rotor angles of all the generators in a system during a power system disturbance. Generators are said to be coherent if the difference between their rotor angles are constant under all conditions of power system. For different power system disturbances, the rotor angles of the machines are observed. In this two-area system as shown in Figure 5.3, generators G1 and G2 are swinging together and generators G3 and G4 are swinging together for a three-phase-toground fault in line 6-7 at the bus 6 end (Case 3a). Hence it is determined empirically that generators G1 and G2 are coherent and generators G3 and G4 are coherent. 


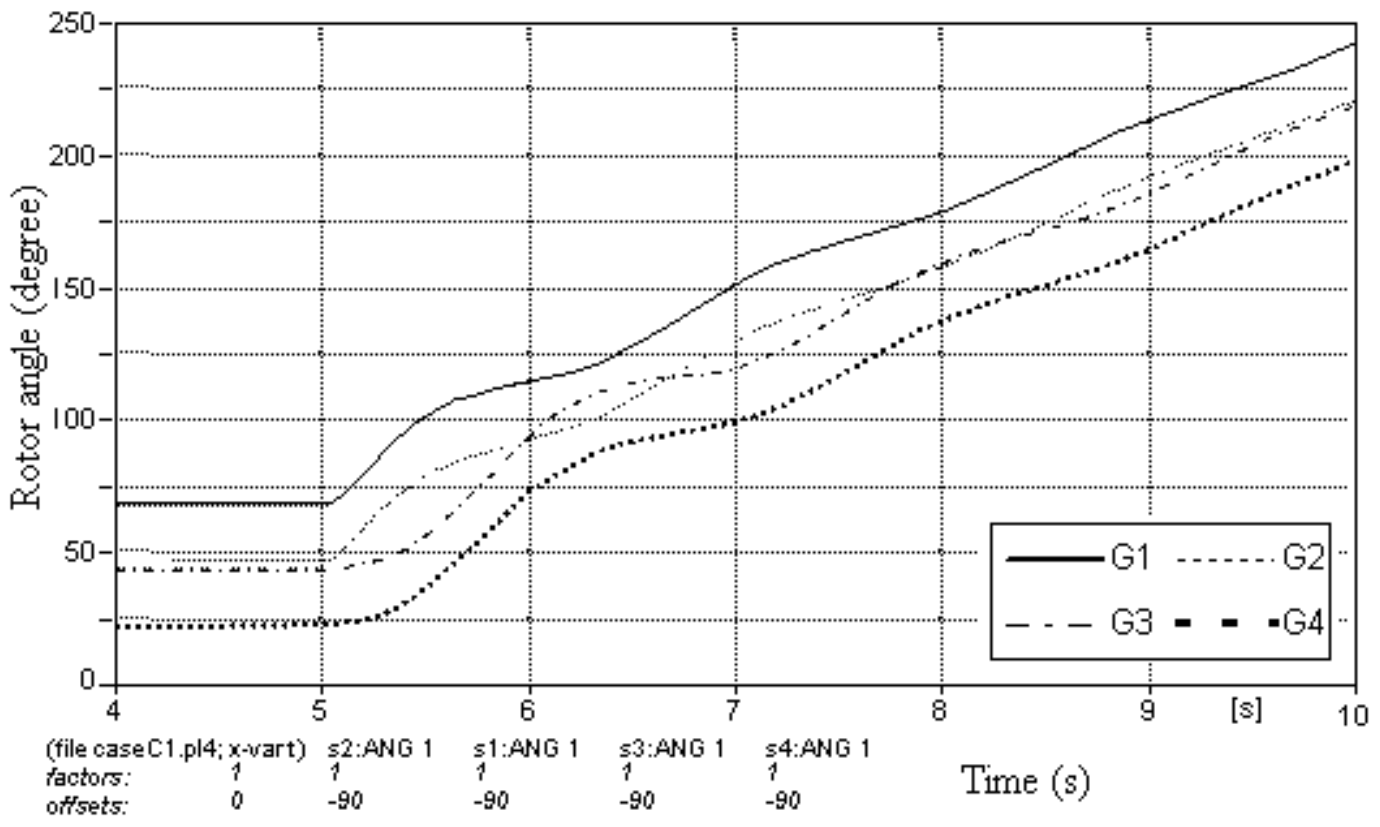

Figure 5.3: Rotor angles (in degree) for a fault in area 1(Case 3a)

\subsubsection{Generator Aggregation}

According to [21] and [22], once the coherent generators are identified, the next step is to aggregate the generators. In this step each group of coherent generators is replaced by one equivalent aggregate generator. The terminal voltage magnitude and phase angle of the equivalent generator will be the average of those of coherent generators. The d-axis and q-axis reactances of the equivalent generator are obtained by paralleling the reactances of the coherent generators. Coherent generators G1 and G2 are replaced by an equivalent generator G12 and coherent generators G3 and G4 are replaced by an equivalent generator G34. Since the generating voltage and transformation ratio of all the generators in this two-area system are the same, there is no need of additional transformers. Generator aggregation is discussed in Section 2.6.2.

$$
\begin{aligned}
& V_{12}=\frac{V_{1}+V_{2}}{2}=\frac{1.03+1.01}{2}=1.02 \text { p.u. } \\
& V_{34}=\frac{V_{3}+V_{4}}{2}=\frac{1.03+1.01}{2}=1.02 \text { p.u. } \\
& \theta_{12}=\frac{\theta_{1}+\theta_{2}}{2}=\frac{20.2+10.5}{2}=15.35^{\circ}
\end{aligned}
$$




$$
\theta_{34}=\frac{\theta_{3}+\theta_{4}}{2}=\frac{-6.8-17}{2}=-11.9^{\circ}
$$

The equivalent machine will be on the same base of $20-\mathrm{kV}$ and 900-MVA. The new generator parameters are given in Table 5-7. The time constants remain the same. The inertia constants of the equivalent machines will be sum of the inertia constants of the aggregated coherent machines.

Table 5-7: Generator parameters of the reduced system

\begin{tabular}{|c|c|c|c|c|c|c|c|}
\hline $\mathbf{R}_{\mathbf{a}}$ & $\mathbf{X}_{\mathbf{L}}$ & $\mathbf{X}_{\mathbf{d}}$ & $\mathbf{X}_{\mathbf{q}}$ & $\mathbf{X}_{\mathbf{d}}{ }^{\prime}$ & $\mathbf{X}_{\mathbf{q}}{ }^{\prime}$ & $\mathbf{X}_{\mathbf{d}}{ }^{\prime \prime}$ & $\mathbf{X}_{\mathbf{q}}{ }^{\prime \prime}$ \\
\hline$(\mathrm{pu})$ & $(\mathrm{pu})$ & $(\mathrm{pu})$ & $(\mathrm{pu})$ & $(\mathrm{pu})$ & $(\mathrm{pu})$ & $(\mathrm{pu})$ & $(\mathrm{pu})$ \\
\hline 0.0005 & 0.4 & 3.6 & 3.4 & 0.6 & 1.1 & 0.5 & 0.5 \\
\hline \multirow{2}{*}{$\mathbf{T}_{\mathbf{d o}}{ }^{\prime}$} & $\mathbf{T}_{\mathbf{q o}}{ }^{\prime}$ & $\mathbf{T}_{\mathbf{d o}}{ }^{\prime \prime}$ & $\mathbf{T}_{\mathbf{q o}}{ }^{\prime \prime}$ & \multicolumn{5}{|c|}{$\mathbf{G 1}_{\mathbf{e q}}$} & \multicolumn{2}{|c|}{$\mathbf{G 2}_{\mathbf{e q}}$} \\
\hline$(\mathrm{s})$ & $(\mathrm{s})$ & $(\mathrm{s})$ & $(\mathrm{s})$ & $\mathrm{H}(\mathrm{s})$ & $\mathbf{J}\left(\mathrm{Mkgm}^{2}\right)$ & $\mathrm{H}(\mathrm{s})$ & $\mathbf{J}\left(\mathrm{Mkgm}^{2}\right)$ \\
\hline 8 & 0.4 & 0.03 & 0.05 & 13 & 0.16474 & 12.35 & 0.156502 \\
\hline
\end{tabular}

The real and reactive power supplied by the equivalent machine is sum of the power supplied by the coherent machines. There will not be any change in the saturation characteristics of the equivalent machines as the generators are identical. The excitation control system of the equivalent generators is modeled by exactly as that of the original generators. Table 5-8 gives the initial generator loading. Power flow is simulated using PSS/E to find the bus voltages and phase angles. The power flow solution is used for the initial steady-state conditions of the machines in the reduced system. The power flow results are given in Table A-4.

Table 5-8: Initial generator loading of the reduced system

\begin{tabular}{|c|c|c|c|c|}
\hline Generator & $\begin{array}{c}\text { Real Power } \\
\text { P (MW) }\end{array}$ & $\begin{array}{c}\text { Reactive Power } \\
\text { Q (MVAr) }\end{array}$ & $\begin{array}{c}\text { Bus voltage } \\
\text { magnitude (p.u.) }\end{array}$ & $\begin{array}{c}\text { Bus voltage } \\
\text { phase angle }\left(^{\circ} \text { ) }\right.\end{array}$ \\
\hline $\mathrm{G} 1_{\mathrm{eq}}$ & 1400 & 420 & 1.02 & 15.35 \\
\hline $\mathrm{G} 2_{\mathrm{eq}}$ & 1419 & 378 & 1.02 & -11.9 \\
\hline
\end{tabular}

\subsubsection{Network Reduction}

The last and final step in the process of dynamic reduction is network reduction. The transmission line and transformer impedances in the area to be reduced are changed. For a very large system, insignificant generators and load buses can be removed from the system. Once the nodes are eliminated the reduced system admittance matrix is found 
and the new network parameters from the admittance matrix are used for the reduced system.

In this two-area system, there are no insignificant load or generator buses. The transmission line between buses 6 and 10 is retained without any change. Buses 2, 4, 5 and 11 are removed. Equivalent impedance of the impedance between buses $1 \& 5,2 \&$ 6 and $1 \& 6$ is represented in the reduced system between bus $1 \&$ bus 6 . Similarly, equivalent impedance between buses $3 \& 11,11 \& 10$ and $4 \& 10$ is represented in the reduced system between buses $3 \& 11$.

The equivalent impedance of the reduced system can be found by reducing the admittance matrix of the system. But this cannot be done manually for a very large system. PSS/E can efficiently handle very large systems and network reduction can be easily done. Power system is divided into a study system and several areas which need to be reduced. If the boundary buses and the buses that have to be retained are specified, PSS/E software package will determine the reduced network parameters. More details are provided in [19].

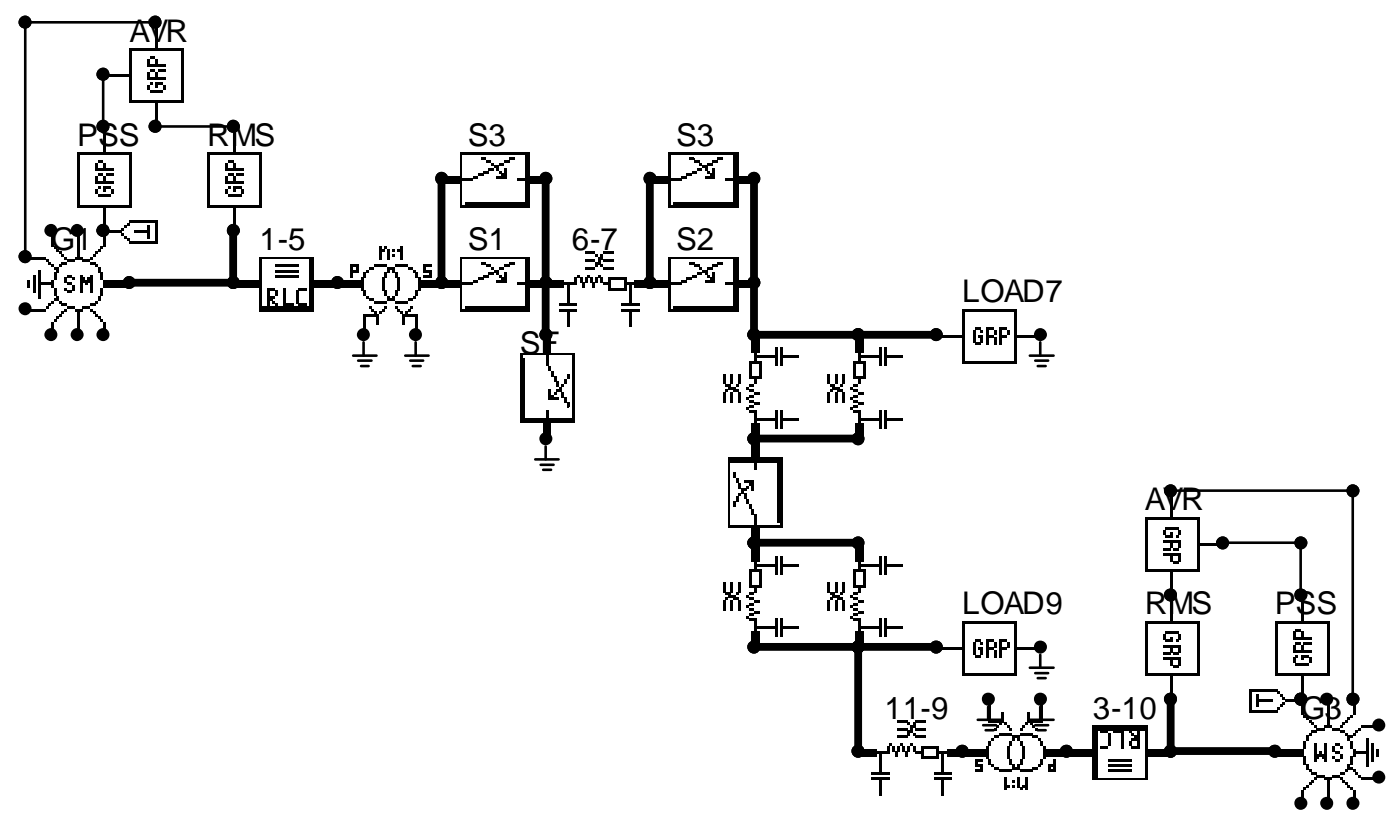

Figure 5.4: Dynamically reduced system

The network parameters of the reduced system are given in Table 5-9. A load flow results from PSS/E [19] are used to find the load bus voltages. Power flow results 
are given in Table A-4. Constant impedance loads of the reduced system are calculated from actual loads and load bus voltages. Impedances used to represent the loads in buses 7 and 9 are given in Table A-5.

Table 5-9: Network parameters of the reduced system

\begin{tabular}{|c|c|c|c|}
\hline $\begin{array}{c}\text { Transmission } \\
\text { line }\end{array}$ & $\begin{array}{c}\mathbf{R} \\
(\mathbf{\Omega})\end{array}$ & $\begin{array}{c}\mathbf{X}_{\mathbf{L}} \\
(\mathbf{\Omega})\end{array}$ & $\begin{array}{c}\mathbf{B}_{\mathbf{C}} \\
(\boldsymbol{\mu} \mathbf{M h o})\end{array}$ \\
\hline $1-6$ & 1.3225 & 13.225 & 0.13232 \\
\hline $6-7$ & 0.529 & 5.29 & 0.33081 \\
\hline $7-8$ & 5.819 & 58.19 & 0.03007 \\
\hline $8-9$ & 5.819 & 58.19 & 0.03007 \\
\hline $9-10$ & 0.529 & 5.29 & 0.33081 \\
\hline $2-10$ & 1.3225 & 13.225 & 0.13232 \\
\hline
\end{tabular}

The reduced system with new parameters, as shown in Figure 5.4, is modeled in ATP. A three-phase-to-ground fault is applied in line 6-7 near bus 6 at time, $t=5.0 \mathrm{~s}$. The line is tripped out of service at time, $\mathrm{t}=5.07 \mathrm{~s}$ and reclosed at time, $\mathrm{t}=5.1 \mathrm{~s}$. Rotor angles and terminal voltages of the machines are monitored and compared with the original system. The power swing observed in the power transferred from Area 1 to Area 2 should remain the same for both the original and reduced system. Figure 5.5 shows the rotor angles in Area 1 of the reduced and the original system for a three-phase line fault (Cases $3 \mathrm{a}$ and $4 \mathrm{a}$ ). Complete results including benchmarking against PSS/E are given in Chapter 6.

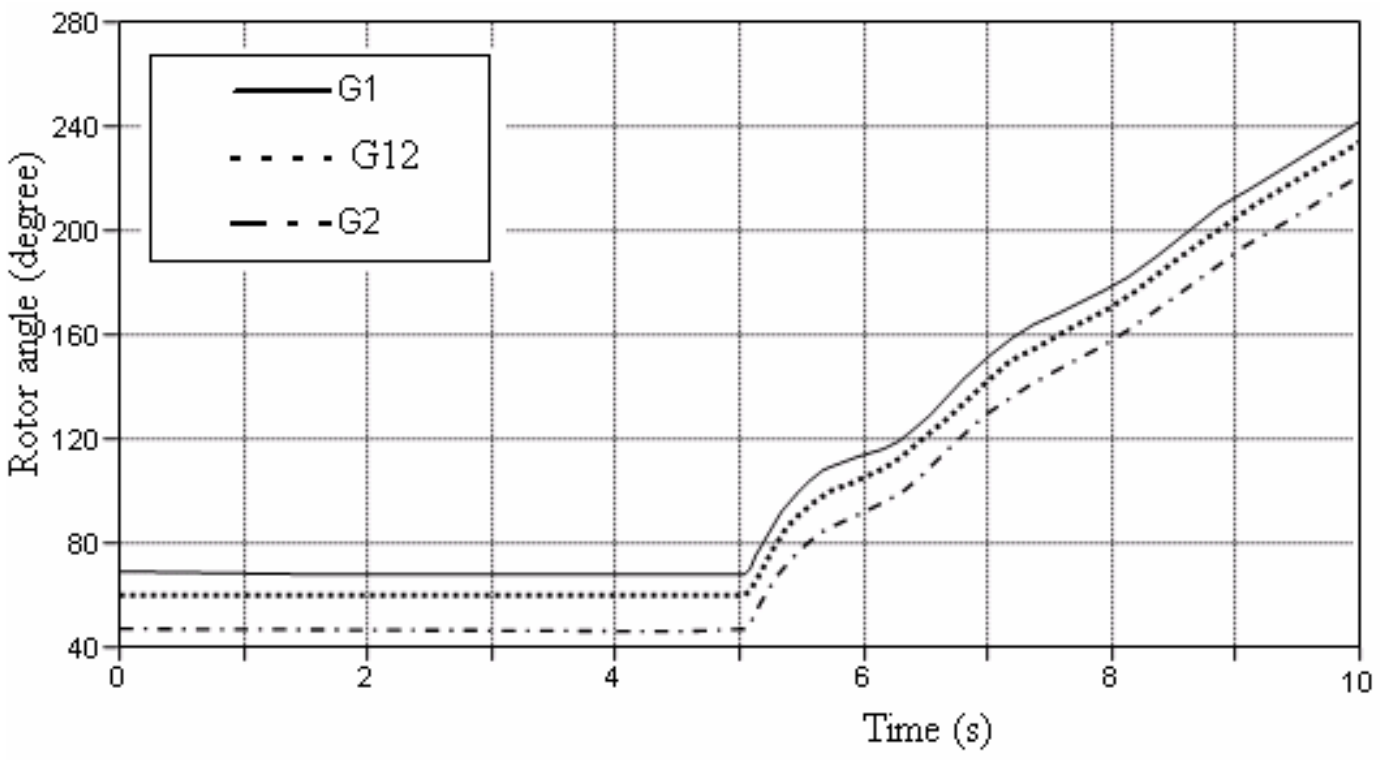

Figure 5.5: Rotor angles of machines in Area 1 (Cases 3a and 4a) 


\section{CHAPTER 6 SIMULATIONS AND RESULTS}

This chapter presents the simulation results for different power system models during various system disturbances. Power systems modeled in ATP are benchmarked against PSS/E and dynamic equivalent models are compared. Benchmarking against PSS/E [19] will determine ATP's suitability for use not only in predicting transient over voltages and currents, but also to be used in stability modeling.

\subsection{SINGLE MACHINE INFINITE BUS CASES}

The single-machine cases implemented in Chapter 4 are used to simulate stability studies. The effects of excitation control systems, fault location, fault type, generator saturation and armature resistance in synchronous machine dynamics are studied by applying faults of different types and locations to the different system models. For most of the cases, benchmarking against PSS/E is done for a three-phase-to-ground fault in one of the two transmission lines connecting the generator to the infinite bus. All the faults were initiated at $5.0 \mathrm{~s}$. According to [9], the duration of the fault for the study is $0.07 \mathrm{~s}$ and the tripped line is brought back into service after $0.03 \mathrm{~s}$ by reclosing the switches. All of the internal variables of the synchronous machine are observed during the disturbances, and the rotor angle and terminal voltage are both used to benchmark the results. Rotor angle $(\delta)$ is used for observing and benchmarking rotor angle stability. Instantaneous voltage output of the synchronous machine model is converted into its per unit value using TACS, and plotted for benchmarking and voltage stability analysis. Different cases, used for the simulations are summarized in Table 6.1

Table 6-1: Three-phase line fault in one of the transmission lines at generator end

\begin{tabular}{|l|l|l|}
\hline 2220-MVA, machine & 1000-MVA, machine & Description \\
\hline Case 5a & Case 1a & With AVR and PSS \\
\hline Case 5b & Case 1b & With constant EFD \\
\hline Case 5c & Case 1c & With AVR \\
\hline Case 5d & Case 1d & With AVR, GOV and PSS \\
\hline Case 5e & Case 1e & With AVR, PSS and saturation \\
\hline Case 5f & Case 1f & With armature resistance \\
\hline Case 5g & N/A & Four individual machine \\
\hline Case 5h & Case $1 \mathrm{~h}$ & With AVR and GOV \\
\hline
\end{tabular}




\subsubsection{Generator Dynamics With and Without Excitation Control Systems}

The single-machine system described in Section 4.2 is used for observing stability for different types of excitation control. A solid three-phase-to-ground fault is applied to one of the two transmission lines, and rotor angles and terminal voltages are observed for the synchronous machine modeled in three different ways as summarized below.

(i) With constant field voltage, (Case 1b)

(ii) With Automatic Voltage Regulator (AVR), (Case 1c)and

(iii) With AVR and Power System Stabilizer (PSS). (Case 1a)

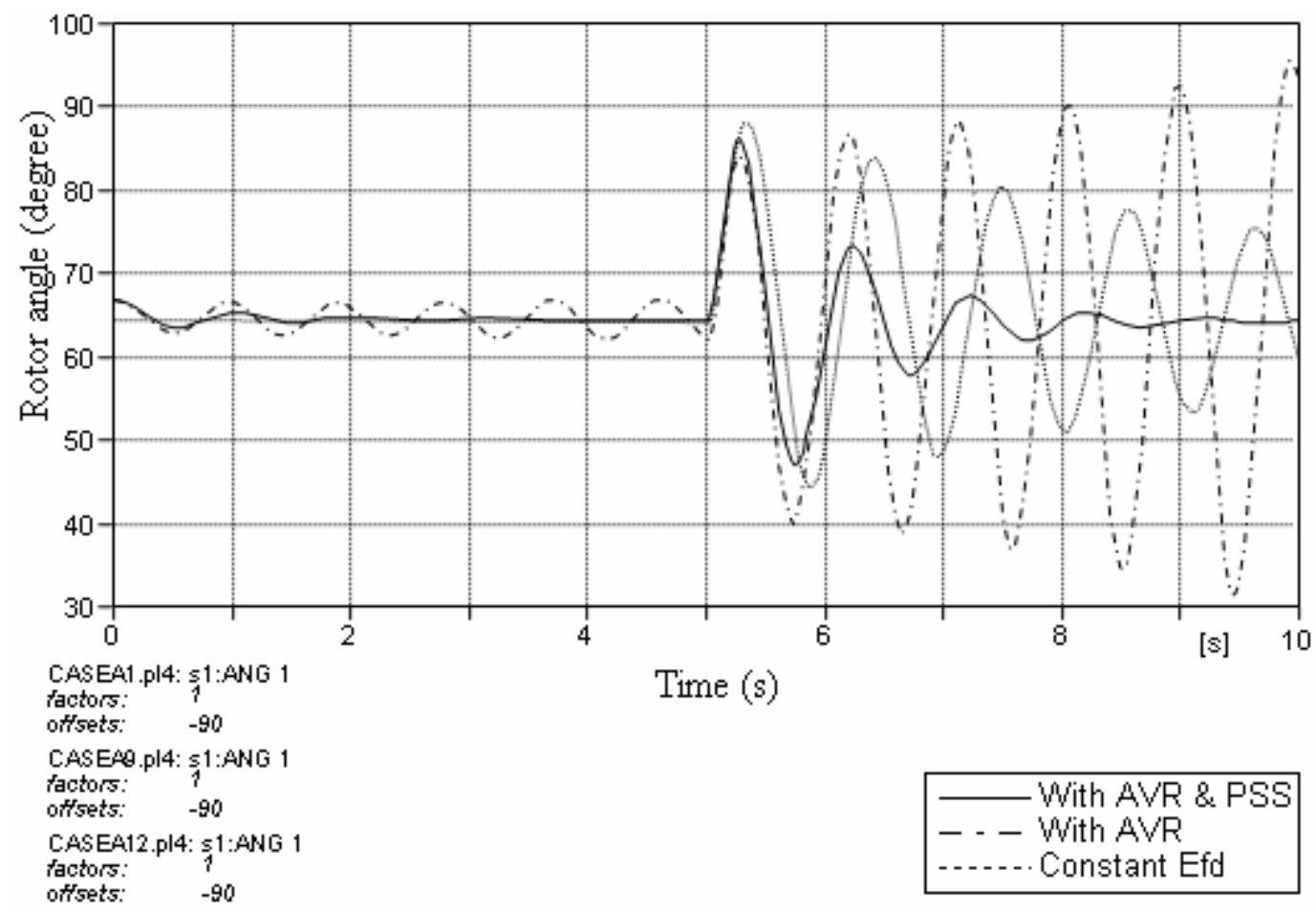

Figure 6.1: Rotor angle for different types of excitation control (Cases 1a, 1b, \&1c)

Figures 6.1 and 6.2 show the rotor angles and terminal voltages for the three different cases. From Figure 6.1, it is clearly seen that with constant field voltage, the system is transiently stable; however, the level of damping is low. The rotor angle settles to the final value after a long time (more than $5 \mathrm{~s}$ ) because of poor damping. With a fast acting AVR and high excitation limits, the first rotor angle swing is reduced; however, the subsequent swings are negatively damped. The system is not stable and loses synchronism. With the PSS along with AVR, the rotor angle oscillations are very well damped, without compromising first-swing stability. First-swing stability is largely 
determined by the peak value of the first oscillation. Various sensitivity analyses, such as increased fault duration and moving fault location closer to the generators to get higher fault currents, are simulated to show system instability and loss of synchronism. Figure B.1 shows the comparison of field voltages for Cases $1 \mathrm{a}, 1 \mathrm{~b}$ and $1 \mathrm{c}$.

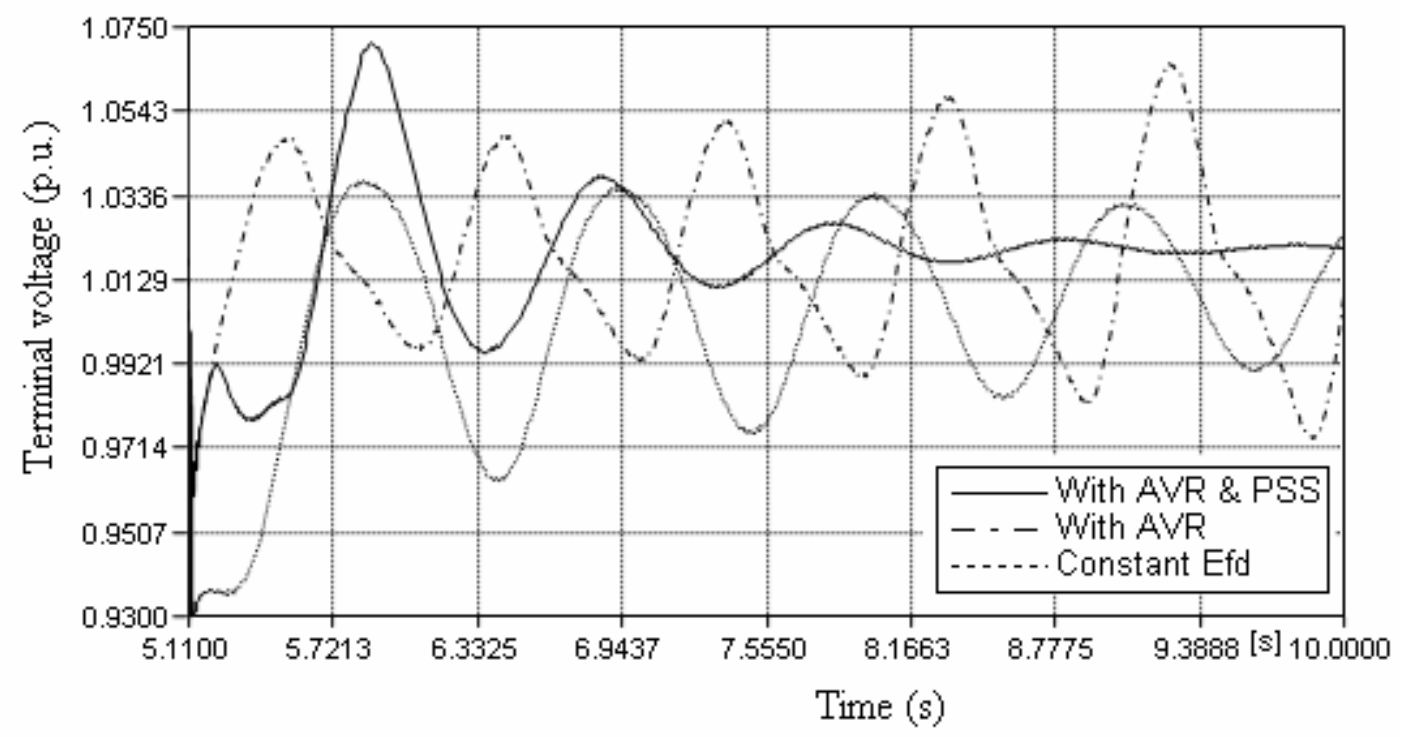

Figure 6.2: Terminal voltage for different excitation controls (Cases 1a, 1b, \& 1c)

Voltage stability is strongly correlated to rotor angle stability for these three models. With constant field voltage, observing the terminal voltage shows that the machine does not lose synchronism, but takes more time to settle. Using an AVR without a PSS, the system becomes unstable which can be clearly seen from the underdamped oscillation shown in Figure 6.2. Using both an AVR and a PSS, peak of the first swing is reduced and the settling time is decreased. Before the peak of first swing there is an initial peak in the voltage, presumably due to the switching transients.

Figure 4.3 shows the instantaneous and per unit terminal voltage of the synchronous machine with AVR and PSS, for a three-phase line fault of duration $0.07 \mathrm{~s}$ without any numerical oscillations. 


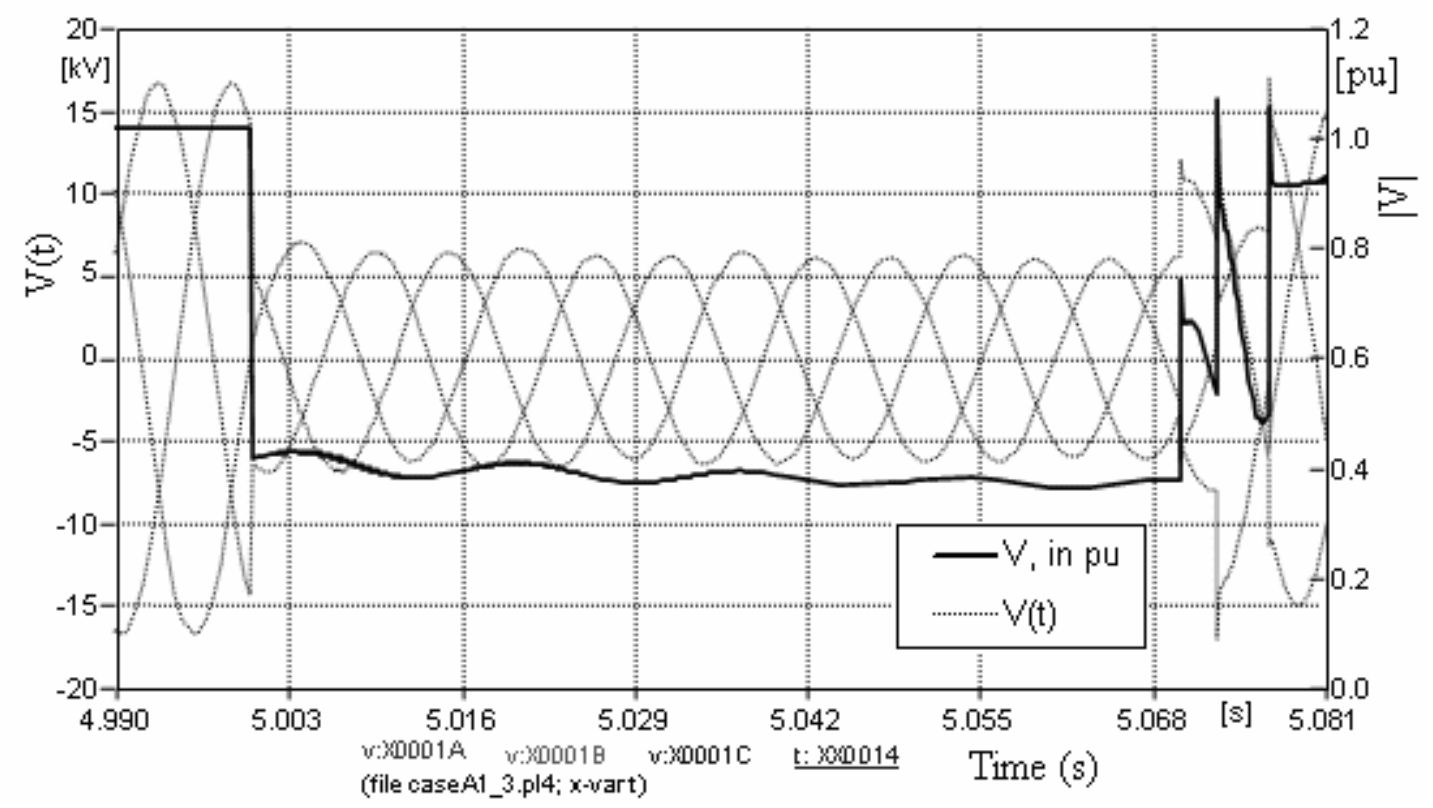

Figure 6.3: Instantaneous and per unit terminal voltage (Case 1a)

\subsubsection{Effects of Generator Saturation and Armature Resistance}

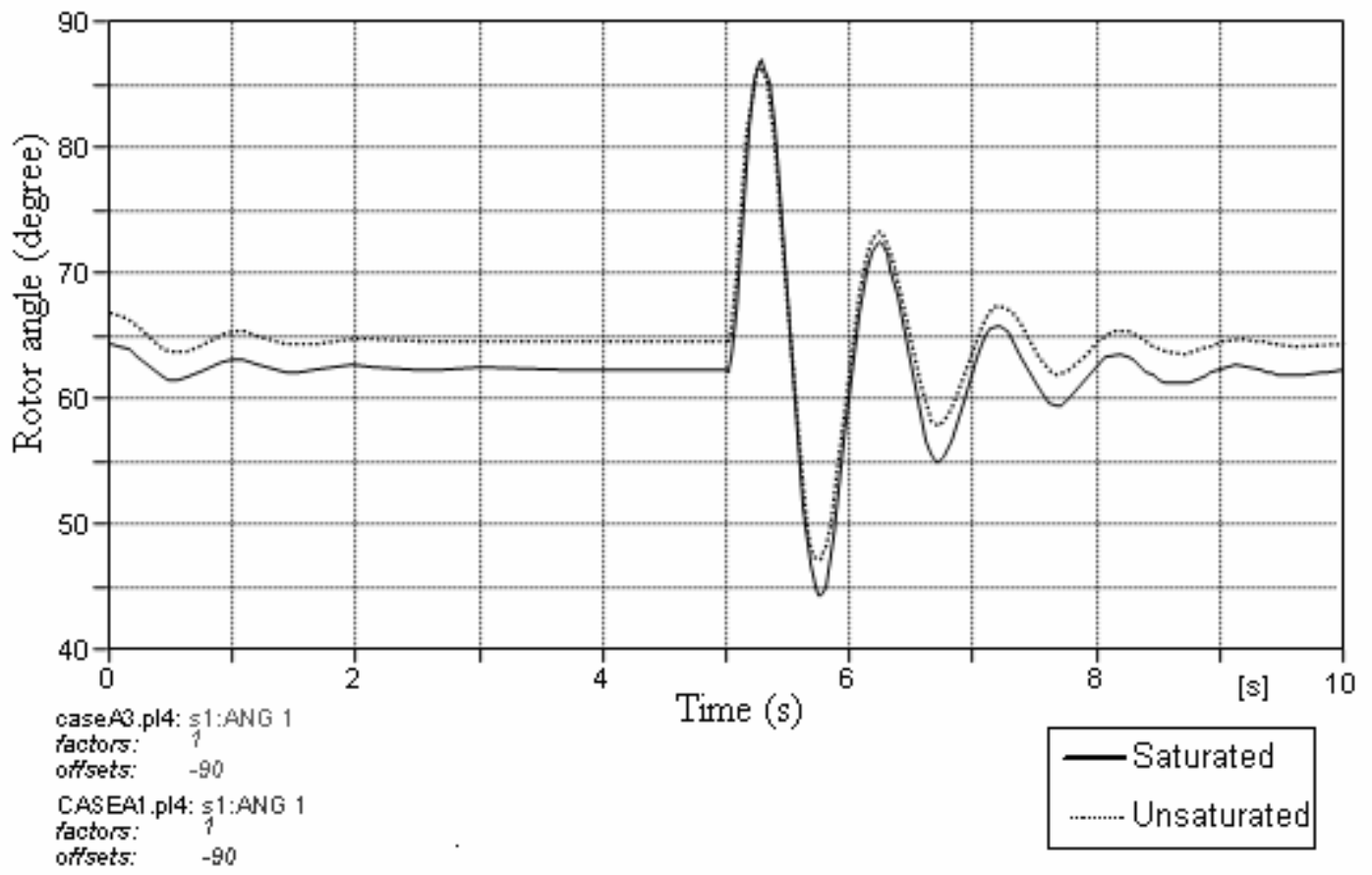

Figure 6.4: Machine models with and without saturation (Cases 1e \& 1a) 
In SM 59 generator model, d-axis and q-axis saturation characteristics were included by making changes to the ATP input data file using a text editor. All the fault types discussed in Section 4.1.3 were simulated for systems with saturated and unsaturated machine model. The saturation characteristic determined by the two-slope method was discussed in Section 3.2, where the open circuit results clearly show that the machine model will operate in saturation region if the voltage is higher than 1.2 per unit. For the cases in this research, the terminal voltage of machine is always within 1.2 per unit. The effect of saturation is minimal and it changes the d-and q-axes reactances of the machine and hence the internal rotor angle of the machine. Rotor angle during a three-phase line fault (Case 1e) for models with and without saturation is shown in Figure 6.4 .

Peak of the first swing for machine model with saturation is more than that of machine model without saturation. In steady state, the rotor angle is $2.19^{\circ}$ less for saturated machine model. This is due to the difference in q-axis reactances $\left(X_{q}\right)$ for the saturated and unsaturated machine models. $X_{q}$ is related to the internal rotor angle of the machine by (6.1).

$$
\delta_{i}=\tan ^{-1}\left(\frac{X_{q} I_{t} \cos \phi-R_{a} I_{t} \sin \phi}{E_{t}+R_{a} I_{t} \cos \phi+X_{q} I_{t} \sin \phi}\right)
$$

The settling time of the rotor angles of both machine models are the same, but the frequency of saturated model is more than that of the unsaturated machine model approximately by $0.5 \%$.

Armature resistance of the machine is neglected in all the simulations mainly because of the fact that machine models in PSS/E are not capable of having armature resistances. In order to observe and study the effects of armature resistance in machine dynamics, several cases with armature resistance $\left(R_{a}\right)$ included are simulated and results are compared. Figure 6.5 shows the rotor angles for cases with and without $\mathrm{R}_{\mathrm{a}}$ after a three-phase line fault (Case 1f). Armature resistance increases the damping and reduces the peak of the oscillations of the rotor angle by $1.2-1.6 \%$. Figure B.2 shows the rotor angles for a LG fault (Case 2b) of machine models with and without armature resistance. 


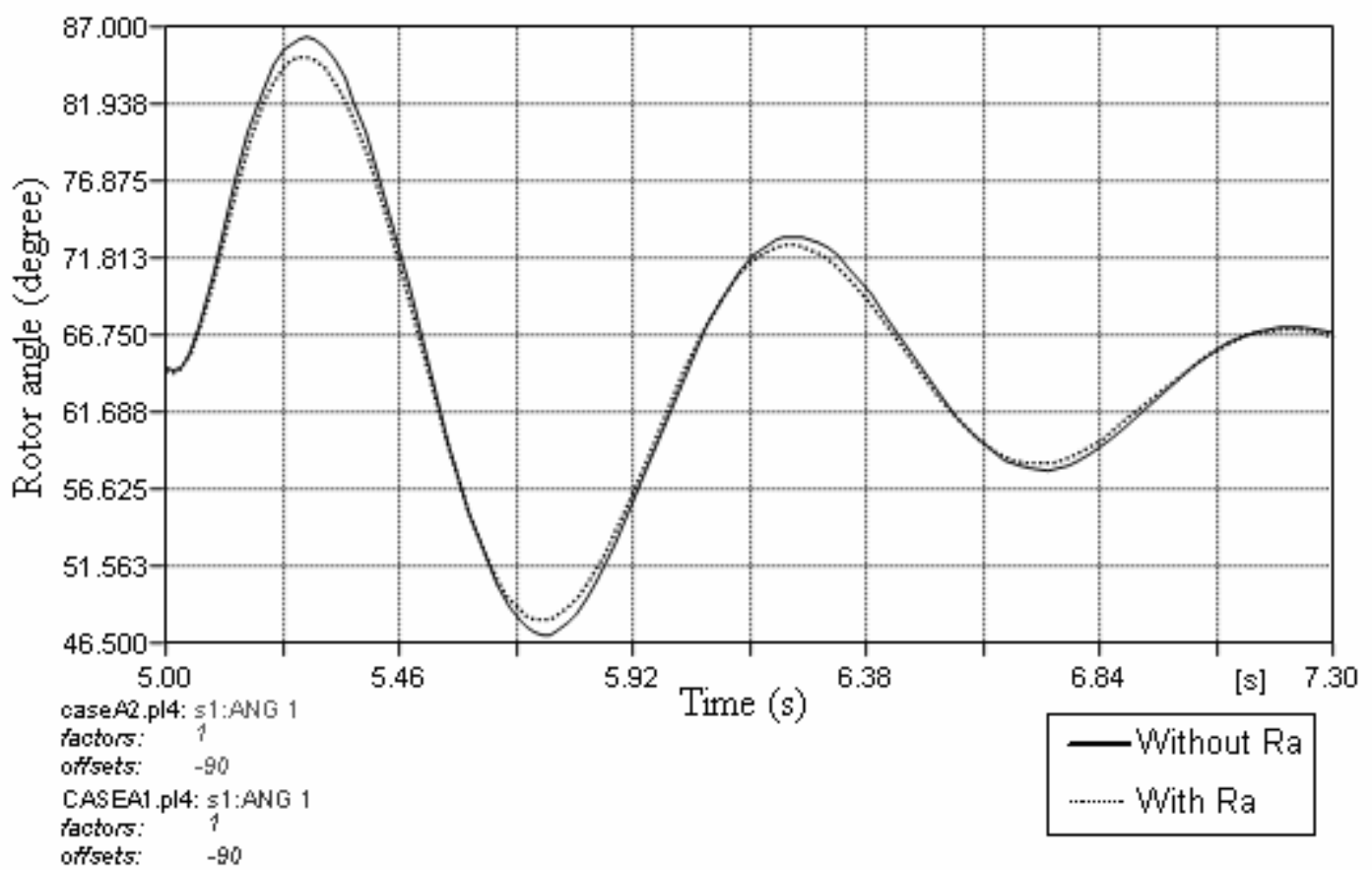

Figure 6.5: Rotor angles of machine models with and without $R_{a}$ (Cases 1 and 1a)

\subsubsection{Speed Governor for Input Power Control}

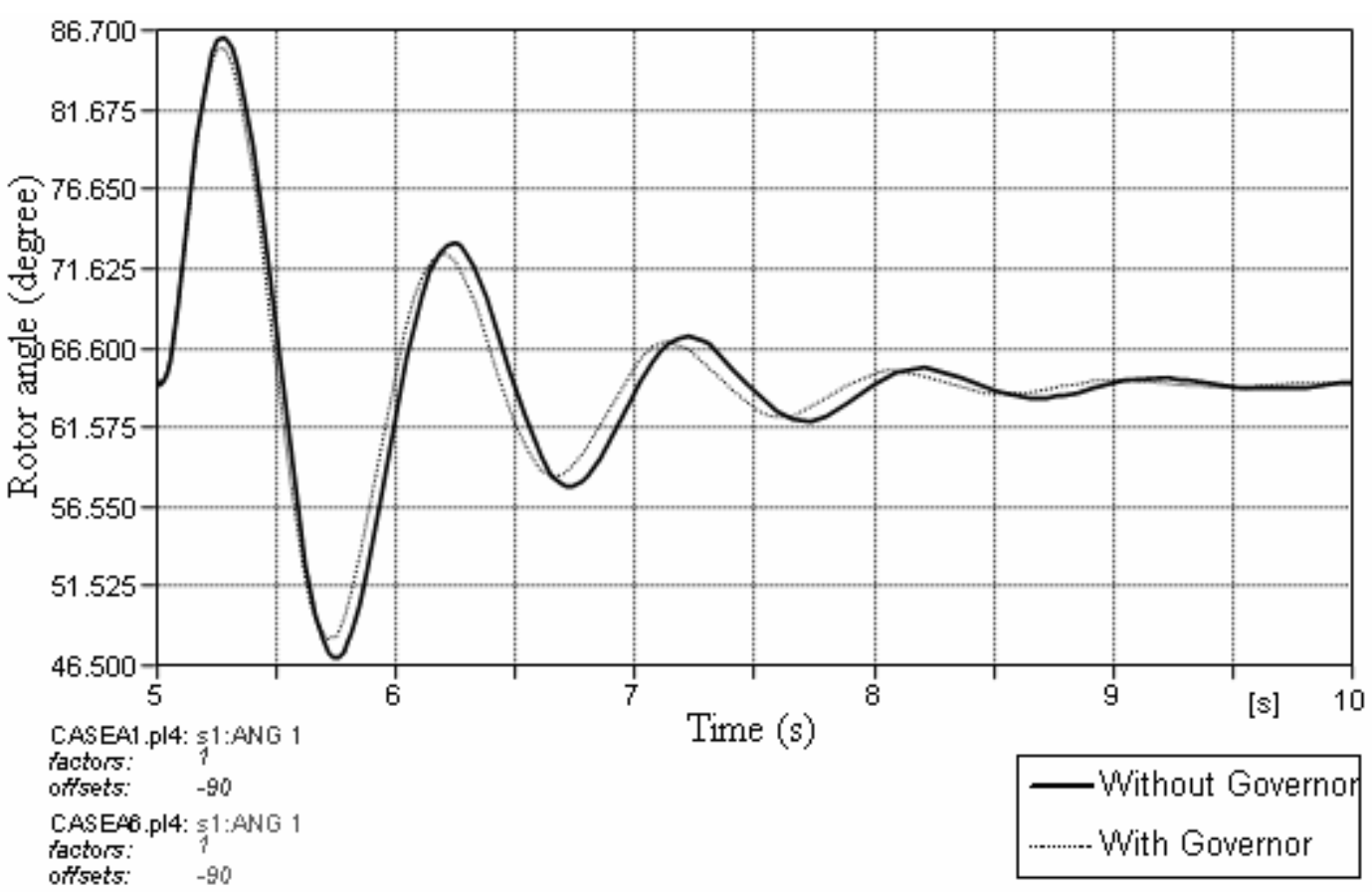

Figure 6.6: Machine models with and without governor (Cases 1d \& 1a) 
The speed governor controls the mechanical power input to synchronous machine by controlling the change in rotor speed. The governor model (IEEE TGOV discussed in Section 3.3), helps to somewhat improve power system stability. When the mechanical power input to the machine is controlled by speed governor, the settling time decreases. The governor can provide additional damping to the machine model with AVR and PSS, damping peak values of oscillations by an additional $0.82 \%$ for a three-phase line fault (Case 1d) as shown in Figure 6.6. Synchronous machine with speed governor settles to steady-state faster by $2.6 \%$ for the case under discussion. Though governor improves stability a little, due to non-availability of specific speed governor system data for synchronous machine under study, it was decided to omit the governor and model machines only with AVR and PSS for other cases. Rotor angles of machines modeled with four different excitation system model (Cases 1a through 1d) are compared in Appendix B (Figure B.3).

\subsubsection{Single versus Multiple Machines}

Another single machine system with 2220-MVA, 24-kV equivalent generator, (discussed in Section 4.1) representing four 555-MVA machines connected to the generator bus in a power plant is used for stability studies. Different cases simulated using the 1000-MVA, 20-kV machine are repeated with this system and consistent results are obtained. The effect of armature resistance, generator saturation, AVR, PSS, governor and fault duration, on power system stability is found to be consistent with that discussed in Sections 6.1.1 through 6.1.3. A severe three-phase fault is applied at the generator bus and cleared after 0.07 s. Rotor angle and voltage stability of the synchronous machine are studied for different types of faults. Figure B.4 shows the rotor angles for Case 5a, when the faulted line is tripped both temporarily and permanently.

As the 2220-MVA machine is an equivalent for the four 555-MVA machines, the system with four generators discussed in Section 4.1.3 was used to simulate with the same faults and compared with the equivalent machine model's results. Figure 6.7 shows the rotor angles of the individual (Case $5 \mathrm{~g}$ ) and equivalent machines. It is clearly seen that the equivalent machine exactly represents the four individual machines connected to same bus. 


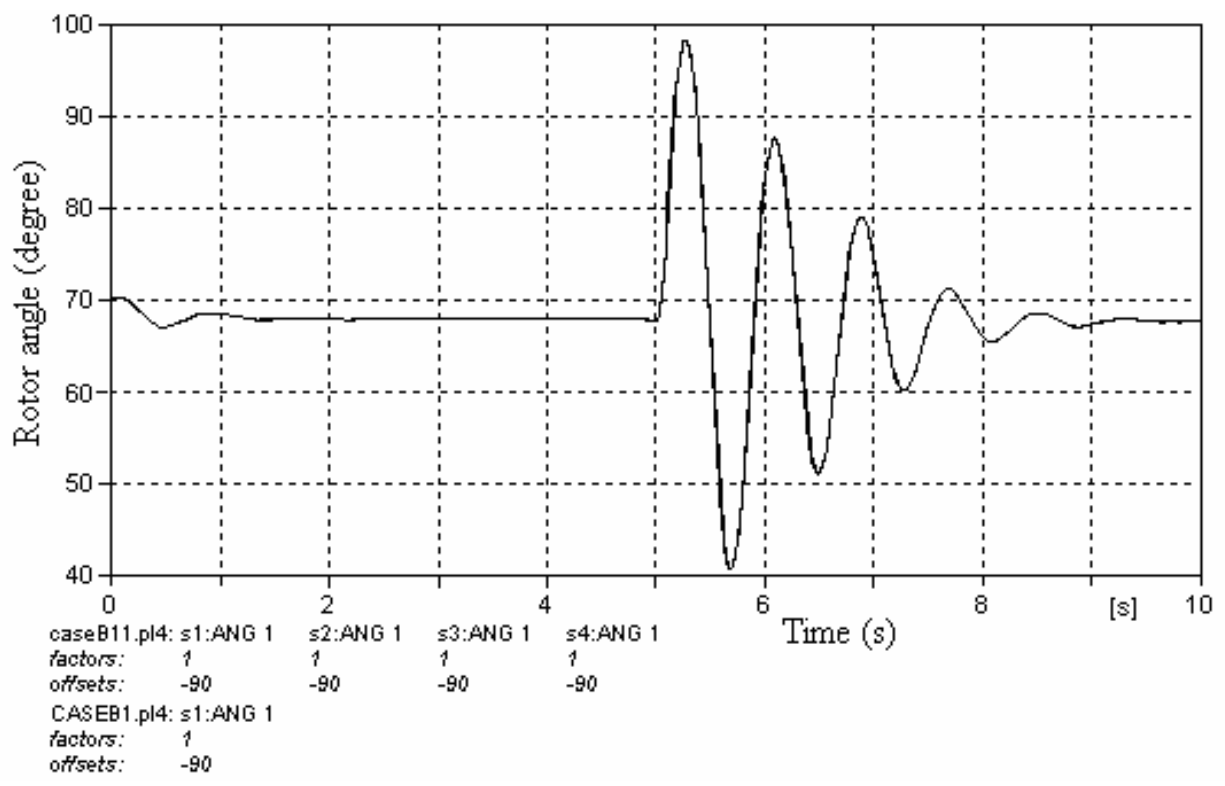

Figure 6.7: Four machines and single machine system (Cases 5g \& 5a)

\subsubsection{Benchmarking Against PSS/E}

Benchmarking the ATP power system models against PSS/E is one of the main contributions of this research work. All the cases discussed above are benchmarked against PSS/E. A few are discussed in this section, with the remaining benchmarked results included in Appendix B (Figures B.5 through B.7). Rotor angles of generator with (Case 1d) and without (Case 1a) speed governor along with AVR and PSS for a three-phase line fault are shown in Figures 6.8 and 6.9 respectively. In PSS/E as the time step size is large $(8.333 \mathrm{~ms})$, small changes in the time at which the faults are applied or cleared affect the peak of the oscillations. Hence it is necessary to carefully enter the times while performing simulations in PSS/E.

For the system without speed governor, the frequency of oscillation of PSS/E and ATP are exactly same. However, PSS/E and ATP exhibit slightly different behaviors in control of field voltage. Although different scaling factors are used, the controller topologies are identical. Thus, there are some internal differences in field voltage control between the machines in these two simulation packages. In all the simulations it is found that the peaks of first swing for ATP models are smaller than that of PSS/E models. And in PSS/E the damping is more and hence the subsequent peaks are less for ATP simulation. 
For the simulations with speed governor for input power control, the frequency of ATP is less than that of PSS/E as seen from Figure 6.8. Although different scaling factors are used for the control of mechanical power, the controller topologies are identical. There is a difference in the settling time of ATP and PSS/E models, but this difference in settling time is very less for simulations without governor.

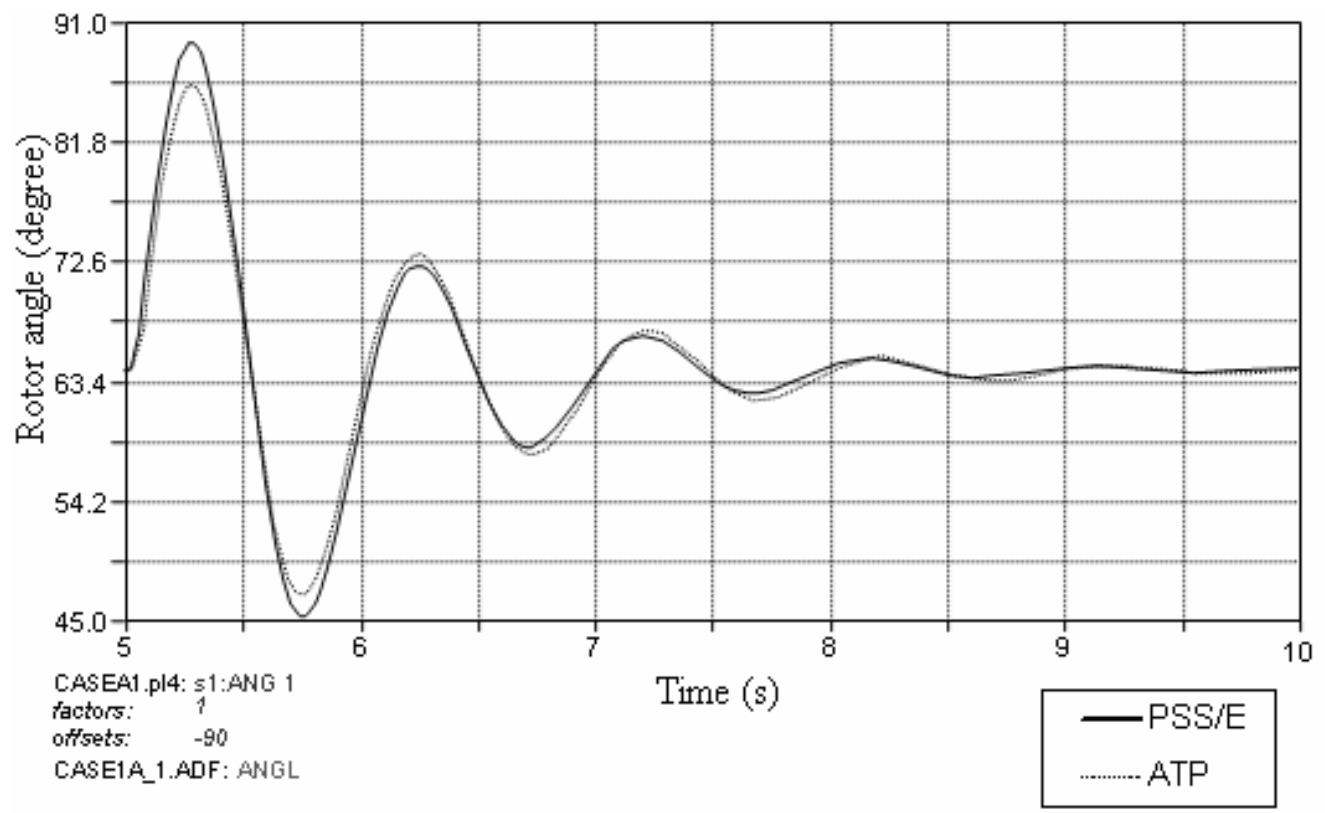

Figure 6.8: Rotor angles of system with AVR and PSS (case 1a)

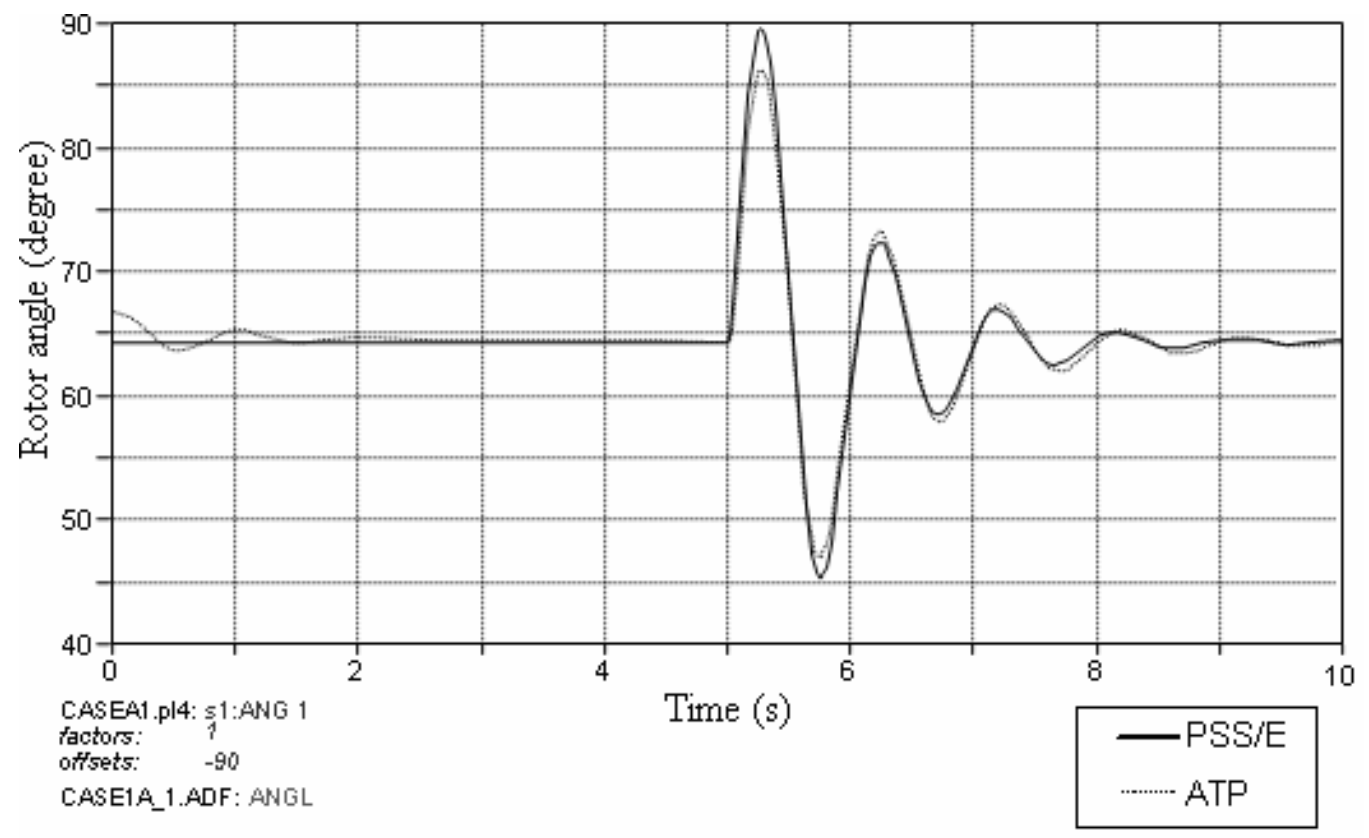

Figure 6.9: Rotor angles of system with AVR, PSS and governor (Case 1d) 
Figure 6.10 shows the terminal voltages in per unit for a three-phase line fault. The initial peak in ATP simulation is due to the transient voltage during the switching operations. When the switches are opened, the transients produce a peak voltage of 1.1 per unit in case of ATP. This is missing in PSS/E as it is not capable of handling transient behaviors of power systems.

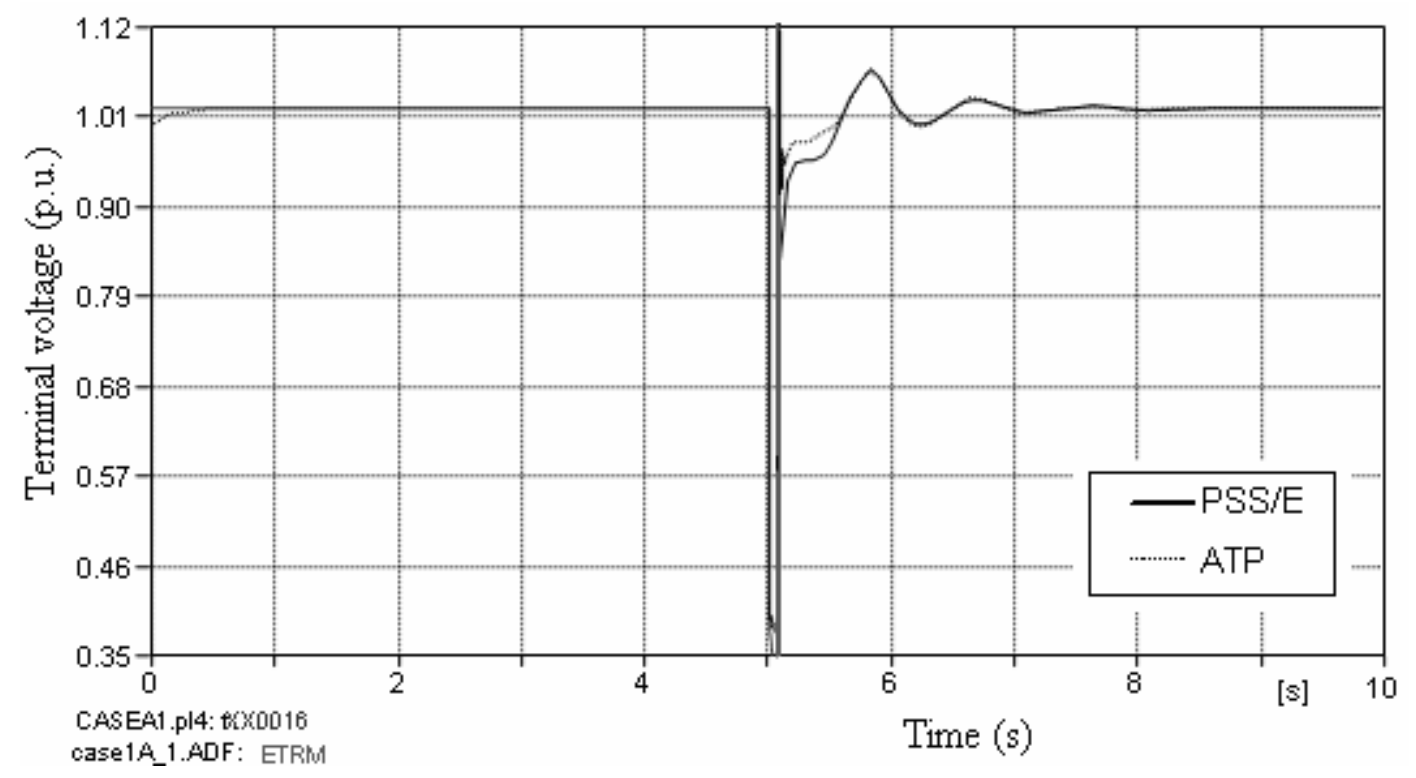

Figure 6.10: Terminal voltages of ATP and PSS/E (Case 1a)

\subsection{POWER SYSTEM UNBALANCE}

In Section 6.1, power system stability during balanced three-phase line and bus faults was discussed. It is also important to look at generator dynamics and stability during unbalanced faults. Previous simulations used just positive sequence data. For unbalanced fault studies, zero sequence and negative sequence data are taken into account. System behavior during line-ground (LG), line-line (LL) and line-line-ground (LLG) fault conditions are compared with each other and with three-phase balanced faults. As PSS/E requires modeling of line charging capacitors for unbalanced fault studies, line charging capacitors are included in three-phase lumped pi-equivalent transmission line models in ATP. One of the advanced power system protection strategies, single pole tripping and reclosing, is employed for protection against LG faults and compared with traditional three-pole tripping and reclosing methods. Power flows, rotor angle, and generator terminal voltages are observed and benchmarked for different 
power system unbalance. All the cases are benchmarked against PSS/E and results are presented in Section 6.2.3. Table 6-2 summarizes the different cases of faults studied in the 1000-MVA system (discussed in Section 4.2).

Table 6-2: Fault in one of the transmission line at generator end (with AVR and PSS)

\begin{tabular}{|l|l|}
\hline CASES & Description \\
\hline Case 2a & Three-phase line fault \\
\hline Case 2b & LG fault, 3-pole tripping \\
\hline Case 2c & LLG fault \\
\hline Case 2d & LL fault \\
\hline Case 2e & LG fault, 1-pole tripping \\
\hline
\end{tabular}

\subsubsection{Generator Stability during Different Unbalance Conditions}

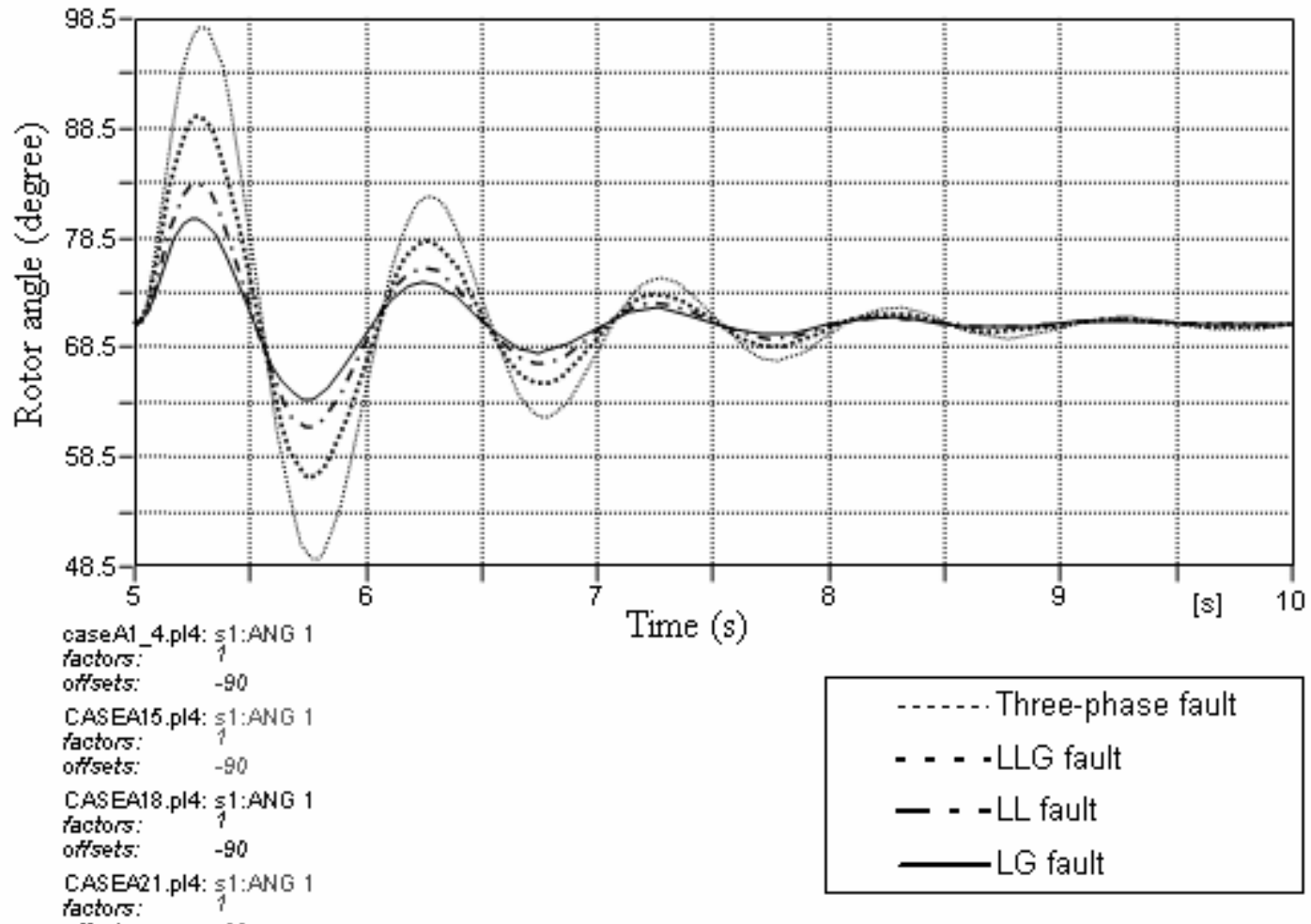

Figure 6.11: Rotor angles for different faults (Cases 2a, 2b, 2c and 3d)

Single-machine infinite bus system (Cases 2a through 2e) is subjected to different types of power system faults. For all simulations the fault is applied at $5.0 \mathrm{~s}$ and cleared after $0.07 \mathrm{~s}$. Reclosing is carried out $0.03 \mathrm{~s}$ after the fault is cleared. Line-charging capacitors are included in the system and so there is an increase in the steady-state rotor 
angle of the machine. Figure 6.11 shows the rotor angles for all different types of power system faults. The three-phase fault is the most severe power system fault and has the highest peak in both rotor angle and voltage oscillation. The line-ground fault has the lowest peak oscillations followed by LL and LLG faults. It is clear from these observations that the peak values of the oscillations depend on the reduction in power transfer. Frequency of the oscillations is the same for all types of faults. Settling time increases with increase in the peak values and hence LG faults have the fastest settling time. Simulation results comparing terminal voltages are shown in Figure B.8.

\subsubsection{Three-pole Vs. Single-pole Tripping and Reclosing}

For single-pole tripping and reclosing, the LG fault occurs at $5.0 \mathrm{~s}$, is cleared at $5.07 \mathrm{~s}$ and reclosed at $\mathrm{t}=5.1 \mathrm{~s}$. The anticipated benefit is from $\mathrm{t}=5.07 \mathrm{~s}$ to $5.1 \mathrm{~s}$ due to the presence of unfaulted phases in service.

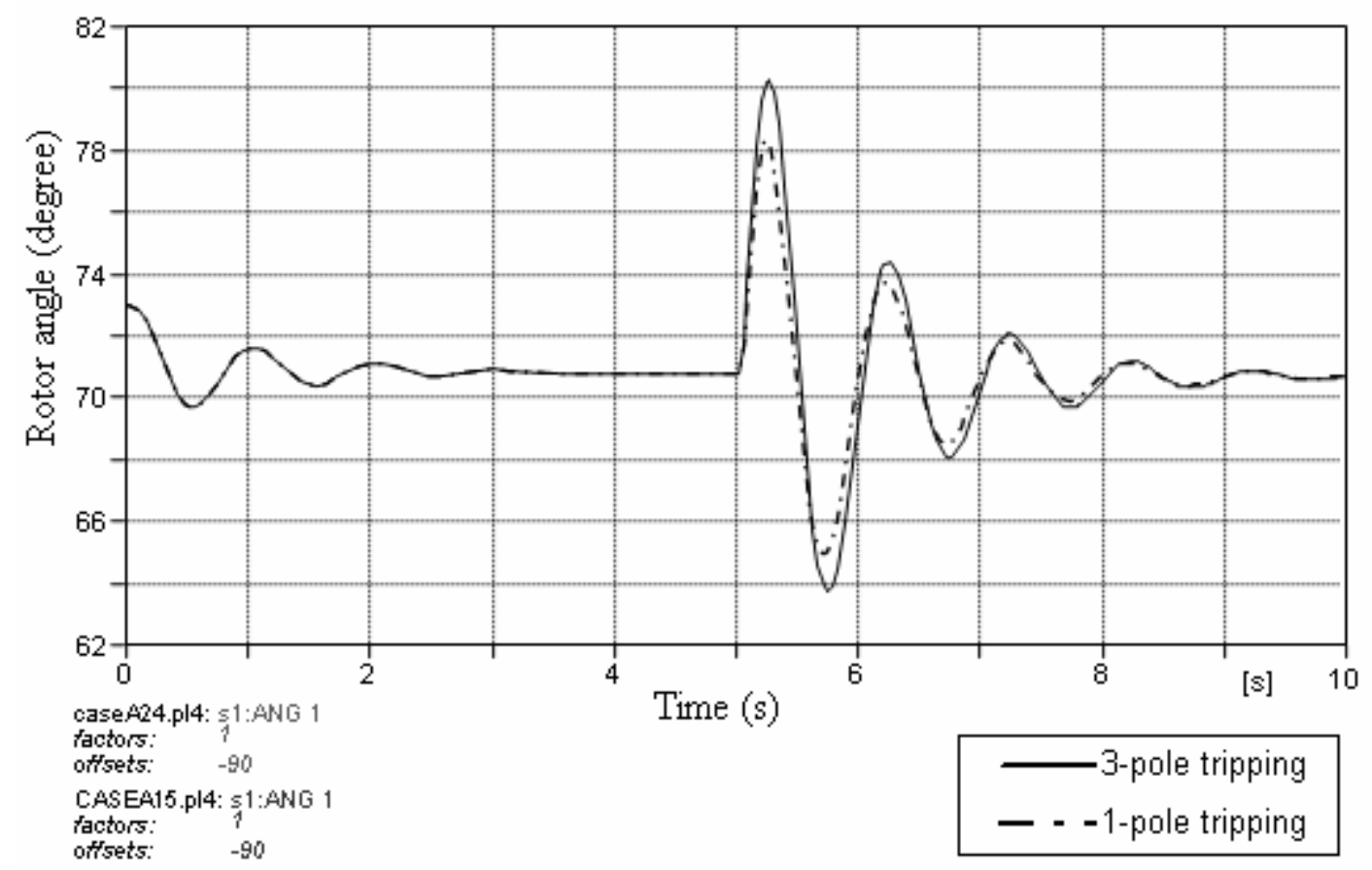

Figure 6.12: Single- and three-pole tripping and reclosing (Cases 2b \& 2e) 


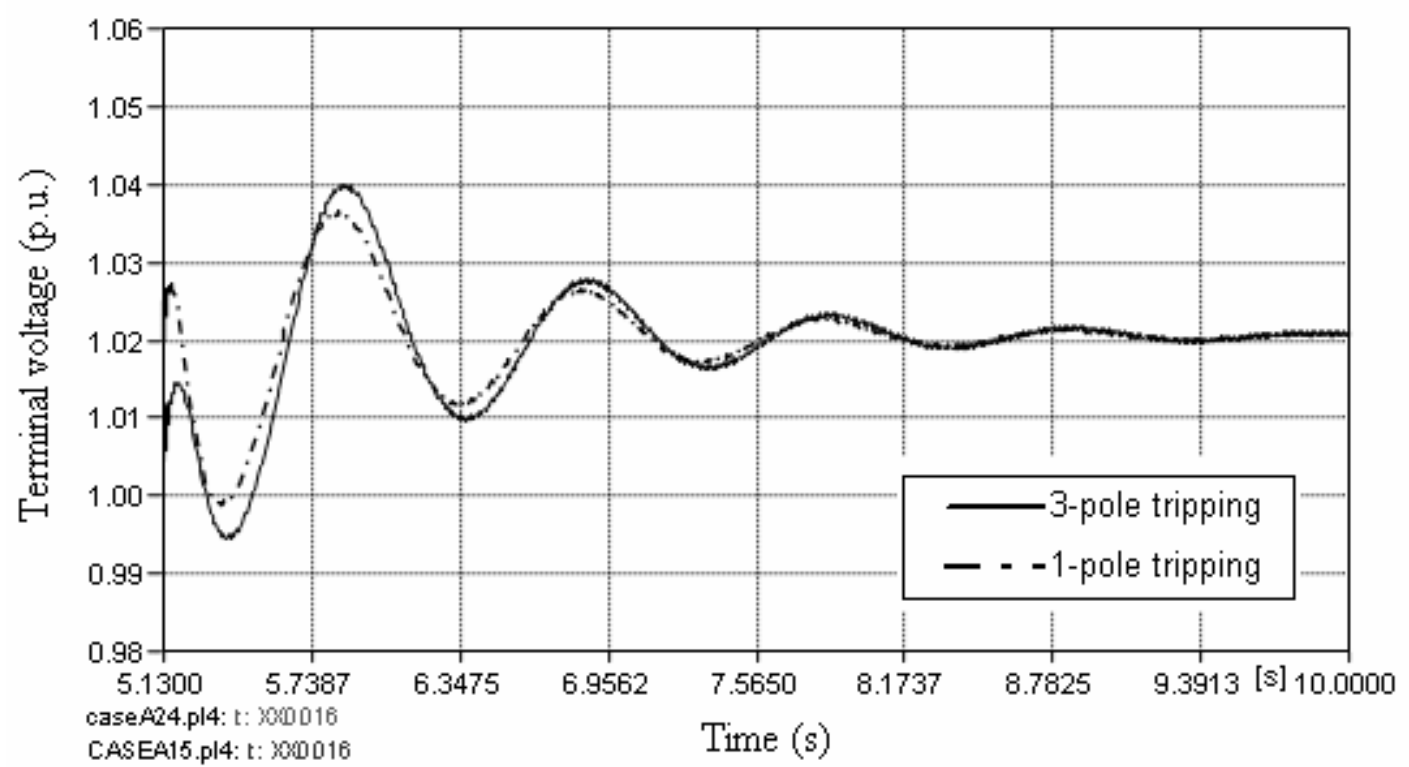

Figure 6.13: Single and three-pole tripping and reclosing (Cases $2 b$ \& 2e)

Switches in unfaulted phases are kept closed throughout the simulation. Rotor angle and terminal voltages are observed for single-pole tripping and reclosing strategy. As clearly seen from Figures 6.12 and 6.13, rotor angle and voltage stability can be improved by single-pole tripping strategies. The peak of first swing decreases by $2.4 \%$ for single-pole tripping and the frequency of oscillation increases by $0.28 \%$. Settling time of rotor angle for three-pole tripping is $3.8009 \mathrm{~s}$ while that for single-pole tripping is $2.9112 \mathrm{~s}$. Thus for the case discussed here, power system returns to steady-state $0.89 \mathrm{~s}$ faster if the system is protected from LG faults by single-pole tripping and reclosing. Waiting a longer time before reclosing will further improve performance. Figure B.9 shows the rotor angles for single-pole and three-pole tripping (Cases $2 \mathrm{~b}$ and $2 \mathrm{e}$ ).

\subsubsection{Benchmarking Against PSS/E}

All four different fault types are benchmarked against PSS/E. Due to the addition of line charging capacitors the steady state rotor angle increases from $64.48^{\circ}$ to $70.78^{\circ}$. Figure 6.14 shows the rotor angles for a three-phase fault and LLG fault. For the threephase fault the difference in peaks for ATP and PSS/E is $2 \%$ and for LLG fault, the difference is 7\%. Benchmarked results for LG fault case is given in Appendix B (Figure B.10). 


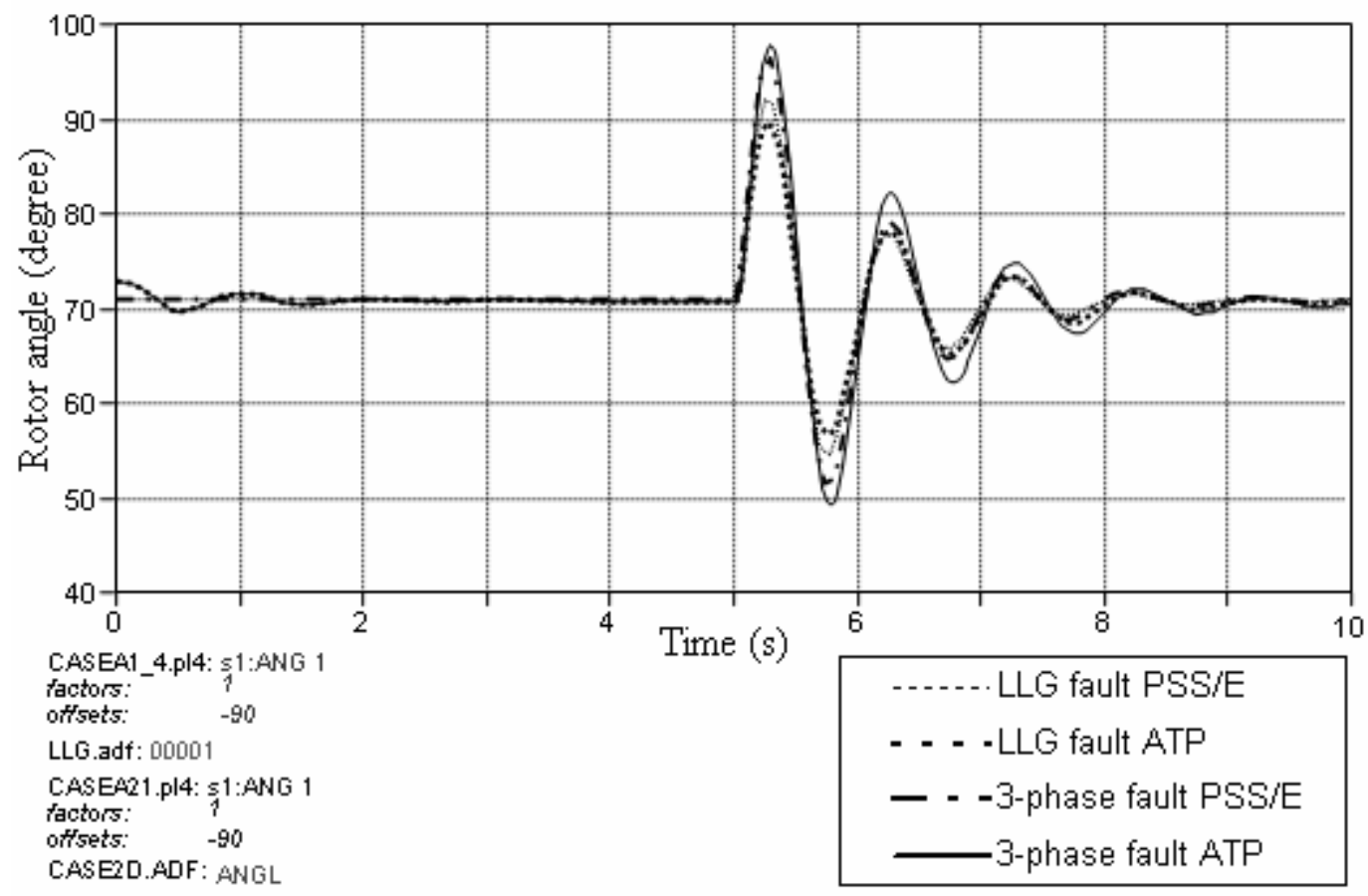

Figure 6.14: Unbalance faults, benchmarking against PSS/E (Cases 2a \& 2c)

Initial steady state values, settling time, peak of first swing and frequency of oscillations for different cases in ATP and PSS/E are compared. Settling time of rotor angle and peak of first swing of terminal voltages are tabulated in Tables 6-3 and 6-4 respectively. Difference in the values are calculated with respect to PSS/E and included in the tables. All the other tables comparing PSS/E and ATP are included in Appendix B (Tables B-1 through B-6).

Table 6-3: $2 \%$ settling time of rotor angle $\left(t_{0.02}\right)$

\begin{tabular}{|r|l|r|r|r|}
\hline \multicolumn{1}{|c|}{ Case no. } & CASES & ATP (s) & PSS/E (s) & \% Difference \\
\hline 1b & WITH CONSTANT EFD & N/A & N/A & N/A \\
\hline 1c & WITH AVR & N/A & N/A & N/A \\
\hline 1a & WITH AVR AND PSS & 3.843 & 3.840 & $0.09 \%$ \\
\hline 1d & WITH AVR, PSS \& GOV & 3.715 & 3.709 & $0.16 \%$ \\
\hline $1 \mathrm{e}$ & WITH SATURATION & 3.843 & 3.843 & $0.01 \%$ \\
\hline $1 \mathrm{f}$ & WITH RA & 3.800 & $\mathrm{~N} / \mathrm{A}$ & $\mathrm{N} / \mathrm{A}$ \\
\hline $2 \mathrm{a}$ & 3-PHASE FAULT & 3.800 & 3.800 & $0.02 \%$ \\
\hline 2b & LG FAULT & 2.911 & 2.890 & $0.73 \%$ \\
\hline 2d & LL FAULT & 2.965 & $\mathrm{~N} / \mathrm{A}$ & $\mathrm{N} / \mathrm{A}$ \\
\hline 2c & LLG FAULT & 3.843 & 3.843 & $0.01 \%$ \\
\hline
\end{tabular}


Table 6-4: Peak of first swing - rotor angle

\begin{tabular}{|r|l|r|r|r|}
\hline Case No. & CASES & ATP $\left(^{\circ}\right)$ & PSS/E $\left(^{\circ}\right)$ & \% Difference \\
\hline 1b & WITH CONSTANT EFD & 24.227 & 31.996 & $24.28 \%$ \\
\hline 1c & WITH AVR & 19.603 & 25.200 & $22.21 \%$ \\
\hline 1a & WITH AVR AND PSS & 21.801 & 25.166 & $13.37 \%$ \\
\hline 1d & WITH AVR, PSS \& GOV & 21.088 & 23.775 & $11.30 \%$ \\
\hline 1e & WITH SATURATION & 24.547 & 24.998 & $1.80 \%$ \\
\hline 1f & WITH RA & 20.614 & $\mathrm{~N} / \mathrm{A}$ & $\mathrm{N} / \mathrm{A}$ \\
\hline 2a & 3-PHASE FAULT & 26.716 & 26.960 & $0.90 \%$ \\
\hline 2b & LG FAULT & 9.716 & 10.500 & $7.46 \%$ \\
\hline 2d & LL FAULT & 11.716 & $\mathrm{~N} / \mathrm{A}$ & $\mathrm{N} / \mathrm{A}$ \\
\hline 2c & LLG FAULT & 18.716 & 21.700 & $13.75 \%$ \\
\hline
\end{tabular}

\subsection{DYNAMIC EQUIVALENCING}

Two-area system discussed in Section 5.1 (Cases 3a through 3h) is modeled with ATP and benchmarked against PSS/E. Different power system disturbances are applied in both areas to identify coherent generators. Coherent generators are aggregated using the method discussed in Section 5.3. Network of the original two-area system is reduced and represented in the reduced system. Power system disturbances applied to the original system are applied to the reduced system and the reduced system is benchmarked against the original system. Then the dynamically reduced system as implemented in ATP is benchmarked against PSS/E. Different cases of the original and reduced systems are summarized in Table 6-5.

Table 6-5: Different cases of the two-area system

\begin{tabular}{|l|l|l|}
\hline Original system & Reduced system & Description \\
\hline Case 3a & Case 4a & 3-phase fault in line 6-7, bus 6 end \\
\hline Case 3b & Case 4b & 3-phase fault in line 10-9, bus 9 end \\
\hline Case 3c & Case 4c & LG fault in line 6-7, bus 6 end \\
\hline Case 3d & Case 4d & LLG fault in line 6-7, bus 6 end \\
\hline Case 3e & Case 4e & LL fault in line 6-7, bus 6 end \\
\hline Case 3f & Case 4f & LG fault in line 10-9, bus 9 end \\
\hline Case 3g & Case 4g & LLG fault in line 10-9, bus 9 end \\
\hline Case 3h & Case 4h & LL fault in line 10-9, bus 9 end \\
\hline
\end{tabular}




\subsubsection{Power Flows in Two-area System}

Area 1 supplies $400 \mathrm{MW}$ of real power to Area 2. A three-phase line fault is applied to the line 6-7 at bus 6 end (Case 3a). This severe fault in Area 1 causes a power swing in the two-area system. Transmission lines 6-7, 7-8, 8-9, and 11-9 are retained while dynamic reduction and hence power flow between Area 1 and Area 2 is observed between buses 7 and 9 and used for benchmarking. The instantaneous power flow waveforms are saved as a MATLAB file and imported to MATLAB. Average power flow is calculated by writing a simple averaging program. While averaging, the calculations used all 200,001 points provided by the ATP simulations, but only 995 were plotted. The program is included in Appendix C.1. Figure 6.15 shows the comparison of average power and instantaneous power flow and the power swing during the three-phase fault. The black area represents the over-plotted instantaneous powers of all three phases. The fault is applied at $5.0 \mathrm{~s}$ and cleared after $0.07 \mathrm{~s}$. Frequency of the power swing is $0.56 \mathrm{~Hz}$ and this is the inter-area oscillation of the two-area system connected by the weak tie lines. A more detailed plot of average power for $4.9 \mathrm{~s}$ to $10 \mathrm{~s}$ is given in Figure 6.16.

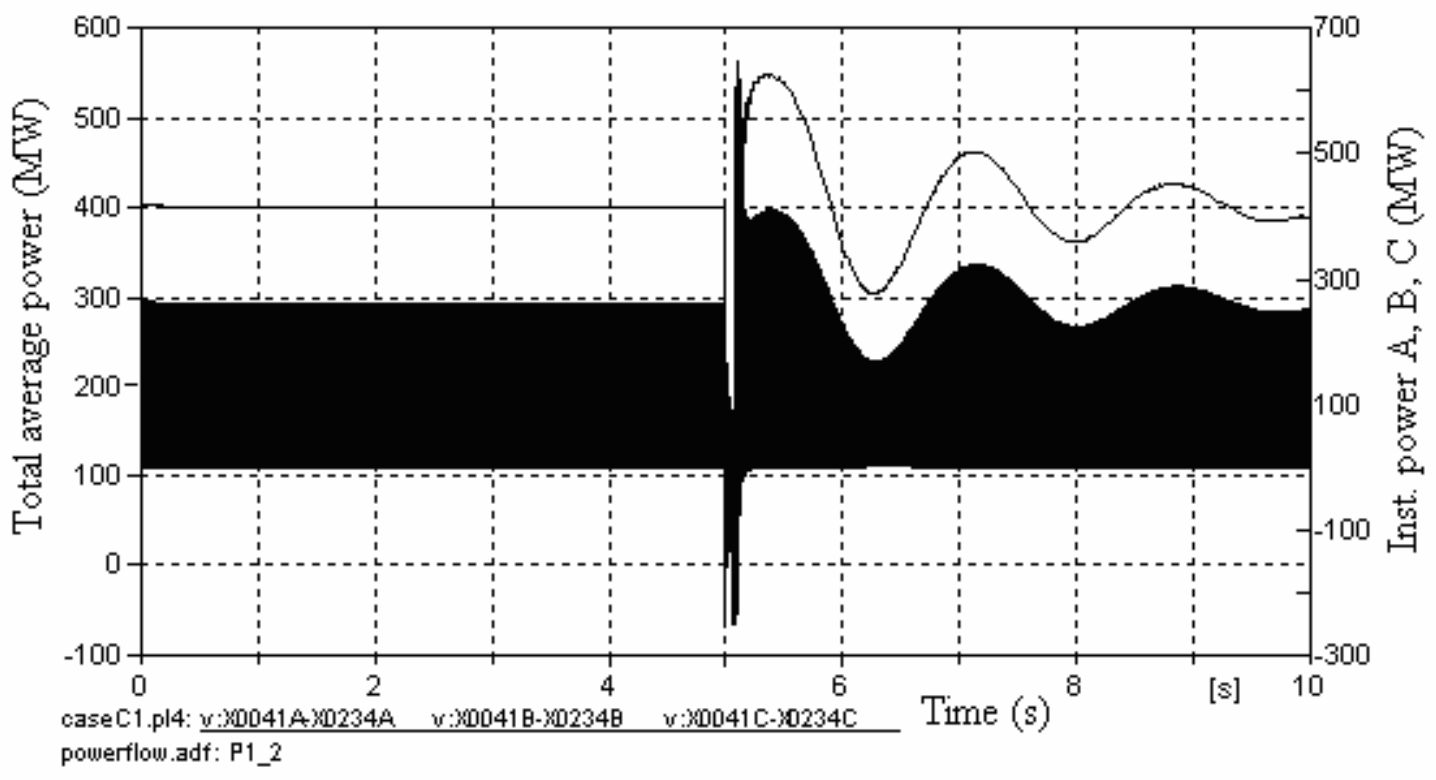

Figure 6.15: Power flow Area 1 to Area 2 (Case 3a) 


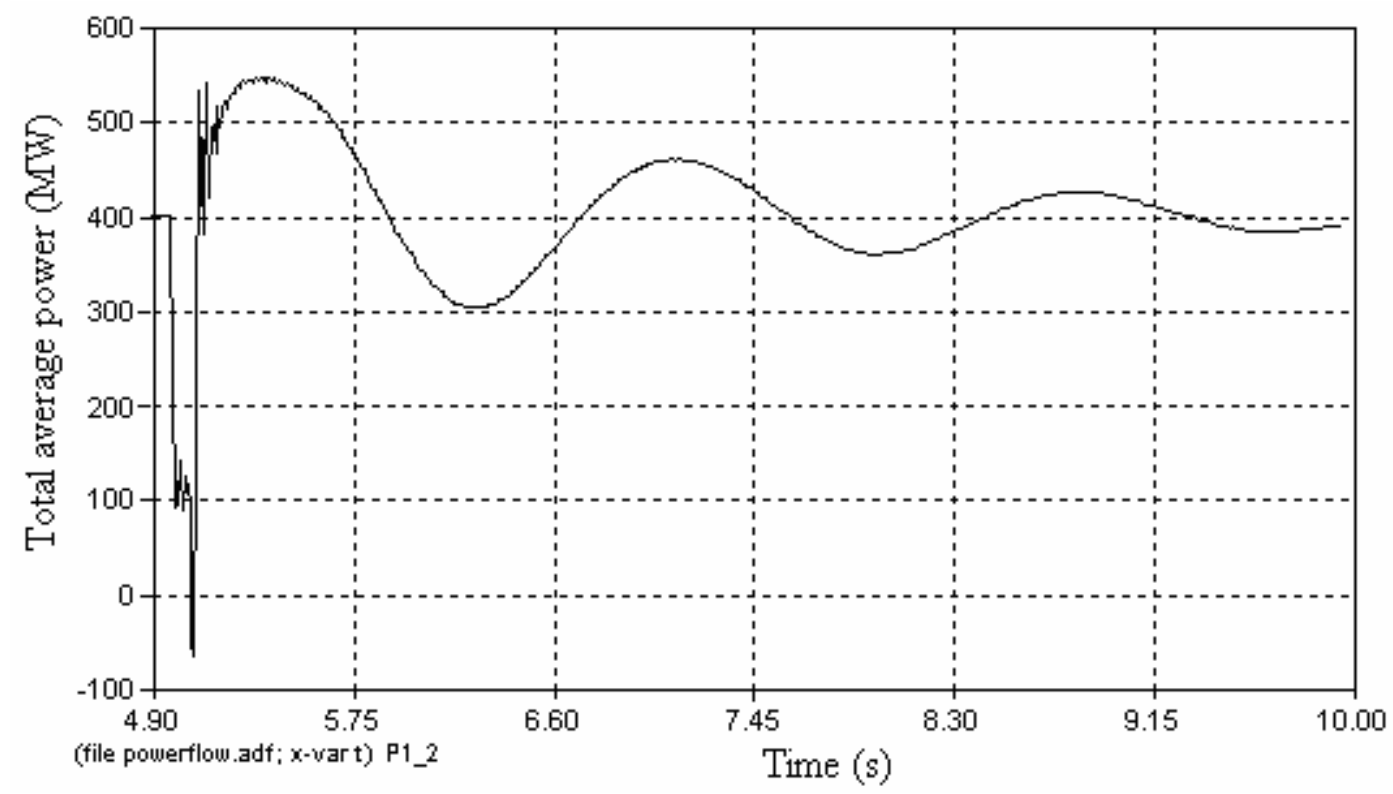

Figure 6.16: Average power flow between areas 1 and 2 after disturbance (Case 3a)

\subsubsection{Stability Studies in Two-area System}

Different faults are applied in both areas of the system and inter- and intra-area oscillations are observed. The network parameters and transformers in the two areas are symmetrical and hence it is easy to observe coherency. Rotor angle of the synchronous machine model is used as the key to identify the coherency.

For the three-phase line fault applied to line 6-7 at bus 6 end (Case 3a), rotor angles of all the machines are observed (shown in Figure 6.17). A similar three-phase line fault is applied in line 10-9 at bus 9 end (Case $3 b$ ) and the rotor angles are plotted (shown in Figure 6.18). The rotor angles are increasing because of the absence of frequency controllers. They attain steady-state after the power system disturbance as the system is stable. In an actual system, frequency controllers are present and there will not be any increasing rotor angle characteristic. It is evident from the plots that machines G1 and G2 in area 1 are coherent. The intra-area oscillation between generators G1 and G2 is very minimal and hence negligible. This is because G1 and G2 are similar generator models with a very short $(25 \mathrm{~km})$ transmission line between them. Similarly G3 and G4 are coherent in area 2. Intra-area oscillation in Area 2 is also minimal and negligible as G3 and G4 are similar generator models with a short transmission line between them. Frequency of the oscillations is high for the generators in the area with fault. As seen 
from Figure 6.17, frequency of rotor angles of G1 and G2 is more than that of G3 and G4. Figure 6.18 shows rotor angles for fault in area 2 and it is clear that frequency of rotor angles of G3 and G4 is high. Several faults are applied in both areas to confirm the coherency of generators G1 and G2 and generators G3 and G4. Simulation results for the four different power system faults are given in Appendix B (Figures B.11 through B.14).

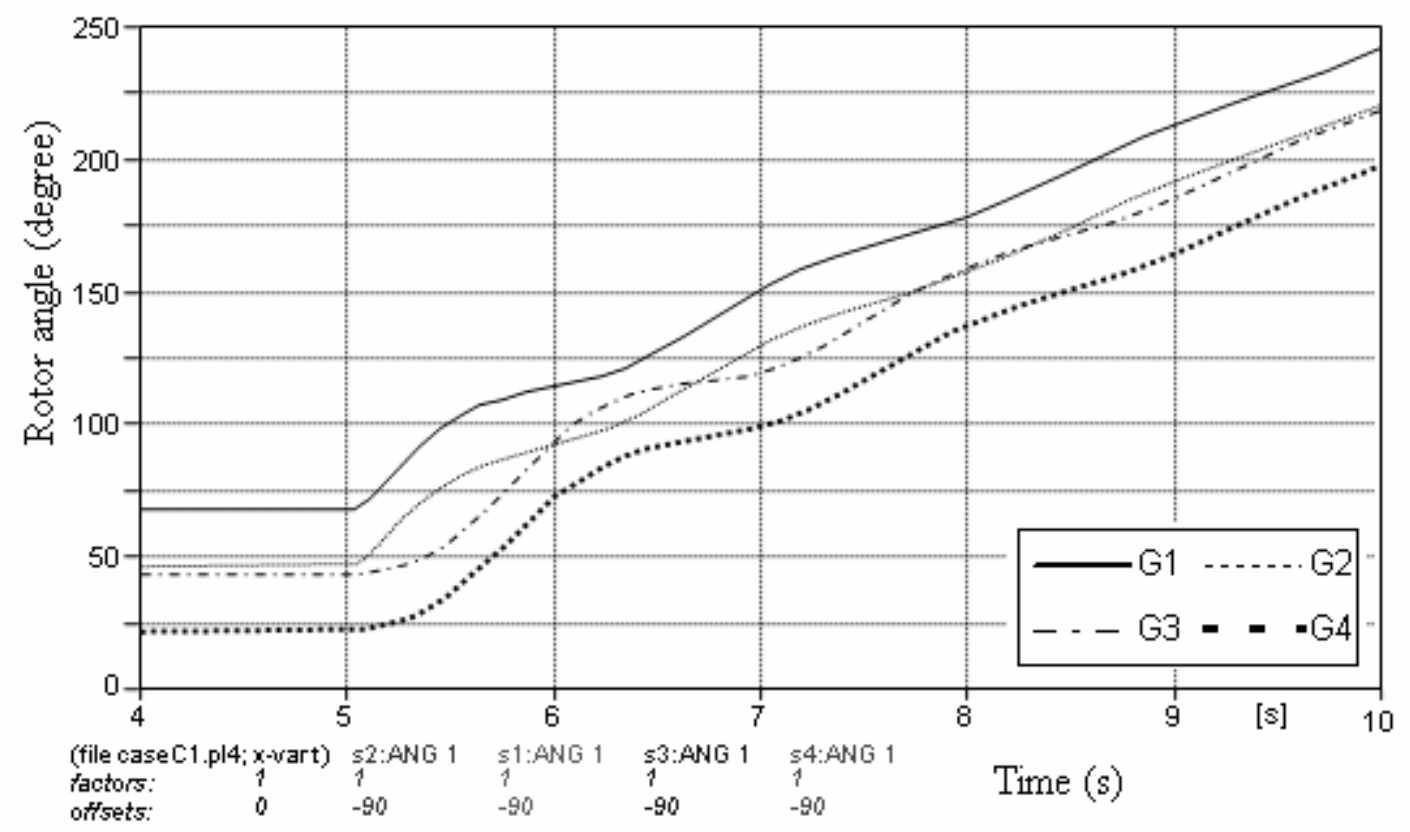

Figure 6.17: Rotor angles for a three-phase line fault in line 6-7 (Case 3a)

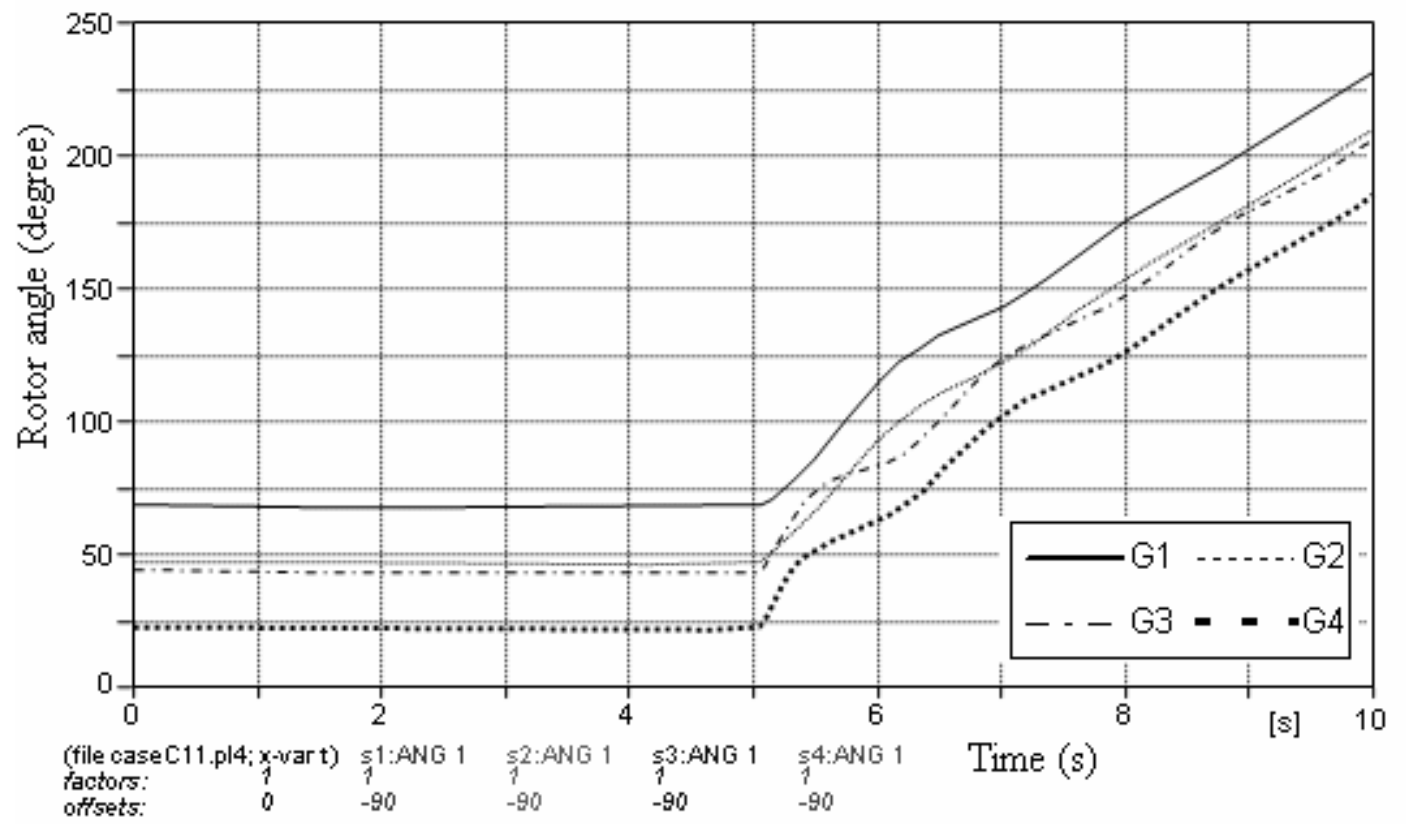

Figure 6.18: Rotor angles for a three-phase line fault in line 11-9 (Case 3b) 


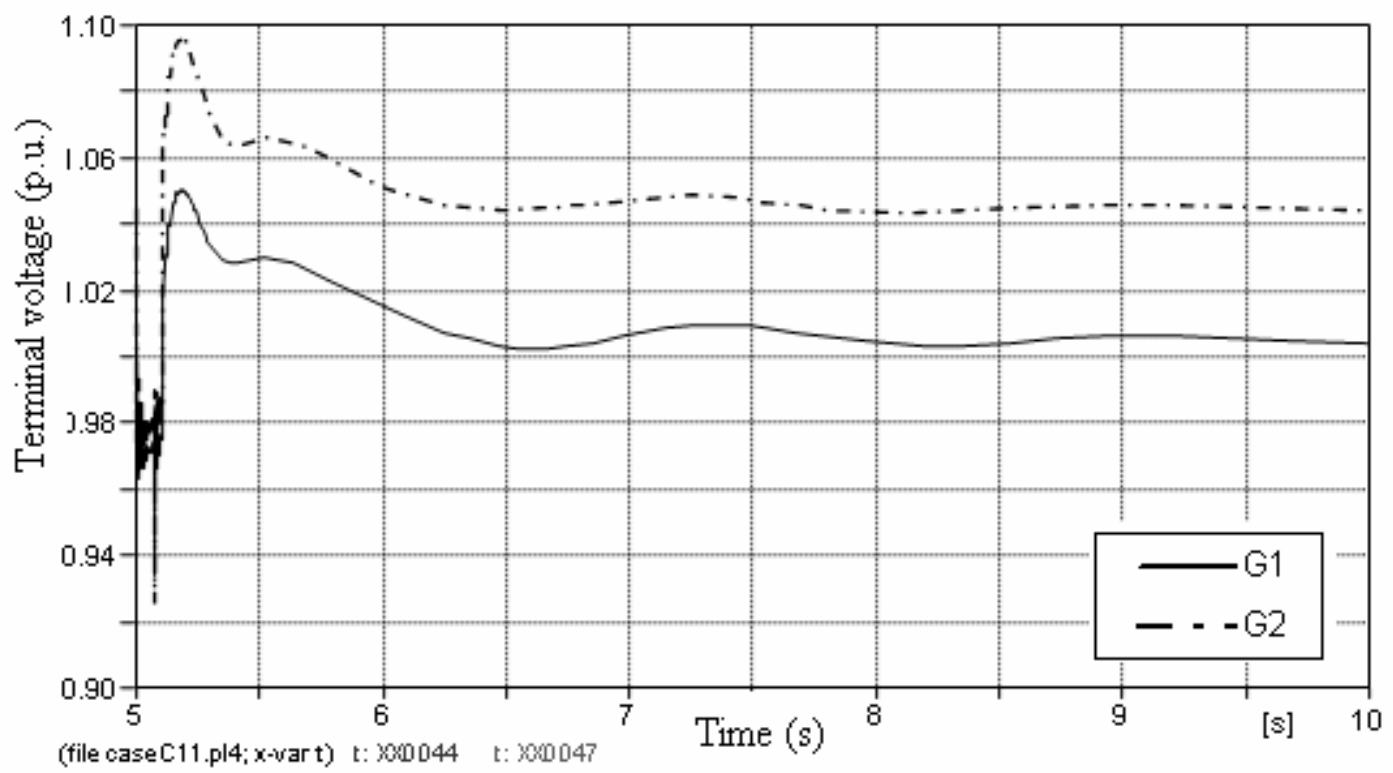

Figure 6.19: Terminal voltages of G1 and G2 for a fault in Area 2 (Case 3b)

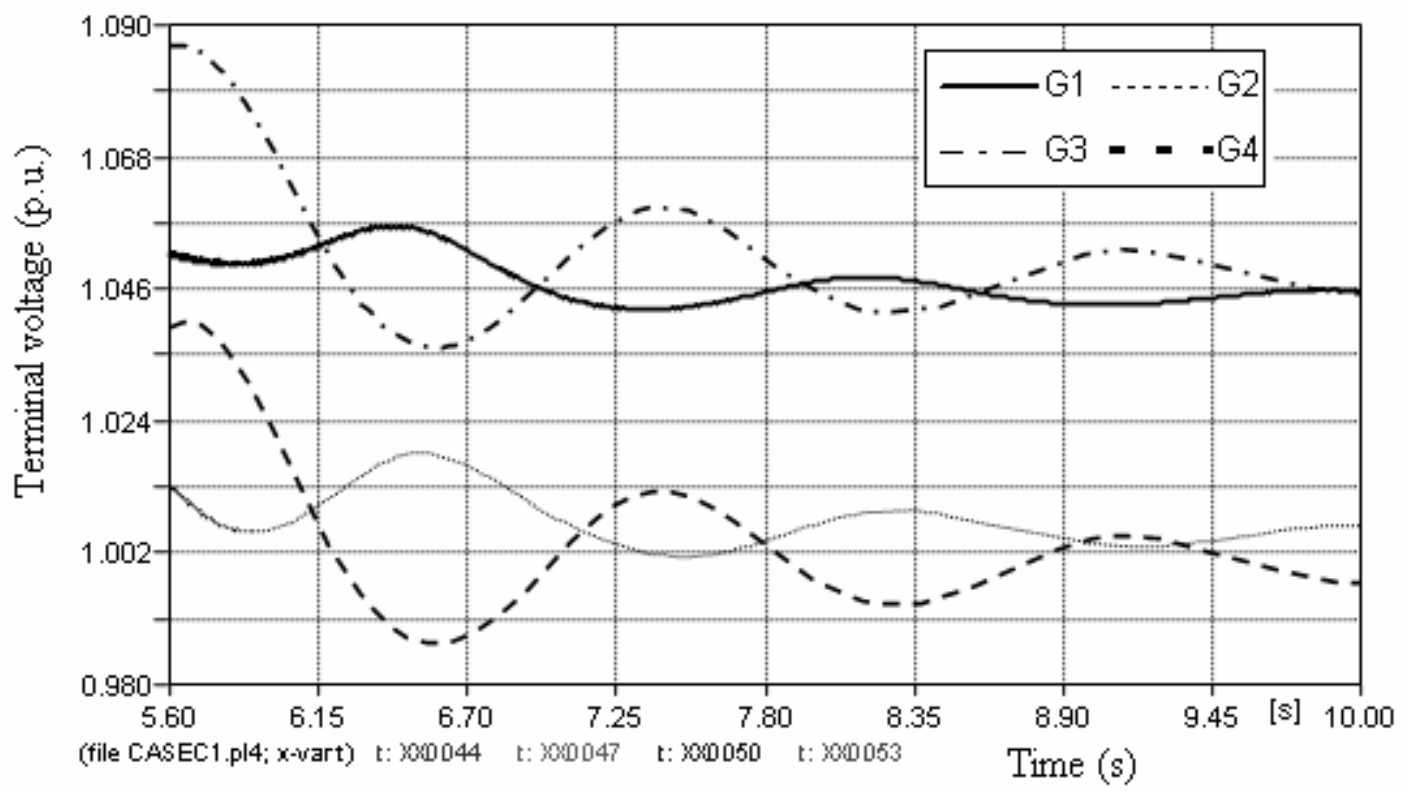

Figure 6.20: Terminal voltages for a fault in Area 1 (Case 3a)

Another important result in observing inter- and intra-area oscillation is regarding the peak of the oscillations. Peak of the first swing is more for the generators operating in the area where the fault is applied. Figures 6.19 and 6.20 show the swing in terminal voltages of the machines in one area when the fault is in the other area. Terminal voltages for three-pole and single-pole tripping are shown in Figure B.15. Also rotor angles of the 
machines in Area 1 and Area 2 are compared for different disturbances in Appendix B (Figures B.16 through B.18)

\subsubsection{Benchmarking of Two-area System}

For all different faults investigated, the waveforms are the main bases of comparison for benchmarking ATP against PSS/E. Figures 6.21 and 6.22 show the rotor angles of machines in area 1 and area 2 respectively.

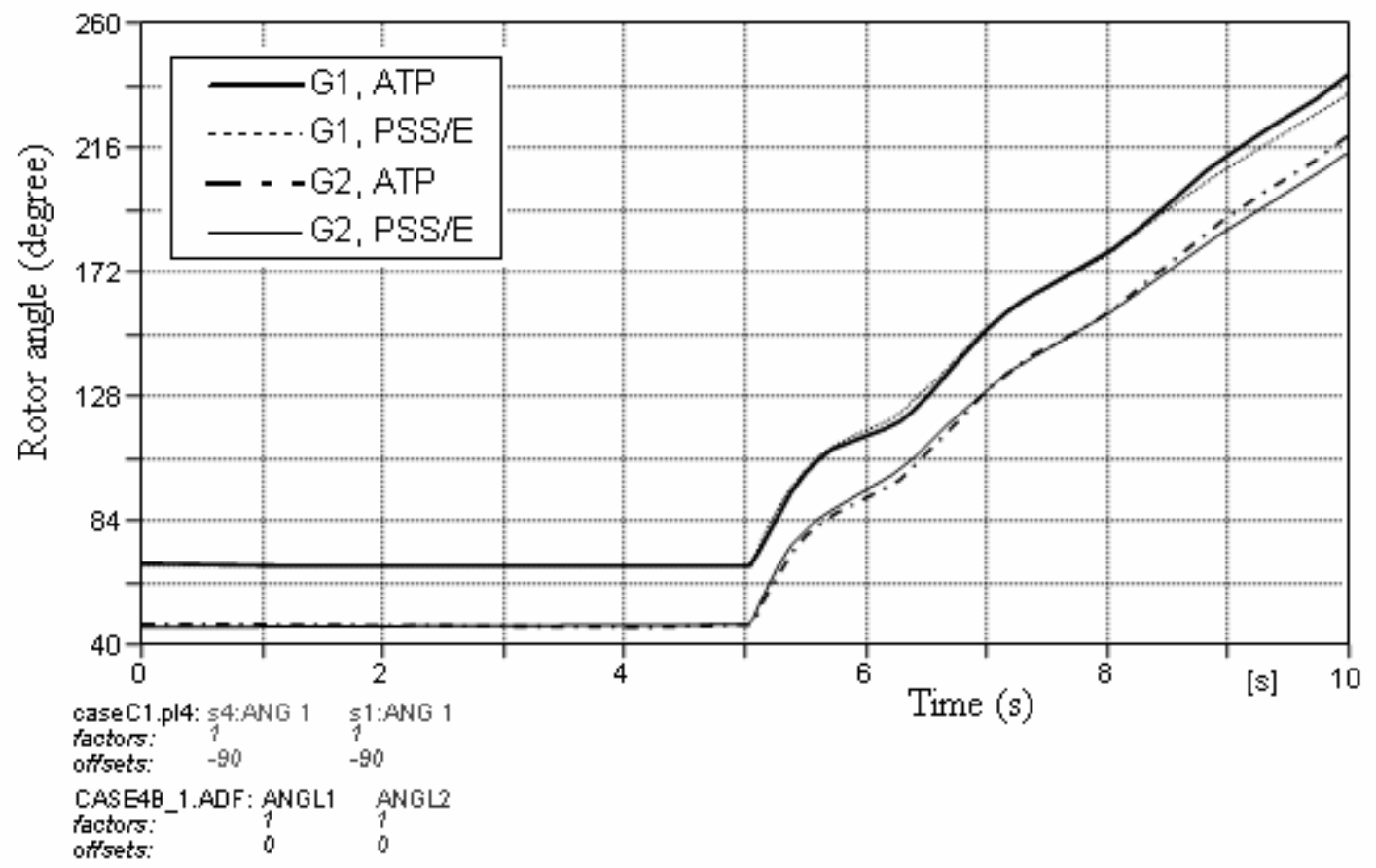

Figure 6.21: Rotor angles of machines in Area 1 (Case 3a)

Benchmarked results for a three-phase fault in transmission line 6-7 (Case 3a) are shown in this section. As discussed in Section 6.1.5 and Section 6.2.3, there are a few small differences between results from ATP and PSS/E. The peak of first swing in ATP is less and damping of subsequent peaks is less. The difference in settling time of rotor angle, field voltage, and terminal voltage between ATP and PSS/E is less than $0.2 \%$ and hence the difference in the damping is negligibly small. The difference in peak of first swing for rotor angles between ATP and PSS/E is 2-6\% for single-machine system. For the two-area system, the difference in peak of first swing is less than $1 \%$. This difference might be significant in the case of a marginally stable system. Frequency of oscillations during power system disturbances in ATP match exactly with PSS/E. There is a small 
difference between ATP and PSS/E in the settling time and this is seen as diverging curves (Figures 6.21 and 6.22) due to the absence of frequency controller. Having actual power system data might help in building more accurate models and the difference in peak of first swing might be reduced.

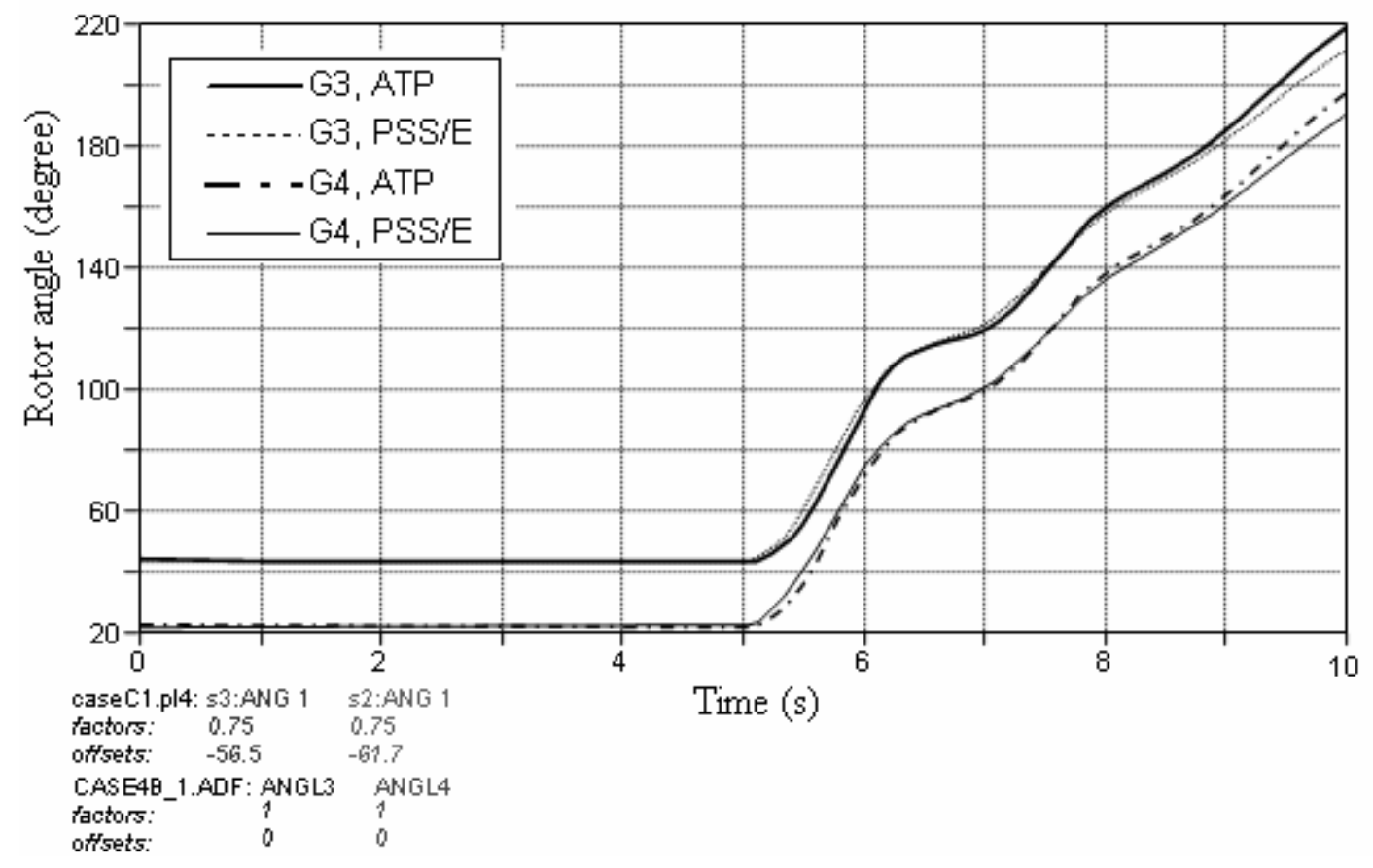

Figure 6.22: Rotor angles of machines in Area 2 (Case 3a)

Area 1 and Area 2 are connected by parallel tie lines and power flow is measured in the individual lines. PSS/E can measure power flow only in individual transmission lines so total power flow between the two areas cannot be directly measured. Figures 6.23 and 6.24 show the power flows in line 7-8 circuit 1 (in Area 1) and in line 8-9 circuit 1 (in Area 2) respectively.

The difference in peak of the first swing and damping is seen in both the power flows; $200 \mathrm{MW}$ of real power flows in circuit 1 of line 7-8 and $196 \mathrm{MW}$ of real power flows in circuit 2 of line 8-9 during the steady state. A loss of $4 \mathrm{MW}$ occurs in the transmission line link. As power is flowing from area 1 to area 2, for a fault in area 1, an accelerating swing is seen as shown in Figures 6.23 and 6.24. For a fault in area 2, a decelerating swing is seen in the power flow. Power flows during different power system 
disturbances including faults in Area 2 are shown in Appendix B. In all cases, the power flows are benchmarked against PSS/E

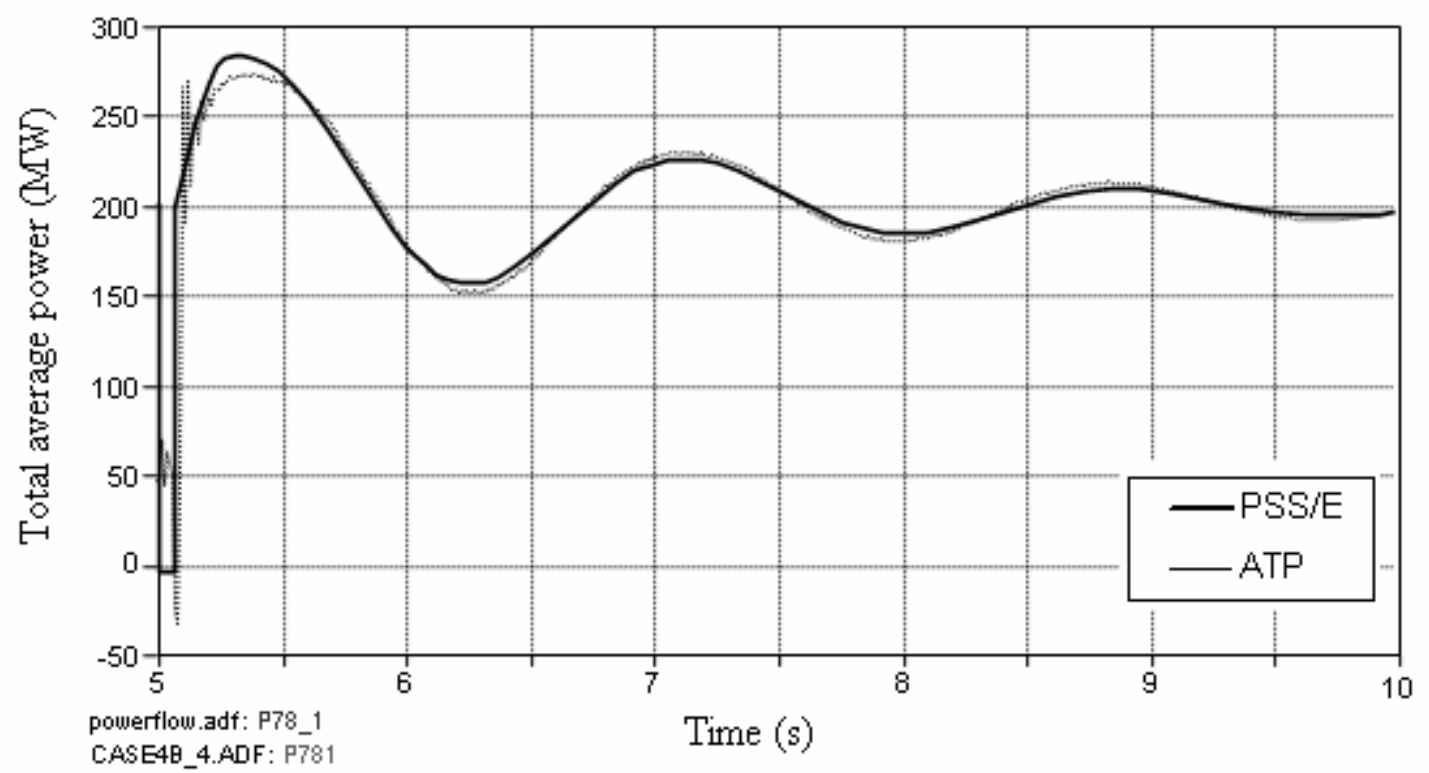

Figure 6.23: Power flow in line 7-8 (Case 3a)

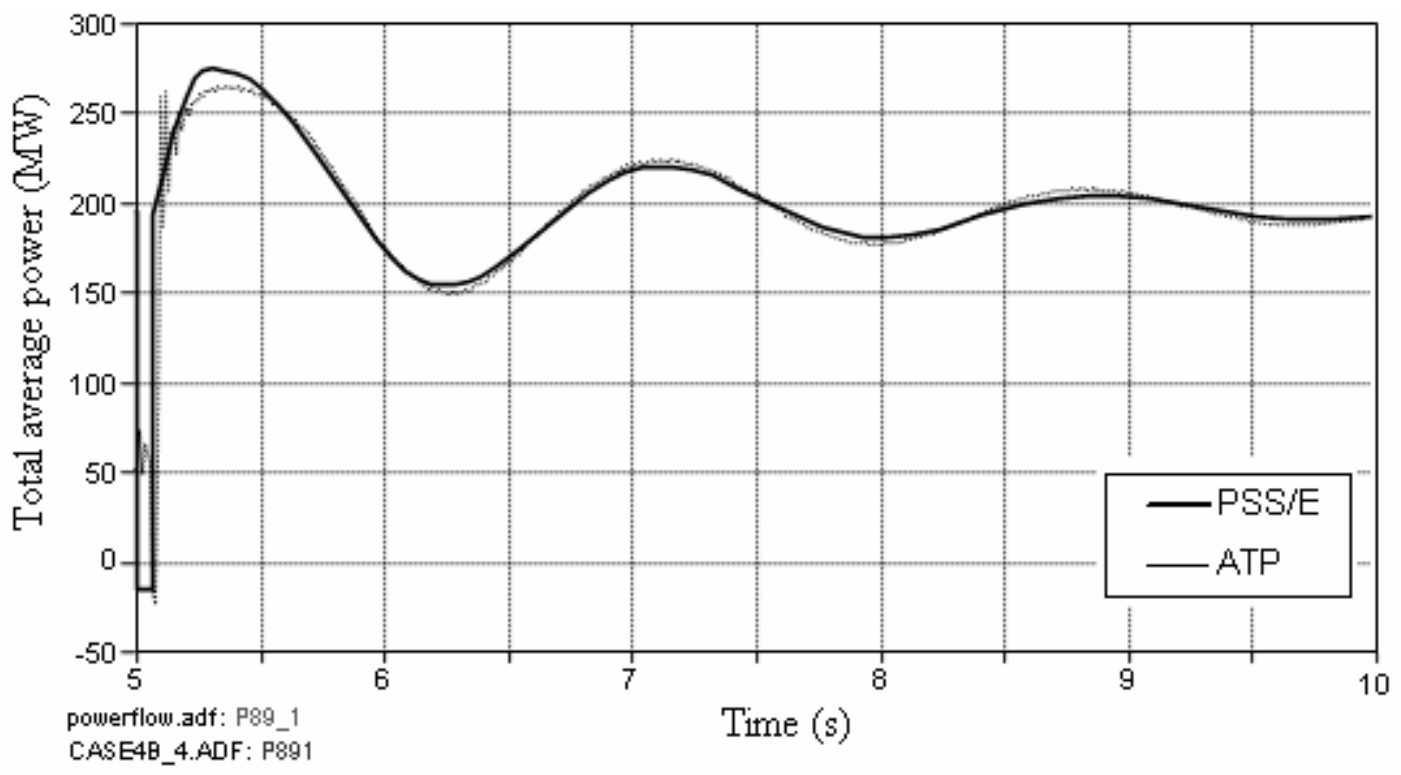

Figure 6.24: Power flow in line 8-9 (Case 3a)

\subsubsection{Power flows in Dynamically Reduced System}

The two-area system with four machines is reduced to a two-machine system by reducing the system dynamically, as addressed in Chapter 5. G1 and G2 in Area 1 are 
represented by generator G12 and G3 and G4 in Area 2 are represented by generator G34. Different power system disturbances (Cases $4 \mathrm{a}$ through $4 \mathrm{~h}$ ) are applied in the reduced system and power flow between Area 1 and Area 2 is observed.

The power flow from Area 1 to Area 2 increased to $406 \mathrm{MW}$ from $400 \mathrm{MW}$. This difference in the power flow is due to the differences in the network parameters. A threephase line fault is applied to line 6-7 at bus 6 end (Case 4a) and power flow between Area 1 and Area 2 is observed. Figure 6.25 shows the power swings during the disturbance in Area 1.

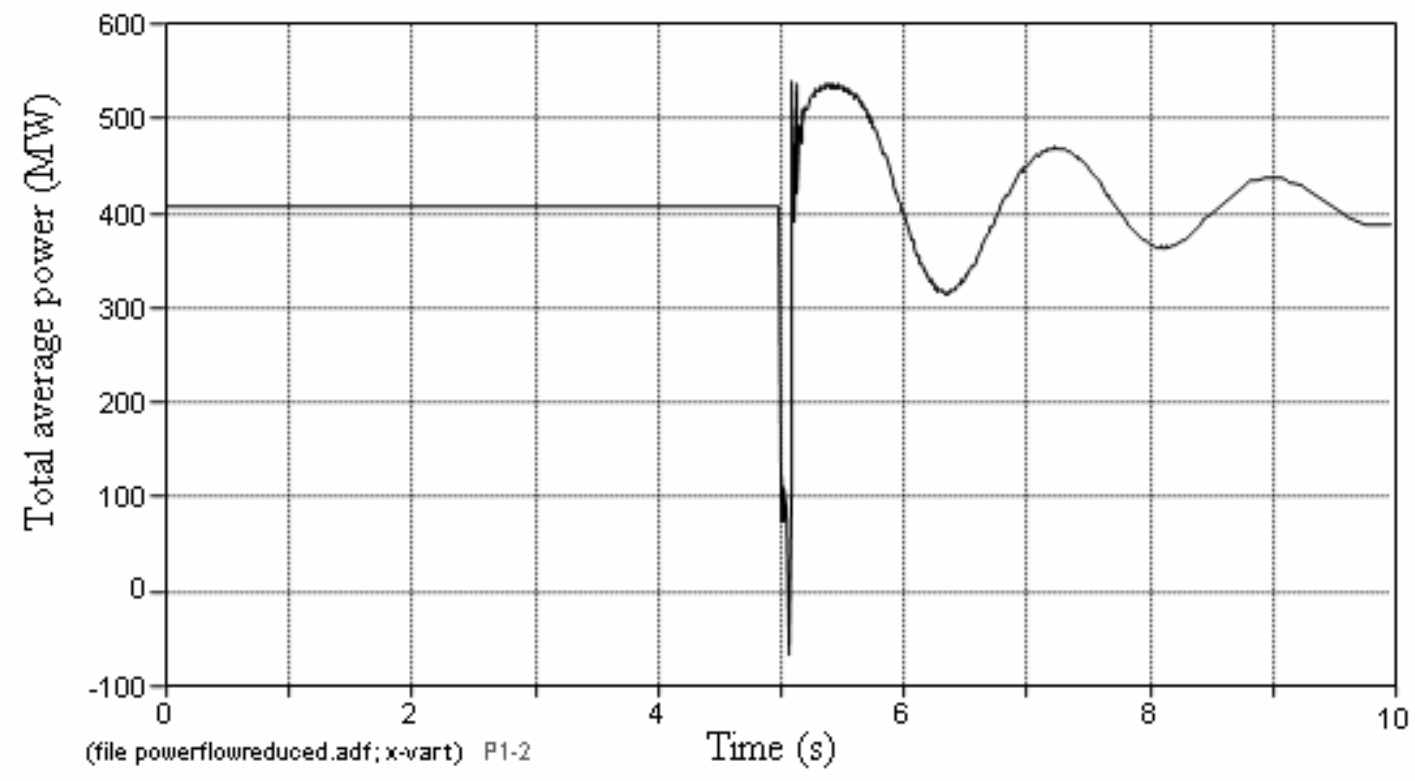

Figure 6.25: Power flow into Area 2 for disturbance in Area 1 (Case 4a)

A three-phase line fault is applied to line 10-9 at bus 9 end (Case $4 \mathrm{~b}$ ) at time $\mathrm{t}=5.0 \mathrm{~s}$ and cleared after $0.07 \mathrm{~s}$. The switches are closed $0.03 \mathrm{~s}$ after the fault is cleared. Figure 6.26 shows the power swing during this disturbance in Area 2. When a fault is in the area (Case 4a)with excess generation (or donor), power flowing out of the area initially increases and when a fault is in the area (Case 4b) with less generation (or acceptor), power received by that area initially decreases. Peak of first swing and settling time of the oscillations depend on the severity of the fault. Simulation results for the remaining power system disturbances for these cases are included in Appendix B. 


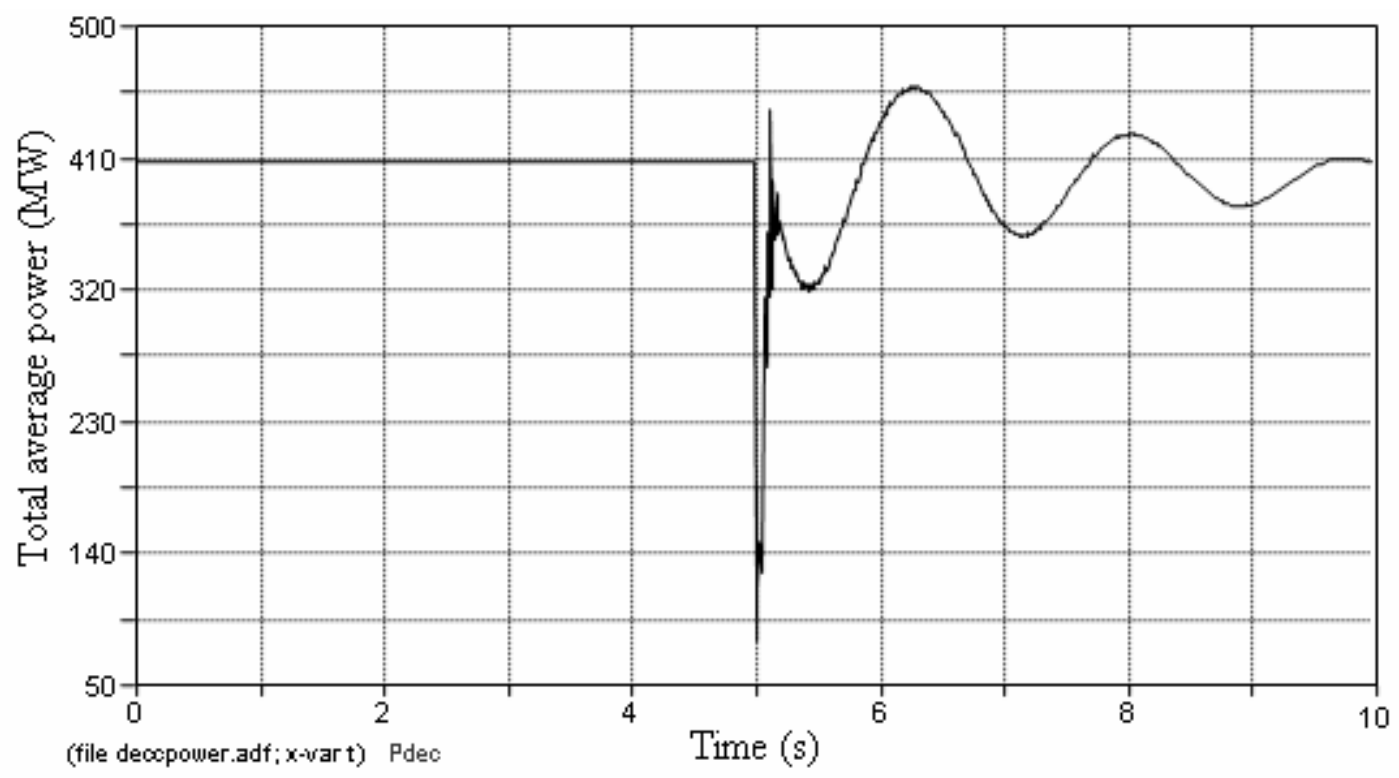

Figure 6.26: Power flow between into Area 2 for disturbance in Area 2 (Case 4b)

\subsubsection{Benchmarking the Reduced System in ATP}

It is important to benchmark the reduced system against the original system. Simulation results obtained for a type of power system disturbance in the original twoarea system is compared with similar disturbances in the reduced system. Rotor angles, power flow and terminal voltages of both the systems are compared.

Results for the three-phase line fault in transmission line 6-7 (Case 4a) is discussed here and other simulation results are included in Appendix B. Comparison of rotor angle for coherency helps in benchmarking the reduced system against the original system. Figure 6.27 shows the rotor angles of machines G1 and G2 in area 1 of the original system and rotor angle of G12 in area 1 of the reduced system. It is clear from Figure 6.27 that G12 is coherent with G1 and G2. Figure 6.28 shows the rotor angles of machines G3 and G4 in area 2 of the original system and rotor angle of G34 in area 2 of the reduced system.

As the phase angle of the equivalent generator is the average of the phase angles of generators in the original system, the rotor angle of the machine in the reduced system is not equal to any of the generators it is representing. For both the generators in the reduced system, the rotor angles are approximately equal to the average rotor angles. As 
in the case of the original system, peak of the first swing and frequency of the oscillations are higher in the area with fault.

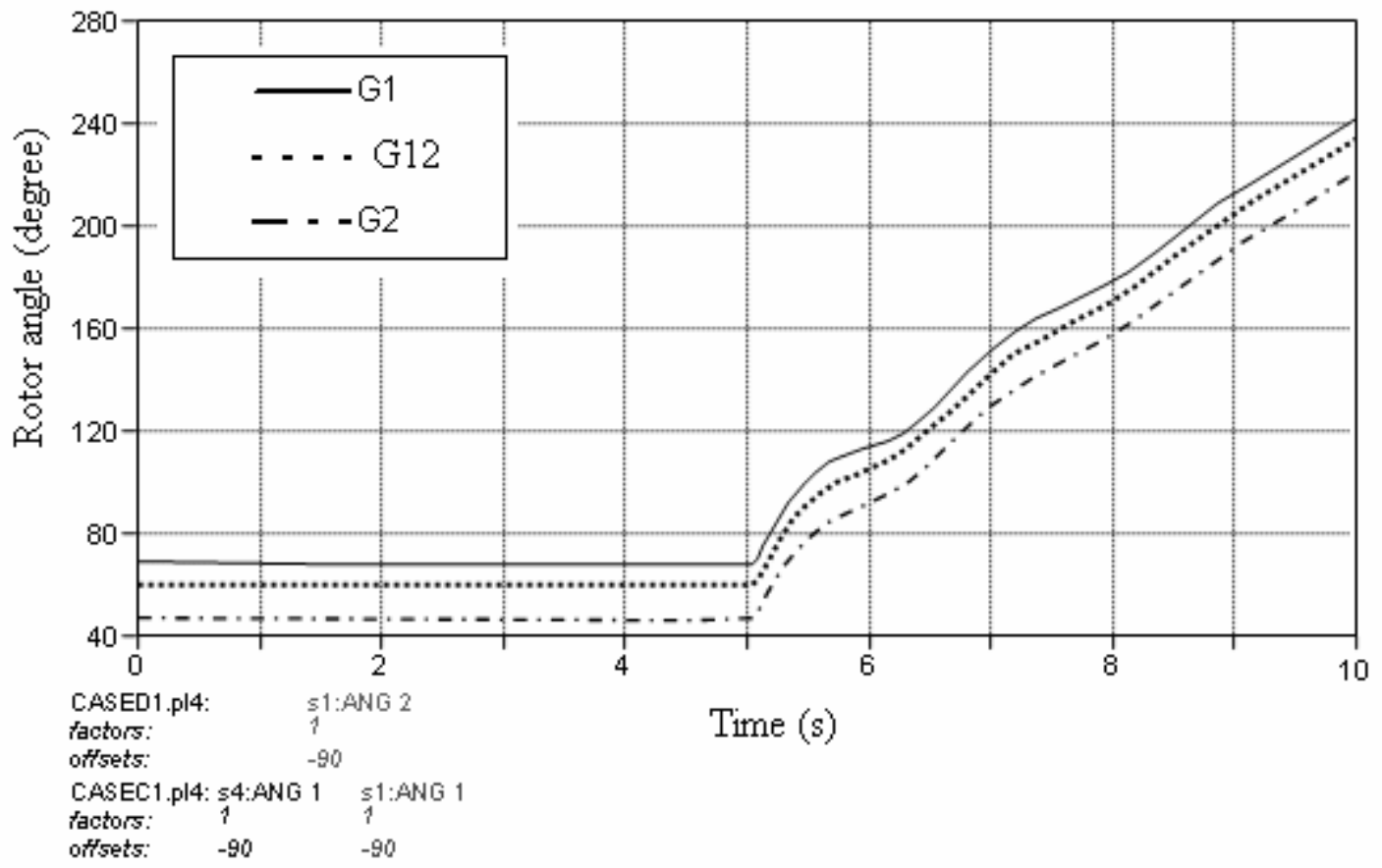

Figure 6.27: Rotor angles of machines in Area 1 (Cases 3a and 4a)

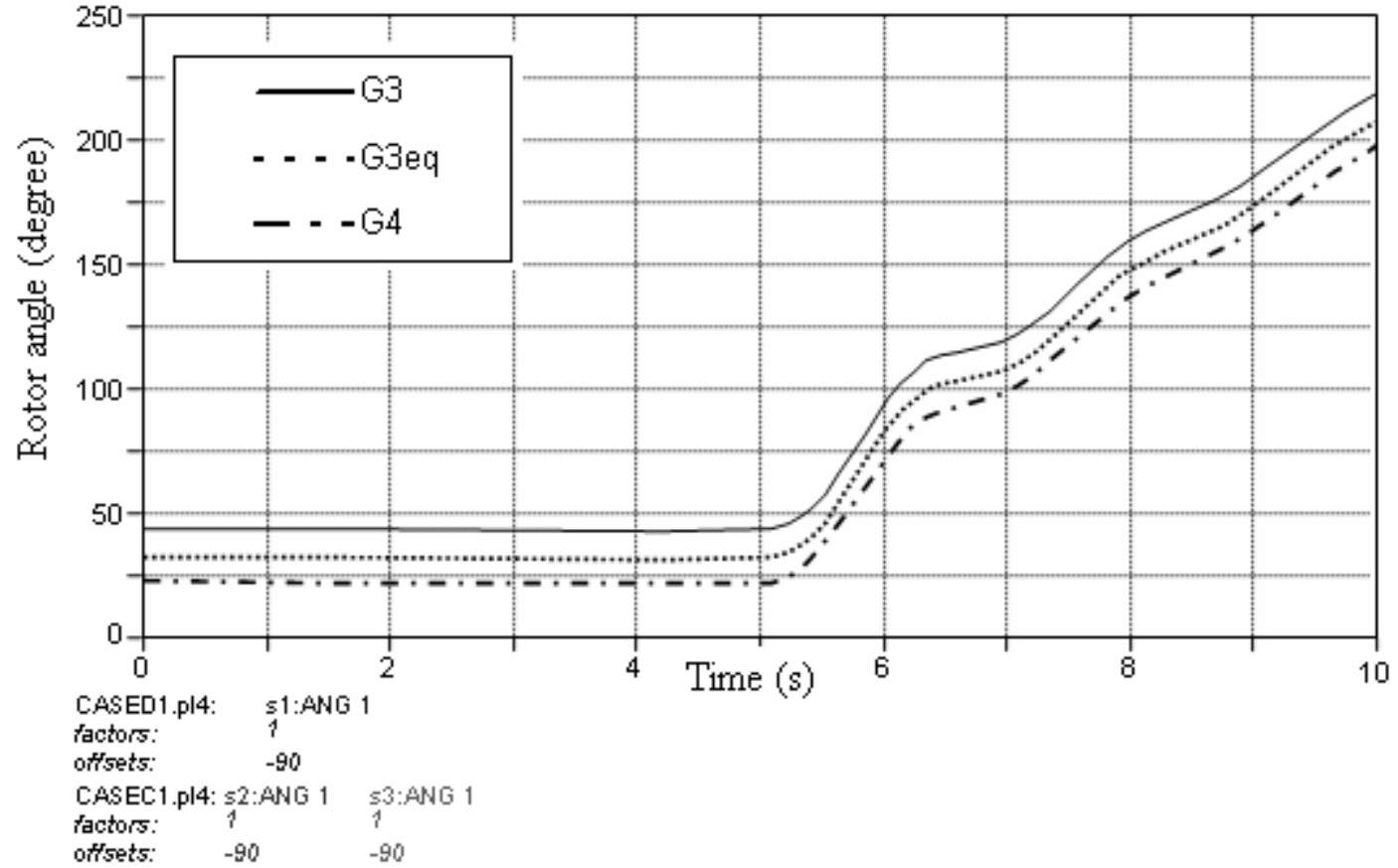

Figure 6.28: Rotor angles (in degree) of machine is area 2 


\subsubsection{Benchmarking of Reduced System in PSS/E}

The reduced system of ATP is also benchmarked against PSS/E. Figures 6.29 and 6.30 shows the rotor angles and power flow in line 7-8 during a three-phase fault in the line 6-7 (Case 4a) for both ATP and PSS/E.

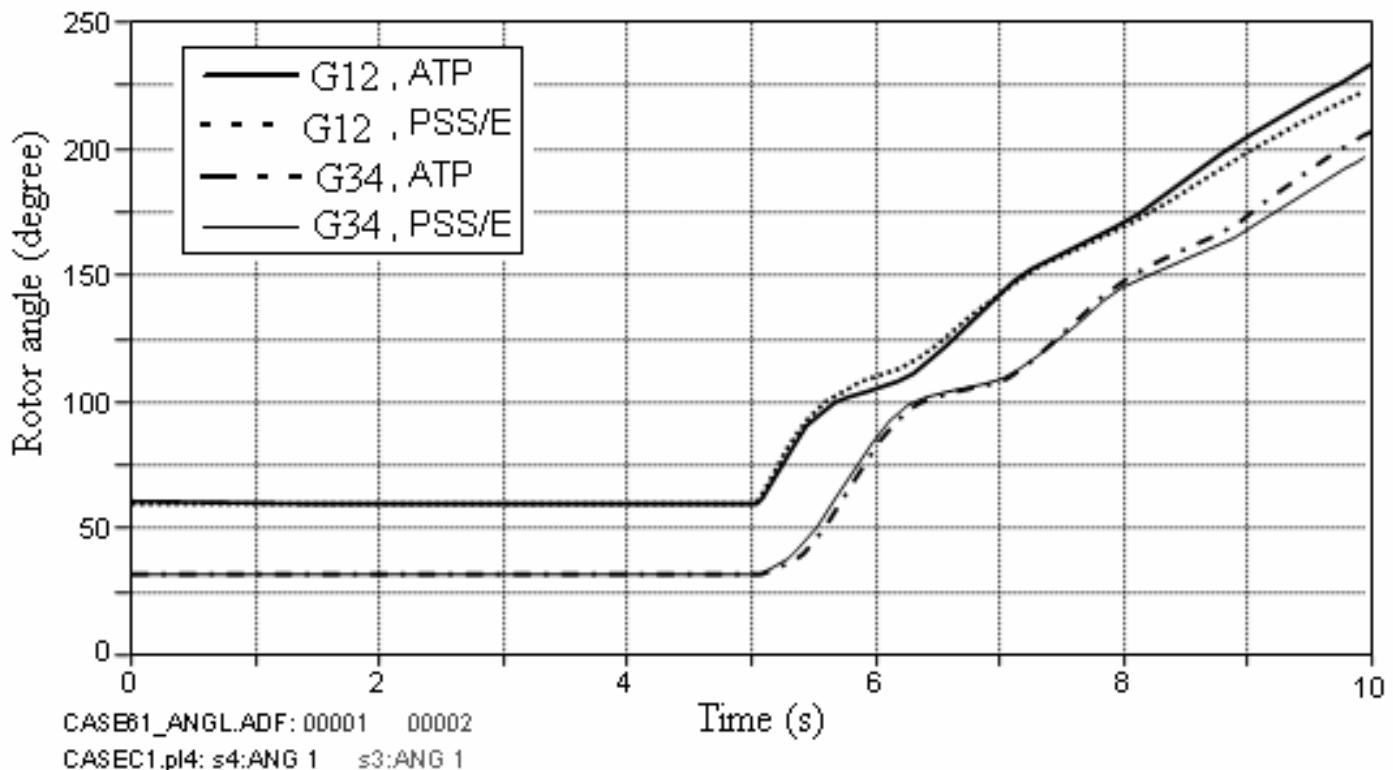

CASEC1.pl4: s4:ANG 1 s3:ANG 1

factors: $\quad-90 \quad-90$

Figure 6.29: Rotor angles of reduced system (Case 4a)

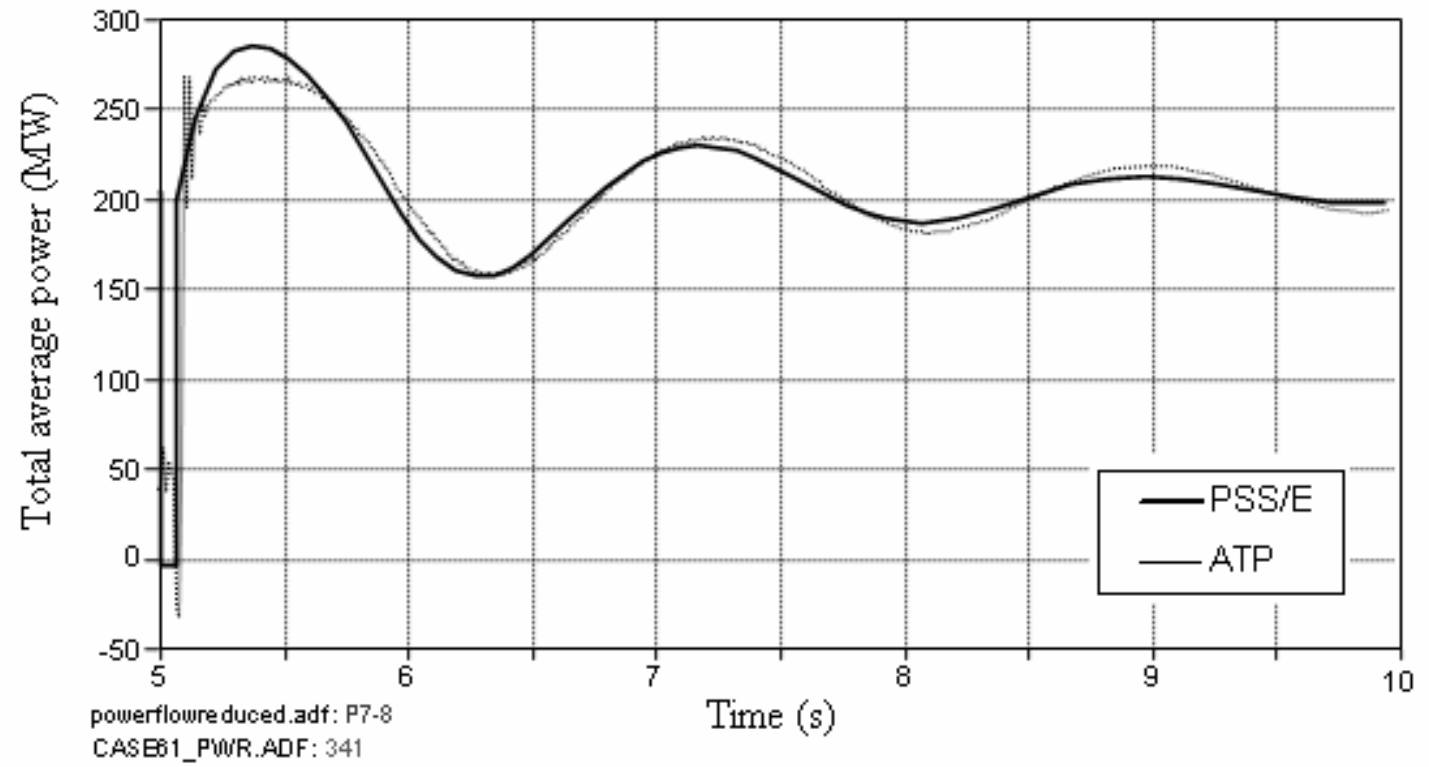

Figure 6.30: Power flow in line 7-8 (Case 4a) 
Steady state power flow, peak of first swing, and frequency of oscillations for different cases of power system faults are tabulated and the percentage difference with respect to PSS/E is calculated. Tables 6-6 and 6-7 give the steady-state rotor angle and peak of the first swing of power flow for different cases respectively. Other comparison tables are given in Appendix B (Tables B-7 and B-8).

There is a noticeable difference in the peak of first swing of power flow between ATP and PSS/E. Maximum difference is $5.18 \%$ which can be significant for a marginally stable system. Differences in settling time, frequency and steady state values are much less. The difference in first peak of power flow may be partially due to inclusion of switching transients in ATP and approximations in MATLAB conversion.

Table 6-6: Steady state rotor angle in degree

\begin{tabular}{|l|c|r|r|}
\hline Machines & ATP & PSS/E & \% Difference \\
\hline G1 & 67.296 & 67.707 & -0.60703 \\
\hline G2 & 45.907 & 46.415 & -1.09447 \\
\hline G3 & 42.631 & 43.067 & -1.01238 \\
\hline G4 & 21.141 & 21.752 & -2.80894 \\
\hline G12 & 58.145 & 58.561 & -0.71037 \\
\hline G34 & 29.656 & 30.52 & -2.83093 \\
\hline
\end{tabular}

Table 6-7: Peak of first swing of power flow

\begin{tabular}{|l|c|c|c|}
\hline \multicolumn{1}{|c|}{ CASES } & $\begin{array}{c}\text { ATP } \\
\text { (MW) }\end{array}$ & $\begin{array}{c}\text { PSS/E } \\
\text { (MW) }\end{array}$ & $\begin{array}{c}\text { \% } \\
\text { Difference }\end{array}$ \\
\hline $\begin{array}{l}\text { Fault in line 6-7, original } \\
\text { system (Case 3a) }\end{array}$ & 73.16 & 84.08 & $12.98 \%$ \\
\hline $\begin{array}{l}\text { Fault in line 10-9, original } \\
\text { system (Case 3b) }\end{array}$ & -46.51 & -54.50 & $14.66 \%$ \\
\hline $\begin{array}{l}\text { Fault in line 6-7, reduced } \\
\text { system (Case 4a) }\end{array}$ & 71.57 & 84.65 & $15.45 \%$ \\
\hline $\begin{array}{l}\text { Fault in line 10-9, reduced } \\
\text { system (Case 4b) }\end{array}$ & -41.47 & -48.92 & $15.22 \%$ \\
\hline
\end{tabular}




\section{CHAPTER 7 CONCLUSIONS AND RECOMMENDATIONS}

This chapter presents the conclusions drawn from this research work. The methods used for obtaining parameters are evaluated. Comments are made about the simulation results and benchmarking of ATP vs. PSS/E. Suggestions and recommendations for future work are also provided.

\subsection{OBSERVATIONS AND CONCLUSIONS}

SM 59 Generator Model in ATP

- Open-circuit tests for both saturated and unsaturated synchronous machine models can be simulated by varying the input field voltage as controlled by TACS. The scaling factor given as a TACS input controls the field voltage. Different slopes can be achieved for the air-gap and saturation region by specifying values of field currents that produce different terminal voltages.

- The TACS input for field voltage control is the normalized value of the actual field voltage. The initial field voltage is determined when ATP calculates initial conditions. A step change in the normalized field voltage is effected by ramping the TACS control variable up or down in subsequent time steps. If a closed-loop control system with limiter is used to control the field voltage, the limiter may hold the scaling factor at 1 . Resulting in the field voltage remaining constant during steady state conditions.

- The TACS node for controlling mechanical power input behaves similar to the field voltage scaling factor. It controls the mechanical power input calculated by the initial conditions with respect to the scaling factor of previous time step.

- The inertia constant $\mathrm{H}$ must be converted to an equivalent moment of inertia $\mathbf{J}$ for the ATP model. If the number of poles of the machine is unknown and if only the 
electrical rotor angle is of interest, then it is convenient to assume a 2-pole machine when calculating $\mathrm{J}$.

Power System Models

- Saturation characteristics do not have significant impact on the results. Models with saturation have higher peak of first swing and there is a decrease in the value of steady-state rotor angle. As the systems are not operated above voltage levels of 1.2 per unit, the machine operates essentially on the air-gap line.

- Benchmarking of single-machine ATP cases against PSS/E also helps to benchmark the TACS control systems which include automatic voltage regulator, power system stabilizer and speed governor. The one time step delay of the TACS system does not influence the results and accurate results are obtained.

- The difference in the settling time and frequency of oscillation between ATP and PSS/E models is very little $(0.2 \%)$. Hence ATP models are comparable to PSS/E models.

Time Step Size and Numerical Oscillations

- As the time step is large in PSS/E (8.333 ms), ATP switching time should be set to exactly match PSS/E to get best results. Otherwise comparisons will not be valid.

- Opening and closing of switches causes numerical oscillations which damp out fast $(0.25-0.5 \mathrm{~s})$. Numerical oscillations during closing of switches are minimal and easily damped by the resistance inherent in the power system. But numerical oscillations caused by opening of switches persist for longer time with higher peaks. The peak value of these oscillations is reduced by adding large shunt resistors and completely mitigated by placing small resistors $(0.5-5 \Omega$ to represent arc resistance) in parallel to the switches before they are opened. The parallel resistors are removed from the system shortly $(0.5$ cycle $)$ after the breakers are opened. 
Power System Unbalance

- Different types of unbalanced faults were simulated and benchmarked against PSS/E. As expected, three-phase faults caused the most severe disturbance, followed by LLG, LL, and LG faults. Results prove that ATP can be reliably used for studying balanced and unbalanced faults.

- System models can be developed to effectively study single-pole tripping and reclosing strategies. With attention to detail and validation, three-pole and singlepole tripping and reclosing strategies for stability studies can be done using these models.

\section{Dynamic Equivalencing}

- The two-area system studied helps in observing inter- and intra-area oscillations and studying small signal stability of the power system. Coherency of generators can be identified by inspecting the rotor angles of the machines during power system disturbances.

- A three-step dynamic reduction procedure was implemented for system reduction and results indicate that the reduced system reproduce essentially the same behavior as the original system without losing the dynamics.

- Since ATP is limited to a maximum of a few thousand nodes, reduced dynamic equivalency must be used to represent the external system, i.e., the portion of the system outside of the detailed local area of interest.

- It is convenient to use PSS/E to identify coherent units and to perform network reduction. PSS/E cannot directly perform aggregation of generators and controls. 
Key Conclusions

- Synchronous machines and their control interfaces are successfully modeled in ATP. Thus, in addition to traditional use for simulating current and voltage transients, ATP can also be used to simulate machine and control dynamics.

- For the two-area system modeled in ATP, the inter- and intra-area oscillations are consistent with PSS/E. ATP acts as an effective tool in studying small signal stability of power systems.

- Results show that ATP simulations for transient and small signal stabilities closely match with PSS/E. Hence it is clear that ATP can be used for both transient and stability analyses.

- Rotor angle and voltage stability were extensively analyzed, showing that ATP can be used to simulate related power system instabilities.

\subsection{RECOMMENDATIONS}

- For this research work, just one model of excitation control system, power system stabilizer, and turbine governor system were used. Additional control systems need to be implemented in ATP in order to be able to model a large power system with a variety of control systems.

- Detailed transformer models including the saturation characteristics should be implemented and effects of generator and transformer saturation on power system stability should be compared. System events which force operation in saturation region should be investigated to observe its effect on stability.

- Numerical oscillations may be further avoided by using detailed transmission line models with shunt capacitance and surge impedance. 
- Instead of constant-impedance load models, constant-current and constant-power load models can be used. Dynamic loads should be modeled. Induction motors and generators should also be included.

- For circuit breaker representation, ideal switches can be replaced by sophisticated switches which include arc resistances and grading and bushing capacitances. Single-pole tripping can be done with these switches, and current and voltage transients can be studied.

- Larger multiple-area systems can be modeled and represented as dynamic equivalents. Benchmarking of two-area system can thus be extended to multiple area systems.

- The concept of dynamic reduction can be applied to a very large power system and a small part of the system can be modeled in detail. Large inter-connected power system such as Mid-continent Area Power Pool (MAPP) can be modeled as reduced dynamic equivalent and benchmarked against real-time events.

- Advanced power system protection decisions such as system islanding, out-ofstep protection and load shedding can be studied in a larger power system represented in ATP.

- More benchmarking with PSS/E's network reduction features will assist in developing and importing reduced models into ATP.

- Protective relaying strategies can be developed and tested with results from ATP models for setting and testing of relays. ATP output files can be converted into COMTRADE format and exported to relay testers for relays for testing purposes. 
- Concepts like Wide Area Monitoring (WAM) can be tested using the large power system models in PSS/E while transient analysis can be done in local areas with external power system represented as dynamic equivalents in ATP.

- Further investigation of implementation details of the TACS field voltage scaling factor is in order. The differences in ATP and PSS/E control signals should be further reconciled.

- Distance relays can be modeled in ATP for transmission line protection and tested for its performance during power system oscillations. Sensitivity analysis for different settings of relays can be performed.

- Eigen values of the power system models should be calculated and used for the analysis of power system oscillations.

- Frequency stability of the power system should be studied in addition to the rotor angle and voltage stability. Effects of different power system components on frequency stability should be analyzed. 


\section{REFERENCES}

[1] J. Arrillaga, Computer Analysis of Power Systems, John Wiley and Sons, (1990.

[2] V. Bhargava, Transient Analysis of Single Pole Switching Strategies, MS Thesis, Michigan Technological University, Feb. 2005.

[3] H. Dommel, EMTP Theory Book, Microtran Power System Analysis Corporation, Vancouver, British Columbia, May, 1992.

[4] J. Esztergalyos, J. Andrichak, K. K. Mustaphi, et al., "Single Pole Tripping and Autoreclosing of Transmission Lines", IEEE Committee Report, IEEE Transactions on Power Delivery, Vol. 7, No.1, Jan. 1992, pp. 182-192.

[5] IEEE Standards Board, "IEEE Guide for Synchronous Generator Modeling Practices in Stability Analysis," IEEE Std. 1110-1991, Nov. 1991.

[6] IEEE Standards Board, "IEEE Recommended Practice for Excitation System Models for Power System Stability Studies," IEEE Std. 421.5-1992, Aug. 1992.

[7] IEEE Standards Board, "IEEE Recommended Practice for Functional and Performance Characteristics of Control Systems for Steam Turbine-Generator Units," IEEE Std. 122-1991, Feb. 1992

[8] IEEE-SA Standards Boards, "IEEE Guide for the Application of Turbine Governing Systems for Hydroelectric Generating Units," IEEE Std. 1207-2004, June 2004.

[9] P. Kundur, Power System Stability and Control, McGraw-Hill, (O1994

[10] P. Kundur, J. Paserba, S. Vitet, "Overview on definition and classification of power system stability," CIGRE/IEEE PES International Symposium, 8-10 Oct. 2003, pp. $1-4$.

[11] K.U. Leuven EMTP center. Alternative Transients Program Rule Book, Leuven EMTP Center, Haverlee, Belgium, revised May 1991, (C1987.

[12] Manitoba HVDC Research Center, PSCAD/EMTDC User's Manual, Ver. 2.0, Canada.

[13] MAPP Operative Review Sub-committee, "Northern MAPP/Northwestern Ontario Disturbance June 25, 1998,” Final Report, September 1998.

[14] J.A. Martinez, J. Martin-Arnedo, "Expanding Capabilities of EMTP-like tools: from analysis to design," IEEE Transactions on Power Delivery, Vol. 18, Issue 4, Oct. 2003, pp.1569-1571. 
[15] NERC Steering Group, "Technical Analysis of the August 14, 2003, Blackout: What Happened, Why, and What Did We Learn?" Report to the NERC Board of Trustees, July 13, 2004.

[16] P.C. Tripathi, R. Balasubramanian, K.S. Prakasa Rao, V.S. Rajamani, "Dynamic Equivalencing and Optimal Choice of Excitation Parameters," IEEE Region 10 International Conference on EC3-Energy, Computer, Communication and Control Systems, Vol. 1, August 28-30, 1991, pp.350 - 354.

[17] S.K. Salman, D.J. King, "Monitoring Changes in System Variables Due to Islanding Condition and Those Due to Disturbances at the Utilities' Network", 1999 IEEE Transmission and Distribution Conference, Vol. 2, April 1999, pp. 460-465.

[18] Siemens Power Transmission and Distribution Inc., PTI, PSS/E Manual, Ver. 30.0, USA.

[19] R. Singh, Phasor-domain, Phasor-Domain Modeling of Power System Stability including Reduced Dynamic Equivalencing, MS Report, Michigan Technological University, June, 2006.

[20] U.S. - Canada Power System Outage Task Force, "Final Report on the August 14, 2003 Blackout in the United States and Canada: Causes and Recommendations," April 5, 2004.

[21] L. Wang, M. Klein, S. Yirga, P. Kundur, "Dynamic Reduction of Large Power Systems for Dynamic Studies," IEEE Transactions on Power System, Vol. 12, No. 2, May 1997, pp. 889-895.

[22] J.P. Yang, G.H. Cheng, Z. Xu, "Dynamic Reduction of Large Power System in PSS/E," IEEE/PES Transmission and Distribution Conference and Exhibition, Dalian, China, Aug 2005, pp. 1-4.

[23] M. Zima, M. Larsson, P. Korba, C. Rehtanz, G. Andersson, "Design Aspects of Wide-Area Monitoring and Control Systems", Proceedings of IEEE, Vol. 93, May 2005, pp. 980-986. 


\section{APPENDIX A \\ MODEL PARAMETERS}

\section{A.1 OPEN-CIRCUIT CHARACTERISTICS}

Table A-1: O. C test results for saturation points $S(1.0)$ and $S(1.2)$

\begin{tabular}{|r|r|r|}
\hline \multicolumn{1}{|c|}{$\mathbf{V}_{\text {ref }}$} & \multicolumn{1}{|c|}{$\begin{array}{c}\text { Terminal } \\
\text { Voltage (pu) }\end{array}$} & \multicolumn{1}{c|}{$\begin{array}{c}\text { Field } \\
\text { Voltage }(\mathbf{V})\end{array}$} \\
\cline { 1 - 2 } 0.1 & 0.09833 & 36.154 \\
\hline 0.2 & 0.19967 & 72.274 \\
\hline 0.3 & 0.2995 & 108.38 \\
\hline 0.4 & 0.39933 & 144.5 \\
\hline 0.5 & 0.49917 & 180.62 \\
\hline 0.6 & 0.599 & 216.73 \\
\hline 0.7 & 0.69884 & 252.97 \\
\hline 0.8 & 0.79867 & 288.97 \\
\hline 0.9 & 0.8985 & 325.08 \\
\hline 1.0 & 0.99834 & 361.2 \\
\hline 1.1 & 1.0982 & 397.31 \\
\hline 1.2 & 1.198 & 433.43 \\
\hline 1.3 & 1.2966 & 718.53 \\
\hline 1.4 & 1.3928 & 1555.5 \\
\hline 1.5 & 1.4598 & 8734.5 \\
\hline
\end{tabular}

Table A-2: O.C. test results for saturation points $S(0.8)$ and $S(1.2)$

\begin{tabular}{|r|r|r|}
\hline \multicolumn{1}{|c|}{$\mathbf{V}_{\text {ref }}$} & $\begin{array}{c}\text { Terminal } \\
\text { Voltage (pu) }\end{array}$ & $\begin{array}{c}\text { Field } \\
\text { Voltage }(\mathbf{V}) \\
\end{array}$ \\
\cline { 1 - 2 } 0.1 & 0.09987 & 45.16 \\
\hline 0.2 & 0.19975 & 90.33 \\
\hline 0.3 & 0.29963 & 135.5 \\
\hline 0.4 & 0.3995 & 180.67 \\
\hline 0.5 & 0.49938 & 225.84 \\
\hline 0.6 & 0.59926 & 271.01 \\
\hline 0.7 & 0.69913 & 316.18 \\
\hline 0.8 & 0.79901 & 361.35 \\
\hline 0.9 & 0.89874 & 458.87 \\
\hline 1.0 & 0.99834 & 604.97 \\
\hline 1.1 & 1.0978 & 817.72 \\
\hline 1.2 & 1.1968 & 1155.5 \\
\hline 1.3 & 1.2951 & 1770.8 \\
\hline 1.4 & 1.3912 & 3207.7 \\
\hline 1.5 & 1.473 & 9835 \\
\hline
\end{tabular}


Table A-3: O.C. test results for unsaturated machine model

\begin{tabular}{|r|r|r|}
\hline \multicolumn{1}{|c|}{$\mathbf{V}_{\text {ref }}$} & \multicolumn{1}{|c|}{$\begin{array}{c}\text { Terminal } \\
\text { Voltage (pu) }\end{array}$} & \multicolumn{1}{c|}{\begin{tabular}{c} 
Field \\
Voltage $(\mathbf{V})$ \\
\cline { 1 - 2 }
\end{tabular}} \\
\cline { 1 - 2 } 0.1 & 19.554 & 0.09998 \\
\hline 0.2 & 39.056 & 0.19969 \\
\hline 0.3 & 58.571 & 0.29943 \\
\hline 1.5 & 283.412 & 1.4982 \\
\hline
\end{tabular}

\section{A.2 GENERATOR PARAMETERS}

\section{Name : SM59_FC - Synchronous Machine. 8 TACS control. TYPE 59.} Balanced steady-state. No saturation. Single mass.

\section{Card : SOURCE}

Data : Volt= Steady-state voltage magnitude in [V] at the terminals of the machine.

Freq $=$ The electrical frequence of the machine in $[\mathrm{Hz}]$. Steady-state.

Angle $=$ The steady-state voltage phasor angle phase A in [deg.]

Poles $=$ Number of poles.

$\mathrm{SMOVTP}=$ Proporsjonality factor which is used only to split the real power among multiple machines in parallel during initialization. No machines in parallel: SMOVTP=1.

SMOVTQ= Proporsjonality factor which is used only to split the reactive power among multiple machines in parallel during initialization.

No machines in parallel: $\mathrm{SMOVTQ}=1$.

Machines in parallel: Requires manually input file arranging.

RMVA= The three-phase volt-ampere rating of the machine in [MVA].

$\mathrm{RkV}=$ The rated line-to-line voltage of the machine in $[\mathrm{kV}]$.

AGLINE $=$ Value of field current in $[\mathrm{A}]$ which will produce rated armature voltage on the d-axis.

Indirect specification of mutual inductance.

$\mathrm{RA}=$ Armature resistance in [pu]. RA $>0$ !

$\mathrm{XL}=$ Aramture leakage reactance in $[\mathrm{pu}]$.

$\mathrm{Xd}=\mathrm{D}$-axis synchronous reactance in $[\mathrm{pu}]$.

$\mathrm{Xq}=\mathrm{Q}$-axis synchronous reactance in [pu].

$\mathrm{Xd}^{\prime}=\mathrm{D}$-axis transient reactanse in [pu].

$\mathrm{Xq}=\mathrm{Q}$-axis transient reactanse in $[\mathrm{pu}]$.

$\mathrm{Xd}=\mathrm{D}$-axis subtransient reactanse in [pu].

$\mathrm{Xq}=\mathrm{Q}$-axis subtransient reactanse in [pu].

Tdo'= D-axis transient time constant in [sec.]

Tqo' $=$ Q-axis transient time constant in [sec.]

Tdo"= D-axis subtransient time constant in [sec.]

Tqo"= Q-axis subtransient time constant in [sec.]

$\mathrm{Xo}=$ Zero-sequence reactance in [pu]

$\mathrm{RN}=$ Real part of neutral grounding impedance [pu].

$\mathrm{XN}=$ Imaginary part of neutral grounding impedance [pu]. 
$\mathrm{XCAN}=$ Canay's characteristic reactance in [pu].

Unknown: Use XCAN=XL.

$\mathrm{HICO}=$ Moment of inertia of mass.

In [million pound-feet ${ }^{\wedge}$ ] if $\mathrm{MECHUN}=0$.

In [million $\mathrm{kg}-\mathrm{m}^{\wedge} 2$ ] if $\mathrm{MECHUN}=1$.

$\mathrm{DSR}=$ Speed-deviation self-damping coefficient for mass.

$\mathrm{T}=\mathrm{DSR}(\mathrm{W}-\mathrm{Ws})$ where $\mathrm{W}$ is speed of mass and $\mathrm{Ws}$ is synchronous speed.

In [(pound-feet $) /(\mathrm{rad} . / \mathrm{sec})]$ if MECHUN $=0$.

In $[(\mathrm{N}-\mathrm{m}) /(\mathrm{rad} . / \mathrm{sec})]$ if MECHUN $=1$.

$\mathrm{DSD}=$ Absolute-speed self-damping coefficient for mass.

$\mathrm{T}=\mathrm{DSD}(\mathrm{W})$ where $\mathrm{W}$ is speed of mass.

In [(pound-feet) $/(\mathrm{rad} . / \mathrm{sec})]$ if MECHUN=0.

In $[(\mathrm{N}-\mathrm{m}) /(\mathrm{rad} . / \mathrm{sec})]$ if MECHUN $=1$.

$\mathrm{FM}=<=2$ : Time constants based on open circuit meassurements.

$>2$ : Time constants based on short circuits meassurements.

MECHUN= 0: English units.

1: Metric units.

Node : $\quad$ OUT $=$ Aramture node. 3 -phase. Phase A: Angle.

Phase B: Angle-120.

Phase C: Angle+120.

TACS1 $=$ TACS node. Type of control: $0 . .22$.

TACS2 $=$ TACS node. Type of control: $0 . .22$.

TACS3 $=$ TACS node. Type of control: $0 . .22$.

TACS4= TACS node. Type of control: $0 . .22$.

TACS5= TACS node. Type of control: $0 . .22$.

TACS6= TACS node. Type of control: $0 . .22$.

TACS7 $=$ TACS node. Type of control: $0 . .22$.

TACS8 $=$ TACS node. Type of control: $0 . .22$.

TACS nodes : Click directly on these to specifiy type of control.

Control type: $0=$ No Control.

$1=\mathrm{D}$-axis armature current. Out.

$2=\mathrm{Q}$-axis armature current. Out.

$3=$ Zero-sequence armature current. Out.

$4=$ Field winding current. Out.

$5=\mathrm{D}$-axis damper current. Out.

$6=$ current in eddy-current winding. Out.

$7=\mathrm{Q}$-axis damper current. Out.

$8=$ Voltage applied to d-axis. Out.

$9=$ Voltage applied to q-axis. Out.

$10=$ Zero-sequence voltage. Out.

$11=$ Voltage applied to field winding. Out.

$12=$ Total $\mathrm{mmf}$ in the machines air-gap. Out.

$13=$ Angle between q- and d- axis component of mmf. Out.

$14=$ Electromagnitic torque of the machine. Out.

$15=$ Not in use.

$16=\mathrm{d}$-axis flux linkage. Out. 
$17=$ q-axis flux linkage. Out.

$18=$ Angle mass. Out.

$19=$ Angular velocity mass. Out.

$20=$ Shaft torque mass. Out.

$21=$ Field voltage. In.

22= Mechanical power. In.

RuleBook: VIII.

\section{A.3 TACS DATA}

Name : EMTP_OUT, probe for passing EMTP information to TACS.

Card : TACS

Data : Type=90: Node voltage

91: Switch current

92: Internal variables

93: Switch status

Switch closed: Probe $=1$

Switch open: Probe $=0$

T_sta $=$ Start time of sampling.

T_sto $=$ Stop time of sampling.

Node : Probe $=$ Signal passed to TACS.

RuleBook: III-E-3 p. 3-15

Name: INIT_T - Initial condition of TACS objects (type 77)

Card: TACS

Data: Init: Initial value of I_node

Node: I_node: TACS variable

RuleBook: 8.5.7 p. 3.34.

Name:. MULTK, multiplication. Simplified FORTRAN statement

Card: TACS

Data: $\mathrm{K}=$ constant

Node: IN= Input signal. Remember the TACS probe to connect to circuit. $\mathrm{OUT}=\mathrm{K} * \mathrm{IN}$

This component is a simplification of the more general Fortran component in

TACS called FORTRAN1. The value kind set in the node input window is not used.

RuleBook: III-E-4 A)

Name : DC_01, step signal source

Card : TACS

Data : Ampl.= Amplitude of source

T_sta $=$ Start time of source [s]

$\mathrm{T} \_$sto $=$Stop time of source [s]

Node $:$ SOURCE $=$ Output signal

RuleBook: III-E-3, p. 3.14 
Name : TRANSF, general TACS Transfer function G(s).

Card : TACS

Data : Gain=Amplification factor

$\mathrm{N} 0=$ Numerator zero order

$\mathrm{N} 1=$ Numerator 1 st order

$\mathrm{N} 2=$ Numerator 2nd order

N3 $=$ Numerator 3rd order

$\mathrm{N} 4=$ Numerator 4 th order

$\mathrm{N} 5=$ Numerator 5 th order

N6 $=$ Numerator 6 th order

$\mathrm{N} 7=$ Numerator 7 th order

D0 $=$ Denominator zero order

D1 $=$ Denominator 1st order

D2= Denominator 2nd order

D3= Denominator 3rd order

D4= Denominator 4th order

D5 $=$ Denominator 5th order

D6= Denominator 6th order

D7 = Denominator 7th order

ATPDRAW determines the order of the function.

Fix_Lo= Fixed lower limit

Fix_Hi= Fixed higher limit

Node : OUT= Output signal

OUT(s)=Gain $*$ sum $($ inputs $) *\left(\mathrm{~N} 0+\mathrm{N} 1 * \mathrm{~s}+\mathrm{N} 2 * \mathrm{~s}^{\wedge} 2 \ldots\right) /\left(\mathrm{D} 0+\mathrm{D} 1 * \mathrm{~s}+\mathrm{D} 2 * \mathrm{~s}^{\wedge} 2 \ldots\right)$

Dynamic limited.

IN1 = Input signal

IN2 $="$

IN $3="$

IN4= "

IN5 = "

Name_L= Name of low limit

Name_H= Name of high limit

The sign of the input is set in the node input window.

$0=$ output, $1=$ positive, $2=$ negative

$3=$ disconnected (not needed).

RuleBook: III-E-2 p. 3-10 


\section{A.4 LOAD DATA}

Table A-4: Load-flow results for the reduced system

\begin{tabular}{|c|c|c|c|c|c|}
\hline $\begin{array}{c}\text { From } \\
\text { bus }\end{array}$ & $\begin{array}{c}\text { To } \\
\text { bus }\end{array}$ & $\begin{array}{c}\text { Real Power } \\
\text { P (MW) }\end{array}$ & $\begin{array}{c}\text { Reactive Power } \\
\text { Q (MVAr) }\end{array}$ & $\begin{array}{c}\text { Bus voltage } \\
\text { magnitude (p.u.) }\end{array}$ & $\begin{array}{c}\text { Bus voltage } \\
\text { phase angle }\left({ }^{\circ}\right)\end{array}$ \\
\hline 1 & 6 & 700 & 185 & 1.000 & 17.28 \\
\hline 6 & 7 & 1388 & 133 & 0.963 & 37.35 \\
\hline 7 & L7 & 904 & -93.4 & 0.940 & 28.61 \\
\hline 7 & 8 & 464 & 27.4 & 0.940 & 28.61 \\
\hline 8 & 9 & 452 & -65.4 & 0.928 & 13.93 \\
\hline 9 & L9 & 1727 & -244 & 0.950 & -4.6 \\
\hline 10 & 9 & 1305 & 78.9 & 0.969 & 8.19 \\
\hline 3 & 10 & 614 & 109 & 1.000 & -11.9 \\
\hline
\end{tabular}

Table A-5: Constant impedance load data for the reduced system

\begin{tabular}{|c|c|c|c|c|c|c|}
\hline \multirow{2}{*}{ Bus } & \multicolumn{2}{|c|}{ Real Power } & \multicolumn{2}{c|}{ Reactive Power } & \multicolumn{2}{c|}{ Reactive Power Supplied } \\
\cline { 2 - 7 } & $\mathbf{P}_{\mathbf{L}}(\mathbf{M W})$ & $\mathbf{R}_{\mathbf{L}}(\mathbf{\Omega})$ & $\mathbf{Q}_{\mathbf{L}}(\mathbf{M V A r})$ & $\mathbf{X}_{\mathbf{L}}(\mathbf{\Omega})$ & $\mathbf{Q}_{\mathbf{C}}(\mathbf{M V A r})$ & $\mathbf{B}_{\mathbf{C}}(\boldsymbol{\mu M h o})$ \\
\hline 7 & 967 & 48.33 & 100 & 467.42 & 200 & 4278.76 \\
\hline 9 & 1767 & 27.018 & 100 & 477.42 & 350 & 7331.03 \\
\hline
\end{tabular}




\section{APPENDIX B \\ RESULTS}

\section{B.1 SINGLE MACHINE SYSTEM BENCHMARKING}

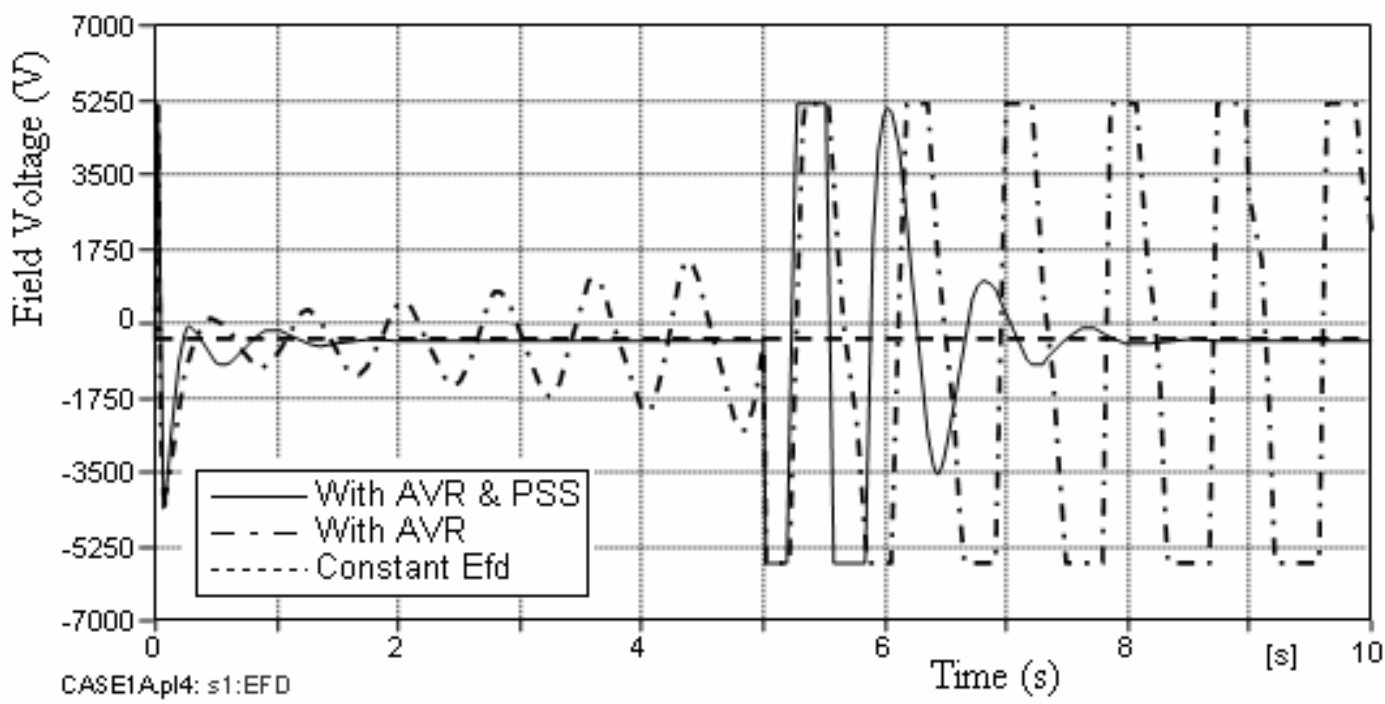

CASE1 18.pl4: $s 1: E F D$

CASE1C.pl4: $s 1: E F D$

Figure B.1: Comparison of field voltage (Cases 1a, 1b, and 1c)

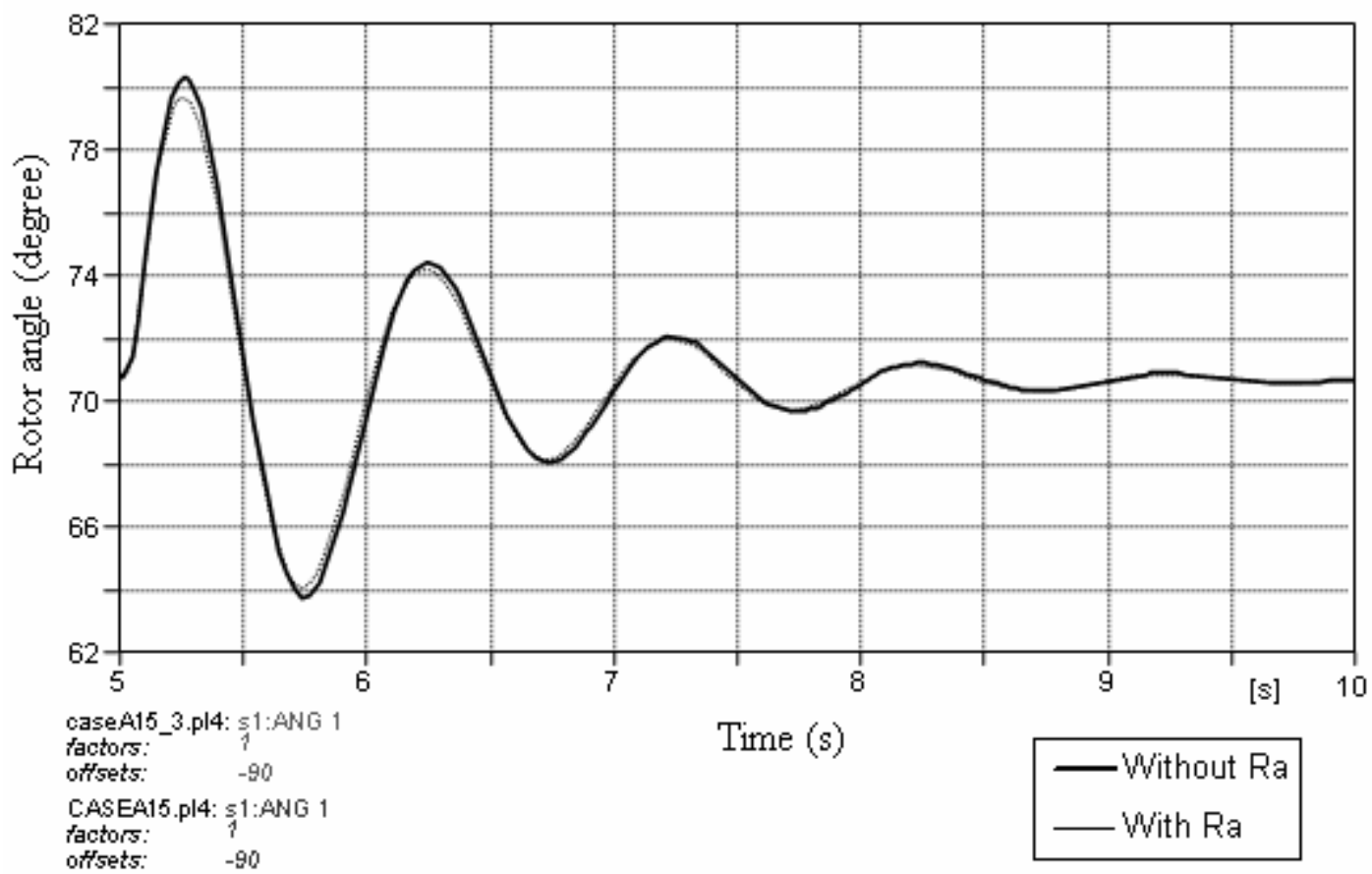

Figure B.2: LG fault, with and without Ra (Case 2b) 


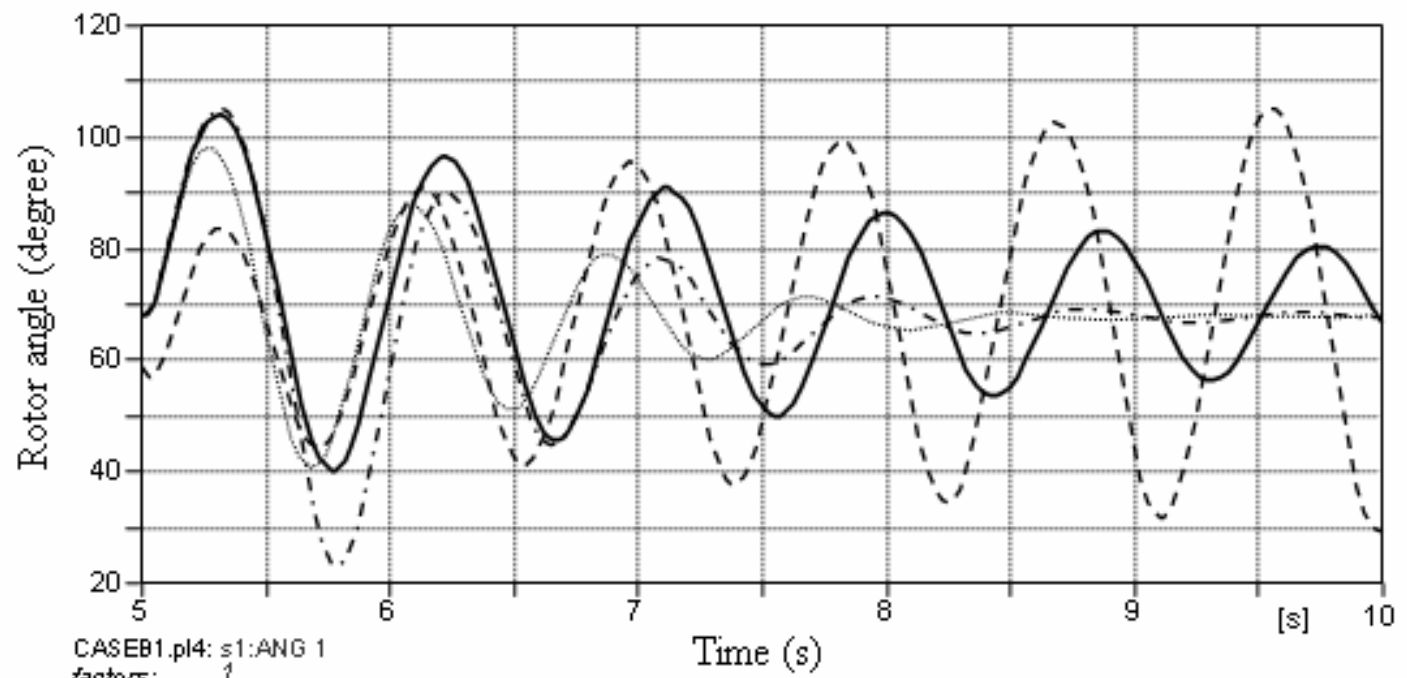

$$
\begin{array}{ll}
\text { offsets: } & -90 \\
\text { CASEB4.pl4: } & 1 \text { 1:ANG } 1 \\
\text { factors: } & 1 \\
\text { offsets: } & -90 \\
\text { CASEB5.pl4: } & \text { s1:ANG } 1 \\
\text { factors: } & 1 \\
\text { offsets: } & -90 \\
\text { CASEB6.pl4: } & \text { s1:ANG } 1 \\
\text { factors: } & 1
\end{array}
$$

Figure B.3: Rotor angle for different excitation systems (cases 1a, 1b, 1c, \& 1d)

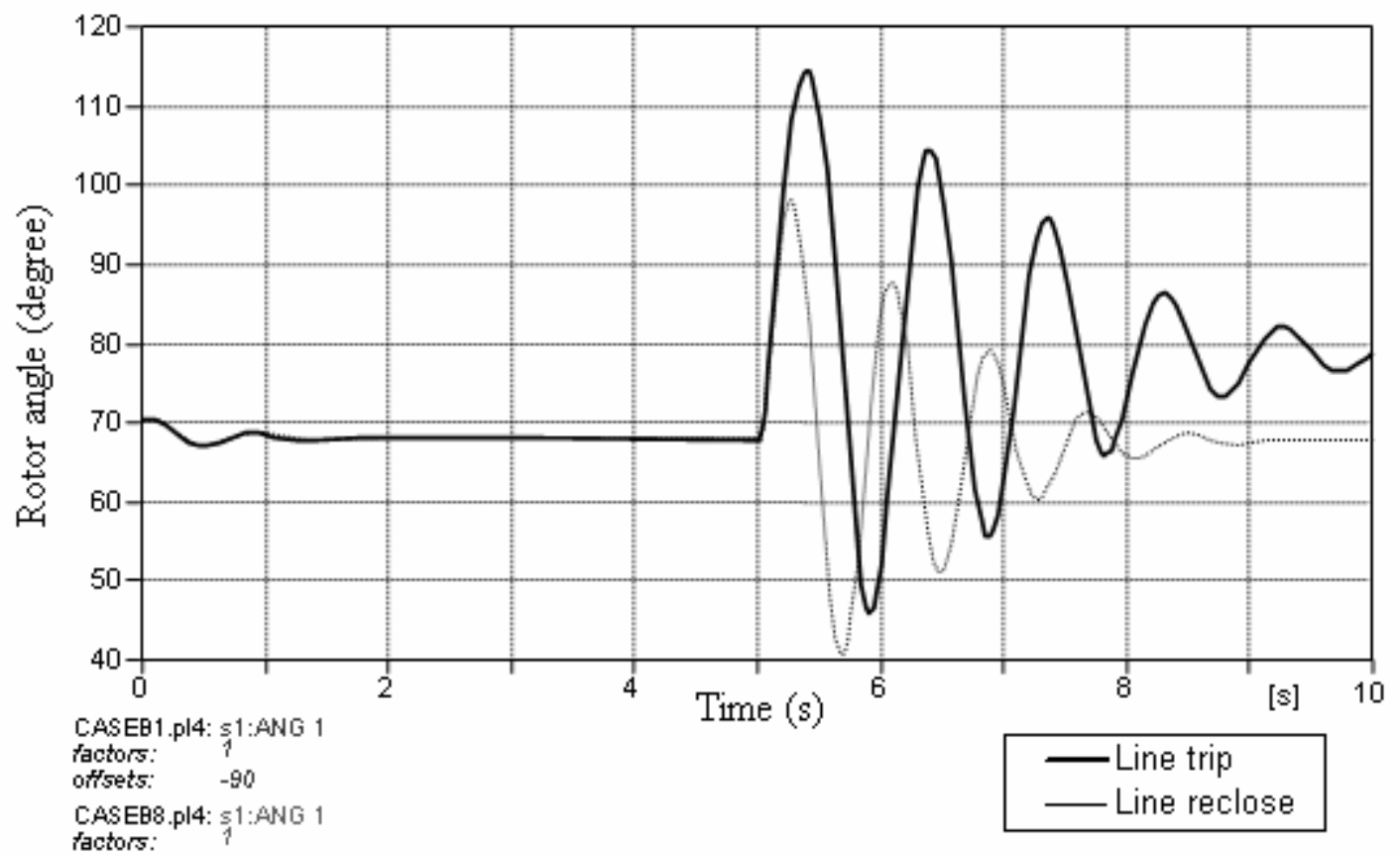

Figure B.4: Rotor angles for line tripping and reclosing (Case 5a) 


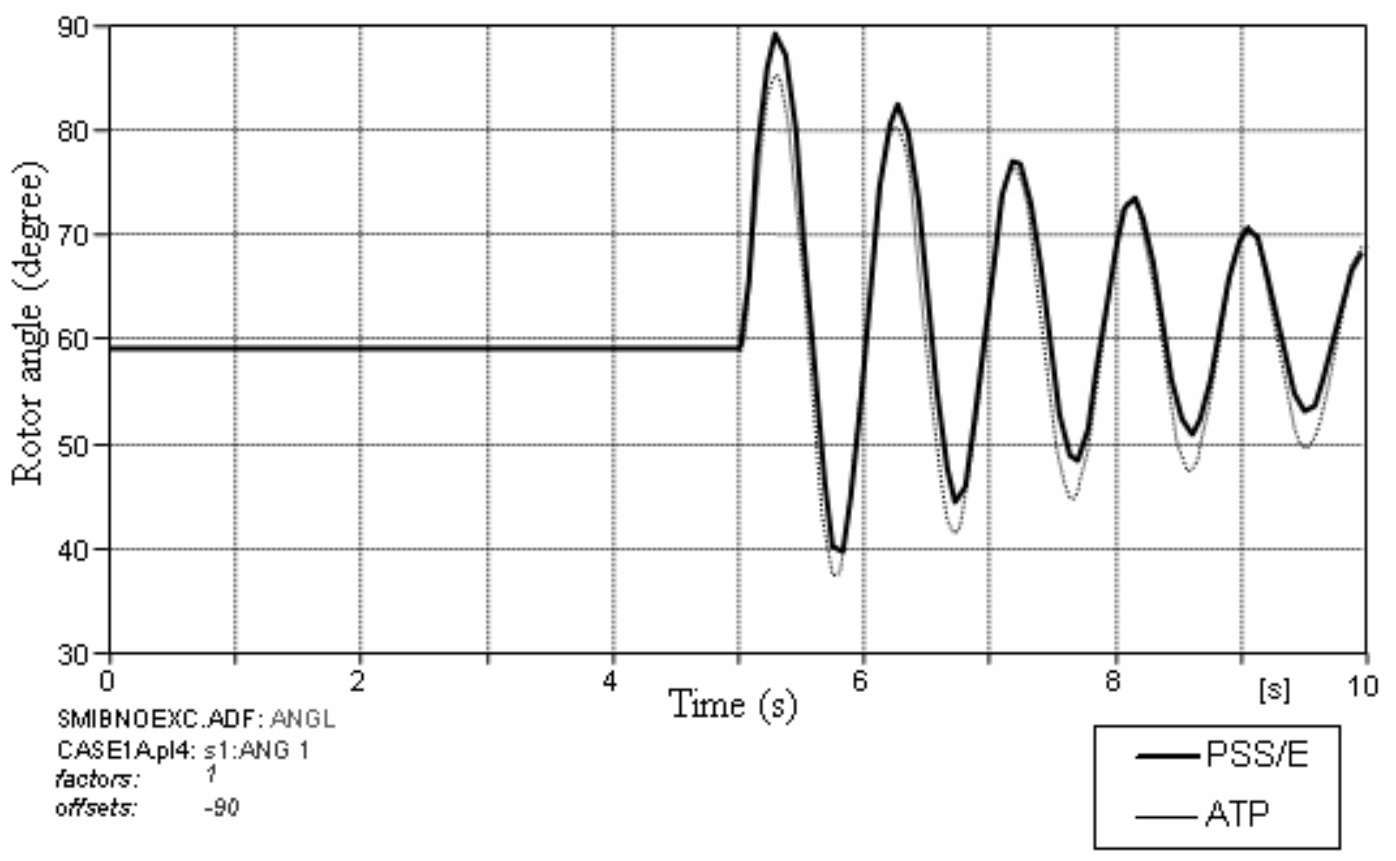

Figure B.5: Rotor angles -constant Efd (Case 1b)

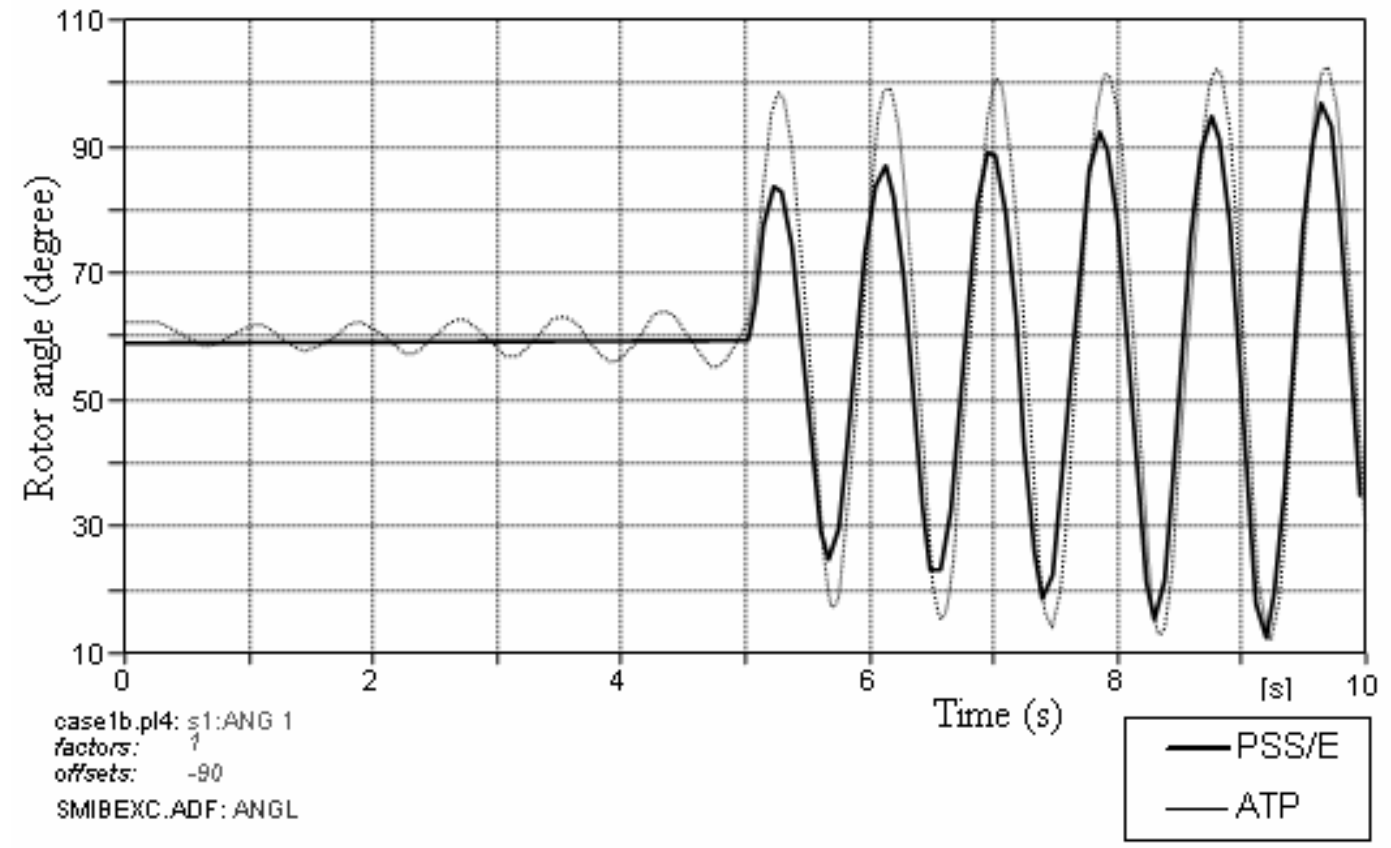

Figure B.6: Rotor angles - with AVR (Case 1c) 


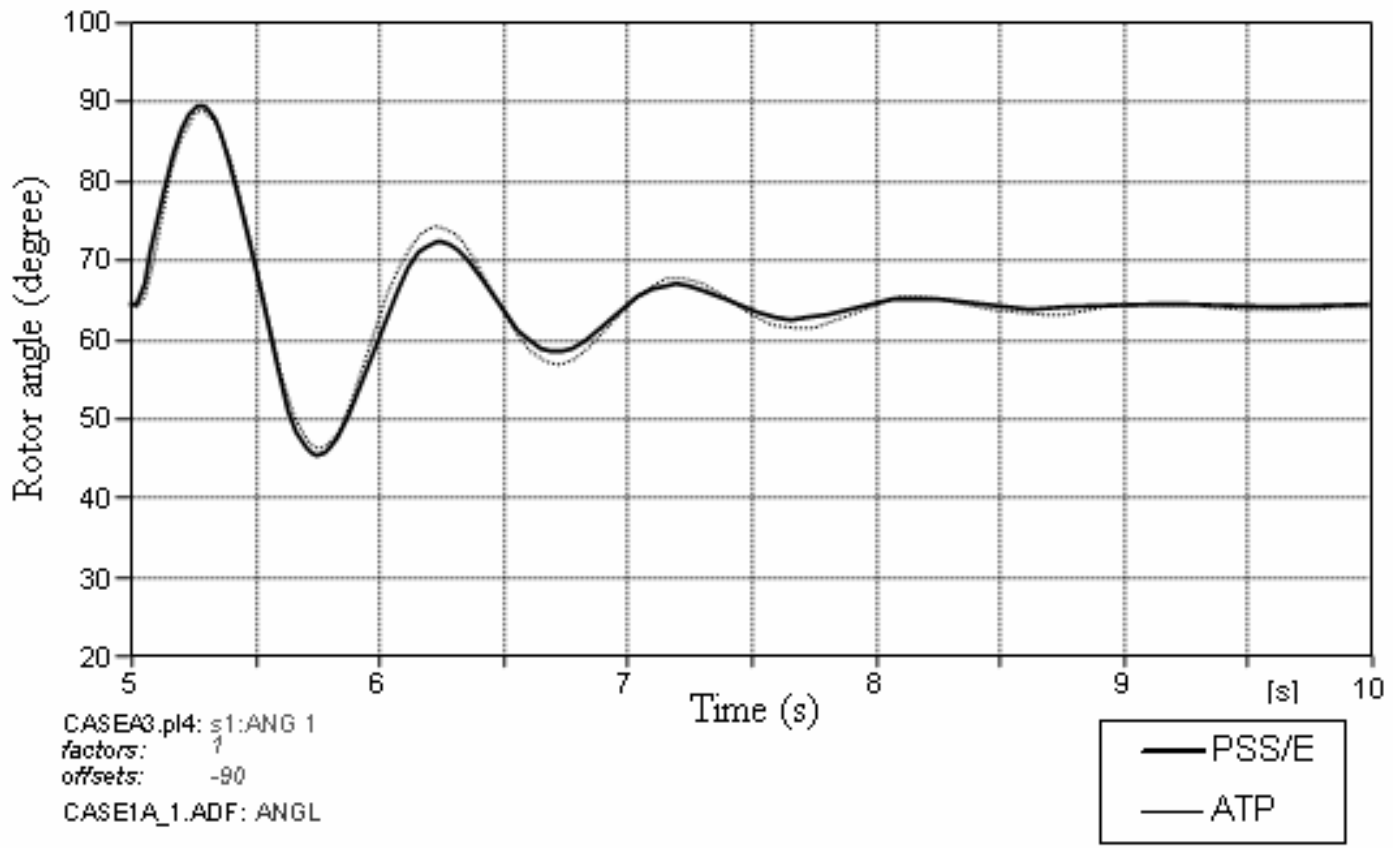

Figure B.7: Rotor angles with saturated generator model (Case 1e)

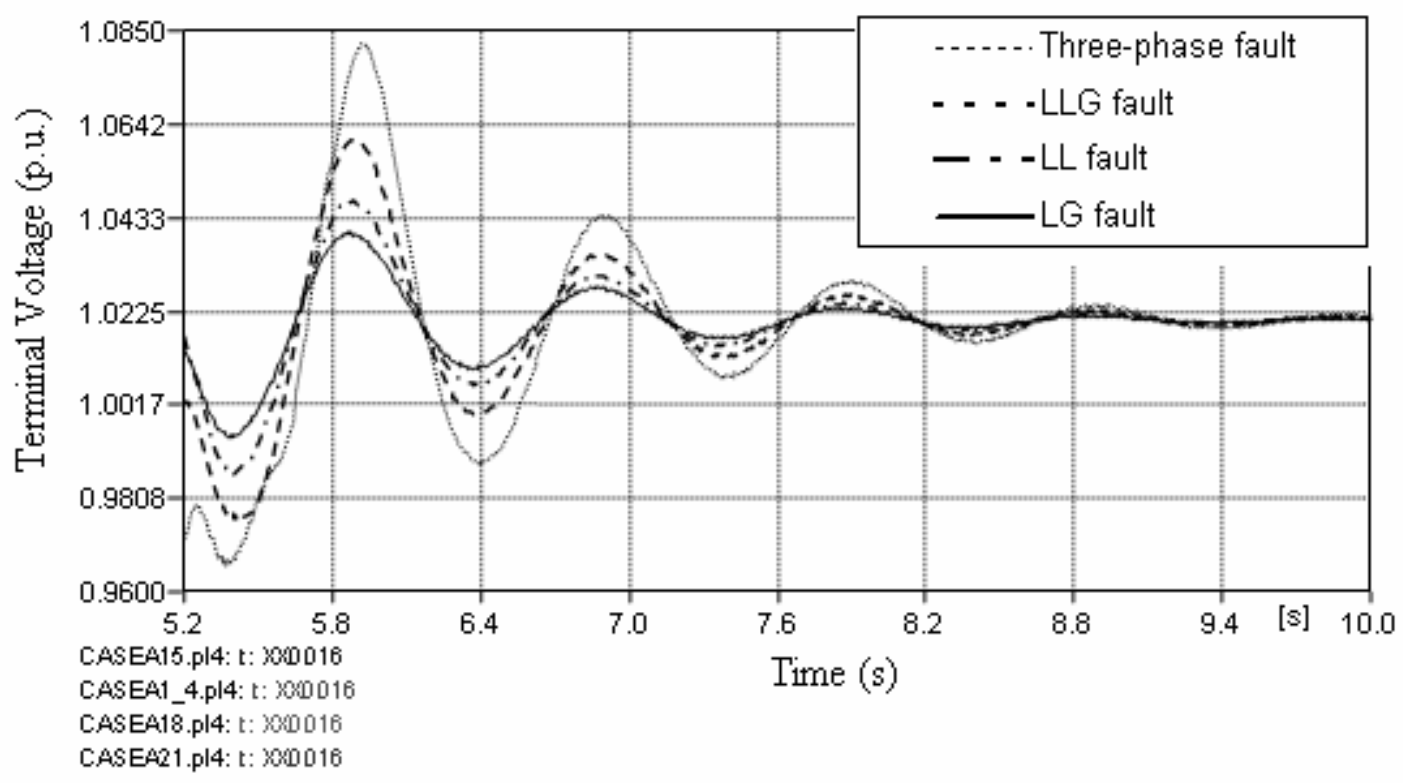

Figure B.8: Terminal Voltage for different fault types (Cases 2a, 2b, 2c and 2d) 


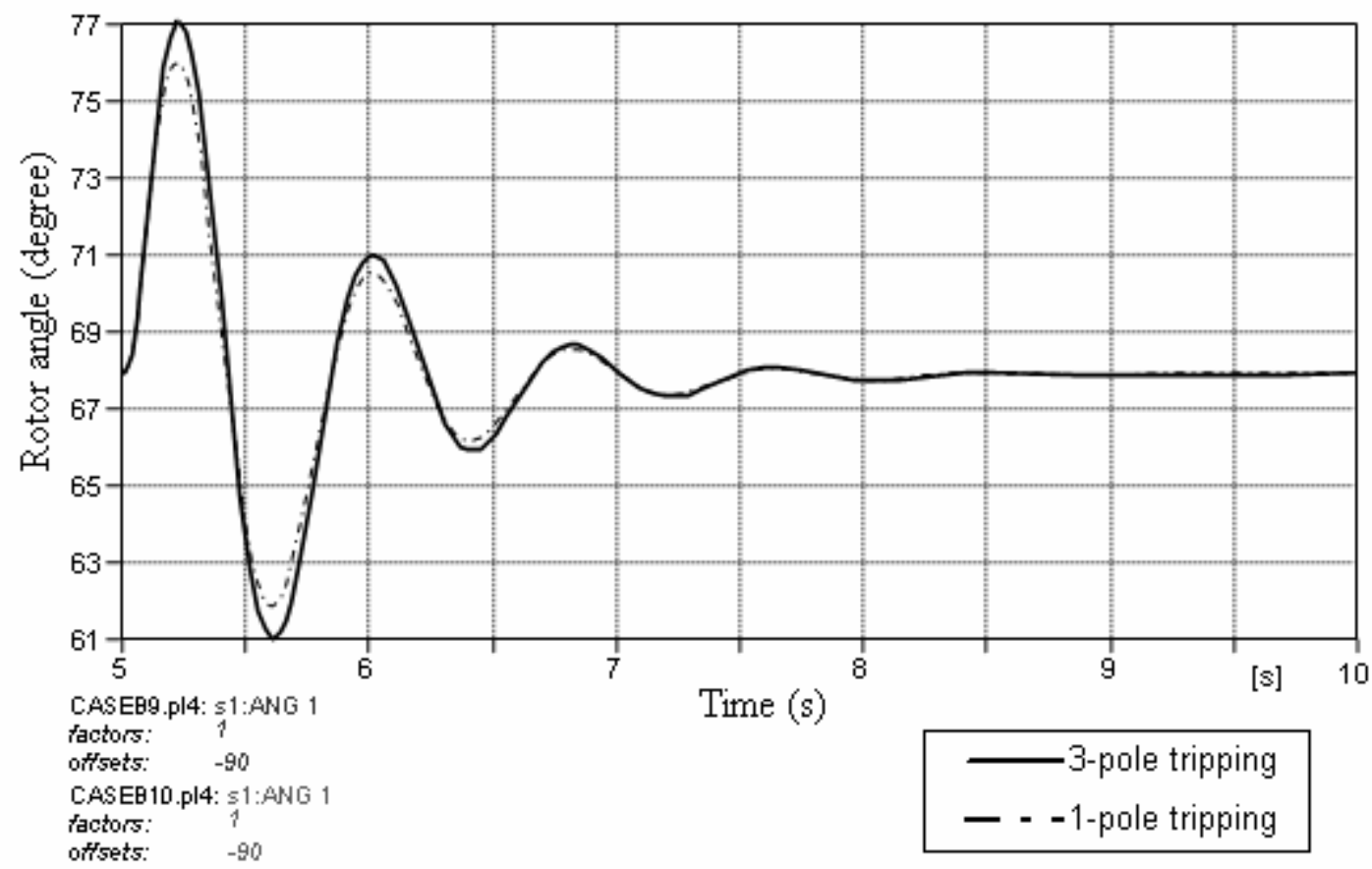

Figure B.9: Rotor angles - single-pole and three-pole tripping (Case $2 \mathrm{~b}$ and 2e)

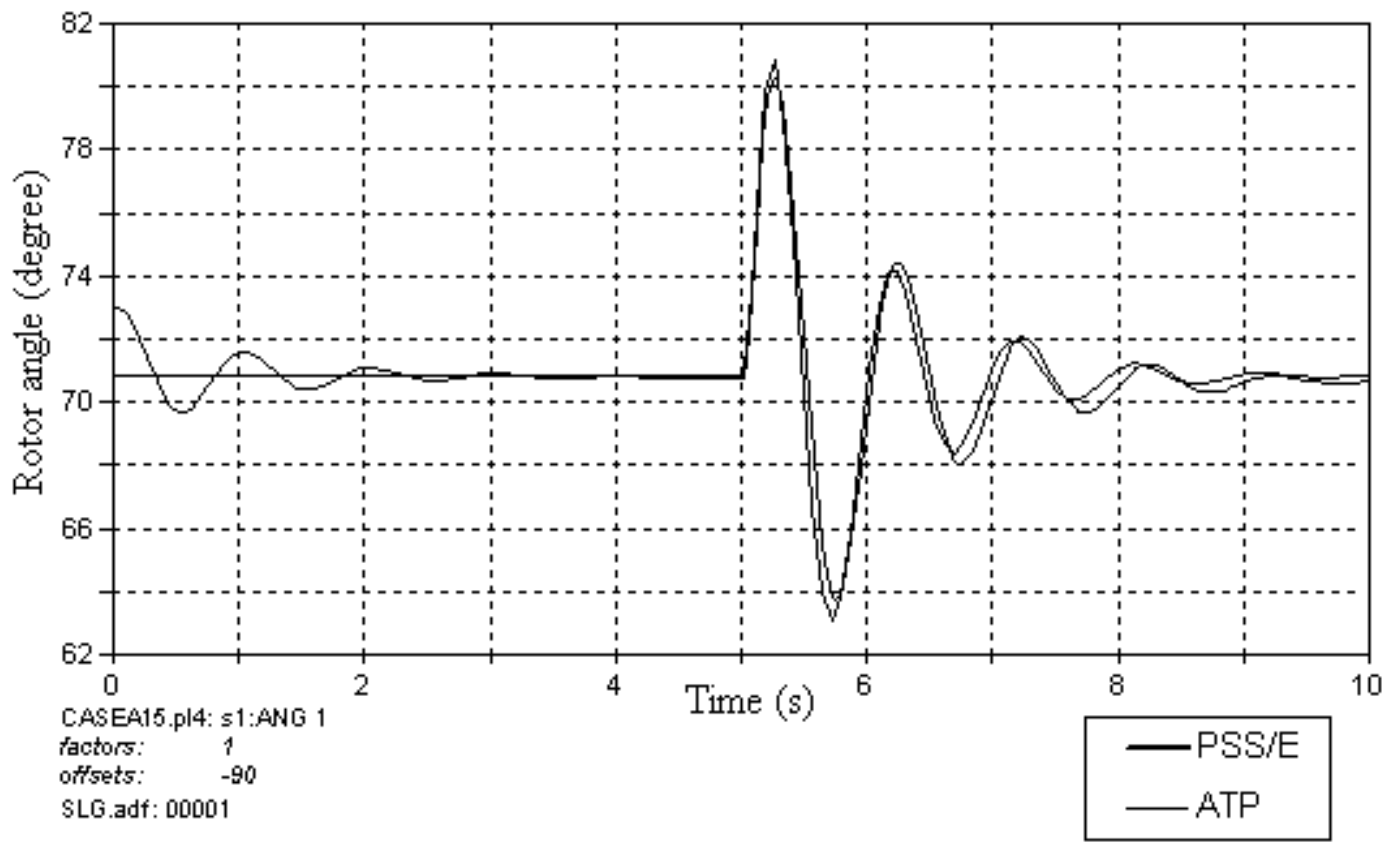

Figure B.10: Rotor angles for a LG fault (Case 2b) 
Table B-1: Steady state rotor angle (in degree)

\begin{tabular}{|l|l|r|r|r|}
\hline Case no. & \multicolumn{1}{|c|}{ CASES } & \multicolumn{1}{c|}{ ATP } & \multicolumn{1}{c|}{ PSS/E } & \% Difference \\
\hline $1 \mathrm{~b}$ & WITH CONSTANT EFD & 64.377 & 64.330 & $0.07 \%$ \\
\hline $1 \mathrm{c}$ & WITH AVR & 64.487 & 64.330 & $0.24 \%$ \\
\hline $1 \mathrm{a}$ & WITH AVR AND PSS & 64.487 & 64.330 & $0.24 \%$ \\
\hline $1 \mathrm{~d}$ & WITH AVR, PSS \& GOV & 64.500 & 64.330 & $0.26 \%$ \\
\hline $1 \mathrm{e}$ & WITH SATURATION & 62.291 & 62.984 & $1.10 \%$ \\
\hline $1 \mathrm{f}$ & WITH RA & 64.427 & $\mathrm{~N} / \mathrm{A}$ & $\mathrm{N} / \mathrm{A}$ \\
\hline 2a & 3-PHASE BUS FAULT & 64.451 & 64.330 & $0.18 \%$ \\
\hline 2b & LG FAULT & 70.784 & 70.840 & $0.07 \%$ \\
\hline 2d & LL FAULT & 70.784 & $\mathrm{~N} / \mathrm{A}$ & $\mathrm{N} / \mathrm{A}$ \\
\hline 2c & LLG FAULT & 70.784 & 70.840 & $0.07 \%$ \\
\hline
\end{tabular}

Table B-2: Peak of first swing of rotor angle (degree)

\begin{tabular}{|l|r|r|r|}
\hline \multicolumn{1}{|c|}{ CASES } & ATP (p.u) & PSS/E (p.u) & \% Difference \\
\hline WITH CONSTANT EFD & 1.0370 & 1.0900 & $4.86 \%$ \\
\hline WITH AVR & 1.0477 & 1.0635 & $1.48 \%$ \\
\hline WITH AVR AND PSS & 1.0705 & 1.0700 & $0.04 \%$ \\
\hline WITH AVR, PSS \& GOV & 1.0680 & 1.0698 & $0.16 \%$ \\
\hline WITH SATURATION & 1.0702 & 1.0751 & $0.45 \%$ \\
\hline WITH RA & 1.0680 & $\mathrm{~N} / \mathrm{A}$ & $\mathrm{N} / \mathrm{A}$ \\
\hline 3-PHASE BUS FAULT & 1.0632 & 1.0712 & $0.74 \%$ \\
\hline LG FAULT & 1.0120 & 1.0398 & $2.67 \%$ \\
\hline LL FAULT & 1.0469 & $\mathrm{~N} / \mathrm{A}$ & $\mathrm{N} / \mathrm{A}$ \\
\hline LLG FAULT & 1.0127 & 1.0603 & $4.48 \%$ \\
\hline
\end{tabular}

Table B-3: Frequency of rotor angle oscillations $(\mathrm{Hz})$

\begin{tabular}{|r|l|r|r|r|}
\hline Case no. & \multicolumn{1}{c|}{ CASES } & ATP & \multicolumn{1}{c|}{ PSS/E } & $\begin{array}{c}\text { \% } \\
\text { Difference }\end{array}$ \\
\hline 1b & WITH CONSTANT EFD & 0.9226 & 0.9230 & $0.03 \%$ \\
\hline 1c & WITH AVR & 1.1033 & 1.0700 & $3.11 \%$ \\
\hline 1a & WITH AVR AND PSS & 1.0399 & 1.0340 & $0.57 \%$ \\
\hline 1d & WITH AVR, PSS \& GOV & 1.0859 & 1.0900 & $0.37 \%$ \\
\hline 1e & WITH SATURATION & 1.0535 & 1.0434 & $0.96 \%$ \\
\hline 1f & WITH RA & 1.0467 & $\mathrm{~N} / \mathrm{A}$ & $\mathrm{N} / \mathrm{A}$ \\
\hline 2a & 3-PHASE BUS FAULT & 1.0376 & 1.0340 & $0.34 \%$ \\
\hline 2b & LG FAULT & 1.0121 & 1.0256 & $1.31 \%$ \\
\hline 2d & LL FAULT & 1.0125 & $\mathrm{~N} / \mathrm{A}$ & $\mathrm{N} / \mathrm{A}$ \\
\hline 2c & LLG FAULT & 1.0119 & 1.0256 & $1.33 \%$ \\
\hline
\end{tabular}


Table B-4: Steady-state terminal voltage (p.u)

\begin{tabular}{|r|l|r|r|r|}
\hline Case no. & \multicolumn{1}{|c|}{ CASES } & ATP & PSS/E & \multicolumn{1}{c|}{$\begin{array}{c}\text { P } \\
\text { Difference }\end{array}$} \\
\hline $1 \mathrm{~b}$ & $\begin{array}{l}\text { WITH CONSTANT } \\
\text { EFD }\end{array}$ & 1.0205 & 1.02 & $0.05 \%$ \\
\hline $1 \mathrm{c}$ & WITH AVR & 1.0205 & 1.02 & $0.05 \%$ \\
\hline $1 \mathrm{a}$ & WITH AVR AND PSS & 1.0205 & 1.02 & $0.05 \%$ \\
\hline $1 \mathrm{~d}$ & $\begin{array}{l}\text { WITH AVR, PSS \& } \\
\end{array}$ & & & \\
\hline $1 \mathrm{GOV}$ & WITH SATURATION & 1.0205 & 1.02 & $0.05 \%$ \\
\hline $1 \mathrm{f}$ & WITH RA & 1.0205 & $\mathrm{~N} / \mathrm{A}$ & $0.05 \%$ \\
\hline $2 \mathrm{a}$ & 3-PHASE BUS FAULT & 1.0205 & 1.02 & $0.05 \%$ \\
\hline 2b & LG FAULT & 1.0205 & 1.02 & $0.05 \%$ \\
\hline 2d & LL FAULT & 1.0205 & $\mathrm{~N} / \mathrm{A}$ & $\mathrm{N} / \mathrm{A}$ \\
\hline 2c & LLG FAULT & 1.0205 & 1.02 & $0.05 \%$ \\
\hline
\end{tabular}

Table B-5: Settling time of terminal voltage (s)

\begin{tabular}{|r|l|r|r|r|}
\hline Case no. & \multicolumn{1}{|c|}{ CASES } & ATP (s) & \multicolumn{1}{c|}{$\begin{array}{c}\text { PSS/E (s) } \\
\text { Difference }\end{array}$} \\
\hline 1b & WITH CONSTANT EFD & N/A & N/A & N/A \\
\hline 1c & WITH AVR & N/A & N/A & N/A \\
\hline 1a & WITH AVR AND PSS & 2.4837 & 2.4830 & 0.02 \\
\hline $1 \mathrm{~d}$ & WITH AVR, PSS \& GOV & 2.9631 & 2.9570 & $0.20 \%$ \\
\hline 1e & WITH SATURATION & 2.4187 & 2.4180 & $0.02 \%$ \\
\hline $1 \mathrm{f}$ & WITH RA & 2.8400 & $\mathrm{~N} / \mathrm{A}$ & $\mathrm{N} / \mathrm{A}$ \\
\hline 2a & 3-PHASE BUS FAULT & 2.4187 & 2.4180 & $0.02 \%$ \\
\hline 2b & LG FAULT & 1.5076 & 1.5060 & $0.10 \%$ \\
\hline 2d & LL FAULT & 2.0065 & $\mathrm{~N} / \mathrm{A}$ & $\mathrm{N} / \mathrm{A}$ \\
\hline 2c & LLG FAULT & 2.2234 & 2.2200 & $0.15 \%$ \\
\hline
\end{tabular}

Table B-6: Frequency of terminal voltage oscillations $(\mathrm{Hz})$

\begin{tabular}{|r|l|r|r|r|}
\hline Case no. & \multicolumn{1}{c|}{ CASES } & ATP & \multicolumn{1}{c|}{ PSS/E } & \multicolumn{1}{c|}{$\begin{array}{c}\text { P } \\
\text { Difference }\end{array}$} \\
\hline 1b & WITH CONSTANT EFD & 0.9433 & 1.0169 & $7.23 \%$ \\
\hline 1c & WITH AVR & 1.0695 & 1.0670 & $0.23 \%$ \\
\hline $1 \mathrm{a}$ & WITH AVR AND PSS & 1.0363 & 1.0390 & $0.25 \%$ \\
\hline $1 \mathrm{~d}$ & WITH AVR, PSS \& GOV & 1.0714 & 1.0850 & $1.25 \%$ \\
\hline $1 \mathrm{e}$ & WITH SATURATION & 1.0652 & 1.0670 & $0.16 \%$ \\
\hline 1f & WITH RA & 1.0412 & $\mathrm{~N} / \mathrm{A}$ & $\mathrm{N} / \mathrm{A}$ \\
\hline 2a & 3-PHASE BUS FAULT & 1.0342 & 1.0250 & $0.89 \%$ \\
\hline 2b & LG FAULT & 1.0202 & 1.0274 & $0.70 \%$ \\
\hline 2d & LL FAULT & 1.0151 & $\mathrm{~N} / \mathrm{A}$ & $\mathrm{N} / \mathrm{A}$ \\
\hline 2c & LLG FAULT & 1.0027 & 1.0100 & $0.72 \%$ \\
\hline
\end{tabular}




\section{B.2 TWO-AREA SYSTEM BENCHMARKING}

Table B-7: Steady-state power flow between Area1 and Area 2

\begin{tabular}{|l|r|r|r|}
\hline \multicolumn{1}{|c|}{ CASES } & \multicolumn{1}{|c|}{$\begin{array}{c}\text { ATP } \\
\text { (MW) }\end{array}$} & \multicolumn{1}{c|}{$\begin{array}{c}\text { PSS/E } \\
\text { (MW) }\end{array}$} & \% Difference \\
\hline $\begin{array}{l}\text { Fault in line 6-7, original } \\
\text { system }\end{array}$ & 200.71 & 200.7 & $0.004 \%$ \\
\hline $\begin{array}{l}\text { Fault in line 11-9, original } \\
\text { system }\end{array}$ & 200.71 & 200.7 & $0.004 \%$ \\
\hline $\begin{array}{l}\text { Fault in line 6-7, reduced } \\
\text { system }\end{array}$ & 203.68 & 203.68 & 0 \\
\hline $\begin{array}{l}\text { Fault in line 11-9, reduced } \\
\text { system }\end{array}$ & 203.68 & 203.68 & 0 \\
\hline
\end{tabular}

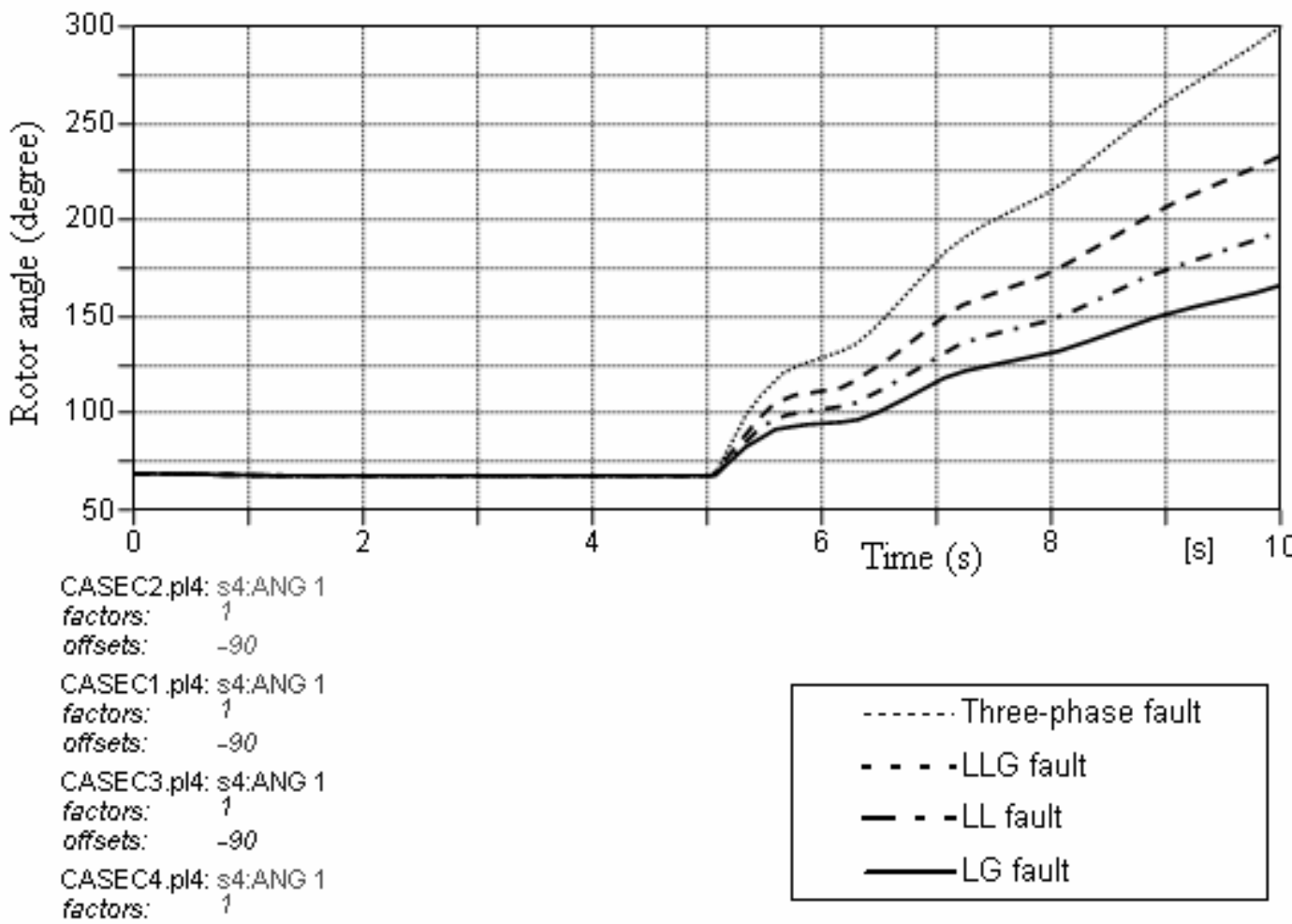

Figure B.11: Rotor angles of G1 for faults in Area 1 (Case 3a, c, d, and e) 


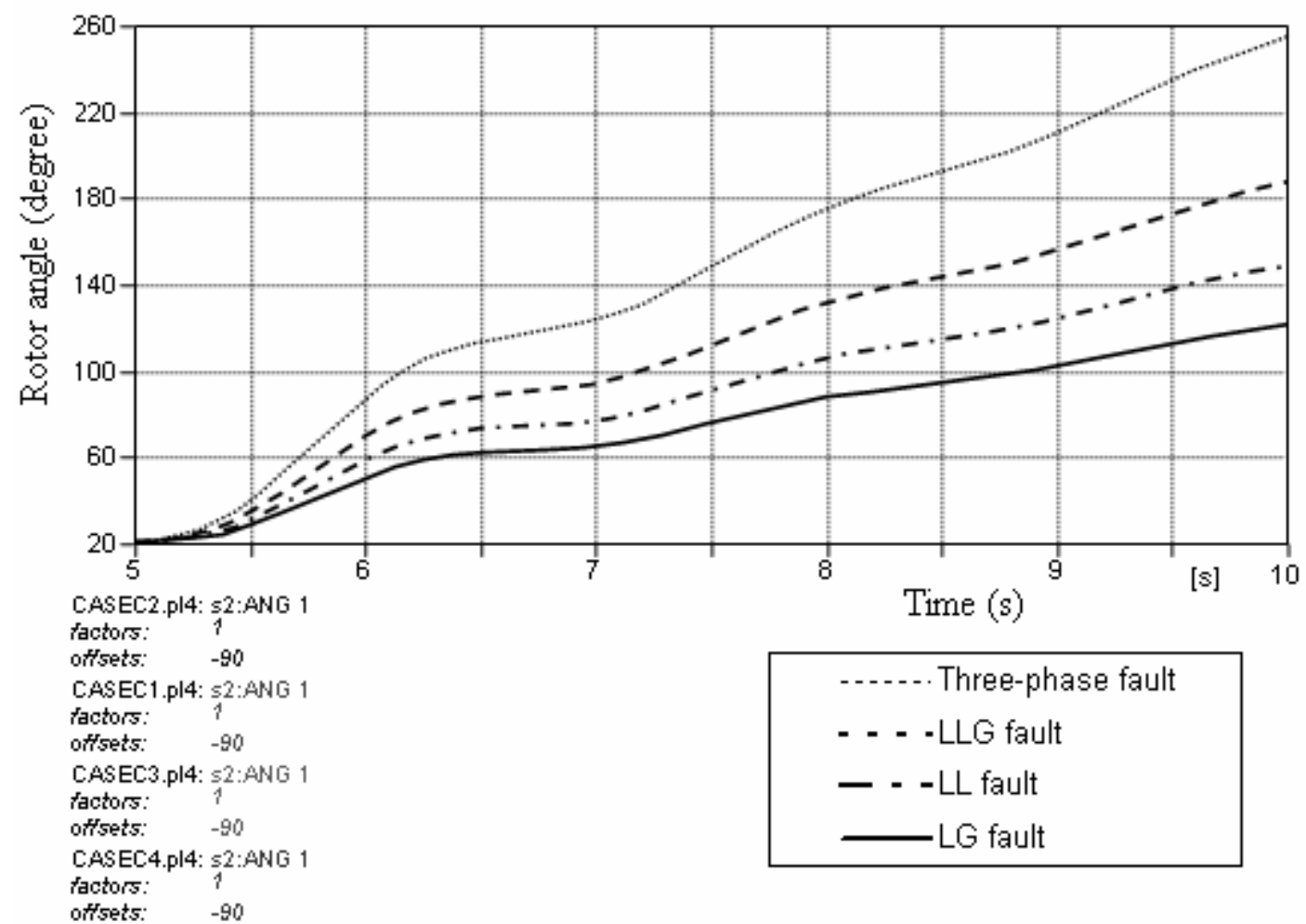

Figure B.12: Rotor angles of G4 for faults in Area 1 (Case 3a, c, d, and e)

Table B-8: Frequency of power flow between Area 1 and Area 2

\begin{tabular}{|l|c|r|r|}
\hline \multicolumn{1}{|c|}{ CASES } & \multicolumn{1}{|c|}{$\begin{array}{c}\text { ATP } \\
(\mathbf{H z})\end{array}$} & \multicolumn{1}{|c|}{$\begin{array}{c}\text { PSS/E } \\
(\mathbf{H z})\end{array}$} & \% Difference \\
\hline $\begin{array}{l}\text { Fault in line 6-7, original } \\
\text { system }\end{array}$ & 0.5679 & 0.5505 & $3.16 \%$ \\
\hline $\begin{array}{l}\text { Fault in line 11-9, original } \\
\text { system }\end{array}$ & 0.5987 & 0.5917 & $1.18 \%$ \\
\hline $\begin{array}{l}\text { Fault in line 6-7, reduced } \\
\text { system }\end{array}$ & 0.5347 & 0.5555 & $3.74 \%$ \\
\hline $\begin{array}{l}\text { Fault in line 11-9, reduced } \\
\text { system }\end{array}$ & 0.5917 & 0.5987 & $1.16 \%$ \\
\hline
\end{tabular}




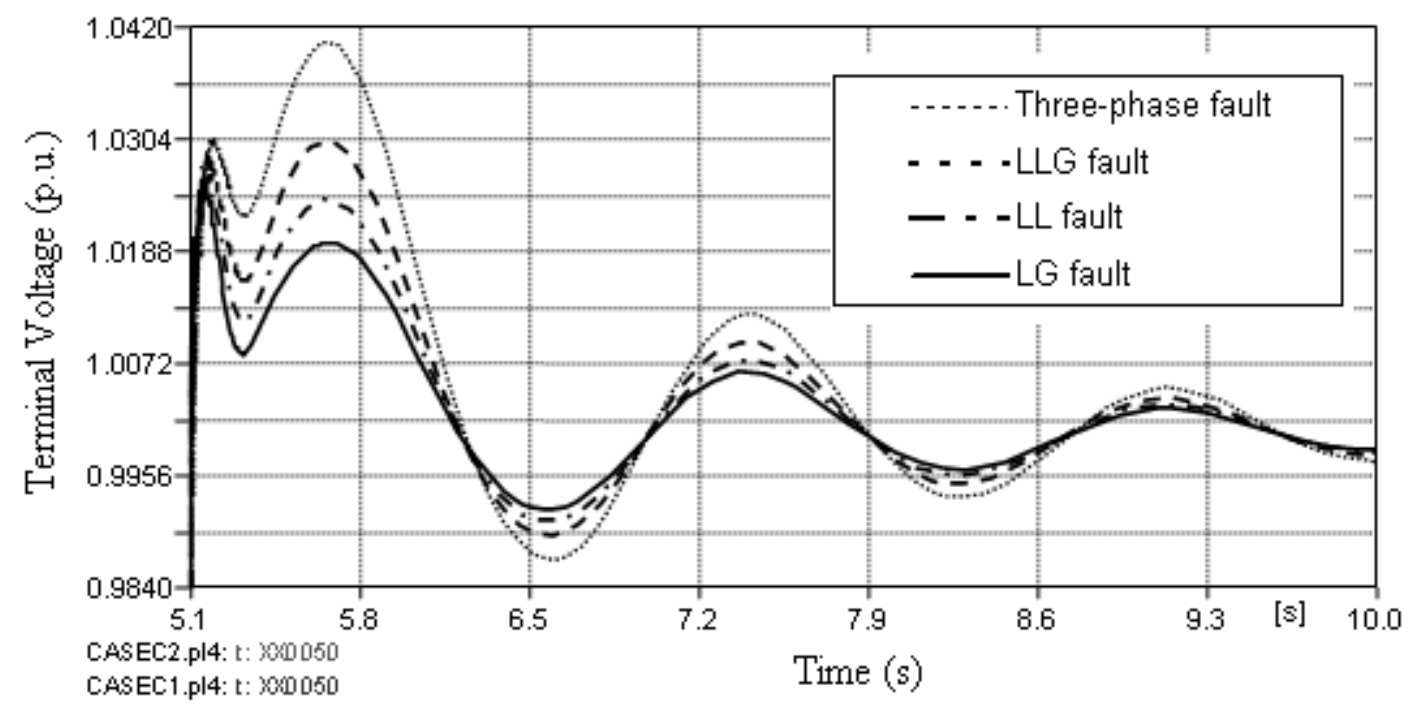

CASEC3.pl4: t: $\$ 0000$

CASEC4.pl4: t: $\$ 0050$

Figure B.13: Terminal Voltage of G3 for faults in Area 1 (Case 3a, c, d, and e)

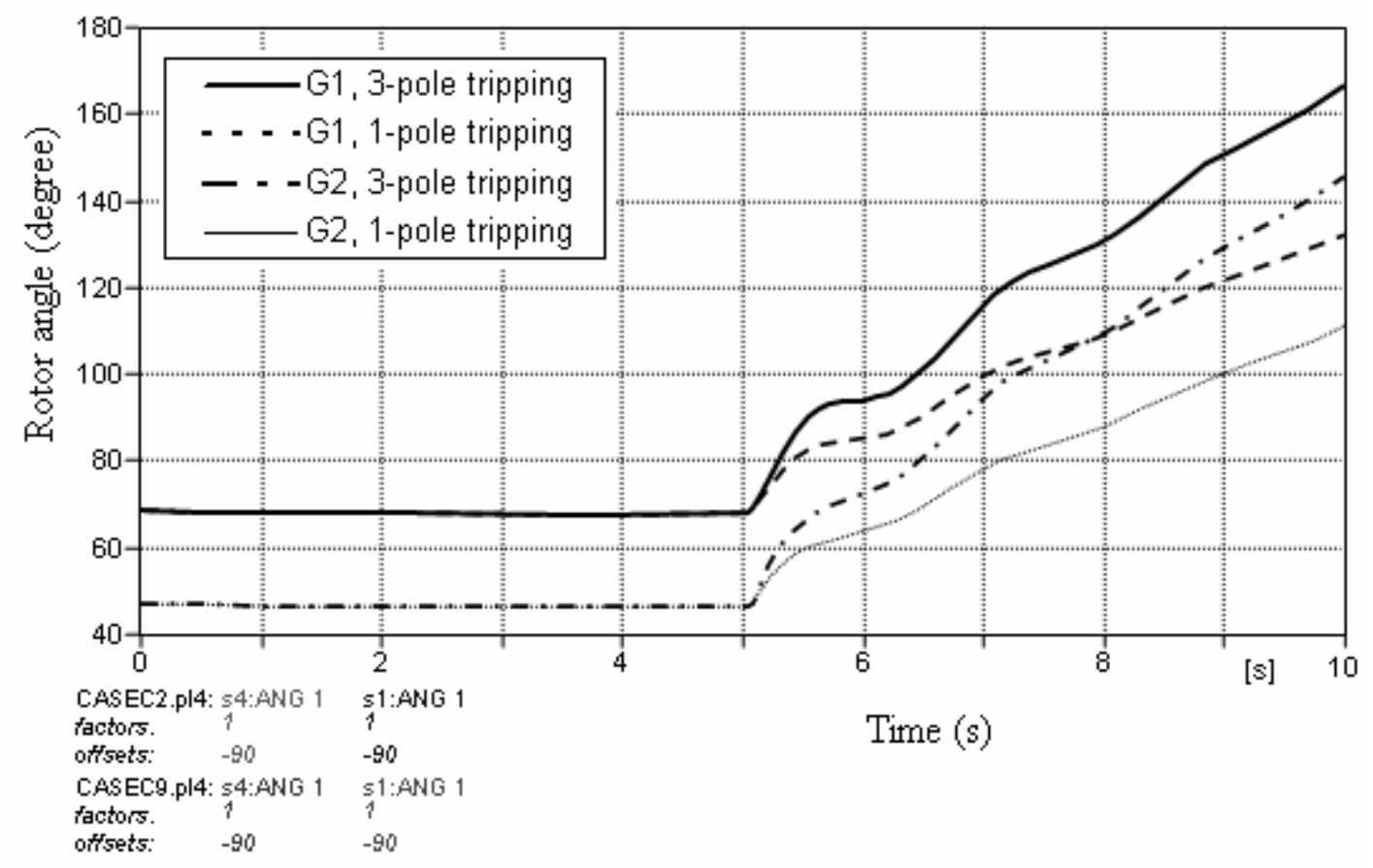

Figure B.14: Rotor angles in Area 1 (Case 3a, c, d, and e) 


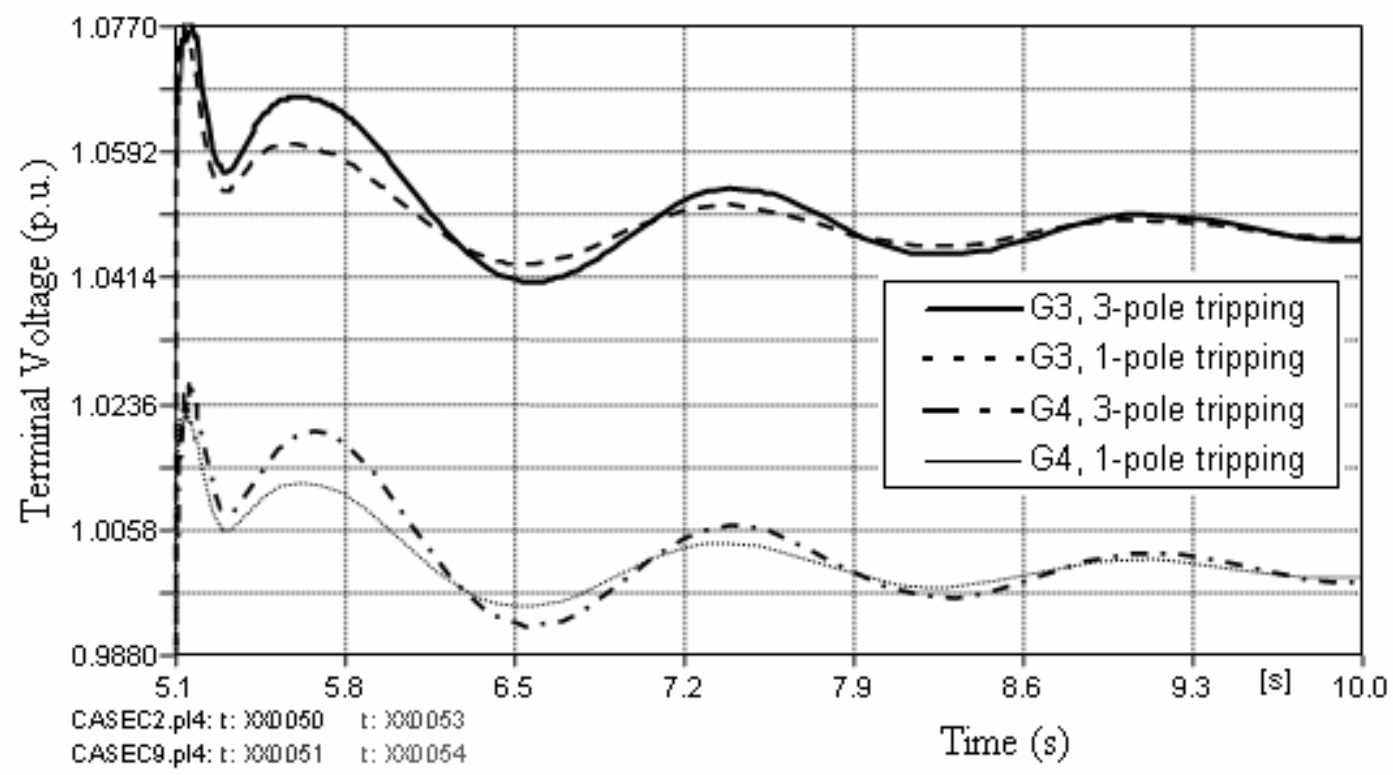

Figure B.15: Terminal voltages in Area 2 (Case 3f)

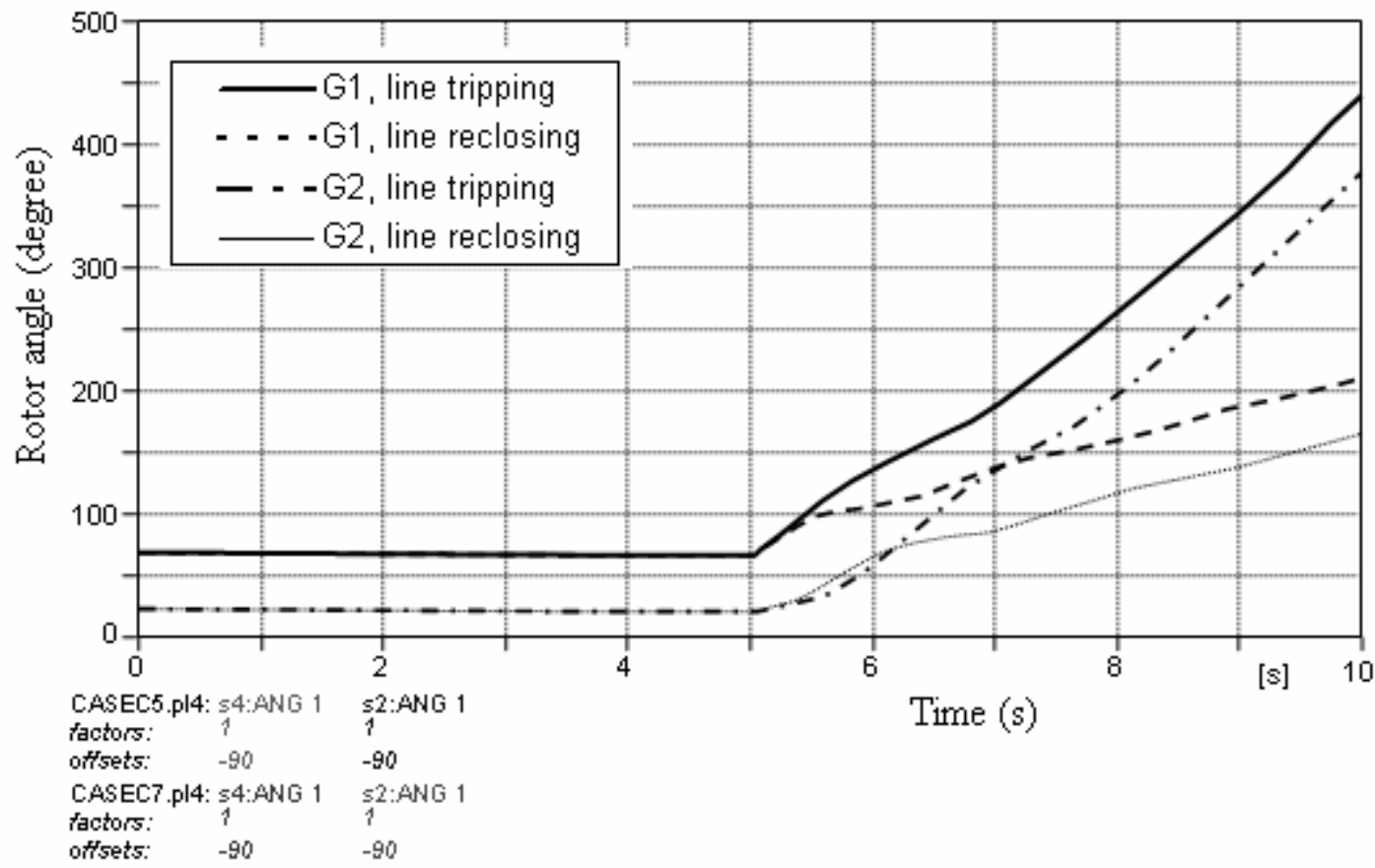

Figure B.16: Rotor angles for line tripping and reclosing (Case 3a) 


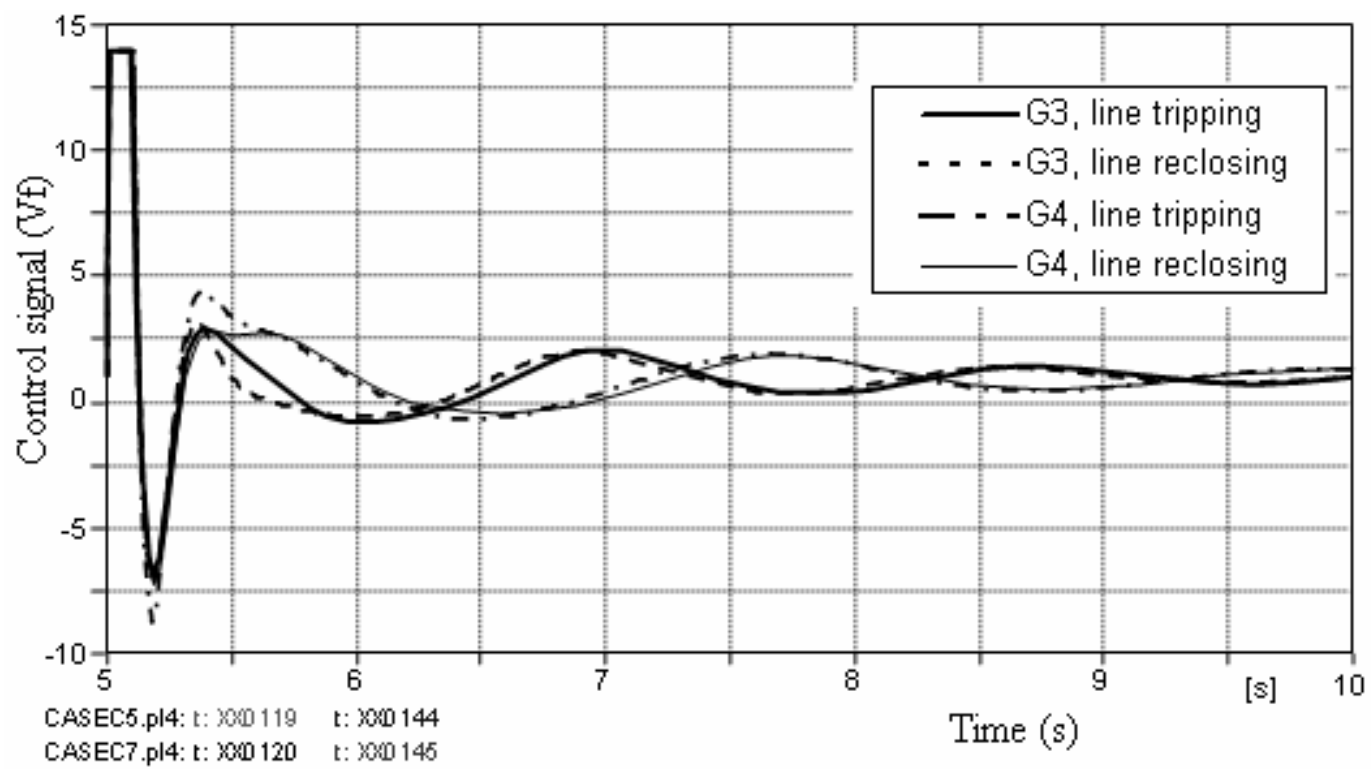

Figure B.17: Field voltage control for line tripping and reclosing (Case 3a)

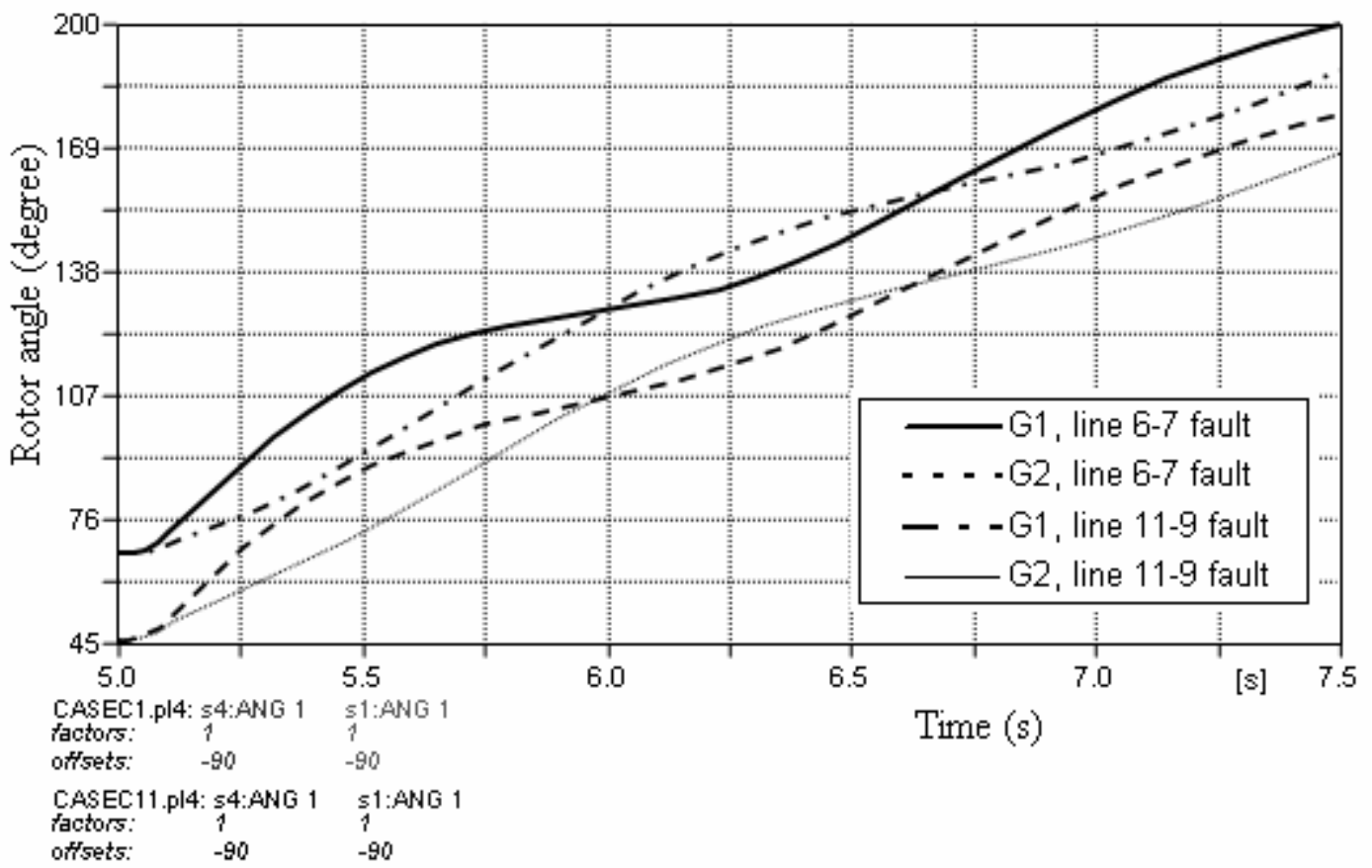

Figure B.18: Rotor angles for remote and local faults (Case 3a and 3b) 


\section{APPENDIX C PROGRAM FILES}

\section{C.1 MATLAB PROGRAM}

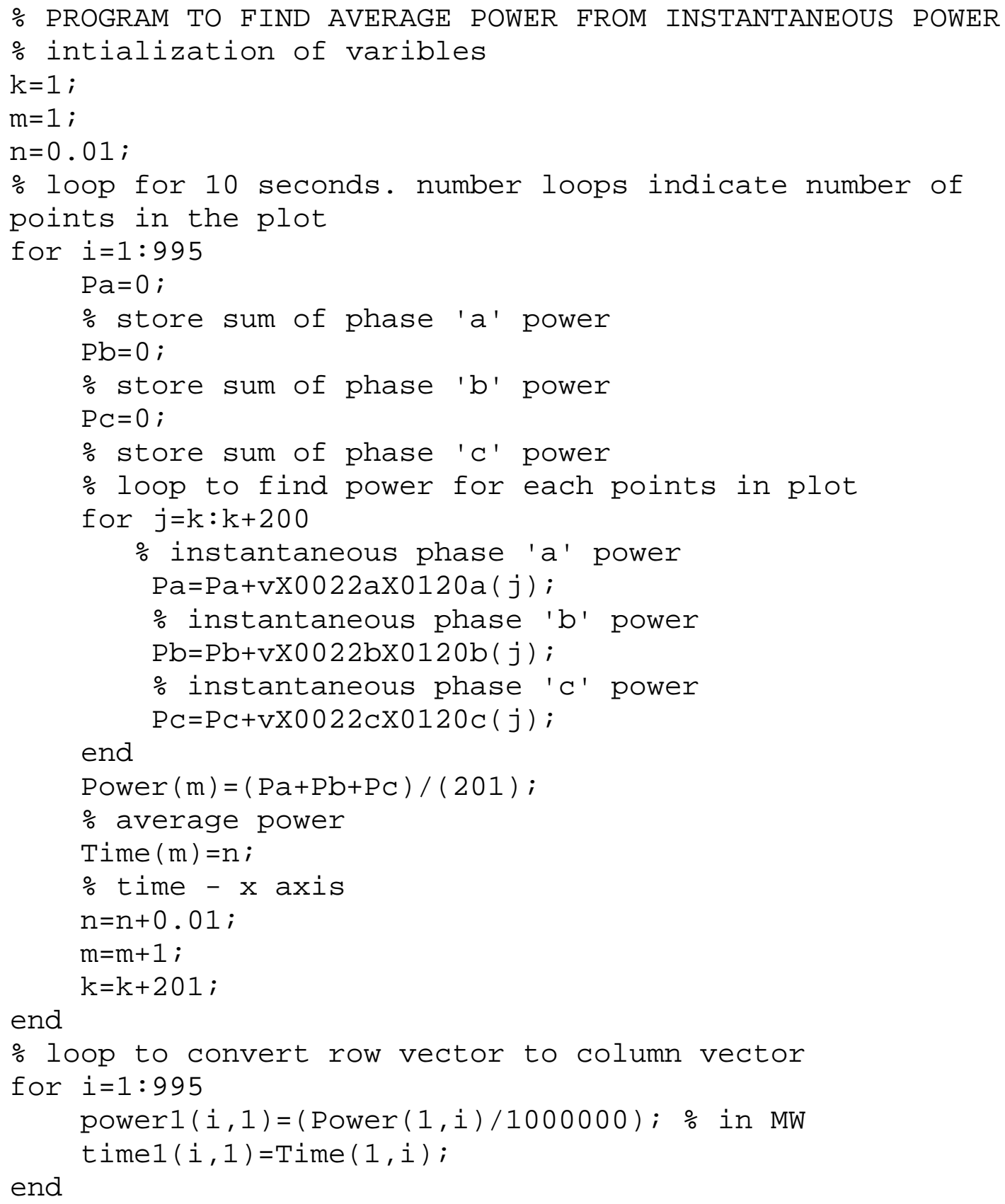




\section{C.2 ATP SAMPLE INPUT DATA CASE}

\section{C.2.1 Saturated single machine system with three-phase line fault} BEGIN NEW DATA CASE

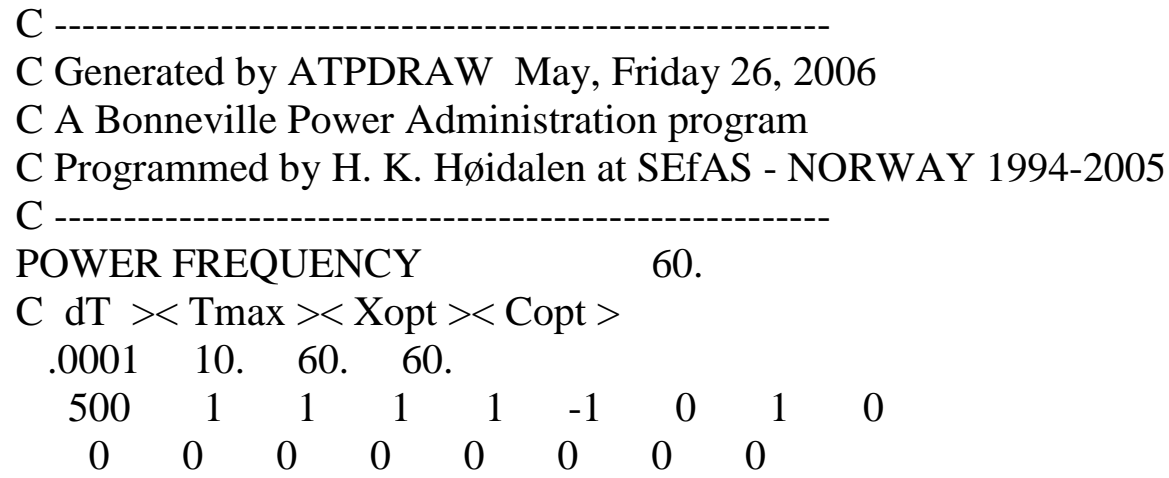




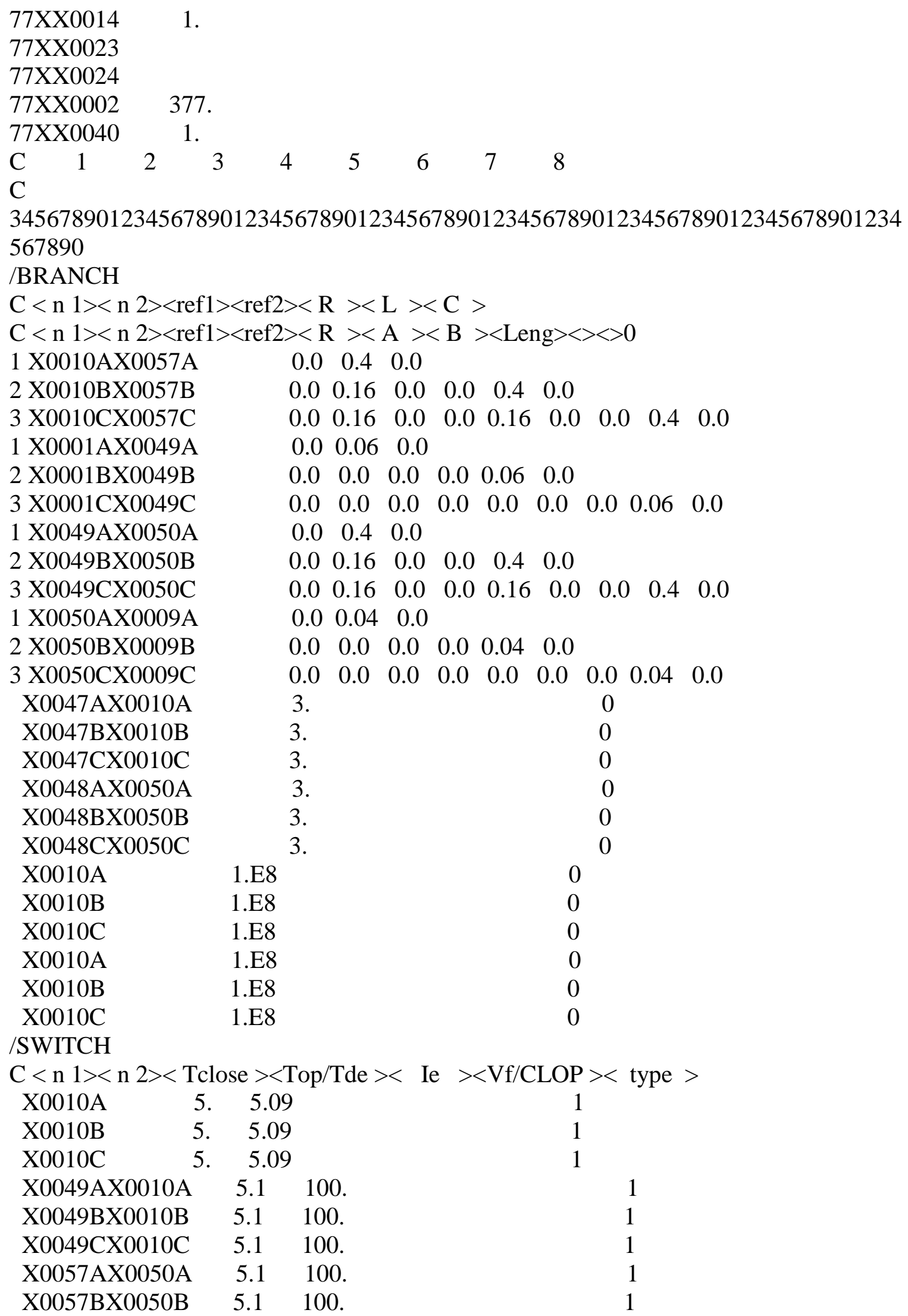




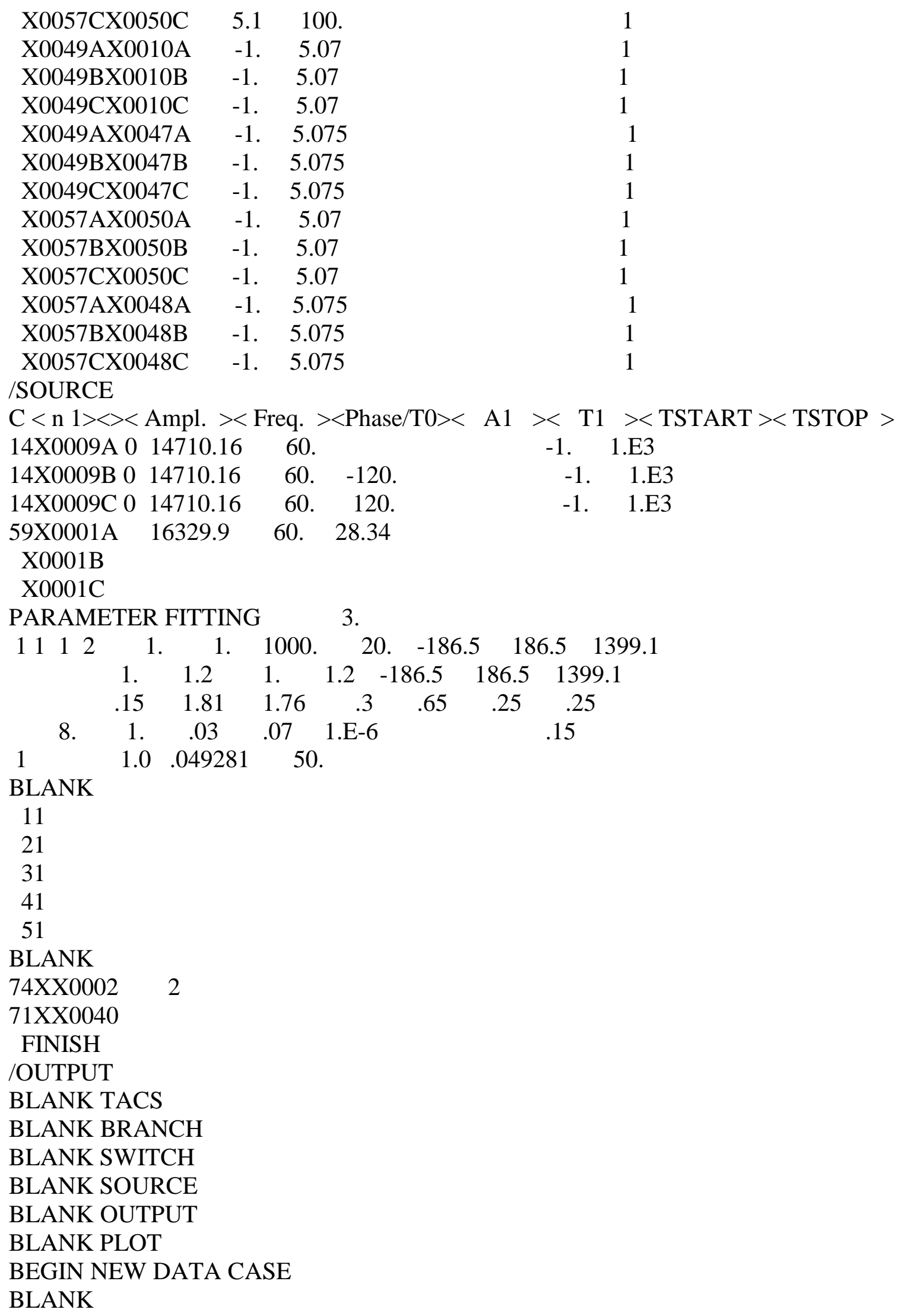




\section{C.2.2 Two-area system with a thee-phase line fault in line 6-7}

\section{BEGIN NEW DATA CASE}

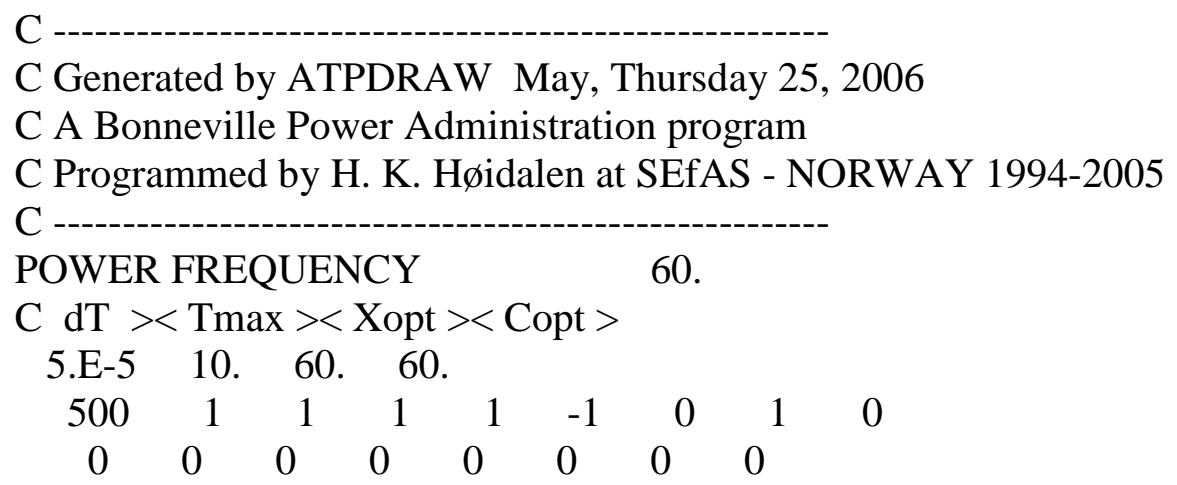

\section{TACS HYBRID}

/TACS

90X0001C

1.E3

90X0001A

1.E3

$90 \times 0001 \mathrm{~B}$

1.E3

$98 \mathrm{XX} 0216=\mathrm{X} 0001 \mathrm{~A} * \mathrm{X} 0001 \mathrm{~A}$

$98 X X 0214=\mathrm{X} 0001 \mathrm{~B} * \mathrm{X} 0001 \mathrm{~B}$

$98 \mathrm{XX0215}=\mathrm{X} 0001 \mathrm{C} * \mathrm{X} 0001 \mathrm{C}$

$98 X X 0042=\mathrm{XX0215}+\mathrm{XX0214}$

$98 X X 0043=$ SQRT $($ XX0217 $)$

$98 X X 0217=\mathrm{XX} 0042+\mathrm{XX} 0216$

$98 \mathrm{XX0044}=5 . \mathrm{E}-5 * \mathrm{XX} 0043$

90X0004C

1.E3

90X0004A

1.E3

90X0004B

1.E3

$98 \mathrm{XX0220}=\mathrm{X} 0004 \mathrm{~A} * \mathrm{X} 0004 \mathrm{~A}$

$98 \mathrm{XX} 0218=\mathrm{X} 0004 \mathrm{~B} * \mathrm{X} 0004 \mathrm{~B}$

$98 X X 0219=\mathrm{X} 0004 \mathrm{C} * \mathrm{X} 0004 \mathrm{C}$

$98 X X 0045=\mathrm{XX} 0219+\mathrm{XX} 0218$

$98 X X 0046=$ SQRT $($ XX0221 $)$

$98 X X 0221=$ XX0045 + XX0220

$98 \mathrm{XX0047}=5 . \mathrm{E}-5 * \mathrm{XX} 0046$

90X0005A

1.E3

$90 \times 0005 \mathrm{C}$

1.E3

90X0005B

1.E3

$98 \mathrm{XX} 0224=\mathrm{X} 0005 \mathrm{C} * \mathrm{X} 0005 \mathrm{C}$

$98 \mathrm{XX} 0222=\mathrm{X} 0005 \mathrm{~B} * \mathrm{X} 0005 \mathrm{~B}$

$98 \mathrm{XX} 0223=\mathrm{X} 0005 \mathrm{~A} * \mathrm{X} 0005 \mathrm{~A}$

$98 X X 0048=\mathrm{XX} 0223+\mathrm{XX} 0222$

$98 X X 0049=\mathrm{SQRT}(\mathrm{XX0225})$

$98 X X 0225=\mathrm{XX} 0048+\mathrm{XX} 0224$

$98 X X 0050=5 . \mathrm{E}-5 * \mathrm{XX} 0049$

90X0006A

90X0006C 


$$
\begin{aligned}
& \text { 90X0006B } \\
& 98 \mathrm{XX0228}=\mathrm{X} 0006 \mathrm{C} * \mathrm{X} 0006 \mathrm{C} \\
& 98 \mathrm{XX0226}=\mathrm{X} 0006 \mathrm{~B} * \mathrm{X} 0006 \mathrm{~B} \\
& 98 X X 0227=\mathrm{X} 0006 \mathrm{~A} * \mathrm{X} 0006 \mathrm{~A} \\
& 98 X X 0051=\mathrm{XX} 0227+\mathrm{XX} 0226 \\
& \text { 98XX0052 = SQRT }(\text { XX0229) } \\
& 98 X X 0229=\mathrm{XX} 0051+\mathrm{XX0228} \\
& 98 \mathrm{XX0053}=5 . \mathrm{E}-5 * \mathrm{XX} 0052 \\
& 1 \mathrm{XX0054+XX0044}
\end{aligned}
$$

\begin{tabular}{|c|c|}
\hline 0XX0055 & +XX0064 \\
\hline $11 X X 0069$ & 1.0071 \\
\hline 98XX0064 & $=\mathrm{XX} 0070+\mathrm{XX} 0069$ \\
\hline $98 \times X 0070$ & $=\mathrm{XX} 0155-\mathrm{XX} 0054$ \\
\hline $98 \times X 0071$ & $=500 . * \times X 0055$ \\
\hline 0XX0072 & $+\mathrm{XX} 0071$ \\
\hline 1XX0079 & $+\mathrm{XX0047}$ \\
\hline
\end{tabular}

1.

1. .015

1.

1. .015

0XX0080
$11 X X 0094$
$98 X X 0089=X X$
$98 X X 0095=X X$
$98 X X 0096=$
0XX0097
1XX0104
1.
1.
.015

0XX0105

$11 \mathrm{XX0119}$

$+\mathrm{XX0114}$

98XX0114 = XX0120 + XX0119

$98 X X 0120=\mathrm{XX0183}-\mathrm{XX0104}$

$98 X X 0121=500 . * \mathrm{XX} 0105$

0XX0122

$1 X X 0129$

$+\mathrm{XX0121}$

$+\mathrm{XX0053} 1$

$+\mathrm{XX0050} 1$
1.

$-.6 \quad .4$

1.E3
$-12.814$

1.

$-.6 \quad .4$

1.E3

1.

1. .015

0XX0130

$11 \times X 0144 \quad 1.0501$

+ XX0139

-12.814 .

$98 X X 0139=\mathrm{XX} 0145+\mathrm{XX0144}$

$98 X X 0145=\mathrm{XX} 0198-\mathrm{XX0129}$

$98 X X 0146=500 . * \mathrm{XX} 0130$

0XX0147 +XX0146

$98 X X 0156=0.0027 * \mathrm{XX} 0032$

$-.6 \quad .4$

1.E3

$11 X X 0231 \quad 1.0179$

-12.814 .

1.

$-.6 \quad .4$

1.E3

-12.814 .

1.E3 


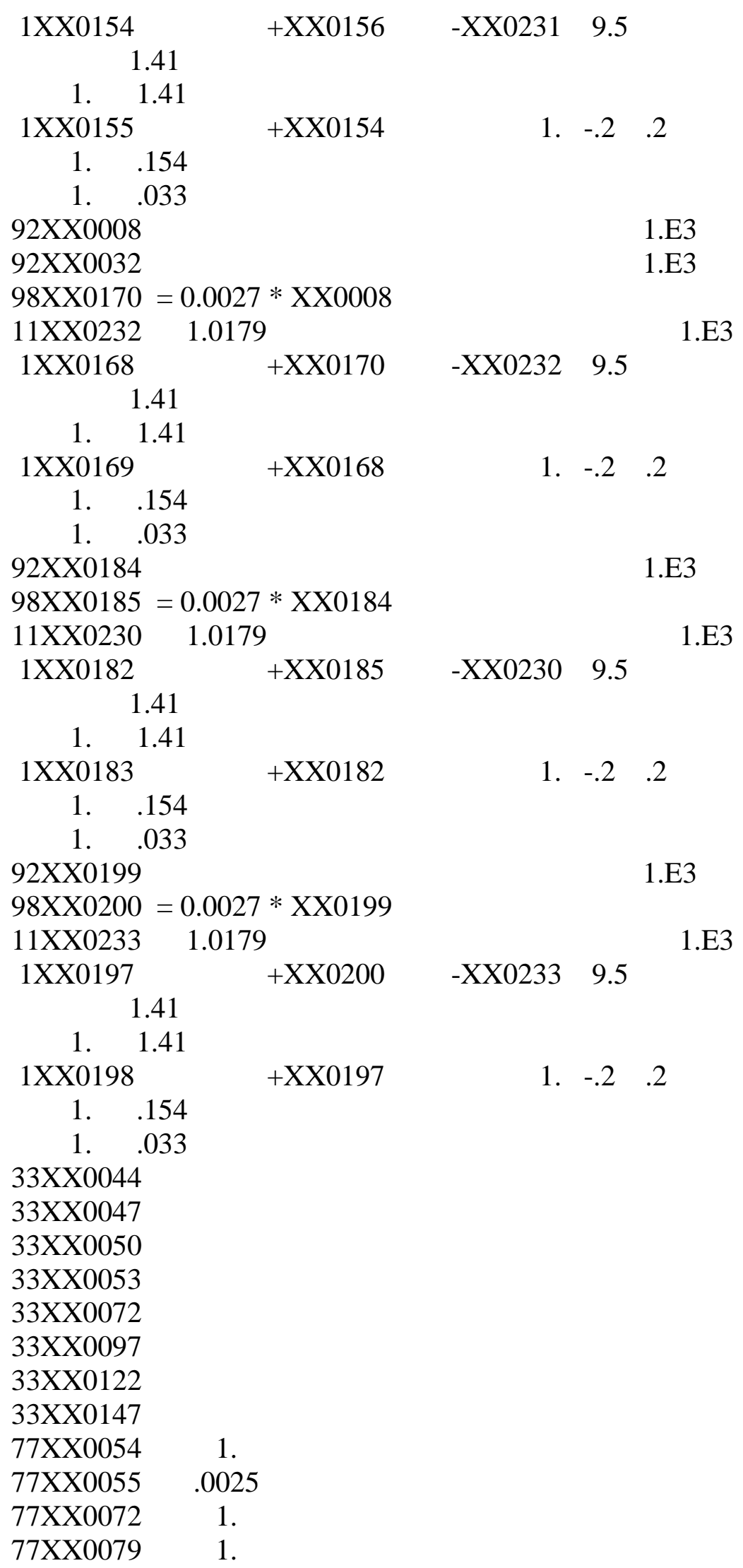




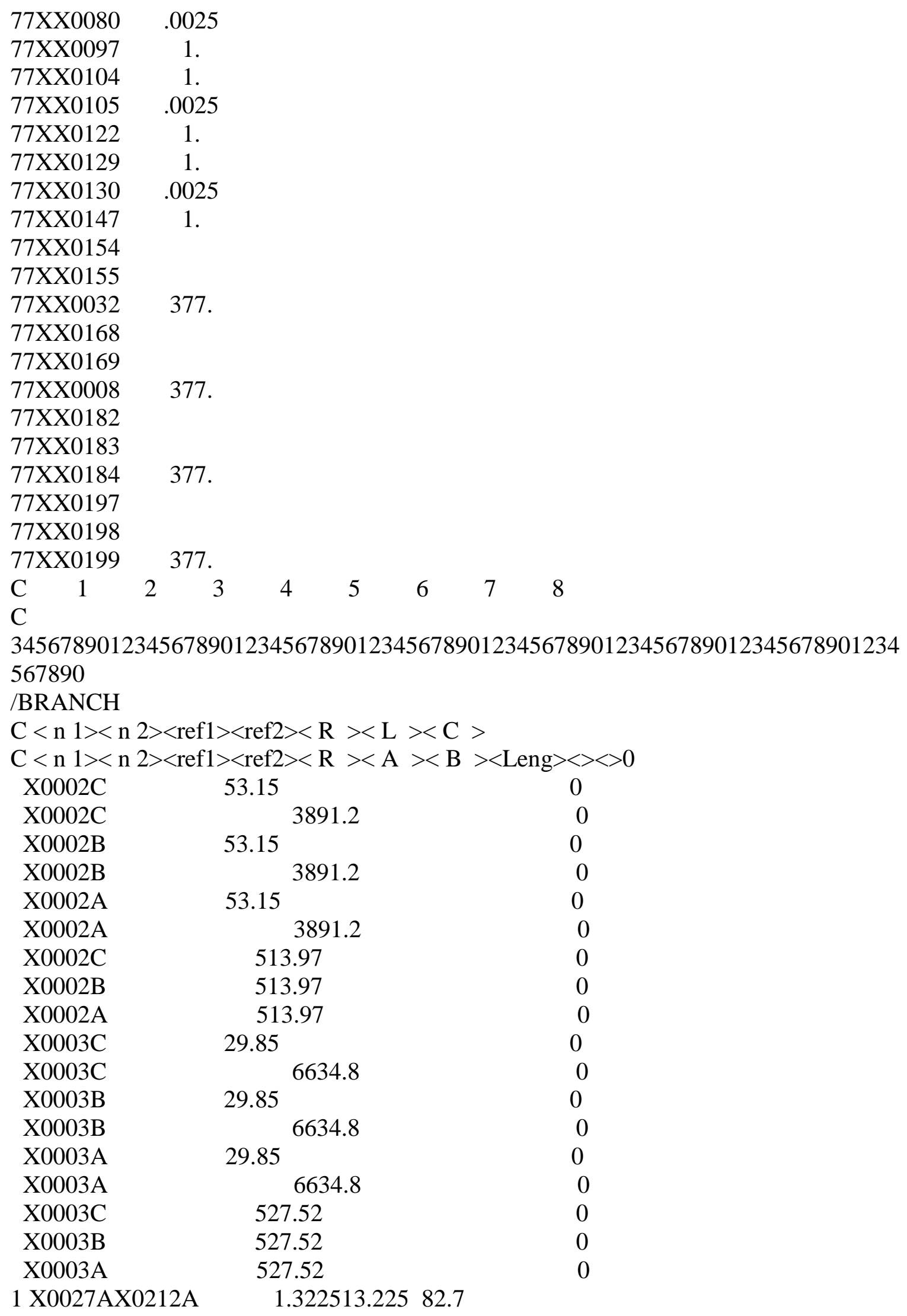

$\begin{array}{ll}6634.8 & 0 \\ 527.52 & 0 \\ 527.52 & 0 \\ 527.52 & 0\end{array}$




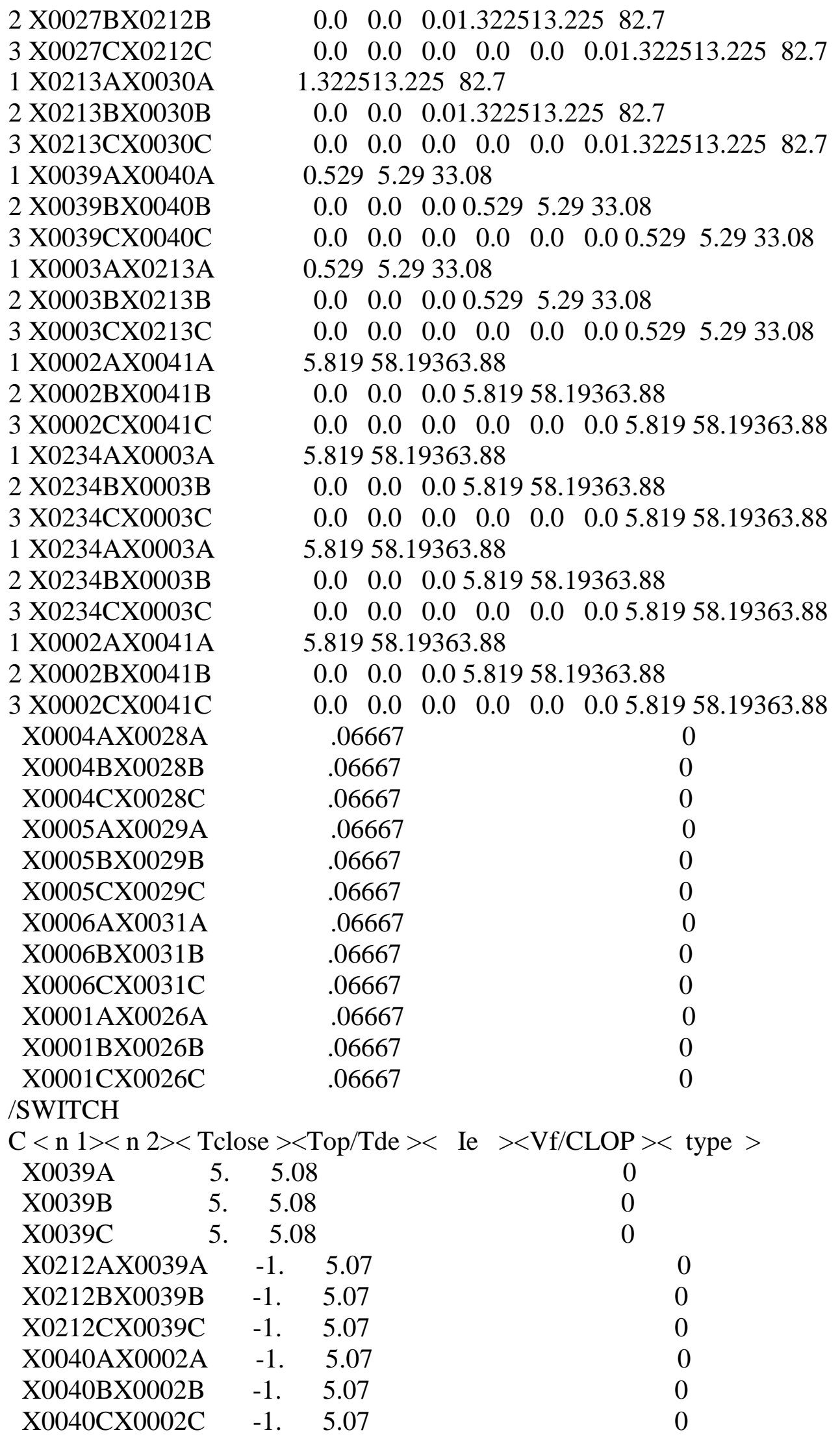




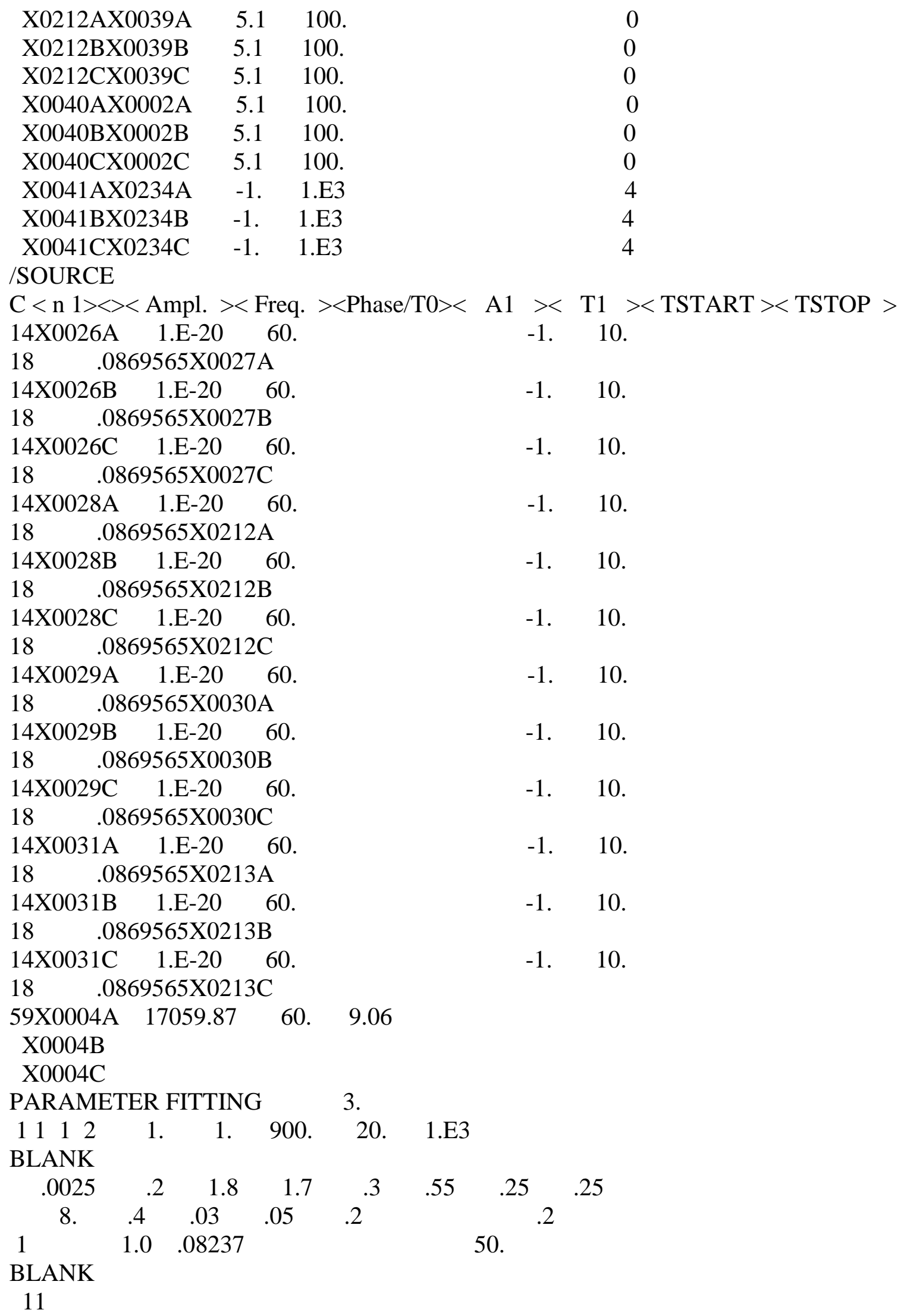




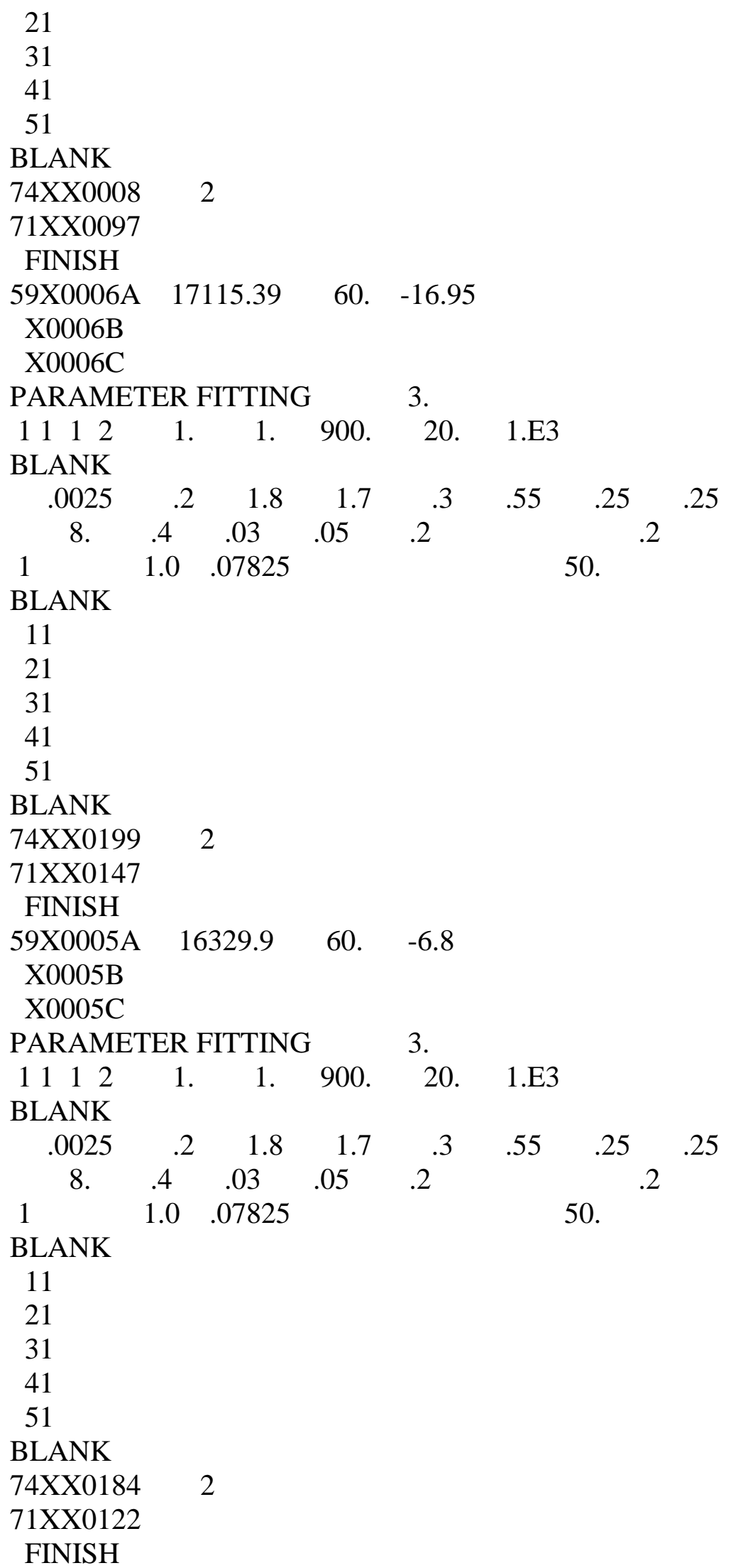




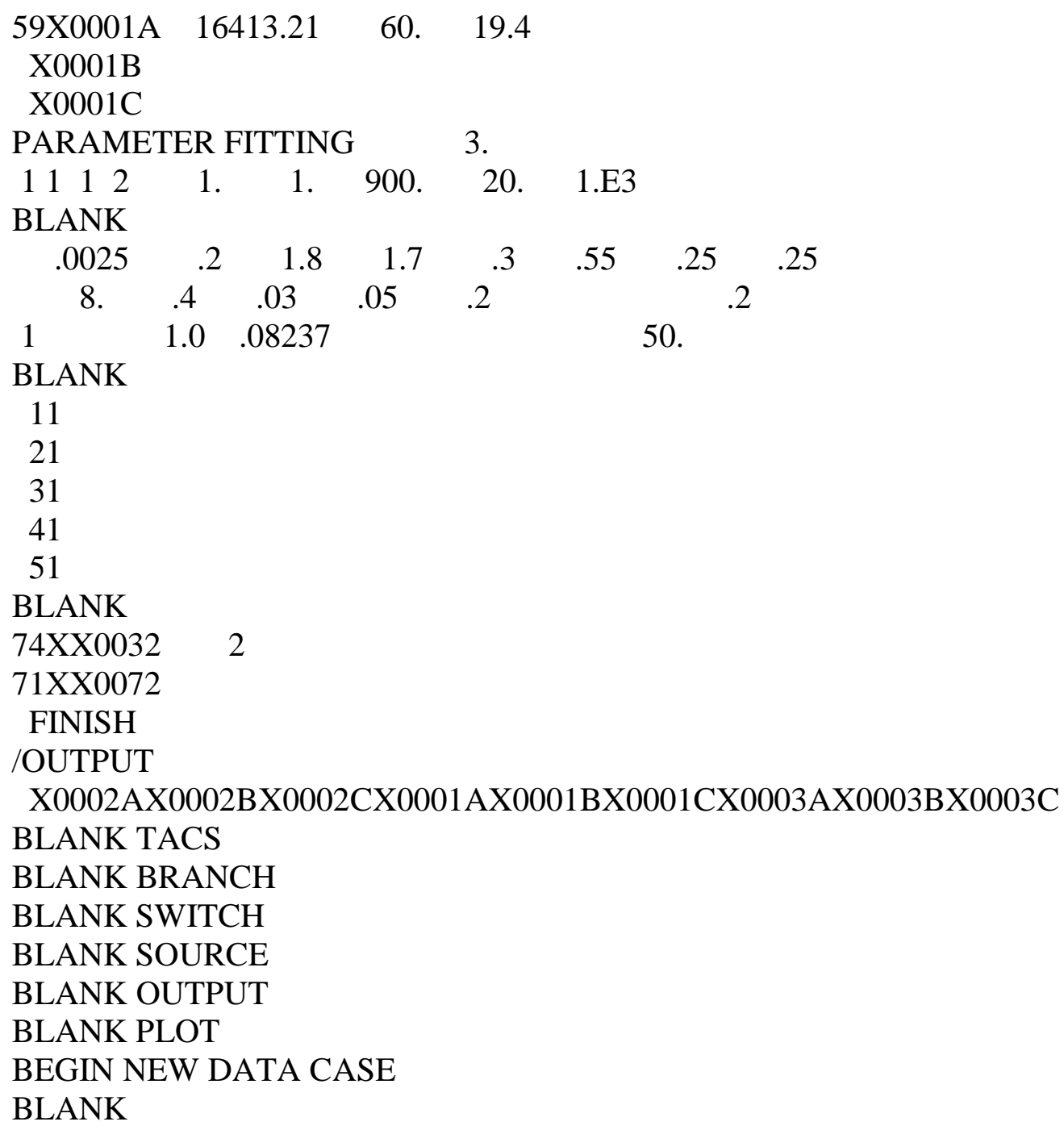

